\title{
Sobre os nomes populares conferidos às espécies sul-americanas de Tapirus (Mammalia, Perissodactyla, Tapiridae)
}

\author{
Nelson Papavero ${ }^{1,2}$ \\ 1 Universidade de São Paulo (USP), Museu de Zoologia (MZUSP). São Paulo, SP, Brasil. E-mail: pavotnel@gmail.com \\ 2 Pesquisador Senior do Conselho Nacional de Desenvolvimento Científico e Tecnológico (CNPq).
}

\begin{abstract}
A wealth of names has been applied to the South American species of Tapirus: acuraua, acuré, açurê, amta, ánta, antá, anta-batupeva, anta-batuvira, anta-caá-pororoca, anta-chure, anta-churé, anta-cinzenta, anta-commum, antacuré, anta-das-ordinarias, anta-do-matto, anta-gameleira, anta-gamelleira, anta-grande, anta-mirim, anta-nambi-tinga, antanegra, anta-pequena, anta-pororoca, anta-preta, anta-rosia, anta-rosilha, anta-sapateira, anta-sapatera, anta-verdadeira, antaxuré, anta-xuré, anta-xurê, ante, antes, apiroupsou, apyropsou, assobio, batovi, batuvi, batuvira, boi-sylvestre, boy-domatto, boy-silvestre, caapoára, caápoára, caâpoára, caapora, caapóra, caá-pora, çaba-tyra, cambassica, capoava, capororoca, cauara-tapyira, curé, dant, danta, dante, ent, grã-besta, grambesta, grande-besta, grão-besta, icuré, icurê, içuré, icurí, icútê, iguré, ituré, kaiwara, mbore, mborebi, mborebí, mbórebi, mborepi, mborevi, mboreví, mboreví-hovíh, mboreví-jovî, morebí, öaçurê, paraná-tapi'ira, pororoca, sapateira, taparuçu, taperuçu, taperuçú, tapie, tapié, tapiera, tapiéra-caiuara, tapierete, tapiereté, tapihire, tapihiri, tapii, tapií, tapiì, tapiî, tapîi, tapi'i, tapi'́, tapi'í, tapiiára, tapiierete, tapiiereté, tapiieretê, tapiiereté, tapi-iete, tapiir, tapiira, tapiíra, tapiiira, tapiìra, tapî́ra, tapi'ira, tapii-r-a, tapiira-caapoara, tapiïra-cäápora, tapiira-caiuára, tapiira-caiwara, tapiira-ete, tapi'ira-ka'apura, tapiirete, tapiireté, tapiirété, tapiiretê, tapiire’te, tapiiruçu, tapiirussu, tapi'irusu, tapi'í-rusú, tapijerete, tapijira, tapijrete, tapikira, tapikra, tapir, tapira, tapïra, tapĩra, tapira-caaiúra, tapira-caapora, tapiracaapóra, tapiraçu, tapira-etê, tapir-americano, tapirapoã, tapira-sobaiguara, tapirassou, tapirassu, tapirassú, tapiratí, tapirauborim, tapirete, tapireté, tapiretê, tapiretê, tapirêtê, tapí-reté, tapirierete, tapiro, tapirosú, tapirousou, tapiroussu, tapiroussú, tapirovssov, tapiruçu, tapiruçú, tapirussú, tapiruzú, tapiryra-caapóra, tapir-xuré, tapiy, tapiye-ete, tapiyr, tapiyra, tapiýra, tapiyra-caapora, tapiŷra-caapóra, tapiyra-cauara, tapiyra-ete, tapiyre-ete, tapiyre-été, tapiyré-été, tapiyreté, tappire, tapura, tapüra, tapyi, tapyira, tapyîra, tapyira-caapoara, tapyîra-caápoára, tapyira-caapora, tapyirá-caapóra, tapyíra-caapóra, tapyiracäá-pora, tapyira-cäó-pora, tapyira-eté, tapyíra-eté, tapyire-eté, tapyr, tapyra, tapy'ra, tapyra-assu, tapyra-caapora, tapy'racaapóra, tapyra-caiuara, tapyra-caiura, tapyra-capora, tapyra-sabetyra, tapy'ra-oçu, tapyra-sabetyra, tapyre-eté, tapyrete, tapyreté, tapyretê, tapyyre-été, topiraffore, uaca-do-mato, vaca-do-mato, xuré, xurê. Certain North African antelopes were called oryx by Greek and Roman authors. Arab authors knew them as Lamt (or lamta, elamt, lant, dant) and used their hide to make shields (daraqqa-lamțiyya). With the Arab invasion of the Iberian Peninsula, daraqqa-lamțiyya was transformed into adarga-danta and under this form was cited by numerous Spanish and Portuguese authors. Consequently, the African Oryx was called anta by Gomes Eanes de Zurara (1453) and danta by an anonymous autor (MS Valentim Fernandes, 1507) and Duarte Lopes (in Pigafetta \& Lopes, 1589). Antonio Pigafetta (in Anôn., ca. 1526) referred under the name anta the strange animal that the Tupi Indians of Brazil called tapir. Both tapir and anta (with many variations and with the addition of several qualifications) were used by subsequent authors. Finally, in Brazil, the improper usage of anta to denote the species of Tapirus supplanted that of tapir. A further confusion was added when a few authors confounded the South American antas with the old World elk and called the first grã-bestas (with variations).
\end{abstract}

Key-Words. South American Tapirus; Popular names; Oryx; Lamt; Anta; Tapir; Grã-Besta; History of popular names.

\begin{abstract}
Resumo. Muitos nomes foram aplicados às espécies sul-americanas de Tapirus: acuraua, acuré, açurê, amta, ánta, antá, anta-batupeva, anta-batuvira, anta-caá-pororoca, anta-chure, anta-churé, anta-cinzenta, anta-commum, antacuré, antadas-ordinarias, anta-do-matto, anta-gameleira, anta-gamelleira, anta-grande, anta-mirim, anta-nambi-tinga, anta-negra, anta-pequena, anta-pororoca, anta-preta, anta-rosia, anta-rosilha, anta-sapateira, anta-sapatera, anta-verdadeira, antaxuré, anta-xuré, anta-xurê, ante, antes, apiroupsou, apyropsou, assobio, batovi, batuvi, batuvira, boi-sylvestre, boy-do-matto, boysilvestre, caapoára, caápoára, caâpoára, caapora, caapóra, caá-pora, çaba-tyra, cambassica, capoava, capororoca, cauaratapyira, curé, dant, danta, dante, ent, grã-besta, grambesta, grande-besta, grão-besta, icuré, icurê, içuré, icurí, icútê, iguré, ituré, kaiwara, mbore, mborebi, mborebí, mbórebi, mborepi, mborevi, mboreví, mboreví-hovíh, mboreví-jovî, morebí, öaçurê, paraná-tapi'ira, pororoca, sapateira, taparuçu, taperuçu, taperuçú, tapie, tapié, tapiera, tapiéra-caiuara, tapierete, tapiereté,
\end{abstract}


tapihire, tapihiri, tapii, tapií, tapiì, tapiî, tapiii, tapi'i, tapi'́, tapíí, tapiiára, tapiierete, tapiiereté, tapiieretê, tapiier-eté, tapi-iete, tapiir, tapiira, tapiíra, tapiiira, tapiìra, tapî́ra, tapi'ira, tapii-r-a, tapiira-caapoara, tapiïra-cäápora, tapiira-caiuára, tapiira-caiwara, tapiira-ete, tapi'ira-ka'apura, tapiirete, tapiireté, tapiirété, tapiiretê, tapiire'te, tapiiruçu, tapiirussu, tapi'irusu, tapi'í-rusú, tapijerete, tapïjra, tapijrete, tapikira, tapikra, tapir, tapira, tapïra, tapĩra, tapira-caaiúra, tapira-caapora, tapira-caapóra, tapiraçu, tapira-etê, tapir-americano, tapirapoã, tapira-sobaiguara, tapirassou, tapirassu, tapirassú, tapiratí, tapira-uborim, tapirete, tapireté, tapiretê, tapiretê, tapirêtê, tapí-reté, tapirierete, tapiro, tapirosú, tapirousou, tapiroussu, tapiroussú, tapirovssov, tapiruçu, tapiruçú, tapirussú, tapiruzú, tapiryra-caapóra, tapir-xuré, tapiy, tapiye-ete, tapiyr, tapiyra, tapiýra, tapiyra-caapora, tapiŷra-caapóra, tapiyra-cauara, tapiyra-ete, tapiyre-ete, tapiyre-été, tapiyré-été, tapiyreté, tappire, tapura, tapüra, tapyi, tapyira, tapyîra, tapyira-caapoara, tapyîra-caápoára, tapyira-caapora, tapyirá-caapóra, tapyíra-caapóra, tapyira-cäá-pora, tapyiracäó-pora, tapyira-eté, tapyíra-eté, tapyire-eté, tapyr, tapyra, tapy'ra, tapyra-assu, tapyra-caapora, tapy'ra-caapóra, tapyra-caiuara, tapyra-caiura, tapyra-capora, tapyra-sabetyra, tapy'ra-oçu, tapyra-sabetyra, tapyre-eté, tapyrete, tapyreté, tapyretê, tapyyre-été, topiraffore, uaca-do-mato, vaca-do-mato, xuré, xurê. Certos antílopes norte-africanos foram chamados oryx por autores gregos e romanos. Os autores árabes conheciamnos como Lamt (ou lamta, elamt, lant, dant) e usavam sua pele na confecção de escudos (daraqqa-lamțiyya). Com a invasão muçulmana da Península Ibérica, daraqqa-lamtiyya tranformou-se em adarga-danta e sob esta forma foi citada por numerosos autores espanhóis e portugueses. Consequentemente, os Oryx africanos foram chamados anta por Gomes Eanes de Zurara (1453) e danta por um autor anônimo (MS Valentim Fernandes, 1507) e Duarte Lopes (in Pigafetta \& Lopes, 1589). Antonio Pigafetta (in Anôn., ca. 1526) referiu-se, sob o nome anta, ao estranho animal que os índios de língua Tupi do Brasil denominavam tapir. Tapir e anta (com muitas variantes e com a adição de vários qualificativos) foram usados por autores subsequentes. Finalmente, no Brasil, o uso impróprio de anta para designar as espécies de Tapirus suplantou a de tapir. Uma confusão adicional foi acrescentada por alguns autores, que confundiram as antas sul-americanas com o alce do Velho Mundo, chamando as primeiras de grã-bestas (e variantes).

Palavras-Chave. Tapirus; América do Sul; Nomes populares; Oryx; Lamt; Anta; Tapir; Grã-Besta; História dos nomes populares.

\section{SUMÁRIO}

1. AS ESPÉCIES DE ORYX E O ADDAX NO NORTE E NORDESTE DA ÁFRICA $\ldots \ldots \ldots \ldots \ldots \ldots \ldots \ldots \ldots \ldots$

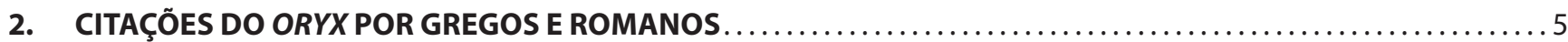

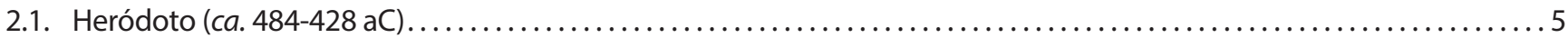

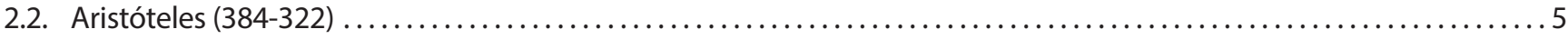

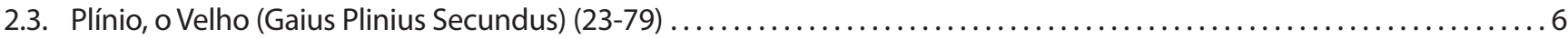

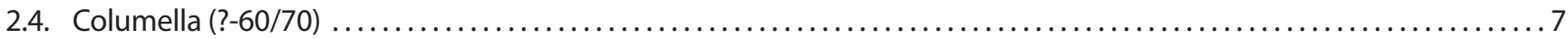

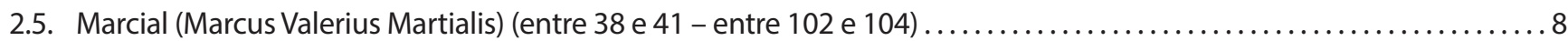

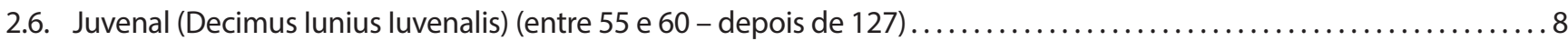

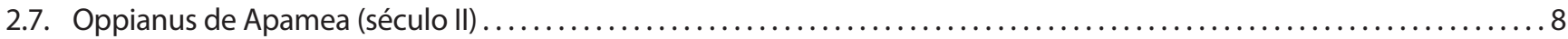

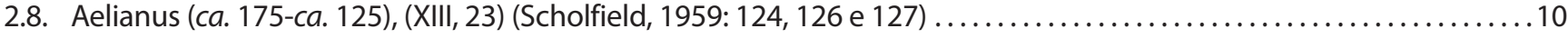

\section{O LAMT (ادل) (OU LAMTA, ELAMT, LANT, DANT) (ORYX DAMMAH) E O DARAQQA-LAMTIYYA DOS}

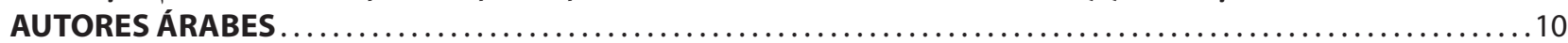

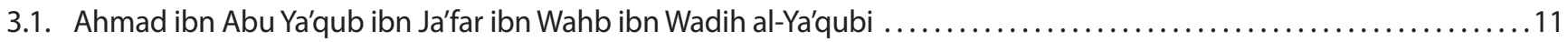

3.4. Abū 'Ubayd 'Abd Allāh ibn 'Abd al-'Azīz ibn Muḥammad ibn Ayyūb ibn 'Amr al-Bakrī, or simply Al-Bakri ............. 12

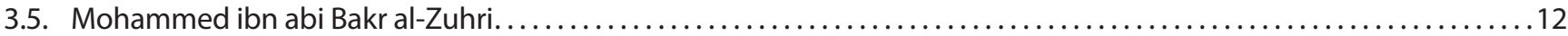

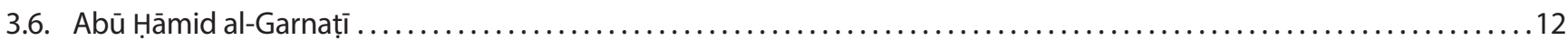

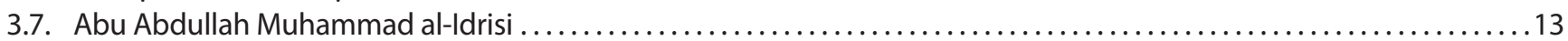

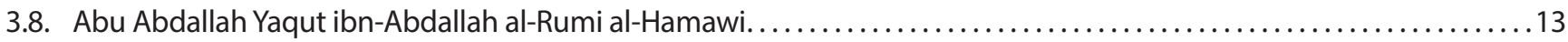

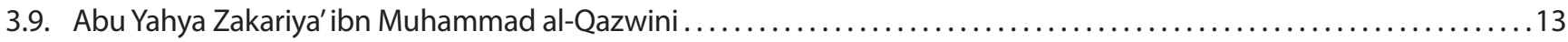

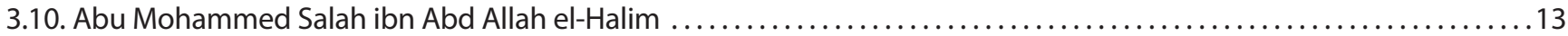

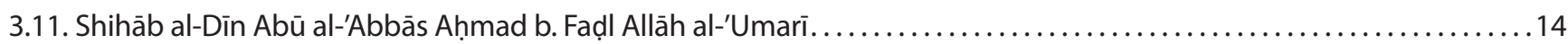

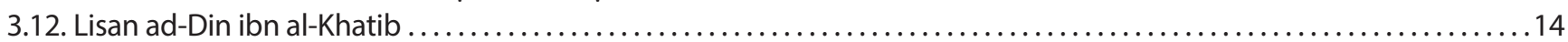

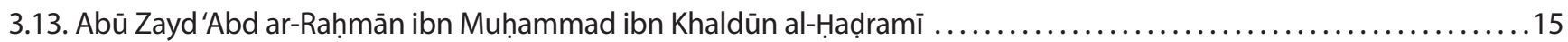

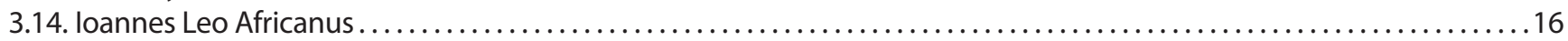

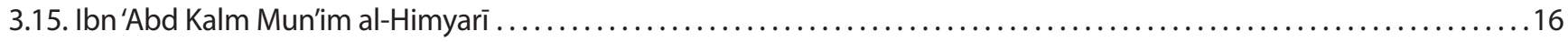

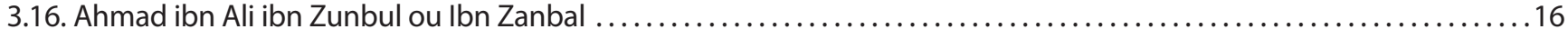

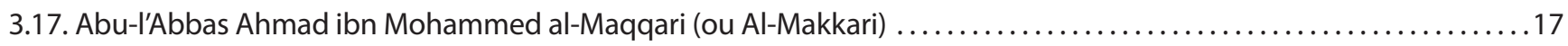

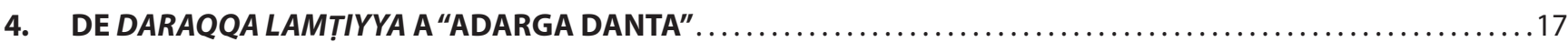




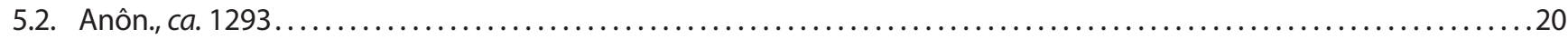

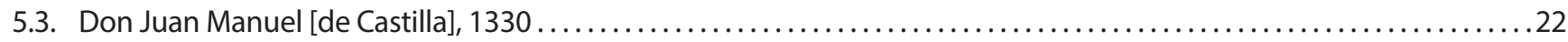

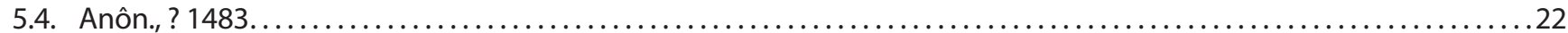

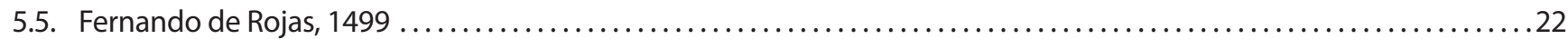

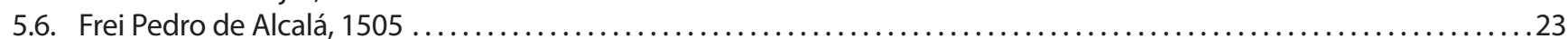

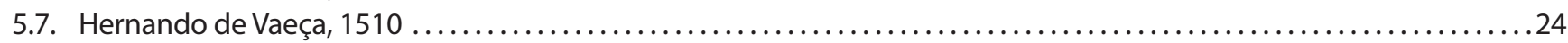

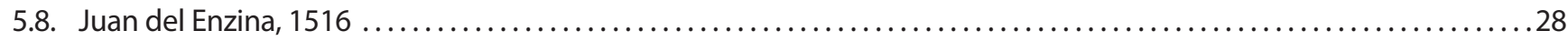

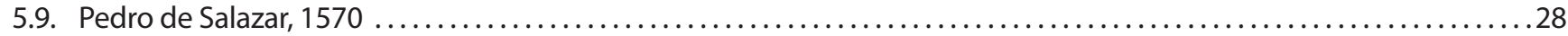

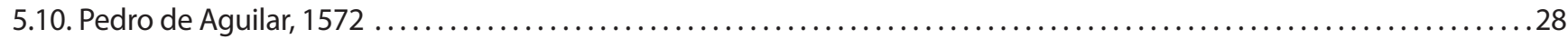

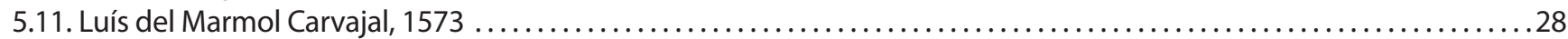

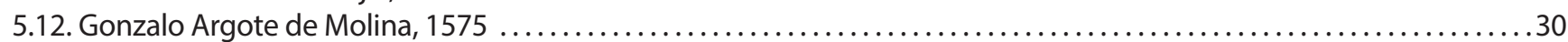

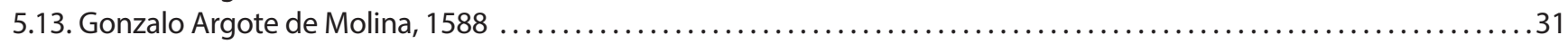

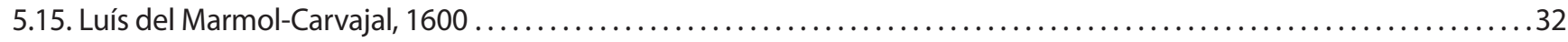

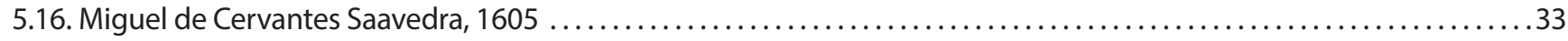

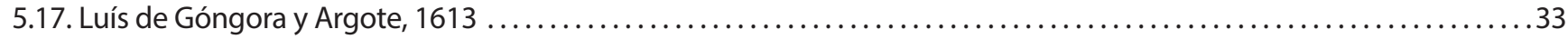

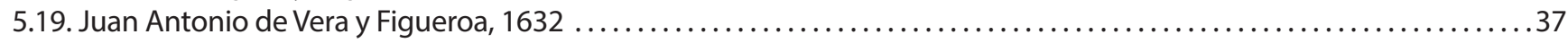

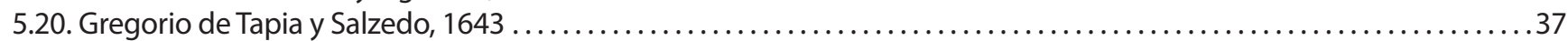

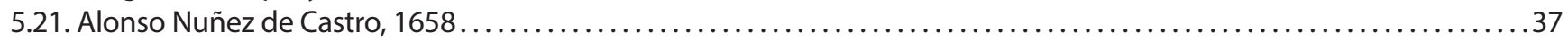

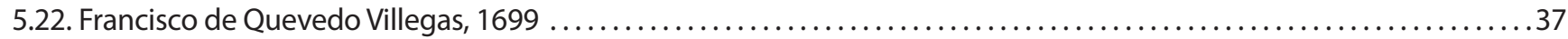

6. ALGUMAS CITAÇÕES DA ADARGA NOS ESCRITOS DE AUTORES PORTUGUESES DOS SÉCULOS XV A XVII. . .38

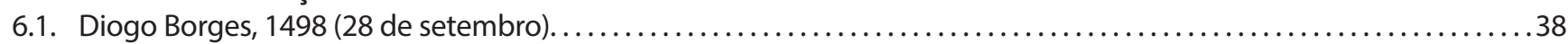

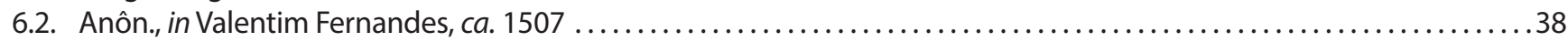

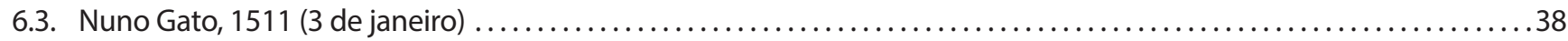

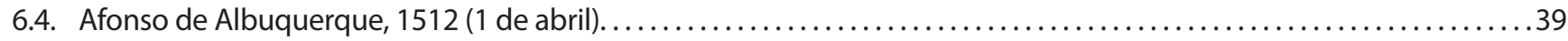

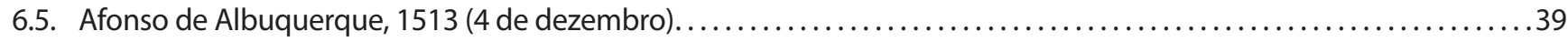

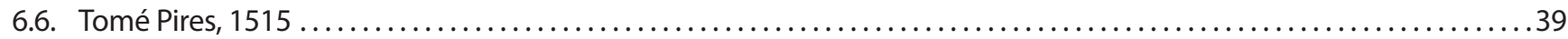

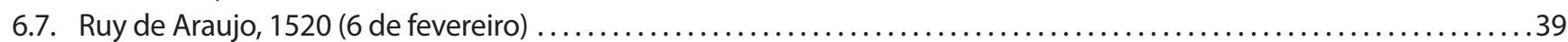

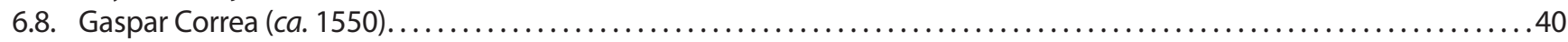

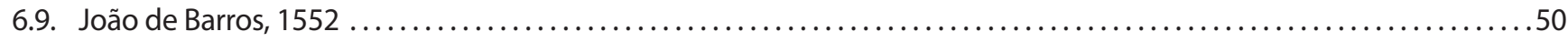

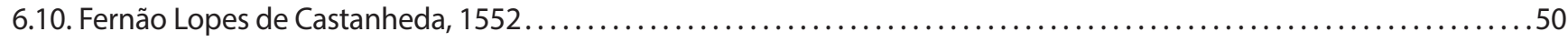

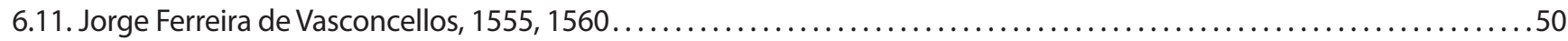

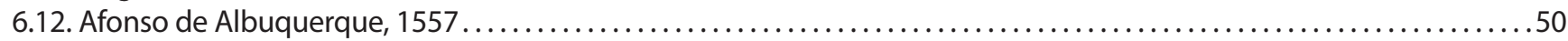

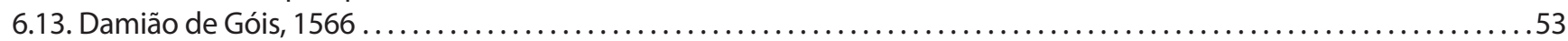

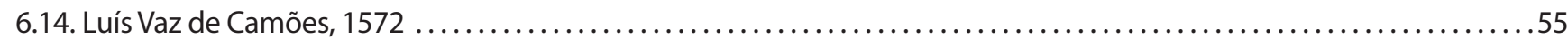

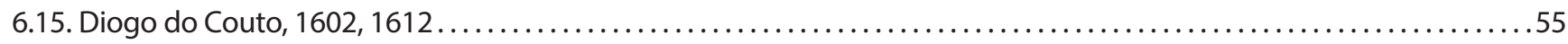

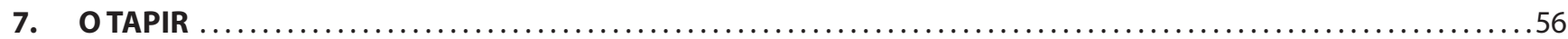

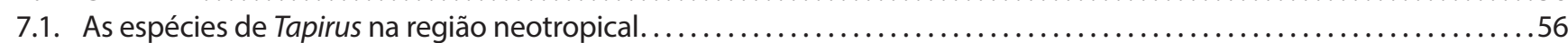

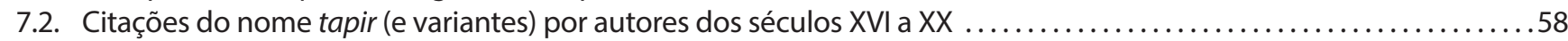

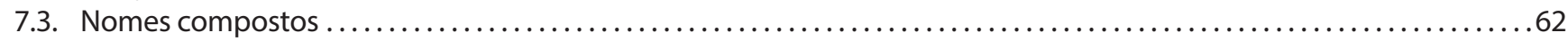

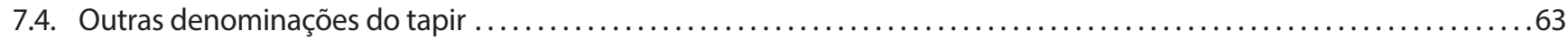

8. A ANTA OU DANTE DA ÁFRICA E A ANTA (ANTE, DANTA, DANTE) SUL-AMERICANA .................64

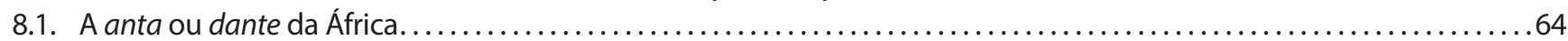

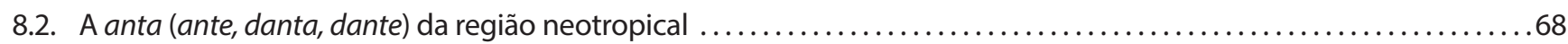

8.3. Citações do nome "anta" (e variações) por autores dos séculos XVI a XVIII ............................

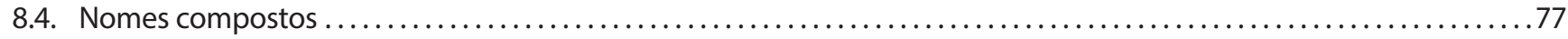

9. UMA QUESTÃO EM ABERTO: ANTA-SAPATEIRA E ANTA-XURÉ: DUAS ESPÉCIES DISTINTAS?.............78

9.1. A anta-sapateira (ou anta-batupeva, caapora, gameleira, lubuna, tapira-caapora, tapirassu) .....................78

9.2. A anta-xuré (ou anta-batuvira, cambacica, anta-chure, antacuré, anta-mirim, anta-pequena, anta-pororoca,

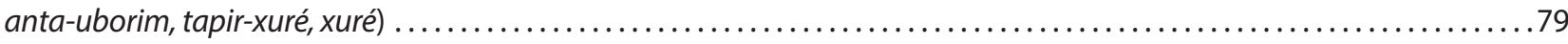

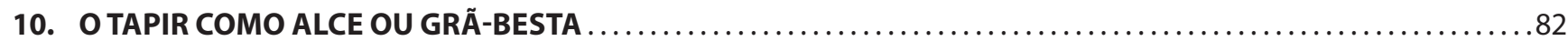

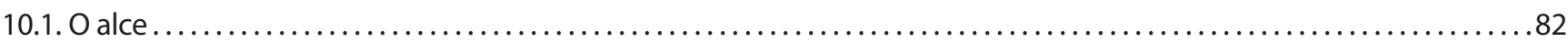

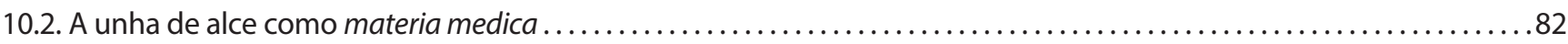

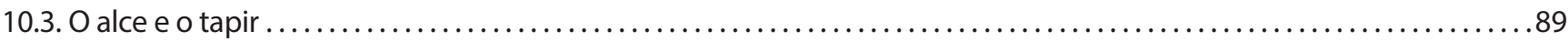




\section{AS ESPÉCIES DE ORYX E O ADDAX NO NORTE E NORDESTE DA ÁFRICA}

Três espécies de Oryx (Artiodactyla, Bovidae, Hippotraginae) ocorriam no norte e nordeste da África.

O Oryx dammah (Cretzschmar, 1827) [Figura 1.1 e 1.3], conhecido em inglês como scimitar oryx, scimitar-horned oryx ou Sahara oryx, antes largamente distribuído no Norte da África, foi extinto, no estado selvagem, em 2000. Esse antílope tem pouco mais de um metro na altura do ombro. Os machos pesam entre 140 e $210 \mathrm{~kg}$ e as fêmeas entre 91 e $140 \mathrm{~kg}$. A pelagem é branca, com o peito vermelho-acastanhado e manchas pretas na fronte e ao longo do nariz.

Os filhotes nascem com uma pelagem amarelada sem manchas ditintas e mudam sua cor com 3 a 12 meses de idade.

Esse oryx formava rebanhos com ambos os sexos de até 70 membros, normalmente guiados por machos. Habitavam desertos e semi-desertos e estavam adaptados para viver sob calor extremo graças a seu eficiente mecanismo de resfriamento e baixíssima necessidade de água. Alimentavam-se de folhagens, capins e plantas suculentas durante a noite ou a madrugada. O pico dos nascimentos ocorria entre março e outubro. Após uma gestação de oito ou nove meses nascia um filhote.

O declínio da espécie iniciou-se como um resultado da mudança climática e mais tarde pela intensa caça, para a obtenção de seus cornos. Atualmente é criado em cativeiro em reservas especiais na Tunísia, Marrocos e Senegal, e em ranchos de animais exóticos no Texas. Em 2016 foi lançado um programa de reintrodução e atualmente um pequeno rebanho foi reintroduzido com sucesso no Chad.

O Oryx dammah fora domesticado no Antigo Egito, acreditando-se que era utilizado como alimento e como oferendas aos deuses. $\mathrm{O}$ uso de suas valiosas peles começou durante a Idade Média. [veja em: wikipedia].

O Oryxdammah (Cretzschmar, 1827) (=Antilopeleucoryx Lichtenstein, 1828) (Sclater \&Thomas, 1899: pl. LXXXI) [Figura 1.2], em inglês Arabian oryx oy white oryx, é um antílope de tamanho médio, o menor do gênero, com uma gibosidade nos ombros, cornos retos e longos e uma cauda tufada, nativo das áreas de deserto e estepes da Península Arábica. Foi extinto na natureza no início dos anos de 1970, mas salvo em zoológicos e reservas particulares e reintroduzido na natureza em 1980.

O Addax nasomaculatus (Blainville, 1816) [Figura 1.4] é provido de longos cornos anelados desenvolvendo-se em espiral. Próprio das regiões de deserto, possui cascos largos e arredondados, bem adaptados à marcha sobre a areia. A sua cor é amarelada, com cabeça e pescoço negros, sendo a cauda e as patas brancas. Sobre a distribuição geográfica desta espécie escreveram Krausman \& Casey (2007: 1):

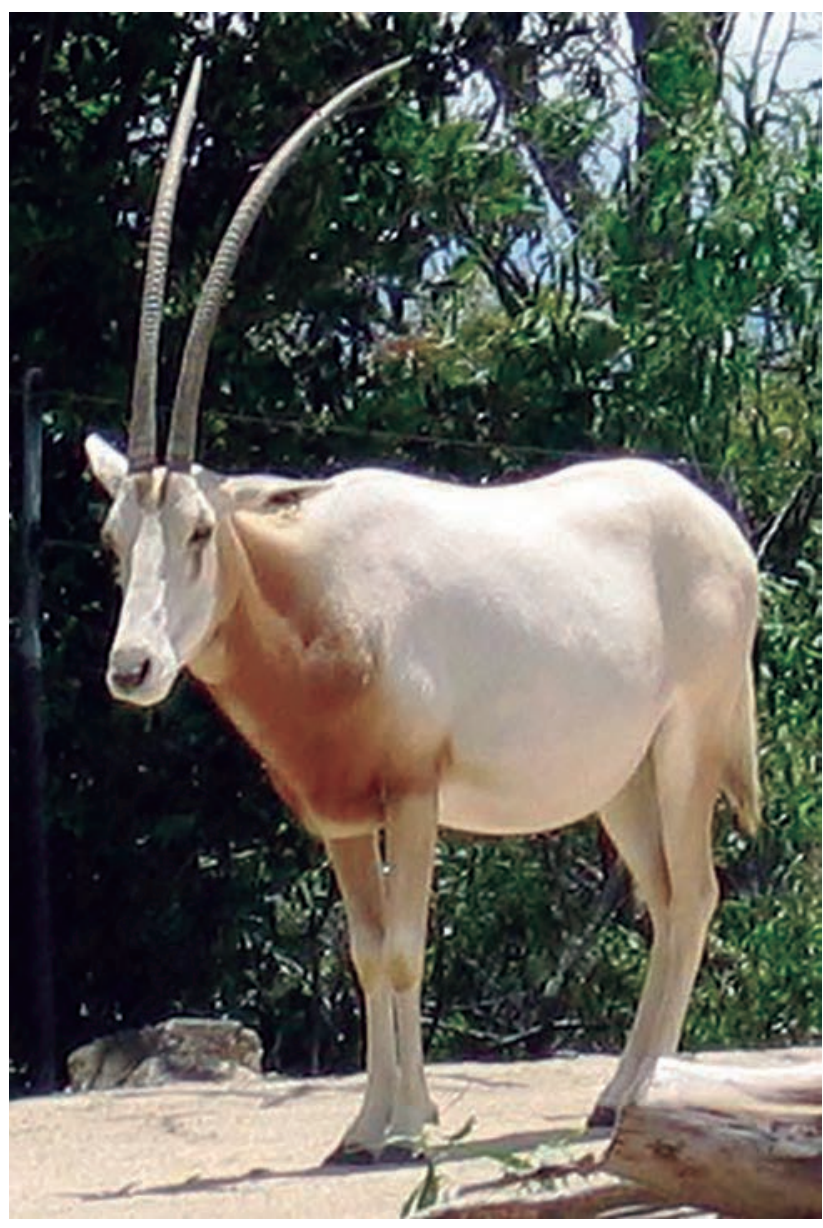

Figura 1.1. Oryx dammah (Cretzschmar, 1827).

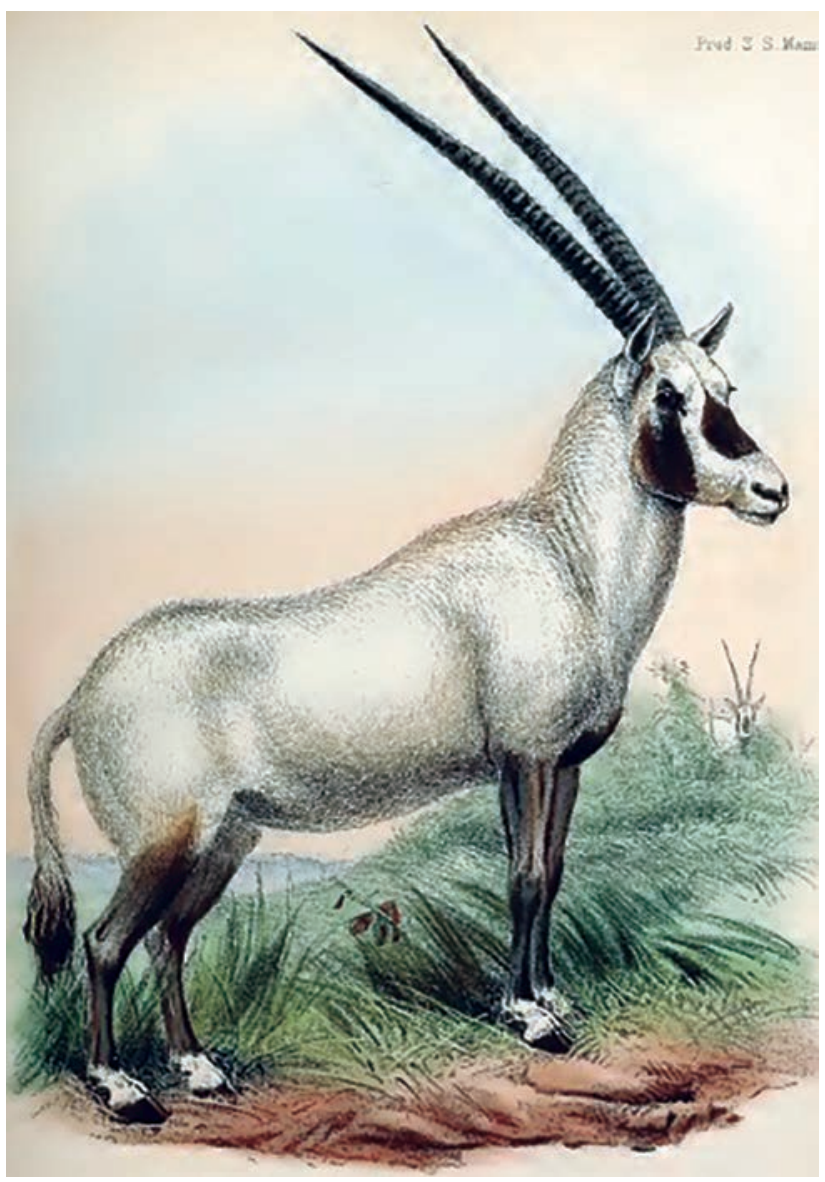

Figura 1.2. Oryx leucoryx (Pallas, 1777) (Gray, 1857: pl. LV, como Oryx beatrix). 


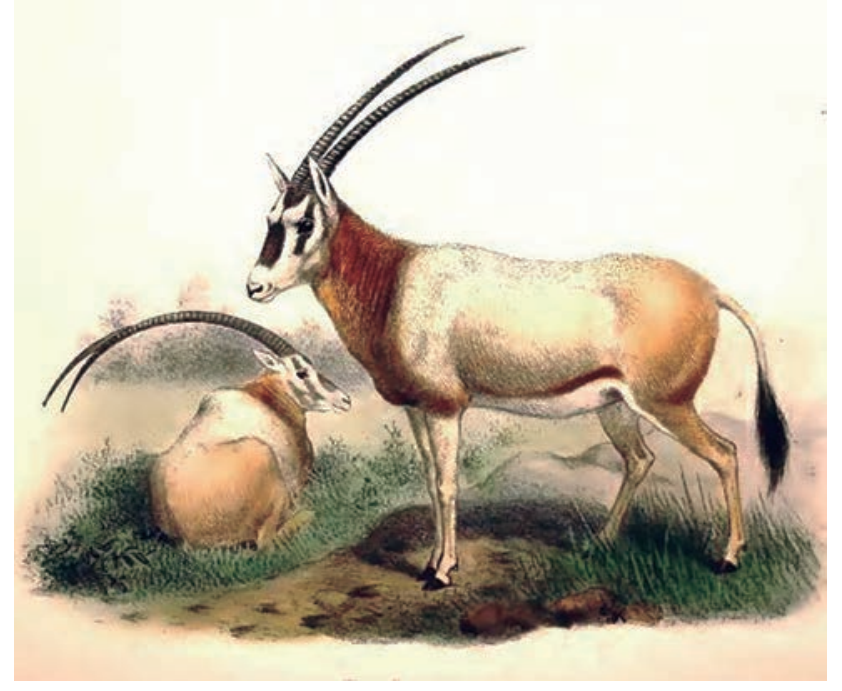

Figura 1.3. Oryx dammah (Cretzschmar, 1827) (= Antilope leucoryx Lichtenstein, 1827) (Sclater \& Thomas, 1899: pl. LXXXI).

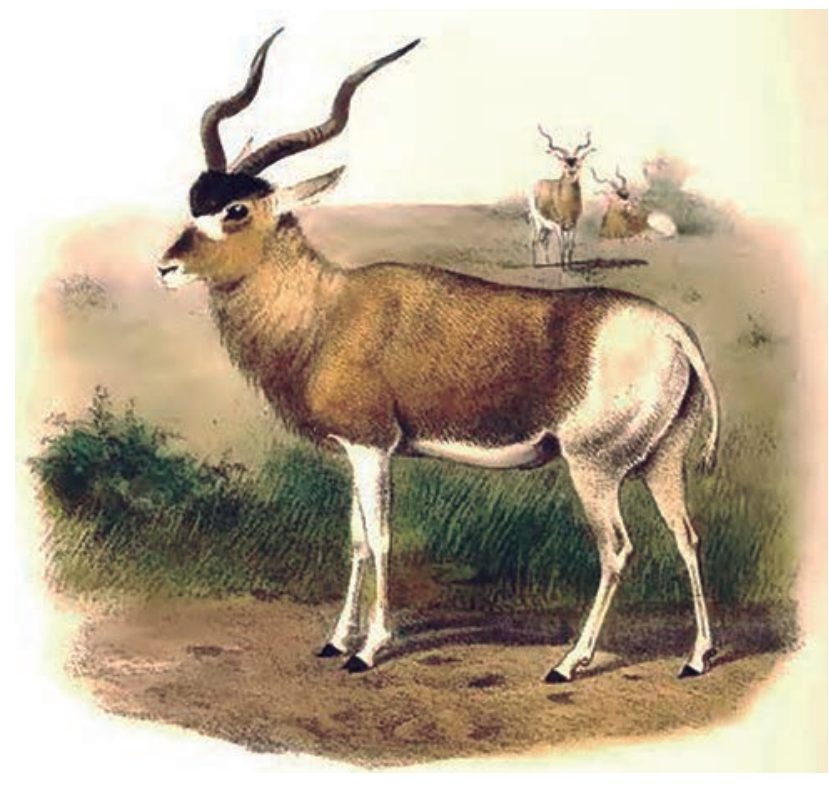

Figura 1.4. Addaxnasomaculatus (Blainville, 1816) (Sclater \& Thomas, 1899: pl. LXXXVI).

"Former distribution of $A$. nasomaculatrus included the entire Sahara and Libyan deserts from Rio de Oro and suthrn Morocco to Egypt and Sudan, from northern edge of sand in Algeria, Tunisia, and Libya to $\mathrm{ca} \cdot 14^{\circ} \mathrm{N}$ in the south Haltenorth \& Diller, 1980). Addax has been extinct in Jordan since ca. 1900 and became extinct in Egypt and Morocco by the mid-20 th century. Addax was exterminated in Algeria, Libya and Tunisia".

\section{CITAÇÕES DO ORYX POR GREGOS E ROMANOS}

\subsection{Heródoto (ca. $484-428$ aC)}

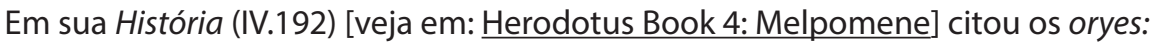

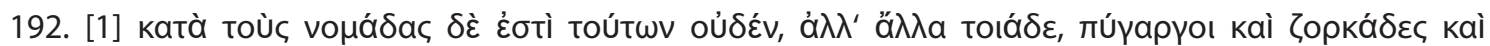

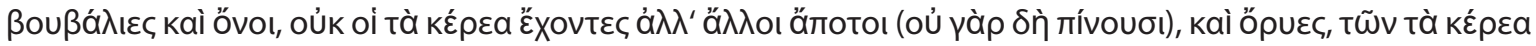

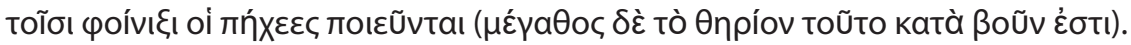

192. In the land of thenomads however there exist none of these, but other animals as follows: whiterump antelopes, gazelles, buffaloes, asses, not the horned kind but others which go without water (for in fact these never drink), oryes, whose horns are made into the sides of the Phenician lyre (this animal is in size about equal to an ox).

\subsection{Aristóteles (384-322)}

Na História dos Animais (II, I, 15-32) (Peck, 1965: 88, 89) consta:

15 "E

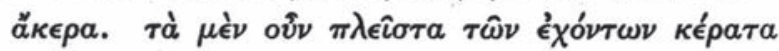

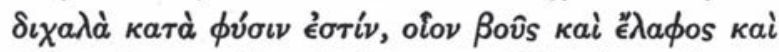

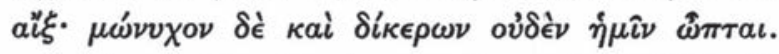

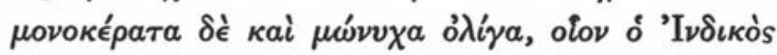

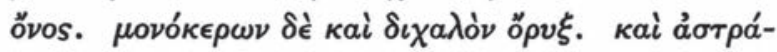

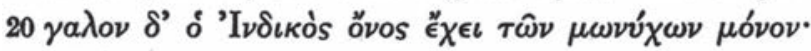

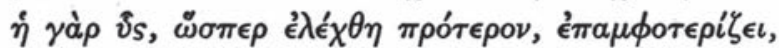

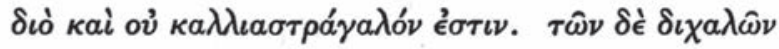

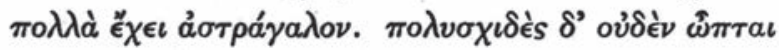




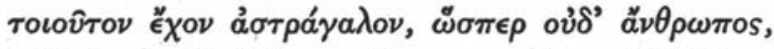

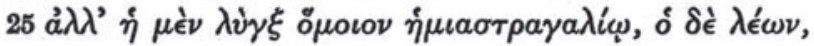

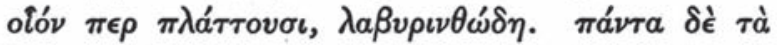

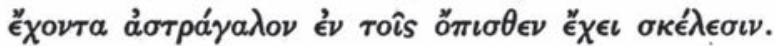

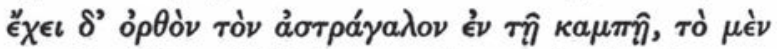

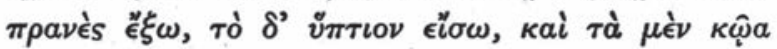

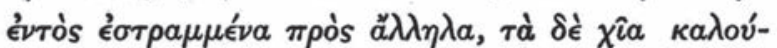

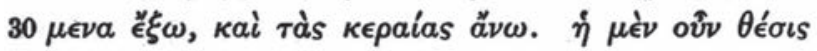

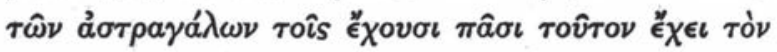
$\tau \rho o ́ \pi o v$.

"Further, some animals are horned, some hornless. Most of the horned ones are cloven-hoofed, e.g., the ox, the deer, and the goat; we have seen no solid-hoofed animal with a pair of horns. But a few, e.g., the Indian ass, have a single horn and are solid-hoofed. The oryx has a single horn [sic] and cloven hooves. The only solid-hoofed animal with a huckle-bone is the Indian ass - as we said before, the pig is a dualizer, and therefore it has no proper huckle-bone. The huckle-bone is present in many of the cloven-hoofed animals. No polydactylous animal has been observed to possess a huckle-bone of this sort, any more than man has. Nevertheless, the lynx has one like a half-astragal, and the lion has one like the 'labyrinth' used in moulding. All those which have a huckle-bone have it in the hind legs. The huckle-bone is set upright in the joint: the upper part outside and the lower part inside: the sides known as the Coan are inside, turned towads each other, the sides known as the Chian are outside, and the keraiai ('horns') are on top. So this is the position of the huckle-bone in all animals that have one".

E em seu livro Partes dos Animais (Peck, 1961: 218, 220 e 219, 221):

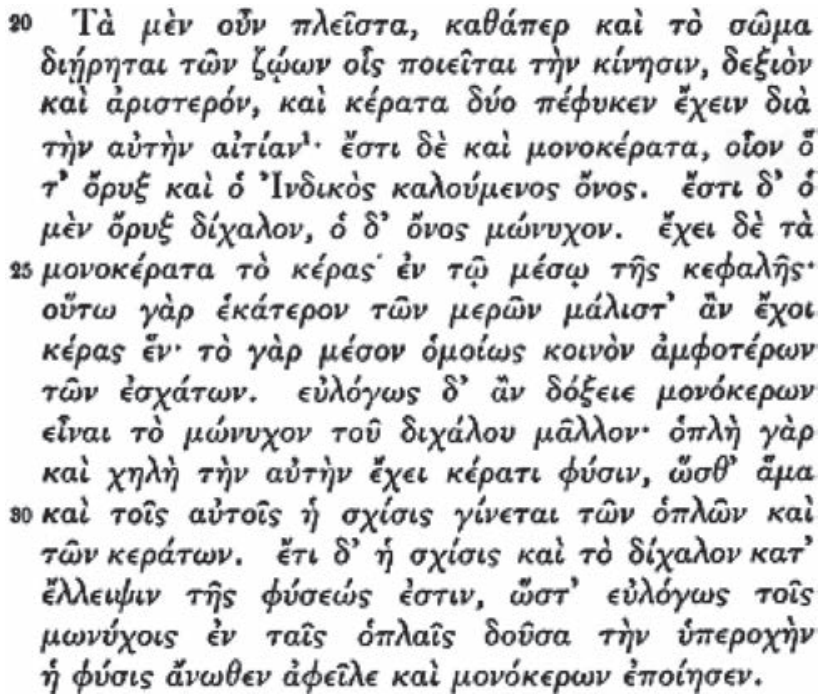

"The great majority of horned animals have two horns, just as, in respect of the parts by which its movement is effected, the body is divided into two - the right and the left. And the reason in both cases is the same. There are, however, some animals that have one horn only [sic], e.g., the oryx (whose hoof is cloven) and the 'Indian Ass' (whose hoof is solid). These creatures have their horn in the middle of the head: this is the nearest approximation to letting each side have its own horn, because the middle is common equally to both extremes. Now it is quite reasonable that the one horn should go with the solid hoof rather than with the cloven hoof, because hoof is identical in nature with horn, and we should expect to find divided hoofs and divided horns together in the same animal. Again, division of the hoof is really due to deficiency of material, so it is reasonable that as Nature has used more material in the hoofs of the solidhoofed animals, she has taken something away from the upper parts and made one horn only".

\subsection{Plínio, o Velho (Gaius Plinius Secundus) (23-79)}




\section{Capítulo VIII, LXXIX:}

"Sunt et oryges, soli a quibusdam dicti contrario pilo vestiri et ad caput verso, sunt et dammae et pygargi et strepsicerotes multaque alia haut dissimilia. Sed illa Alpes, haec transmarine situs mittunt" (Rackham, 1967: 148, 150).

"There are also the oryx, the only species according to certain authorities clothed with hair lying the wrong way, towards the head, and the antelope, the white-rumped antelope, the twisted-horn antelope and a great many other not dissimilar species. But the former we receive from the Alps, the latter from places across the sea" (Rackham, 1967: 149, 151).

\section{Capítulo X, XCIV:}

"In potu autem quibus serrati dentes lambunt, et mures hi vulgares, quamvis ex alio genere sint; quibus continui dentes sorbent, ut equi, boves; neutrum ursi, sed aquam quoque morsu vorant. In Africa maior pars ferarum aestate non bibunt inopia imbrium, quam ob causam capti mures Libyci si bibere moriuntur. orvgem perpetuo sitientia Africae generant ex natura loci potu carentem et mirabili modo ad remedia sitientium: namque Gaetuli' latrones eo durant auxiho repertis in corpore eorum saluberrimi liquoris vesicis' (Rackham, 1967: 420).

"In drinking, animals with serrated teeth lap, and so does our common mouse, though it really belongs to another class; those with teeth that touch suck, for instance horses and cattle; bears do neither, but gulp water as well as food in bites. In Africa the greater part of the wild animals do not drink at all in summer, owing to lack of rains for which reason Libyan mice in captivity die if given drink. The perpetually dry parts of Africa produce the antelope, which owing to the nature of the region goes without drink in quite a remarkable fashion, for the assistance of thirsty people, as the Gaetulian brigands rely on their help to keep going, bladders containing extremely healthy liquid being found in their body" (Rackham, 1967: 421).

\section{Capítulo XI, CVI:}

"Ungulae veterino tantum generi renascuntur. Sues in Illyrico quibusdam locis solidas habent ungulas. Cornigera fere bisulca. Solida ungula et bicorne nullum, unicorne asinus tantum Indicus, unicorne et bisulcum oryx. Talos asinus Indicus unus solidipedum habet, nam sues ex utroque genere existimantur, ideo foedi earum" (Rackham, 1967: 592).

"Only with animals of the draught kind do the hooves grow agam. In some places in Illyria pigs have solid hooves. Horned animals mostly have cloven hooves. No species has both solid hooves and two horns; the only animal with one horn is the rhinoceros, and the only one with one horn and cloven hooves the antelope" (Rackham, 1967: 593).

\subsection{Columella (?-60/70)}

No Re rustica (IX.1.5-8) (Forster \& Heffner, 1954: 426, 427) temos:

1 "Getulia was the name given to an ancient district in North Africa, which in the usage of Roman writers comprised the nomadic tribes of the southern slopes of Mount Aures and the Atlas, as far as the Atlantic, and the oases in the northern part of the Sahara. The Gaetulian people were among the oldest inhabitants of Northern Africa. They mainly occupied the area of modern day Algeria as far north as Gigthis in the southwestern region of Tunisia. They were bordered by the Garamantes people to the right and were under the coastal Libyes people. The coastal region of Mauritania was above them and, although they shared many similar characteristics, were distinct from the Mauri people that inhabited it. The Gaetulians were exposed to the conditions of the harsh African interior near the Sahara and produced skillful hardened warriors. They were known for horse rearing, and according to Strabo had 100,000 foals in a single year. They were clad in skins, lived on meat and milk, and the only manufacture connected with their name is that of the purple dye that became famous from the time of Augustus, and was made from the purple shellfish Murex brandaris found on the coast, apparently both in the Syrtes and on the Atlantic". [veja em: theodora.com].

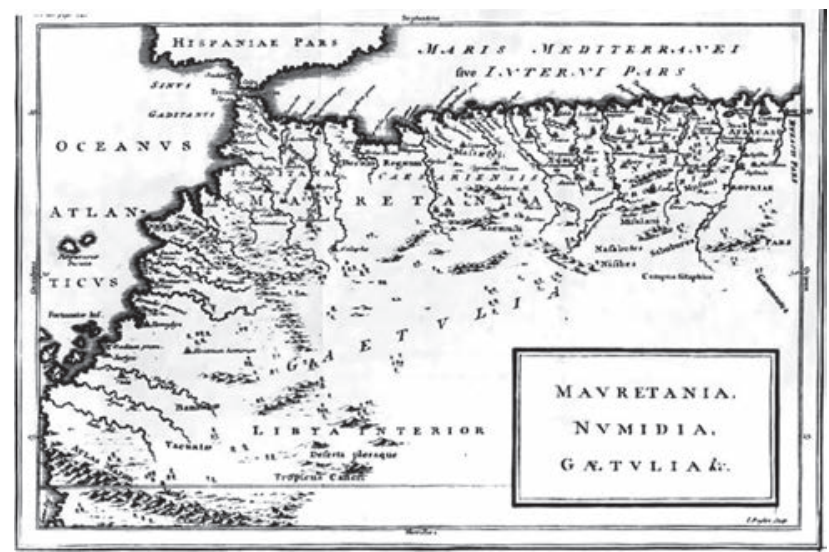


"Itaque custos vivarii frequenter speculari debebit, si iam effectae sint, ut manu datis sustineantur frumentis. Nec vero patiendus est oryx, aut aper, aliusve quis ferus ultra quadrimatum senescere. Nam usque in hoc tempus capiunt incrementa, postea macescunt senectude. Quare dum viridis aetas pulchritudinem corporis conservat, aere mutandi sunt".

"And so the park-keeper will have frequently to be on the watch and see if they have borne their young, in order that their strength may be sustained by cereals given them by hand. Buth neither the antelope nor the wild boar nor any other wild creature should be allowed to live to a greater age than four years. For up to that time they advance in growth, after it they grow old and lean; and so they should be turned into cash while a vigorous time of life preserves their bodily comeliness".

\subsection{Marcial (Marcus Valerius Martialis) (entre 38 e 41 - entre 102 e 104)}

Nos Epigrammata (XIII.XCV. - Oryx) (Ker, 1920: 424, 425) consta:

"Matutinarum non ultima praeda feraeum saevos oryx constat quot mihi morte canum!".

"Not the meanest quarry among the beasts of morning shows, the savage oryx costs me the death of how many dogs!".

\subsection{Juvenal (Decimus Iunius luvenalis) (entre 55 e 60 - depois de 127)}

Em Satyra (XI, 136-141) (Ramsay, 1928: 230, 231), lê-se:

"sed nec structor erit cui cedere debeat omnis pergula, discipulus Trypheri doctoris, apud quem sumine cum magno lepus artque aper et pygargus et Scythicae volucres et phoenicopterus ingens et Gaetulus oryx hebeti lautissima ferro caeditur et tota sonat ulnea cena Subura".

"Nor shall I have a carver to whom the whole carving-school must bow, a pupil of the learned Trypherus, in whose school is cut up, with blunt knives, a magnificent feast of hares and sow's paunches, of boars and antelopes, of Scythian fowls and tall flamingoes and Gaetulian gazelles, until the whole Subura rings with the clatter of the elm-wood banquet".

\subsection{Oppianus de Apamea (século II)}

Em sua Cinegética, citou o oryx duas vezes - na primeira (II, 5-14; cf., Mair, 1928: 54) deve ter-se referido a algum animal inidentificável que habitava a monte Pholoe, na Arcádia, o lar dos Centauros:

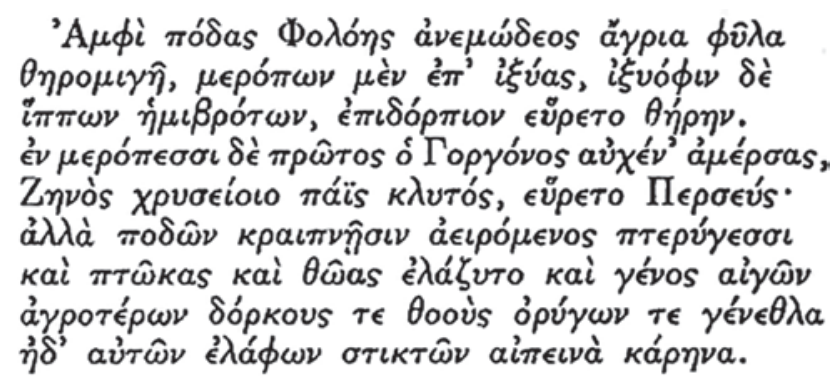

Na tradução de Mair (1928: 95, 97, 99):

"By the foot of windy Pholoe did savage tribes, half-beast half-men, human to the waist but from the waist horses, invent the chase for pastime after the banquet. Among men it was invented first by hum who cut off the Gorgon's head, even Perseus, the son of golden Zeus. Howbeit he soared on the swift winds of his feet to capture Hares, and Jackals and the tribe of wild Goats and swift Gazelles and the breeds of Oryx and the high-headed dappled Deer themselves".

Sua segunda citação (II, 445-493; cf., Mair, 1928: 94, 96, 98) muito provavelmente se refere a Oryx leucoryx:

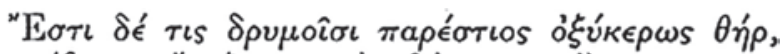
ày 


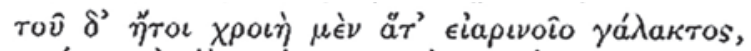

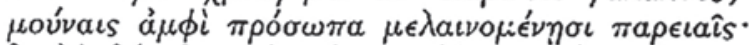

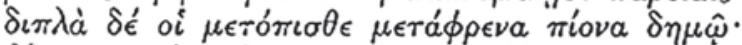

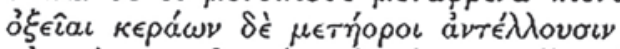

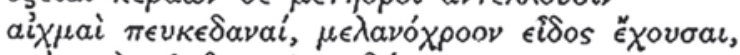

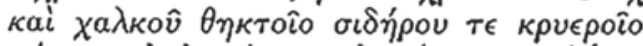

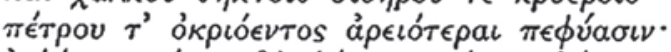

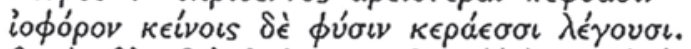

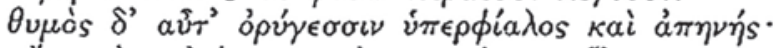

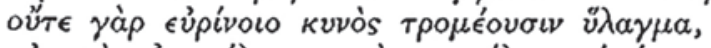

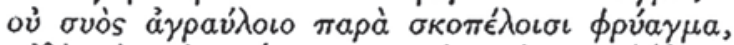

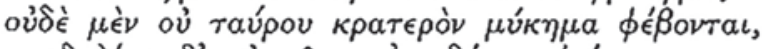

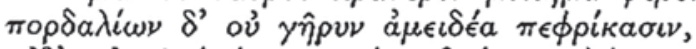

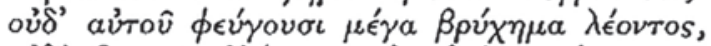

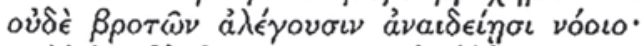

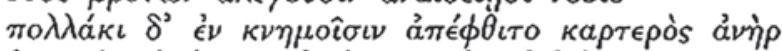

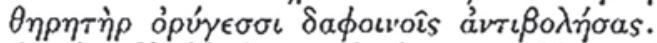

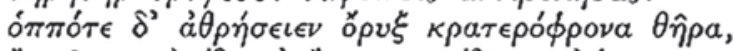

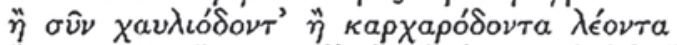

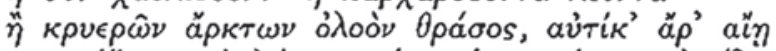

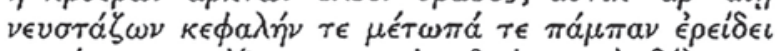

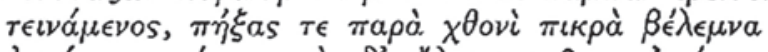

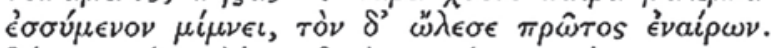

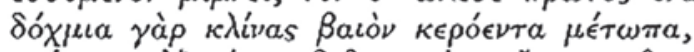

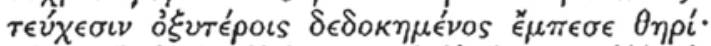

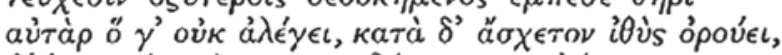

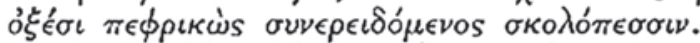

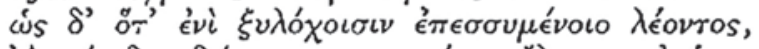

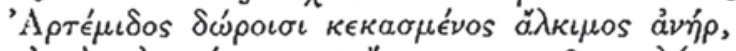

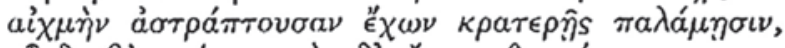

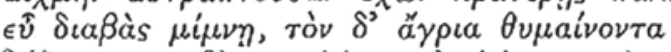

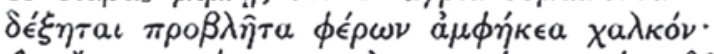

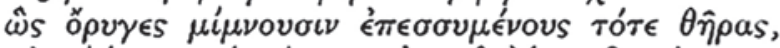

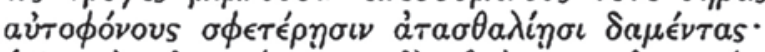

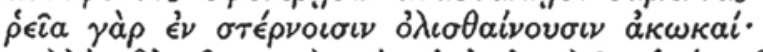

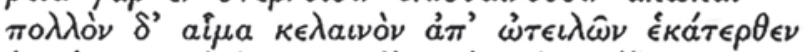

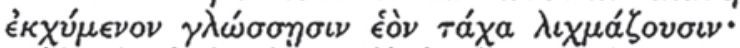

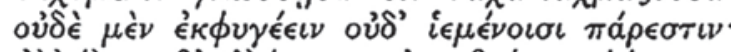

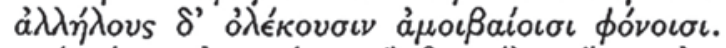

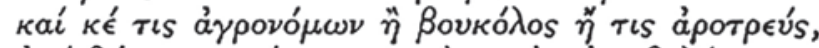

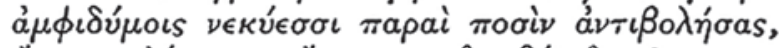

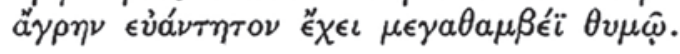

Na tradução de Mair (1928: 95, 97, 99):

"There is a certain shar-horned beast that dwells in the thickets, even the fierce Oryx, most formidable to wild beasts. His colour is even as that of milk in spring, only the cheeks about his face being black [cf., Figura 1.2]. He has a double back, rich in fat. Sharp rise aloft the piercing points of his horns, black of hue, which are mightier than whetted bronze or chilly iron or jagged rock, and men say that those horns have a venomous nature. The spirit of the Oryx is overweening and stern. For they tremble neither at the yelping of the keen-scented Hound nor at the snorting of the wild Boar among the rocks, neither do they fear the mighty bellowing of the Bull nor shudder at the mirthless cry of the Leopard nor the might roar of the Lion himself, nor in the dauntlessness of their heart do they care aught for men: many a time a mighty hunter has perished on the hills when he has encountered the deadly Oryxes. When the Oryx descries a valiant wild beast, a tusked oar or a saw-toothed Lion or chilly Bear of deadly courage, straightway he bows to earth and holds steadfast his outstretched head and brows, and fixing close to the ground his shrp weapons, awaits the onset of the fee and strikes him first and slays. For bending a little aside his horned brows he watches and springs with his sharper weapons on the beast; which, heeding not, rushes incontinently straight on and horribly clashes with the sharp palisade of his horns. As when in the thickets, as a Lion charges, a valiant man, who is skilled in the fifts of Artemis, holding in his hands his flashing spear, with feet set well apart, awaits him, and, as he rages wildly, receives him with his two-edged brazen spear advanced; even so the Oryxes in that hour await the charge of the wild beasts, who are self-slain by their own folly. For the points of the horns glide easily into thrir breasts, and much dark blood, pouring on either side from the wounds - 
their own blood - they speedily lick with their tongues; nor can they escape if they would, but they slay one another with mutual slaughter. And some countryman, a herdsman or a ploughman, chancing on the two corpses at his feet, with marveling heart wins a welcome prey".

2.8. Aelianus (ca. 175-ca. 125), (XIII, 23) (Scholfield, 1959: 124, 126 e 127)

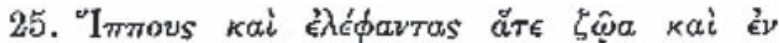

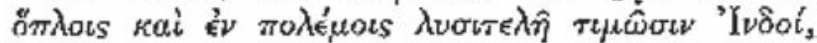

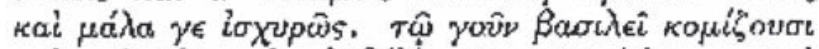

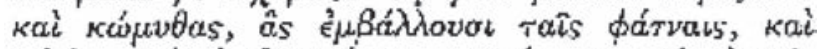

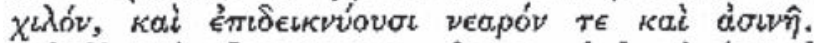

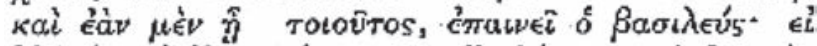

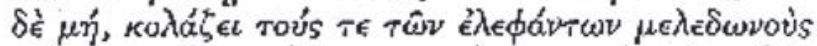

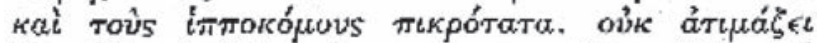
$\delta \dot{~}$ a

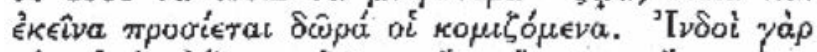

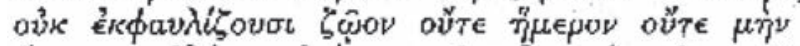

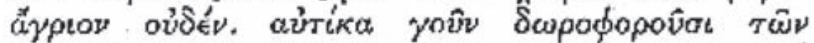

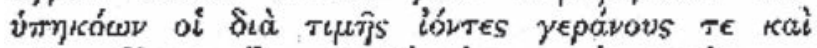

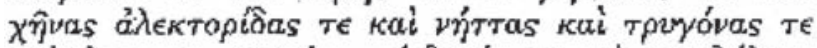

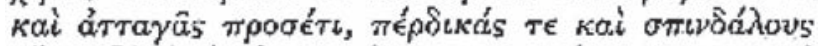

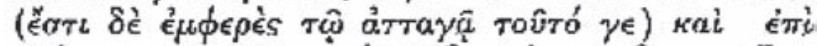

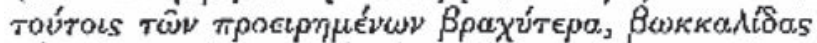

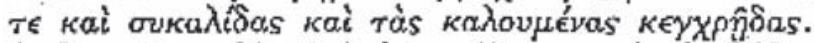

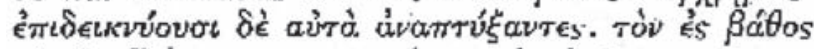

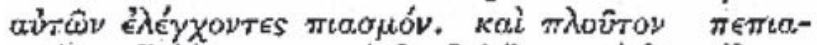

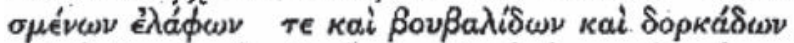

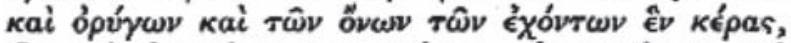

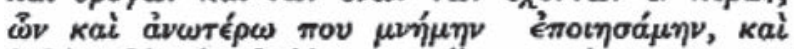

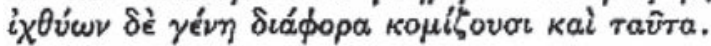

"The Indians value Horses and Elephants as animals serviceable under arms and in warfare; and they value them vry highly. At any rate they bring to the King trusses of hay which they throw into the mangers, and fodder which they show to be fresh and undamaged. And if it is so, the King thanks them; and if it is not, he punishes the keepers of the Elephants and the grooms most severely. But he does not reject even other and smaller animals but accepts the following also when brought to him as presents. For the Indians do not disparage any animal whether tame or wild. For exemple, those of his subjects who hold high office will bring him presents of cranes, geese, hens, ducks, turtle-doves, francolins also, partridges, spindaluses (this bird resembles the francolin), and even smaller birds than the aforenamed, the boccalis, beccaficos, and what are called ortolans. And they uncover their gifts and display them, to prove how thouroghly plump they are. They bring also a wealth of fattened stags, of antelopes [orygon], of gazelles, and one-horned asses, which I have mentioned somewhere earlier on, and different kinds of fish also".

\section{O LAMT (اد)) (OU LAMTA, ELAMT, LANT, DANT) (ORYX DAMMAH) E O DARAQQA-LAMTIYYA DOS AUTORES ÁRABES}

Segundo Viré (1986: 651):

"LAMT, a word of obscure origin which denotes the oryx of the Sahara (...). Now the word is obsolete and occurs only in a proverbial expression inspired by the speed with which it runs: 'he runs like a lamt' (Hadj-Sadok, 1949: 103, no. 159). It is also used in northern Algeria, where Beaussier (Dict., s.v.) ${ }^{2}$ found it applied to a mythical animal which, even though it had only one foot, was very swift.

2 Essa curta passagem está em Beaussier, 1887: 621.

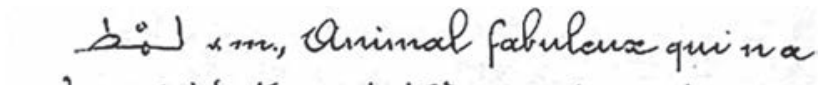

$$
\begin{aligned}
& \text { qu'un pied et court très. rapidernent }
\end{aligned}
$$


Arab geographers of the Middle Ages referred to the lamt in association with the tribe of the Lamța, who were particularly famous for the shields they made from the skin of this animal (daraka lamțiyya). In this expression, the adjective could just as well been derived from Lamța as from lamț, so the two terms may only be apparently related and the connection may be an arbitrary one".

Escreveram sobre o escudo, ou sobre o órix os autores citados na sequência ${ }^{3}$.

\subsection{Ahmad ibn Abu Ya'qub ibn Ja'far ibn Wahb ibn Wadih al-Ya'qubi}

Geógrafo e historiador, era o bisneto de Wadih, um liberto do califa Al-Mansur. Até 873 viveu na Armênia e no Khorasan, trabalhando sob o patrocínio da dinasta iraniana dos Tahirid4; viajou depois para a Índia, o Egito e o Maghreb. Morreu no Egito no ano da Hégira de 284 (897/8). Escreveu Kitab al-Buldan (Árabe: نادلبلا باتك) (Livro dos Países). Goeje (1892) publicou essa obra, em árabe; Wiet (1937) uma tradução francesa.

Segundo Viré (1986a: 611):

"The earliest mentions of these shields (darak) may be found in al-Yakūbī (K. al-Buldān, 345, tr. Wiet, Cairo 1957,206, n.I.), who says simply that they were white in colour".

\subsection{Ibn al-Faqih al-Hamadhani}

Ibn al-Faqih al-Hamadhani (ca. 903) (Persa: (عناذمهل oىف نب) foi autor de uma obra sobre geografia, o Mukhtasar Kitab al-Buldan ("Livro conciso das terras"), escrito ao redor do ano de 903 . O texto original está perdido, mas uma versão resumida, possivelmente composta ao redor de 1022, sobreviveu em vários manuscritos, dos quais apenas três eram conhecidos quando Goeje (1885) publicou uma edição (em árabe). Uma tradução francesa foi publicada por Massé (1973).

\subsection{Abu al-Ḥasan ‘Alī ibn al-Ḥusayn ibn ‘Alī al-Mas`ūdī}

Abu al-Ḥasan 'Alī ibn al-Ḥusayn ibn 'Alī al-Mas'ūdī (Arabic: بيدو عسجا يل ca. 896-956) was an Arab historian and geographer. He is sometimes referred to as the Herodotus of the Arabs. Al-Mas'udi was one of the first to combine history and scientific geography in a large-scale work, The Meadows of Gold and Mines of Gems (Arabic: رoاو جلا نداعجو بهذل جورم, Muruj adh-dhahab wa ma'adin al-jawhar), a world history.

Barbier de Meynard \& Courteville (1869: 18) reproduziram o seguinte trecho em árabe:

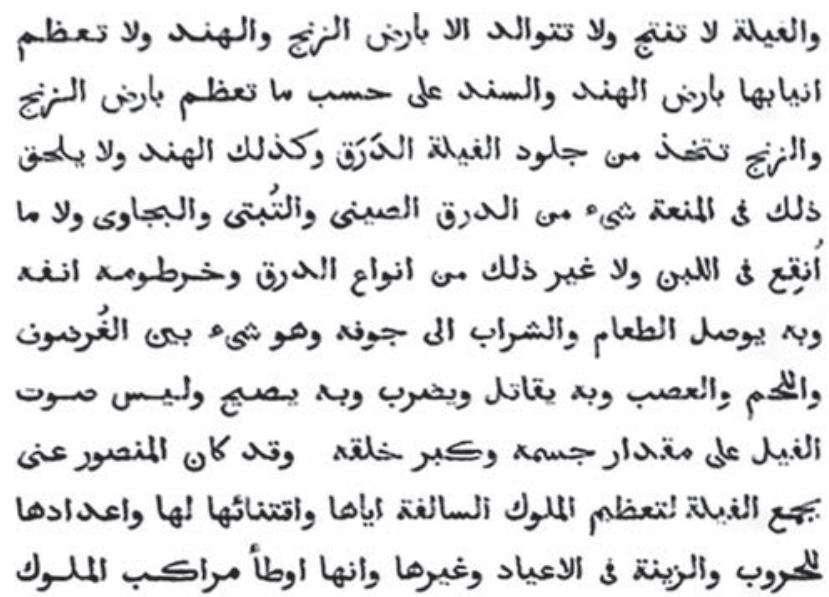

Na mesma página, em sua tradução, o trecho que nos interessa é o seguinte:

“C'est seulement chez les Zendjes et dans I'Inde que les éléphants sont aptes à la reproduction. Dans I'Inde et le Sind, leurs defenses n'ont pas le meme développement que chez les Zendjes; ceux-ci, de meme que les Indiens, fabriquent des voucliers avec le cuir de l'éléphant; mais ces boucliers sont loin d'être aussi solides que si fnt en Chine, au Tibet, et chez les Bedjah. Le cui rest inférieur à celui qui a été macré dans le lait, et às plusieurs autres espèces de boucliers".

3 De alguns deles não foi possível obter a obra traduzida.

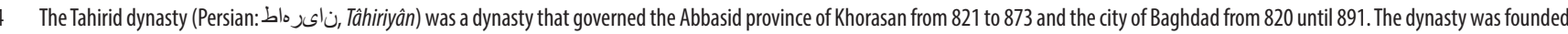
by Tahir ibn Husayn, a leading general in the service of the Abbasid caliph al-Ma'mun. Their capital in Khorasan was initially located at Merv but was later moved to Nishapur. The Tahirids enjoyed a high degree of autonomy in their governance of Khorasan, but they remained subject to the Abbasid caliphate and were not independent rulers. 


\subsection{Abū ‘Ubayd 'Abd Allāh ibn ‘Abd al-‘Azīz ibn Muḥammad ibn Ayyūb ibn ‘Amr al-Bakrī, or simply Al-Bakri}

Abū 'Ubayd 'Abd Allāh ibn 'Abd al-'Azīz ibn Muḥammad ibn Ayyūb ibn 'Amr al-Bakrī, or simply Al-Bakri (Arabic: (ca. 1014-1094) foi um geógrafo e historiador andalus; escreveu sobre a Europa, o Norte de África, e a península Arábica. Duas de suas obras sobreviveram. Sua obra mais importante é Kitāb al-Masälik wa-al-Mamälik ("Livro das Estradas e dos Reinos") المهالن والمسالك.. Escrito em 1068, baseia-se na literatura e em relatos de mercadores e de viajantes, Foi traduzido por Quatremère (1831), onde se lê (pp. 634-635):

“Parmi les animaux qui habitent le désert, on remarque le lamat, bل dont la taille est un peu moins haute que celle bu boeuf, et qui a des cornes minces et pointues, que portent également les males et les femelles. Plus l'individu est âgé, plus ses cornes sont grandes; quelquefois elles atteignent une longueur de quatre palmes. Les boucliers les meilleurs et les plus chers sont faits du cuir des femelles, apprelées awatik, العوأعب, c'est-à-dire, dont les cornes, avec l'âge, ont pris un si grande accroissement, qu'elles empêchent le males d'effectuer l'accouplement".

Esse trecho foi também publicado por Slane (1859: 499; também, com pequenas diferenças, em Fagnan, 1900: 189):

"Parmi les animaux qui habitent le désert on remarque le lamt, quadrupède moins grand qu'un boeuf, et dont les mâles, ainsi que les femelles, portent des cornes minces et effilées. Plus l'individu est âgé, plus ses cornes sont grandes; quelquefois elles atteignent une longueur de quatre empans. Les boucliers les meilleurs et les plus chers sont faits de la peau de vieilles femelles, dont les cornes, avec l'âge, sont devenues assez longues pour empêcher le male d'effectuer l'accouplement".

\subsection{Mohammed ibn abi Bakr al-Zuhri}

Mohammed Ibn Abi Bakr al-Zuhri, de Granada (fl. 1130s-1150s) foi um geógrafo, autor da obra, Kitab al-Dja'räfyya (Book of Geography); uma tradução francesa desta obra foi feita por Hadj-Sadok (1968). Al-Zuhri utilizou-se dos escritos de geógrafos do reino do califa Al-Ma'mun de Bagdá (m. 456/1068). Al-Zuhri morreu entre 1154 e 1161.

Segundo Viré (1986: 651-652):

"Al-Zuhrī (K. al-Djäräfyya, ed. Had-Sadok in BEO, Damascus (1968), §§ 314-15), in his description of the lamt, records that lamțiyya shields were offered to the kingsof the Maghrib and al-Andalus".

\subsection{Abū Ḥāmid al-Garnațī}

Abū Hāmid al-Garnațī (em árabe: بيطانر غلا دماح وباً nome completo Abu Hamid Muhammad ben Abd al-Rahman (ou Abd al-Rahim) ben Sulayman al-Mazini al-Qaysi al-Gharnati) (1080-1170) escreveu o Tuhfat al-Albāb (O Regalo dos Espíritos). Na edição de Ferrand (1925: 43-44), consta:

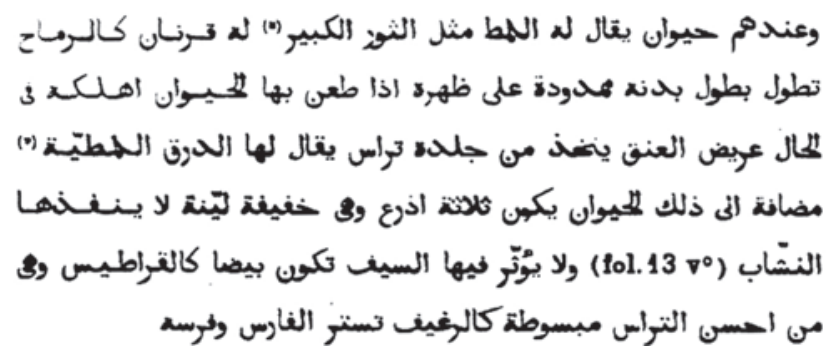

Fagnan (1924: 20):

"C'est dans ce désert qu'on rencontre le lamt, animal gros comme un veau ou même plus petit, qui a un long cou et une tête semblable à celle de l'achker et des oreilles semblables à celle de la chèvre; il n'a qu'une seule corne qui, partant du sinciput, retombe en arrière jusqu'à la croupe. C'est du cuir de cet animal que sont fabriqués les boucliers appelés lamti, du nom même de lamt. La trace du coup de flèche ou de lance qui les atteint se trouve refermée au commencement de l'année [suivante] et ne laisse pas de trace". 
"Hay entre ellos um animal llamado lamt parecido a un toro grande. Posee dos cuernos como lanzas que tienen la longitud de su cuerpo, prolongándose sobre su dorso. Cuando alcanza con ellos a un animal lo mata al punto. Es ancho de cuello; con su piel se hacen escudos, que se llaman daraq al-lamțiyya (...) del nombre del animal. [La adarga] tiene tres codos de larga y es ligera y suave; no la penetran las flechas ni deja en ella marcas la espada. Es blanca como papel; es el más bello de los escudos. Plana como un pan protege al caballero y a su caballo".

\subsection{Abu Abdullah Muhammad al-Idrisi}

Abu Abdullah Muhammad al-Idrisi (em árabe: بيسيردإلا دمحم مّلا دبع وبأ (1110-1165 ou 1166), também conhecido como Al Idrissi, Al-Idrīsī, Charif Al-Idrissi ou simplesmente Edrisi ou Idris ou, ainda, pelo nome latino de Dreses; seu nome completo era Abu Abdallah Muhammad Ibn Muhammad Ibn Abdallah Ibn Idris al-Qurtubi al-Hassani. Em sua Geografia (Jaubert, 1836: 205) consta:

“Noul est une ville bien peuplée, située sur une rivière qui vient du côté de l'orient, et dont les rivages sont habités par les tribus de Lanmtouna et de Lamta. On y fabrique des boucliers connus sous le nom de boucliers de Lamta, qui sont les plus parfaits qu'on puísse imaginer. Ces boucliers étant d'une très bonne defense et très-légers à porter, les peoples du Maghreb s'en servent dans les combats".

\subsection{Abu Abdallah Yaqut ibn-Abdallah al-Rumi al-Hamawi}

Abu Abdallah Yaqut ibn-Abdallah al-Rumi al-Hamawi (em árabe: بودحلا توقاي), mais conhecido apenas como Yaqut (ano 574 da Hégira/ 1179 da era cristã - ano 626 da Hégira/ 1229 da era cristã), foi um geógrafo e biógrafo de origem síria. Al-Rumi refere-se ao fato de ter sido um escravo descendente de cristãos gregos oriundos do Império Romano do Oriente (aos quais, por isso mesmo, os árabes chamavam de "Romanos"); al-Hamawi, ao facto de ter nascido na cidade de Hama, na Síria. As suas principais obras são o Mu'jam al-Udabā' (عابدأل إعجعر, ou Biografias de Homens Sábios), uma colectânea de bi-

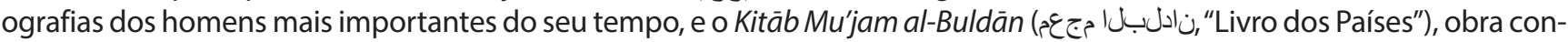
cluída em 1228, com informações relativas à história, geografia e etnografia das nações por que viajou, desde o Turquestão à Península Ibérica. De fato, constitui uma obra de grande valor para o conhecimento do Al-Andalus dessa época.

O Kitäb Mu'jam al-Buldān foi publicado (em árabe) por Wüstenfeld (1866-1873). Uma tradução foi feita por Hopkins \& Levtzion (2000); o trecho que nos interessa assim consta publicado em Mohamed (2012: 112):

"Lamta: ... a place belonging to a Berber qabila in the Maghrib al-Aqsa... both the place and the people are called Lamta... the Lamti shiels are named after them... Nul Lamta... is a town in the south of the Maghrib, it is the capital of the Lamta".

\subsection{Abu Yahya Zakariya' ibn Muhammad al-Qazwini}

Abu Yahya Zakariya' ibn Muhammad al-Qazwini (بين) ou Zakariya Qazvini (em persa: (1203-1283) foi um médico, astrônomo, geógrafo e escritor persa. cosmography titled "The Wonders of Creation" (تادو جو جلا بئارغو تاقولخحلا بئاجع, Marvels of Creatures and Strange Things Existing). This treatise, frequently illustrated [Figura 3.1], was immensely popular and is preserved today in many copies. It was translated into his native Persian language, and later also into Turkish. Sua obra (em árabe) foi editada por Wüstenfeld (1849). Ilustrou um órix [Figura 3.1].

\subsection{Abu Mohammed Salah ibn Abd Allah el-Halim}

Abou Mohammed Salah ibn Abd Allah el-Halim, de Granada, em 1326, escreveu Roudh el-kartas. Na tradução de Beaumier (1860: 141), lê-se:

"Zyry ban Athya s'empara de tout le pays abandonné par El-Behary, et devint ainsi souverain maître du Maghreb, depuis le Zab jusqu'au Sous el-Aksa. Son premier soin fut de rendre compte de ses succès à ElMansour ben Aby Amer, et il accompagna son message de riches présents, composés, entre autres choses, de deux cents magnifiques chevaux de race, cinquante chameaux Mehary, mille boucliers recouverts de peau de lamt, de nombreuses charges d'arcs em bois de zan, de chats musqués, de girafes, de lamts et autres animaux du Sahara, de mille charges de dattes et d'une quantité d'étoffes en laine fine". 


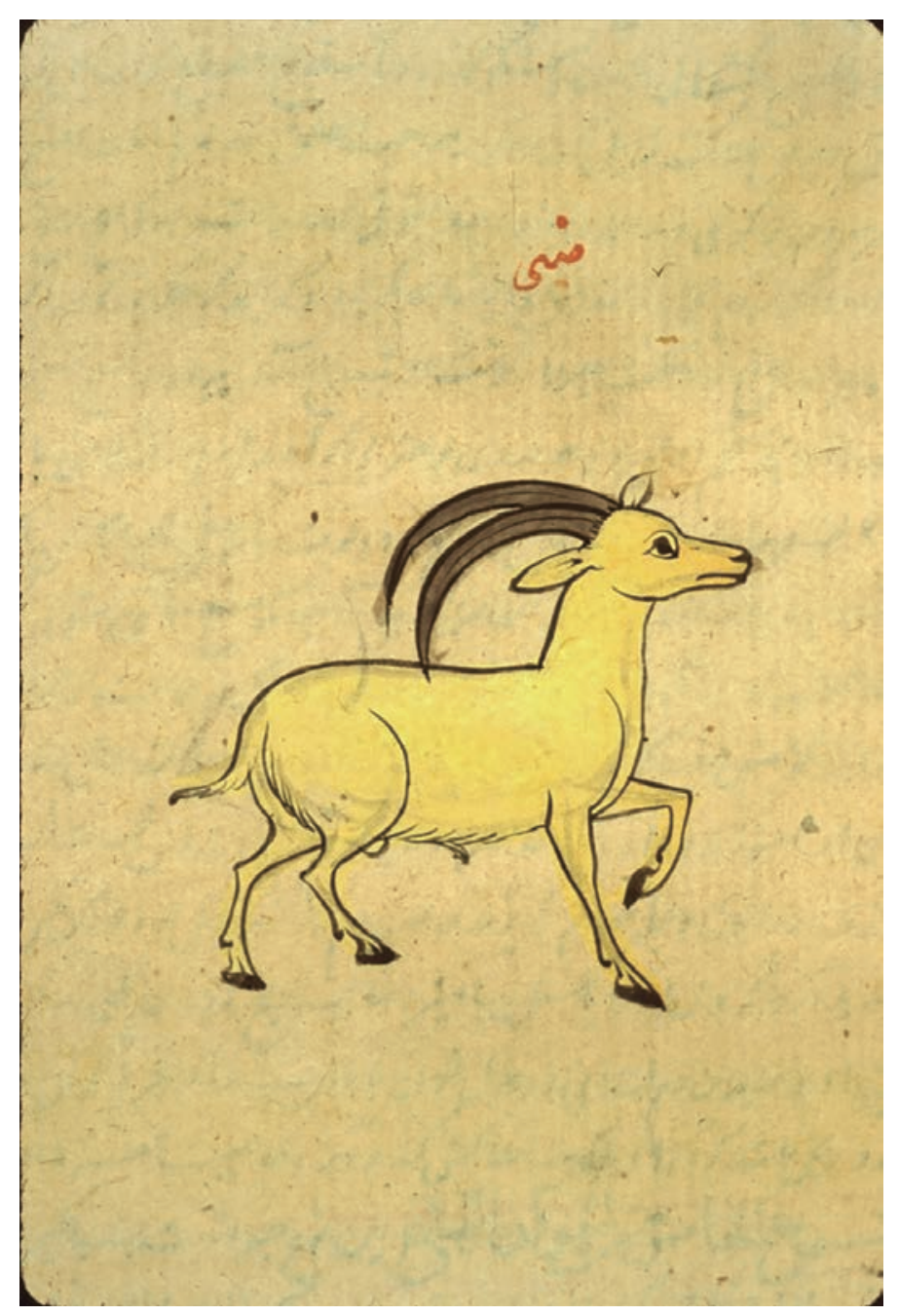

Figura 3.1. Al-Qazwini, figura de um órix. (Islamic Medical Manuscripts at the National Library of Medicine, MS P 2, fólio 169a; "The nature of papers, script, ink, illuminations, and illustrations suggest that is was produced in Mughal India, possibly the Punjab, $17^{\text {th }}$ century"). [veja em: Islamic Medical Manuscripts].

\subsection{Shihāb al-Dīn Abū al-'Abbās Aḥmad b. Fạ̣l Allāh al-'Umarī}

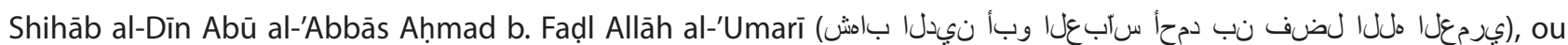
simplesmente al-'Umarī (1300-1349) foi um historiador árabe nascido em Damasco, no seri de uma família de burocratas. Escreveu o Masālik al-abșār fi mamālik al-amșār, an encyclopedic compendium which also related to administrative practices.

Fagnan (1924: 74) publicou o seguinte trecho:

"NOUL est située sur une rivière qui vient du côté de l'Orient. On y fabrique des boucliers lamtiens, qui sont plus beaux que tous autres, des selles, des mors, des bates de chameauxm des manteaux sefsâriyya, des bournous de prix".

\subsection{Lisan ad-Din ibn al-Khatib}

Lisan ad-Din ibn al-Khatib (Arabic: بيطخل نبا نيدل ناسل) (16 de novembro de 1313, Loja - 1374, Fes, Marrocos). Seu

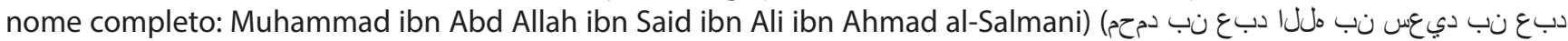

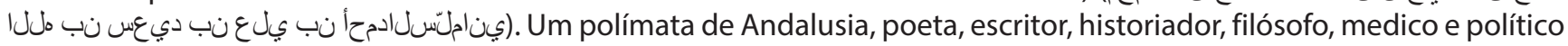
do Emirado de Granada. Alguns de seus poemas decoram as paredes da Alhambra em Granada. Sua grande obra histórica, al-Ihata fi akhbar Gharnata (The Complete Source on the History of Granada), written in 1369, inclui sua autobiografia.

Casiri (1770: 246ss) publicou o texto árabe com uma tradução em latim. Mas, segundo Gayangos (1840: 407-408):

"... as the text printed by Casiri is full of faults, and the translation incorrect, I have deemed it necessary to reproduce this passage, after collating it with a copy of the same work in my possession. It reads thus: 


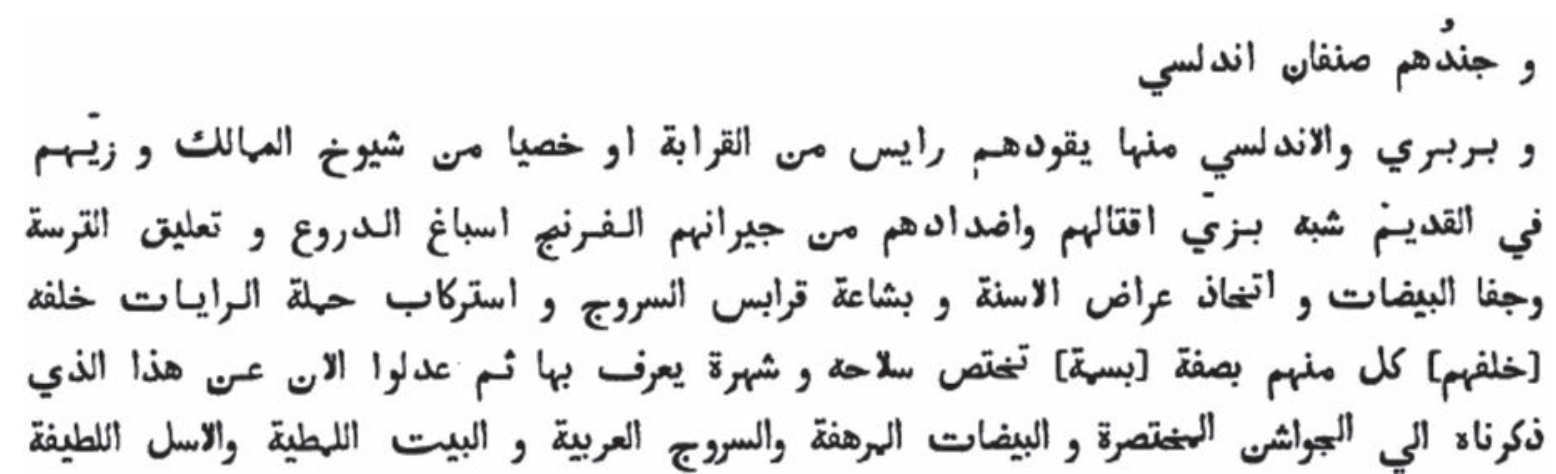

And their army (the author is speaking of the Kings of of Granada) is of two kinds, Andalusian and Berber. The Andalusian is generally commanded by a prince of the blood, or by some noble of the kingdom who is in favour with the court. Their dress and accoutrements in ancient times were similar to those of their neighbours and foes among the Franks; they were clad in complete mail, they wore the shield slung at the back, steel helmets, huge spears with broad ends, and saddles rudely constructed and projecting very much in front and beind. The riders rode with pennons fluttering behind them, each man in his rank being known by his arms, or some other distinction about his person. However, in our days military men have left off these customs, and, returning to their old practices, have taken short and slender breast-plates, light head-pieces, the Arabian saddle, eather bucklers called lamattí, and long and slender spears".

Na mesma página 408 Gayangos acrescentou a seguinte nota de rodapé:

"These shields were manufactured from the skin of a species of antelope, called lamat ou lamt in the dialect of the nartives, and found at Dar'ah and other places of Africa bordering on Súdán. The author of the Kitpábu-l-ja'ráfiyyah (Ar. Ms. in my possession), from whom the preceding informartion is borrowed, adds that 'shieds covered with one or two skins of this quadruped proved impenetrable to either spear, arrow, or sword'. However, Ibnu Khaldún (Ar. MS. in the Brit. Mus., fo. 52) says that Lamtah is the name of a tribe of the great family of Senhájab, and that these shields were so called from their being manufactured in the country which they occupied".

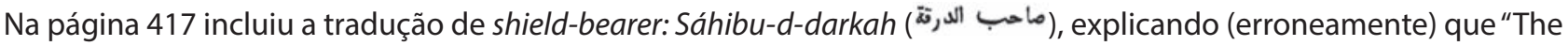
Word darkah, means 'a sort light shiels, target, or buckler', made of a buffalo's hide [sic]".

\subsection{Abū Zayd ‘Abd ar-Raḥmān ibn Muḥammad ibn Khaldūn al-Ḥaḍramī}

Ibn Khaldun (بيجرض ضلا نودلخ نب دمحم نب نمحرلا دبع ديز وبأ Abū Zayd 'Abd ar-Raḥmān ibn Muḥammad ibn Khaldūn al-Ḥaḍramī, 27 de maio de 1332 - 17 de março de 1406) foi um historiador árabe, precursor das modernas disciplinas da historiografia, sociologia, economia e demografia.

Há quatro referências ao lamt tem sua história dos berberes:

"Pour se conformer à cet ordre, Zîri ${ }^{5}$ se mit en marche, avec une foule de tribus, tant zenatiennes que berbères, et contraignit le chef sanhadjien à s'enfuir jusqu'à Cairouan. Devenu maître de Tiemcen et de tous les autres états d'Abou-l'-Behar, il s'acquit une grande puissance et étendit son autorité depuis le Maghrebel-Acsa jusqu'au Zab. La dépêche par laquele il fit par de son succès à Ibn-Abi-Amer fut accompagnée d'un cadeau ainsi composé: deux cents chevaux de race; cinquante chameau mehari d'une vitesse extraordinaire; mille boucliers en peau de lamt, plusieurs faisceaux d'arcs en bois de zan. Quelques civettes, une giraffe, quelques lamt et plusieurs autres animaux sauvages du Désert; milles charges de dattes; plusieurs charges d'étoffes en laine fine" (Slane, 1856a: 243).

"Ces deux chefs proposèrent alors à Ouadeh de lui envoyer chaque année une somme fixe, un cetain nombre de chevaux et de boucliers [em peau de lamt] et de lui laisser ses enfants comme otages, pourvu qu'il donnât le gouvernement de Sidilmessa à Ouanoudîn" (Slane, 1956a: 257).

"Plusiers boucliers tirés des régions du Désert et enduîts de ce fameux vernis qui les rend si solides; on les appelle lamtiens, du nom de l'animal dont la peau sert à leur fabrication; plusieurs de ces objets

5 Ziri ibn Atiyya (na lingua Berbere: Ziri n Eațiyya Ameyraw), também conhecido como Ziri ibn Atiyya ibn Abd Allah ibn Tabādalt ibn Muhammad ibn Khazar az-Zanātī al-Maghrāwī al-Khazarī (falecido em 1001) foi o primeiro líder tribal da confederação tribal e reino dos berberes Maghrawa. "Un chef berbère du Maghreb, Zirī ben 'Atiyya, fit present en 991 au calife de Cordoue de 1000 boucliers en peau de 'lamt', impenetrables aux flèches et aux coups de sabre" (Lombard, 1969: 580). 
d'ameublement que l'on fabrique au Maghreb et qui sont très-recherchés en Orient; de plus, une mesure de perles et rubis" (Slane, 1956b: 241).

"Pour accomplir cette cérémonie, on posa par terre un bouclier lamtien sur lequel on le fit asseoir...."

\subsection{4. loannes Leo Africanus}

Ioannes Leo Africanus (ca. 1494-ca. 1554?) (or al-Hasan ibn Muhammad al-Wazzan al-Fasi, (em árabe: دمح نبا نسح نوف) (يسافلا نازول - citou várias vezes o elamt, lamt ou lant:

“Di mio ricordo questo signore mandò al re un superbo presente, che fu, cinquanta schiavi negri, e altrettante femmine schiave, dieci eunuchi, e dodici cammelli da cavalcare, una giraffa, dieci struzzi, sedici gatti di quelli che fanno il zibetto; una libbra di muschio fino, una di zibetto, e un'altra di ambracane; e appresso, seicento cuoj d'un animale ch'è detto elamt, con li quali si fa di finissime targhe: e ogni pezzo di detto cuojo vale in Fez otto ducati; gli schiavi si apprezzano venti scudi l'uno, e le femmine quindici; ciascuno eunuco è di valor di ducati quaranta; i cammelli nel paese del detto signore vagliono cinquanta ducati per ciascuno; i gatti, dugento; il muschio, il zibetto e l'ambracane vagliono, l'un sopra I'altro, sessanta ducati la libbra". (Leo Africanus, 1563: fólio 24v; Ramusio, 1837: 51).

"Guaden è certo casale nel diserto di Numidia, che confina con Libia, il quale è abitato da un popolo bestiale e povero: e in questo, altro non nasce, che qualche poca quantità di datteri. Sono gli abitatori poveri, e vanno quasi ignudi: nè possono andar fuori delli loro casali, per le nimicizie che tengono co' vicini. si dánno alla caccia con trappole, e pigliano qualche animal salvatico di quei paesi, come elamt e struzzi; e non si truova altra carne, eccetto di questi animali: è ben vero che ánno qualche capra, ma la tengono pel latte. sono piuttosto neri, che bianchi". (Leo Africanus, 1536: fólio 72v; Ramusio, 1837: 130)7.

"La maggiore esperienza, nel corso, che si possa fare d'uno di questi cavalli si è quando essi giungono una fiera detta lant, ovvero uno struzzo..." (Leo Africanus, 1563: fólio 92r; Ramusio, 1837: 162) ${ }^{8}$.

“Lant ovver Dant. Questo è un'animale, che somiglia al Bue in forma, ma è piu piccolo, \& ha piu gẽtili gambe,/ \& corna. il suo colore è quase biãco, \& lunghie de piedi sono negrissime. è velocissimo di corso:/ in modo, che non è altro animale, che lo auanzi, fuor, che come s'è detto, qualche cauallo barbe-/ro. piu ageuolmente si piglia la state: percioche per lo calor dell’harena \& per la velocità del cor/rere, l'unghie gli si mouono. onde per la sua passione non puo correre. cosi parimente si pigliano/ i caprioli \& i cerui. del cuoio di questo si soglion fare alcune targhe fortissime: per modo, che al/tra cosa non le puo passare, che vn schioppo, ma molto care si vendono" (Leo Africanus, 1563: fólio 92r; Ramusio, 1837: 162)․

\subsection{Ibn 'Abd Kalm Mun'im al-Himyarī}

Ibn 'Abd Kalm Mun'im al-Himyarī (ou al'shayk al-faḳīh al-'adl Abū Abd-Allāh Muḥammad b. Abī'Abd-Allāh Muḥammad ibn'Abd al-Mun'im b. 'Abd al-Nūr al-Himyarī) foi o autor do dicionário geográfico intitulado Kitāb al-Rawḍ al-mi'țār fi khabar al-akțār. Foi um jurisconsulto (faḳih) e um assessor ou notário ('adl) de um kāọị. Lévi-Provençal (1938) editou grande parte de sua obra (em árabe). Uma tradução espanhola foi publicada por Maestro González (1963).

\subsection{Ahmad ibn Ali ibn Zunbul ou Ibn Zanbal}

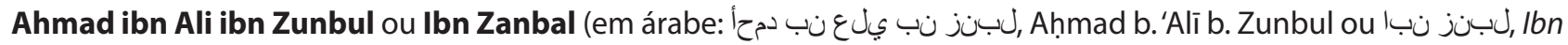

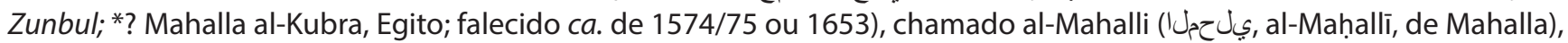

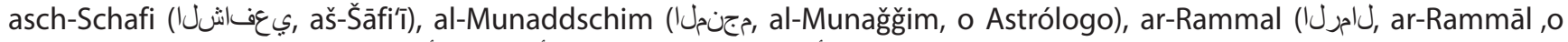

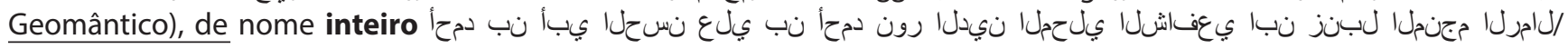

6 Na tradução de Pory (1600), republicada por Brown (1896a: 309): "My selfe (I remember) once saw a most magnificent gift presented to the saide king in the name of this prince, to wit, fiftie men salues, and fiftie women slaues brought out of the land of Negroes, tenne eunuchs, twelue camels, one Giraffa, sixteene ciuet-cats, one pound of ciuet, a pound of amber, and almost sixe hundred skins of a certain beast called by them Elamt, whereof they make their shields, euerie skin being worth at Fez, eight ducates; twentie of the men slaues cost twentie ducates a peece, and so did fifteen of the women slaues; euery eunuch was valued at fortie, euery camel af fiftie, and euery ciuet-cat at two hundredth ducates: and a pound of ciuet and amber is solde at Fez for threescore ducates".

7 Na tradução de Pory (1600), republicada por Brown (1896b: 777): "On the village of Guaden. This village situate vpon the Numidian desert neere vnto Libya, is inhabited by most miserable and grosse people. Here growth nothing but dates: and the inhabitants are at such enmities with their neighbours, that it is dangerous for them to go abroad. Howbeit they giue themselves to hunting, and take certain wilde beasts called Elamt, and ostriches, neither do they eate any other flesh. All thir goates they reserue for milke. And these people are blacke of colour". 
Aḥmad b. Abī'l-Ḥasan 'Alī b. Ahmmad Nūr ad-Dīn al-Maḥallī aš-Šāfi'i b. Zunbul al-Munaǧǧim ar-Rammāl', foi o autor de uma enciclopédia geográfica escrita em três etapas. A versão mais curta e antiga intitulava-se Muhtasar al-jugrafiya, posteriormenre expandida como Tuhfat al-muluk wa'l-raga'ib li-ma fi l-barr wa-l-bahr min al-aja'ib wa'l-gara'ib, e finalmente apresentada na versão mais completa, Qanun al-dunya. Na tradução de Fagnan (1924: 179-180) há o seguinte trecho:

"Un autre produit particulier de ce pays, c'est le lamt. Animal qui est de la taille du veau, avec un long cou, une tête d'ackker et des oreilles de chèvre, ayant au milieu du crâne une grande et longue corne noire qui se recourbe en arrière en s'étendant jusqu'à l'arrière train; elle est absolument compacte et non creuse, sans aucune ouverture. Une seconde corne a son point d'attache à la fontanelle. Du cuir de cet animal on fait des boucliers auxquels on donne le nom de de lamți, à raison de leur provenance. Ils presentent cette particularité que les trous qu'y peuvent faire les coups de flèche ou de lance qui les traversent se rebouchent d'eux-mêmes, et que ces armes defensives ne perdent ainsi rien de leur valeur. Cet animal se rencontre dans le pays des Almoravides, mais nulle part ailleurs dans les regions habitués".

\subsection{Abu-l'Abbas Ahmad ibn Mohammed al-Maqqari (ou Al-Makkari)}

Abu-l'Abbas Ahmad ibn Mohammed al-Maqqari (ou Al-Makkari) ca. 1578-1632). Maqqari, ou Makkari, nome completo Ahmed bin Mohammed al-Maqqari (em árabe: (بر آكمل دمحم نب دمح), (Tlemcen, Argélia, ca. 1591-1632), historiador árabe, estudou em Fez e Marraquexe, onde permaneceu engajado nos trabalhos literários até a peregrinação a Meca em 1618. Nos anos seguintes estabeleceu-se no Cairo. Em 1620 visitou Jerusalém e Damasco, e durante os próximos seis anos fez peregrinações mais cinco vezes. Em 1628 retornou a Damasco.

Na tradução de Gayangos (1843) há as seguintes passagens:

\section{Pp. 190-191:}

"In the year 381 (beginning March 19, A.D. 991), says the diligent historian Ibnu Hayyán - who, as is well known, has dwelt longer on the events of that time than on any other comprised in his voluminous work tvaluable present consisting of various rarities and productions of Aftrica; among which were two hundred generous steeds; fifty camels of the species called mehriyyah, which are renowned for their fleetness; one thousand shields covered with the skin of the lamt or hippopotamus [sic]; several loads of bows and arrows made in the country of Záb, many civet-cats, giraffes, and other quadrupeds of the desert, as rhinoceroses, elephants, lions, tigers, leopards, and so forth; one thousand loads of the best dates; one hundred and fifty ostrich-feathers; eight thousand pounds weight of the purest ivory, and other curiosities of that country".

\section{P. 273:}

"On the receipt of this letter Al-mu'tamed wrote on the back $f$ it - 'We have perused thy letter, and understood its arrogant and taunting contents; we inted to procure thee shortly such a shadowy spot, made of the hide of the lamt, as thou will comfortably lie under, if God ne pleased [meaning the shields of the Almoravides]".

\section{P. 277:}

"The letter being written, the secretary read it in his native tongue to Yúsuf, who approved of its contents. Having then prepared some suitable presents for the Andalusian rulers, among which were many valuable shields covered with the skins of the lamt, and which could not be procured elsewhere than in own dominions, Yusúf gave his reply to the messenger and dismissed him".

\section{DE DARAQQA LAMTIYYA A "ADARGA DANTA"}

Segundo Thiry (1995: 196-197):

“Le bouclier des Lamța/daraqqa lamțiyya [Figuras 4.1 e 4.2] a trop suscité l'admiration des géographes árabes pour qu'on puísse le passer en silence. Ce bouclier était fabrique en peau de lamț/oryx, antilope saharienne blanche, en voie de disparition depuis l'avènement de l'automobile. On ignore si l'ajectif lamțiyya a été forme sur le nom de la tribu ou sur celui de l'animal. D’après Abû Hämid al-Andalusï, le nom du boucler vient de l'animal. Al-Yacqūbï nous apprend seulement que ce bouclier est blanc. La 


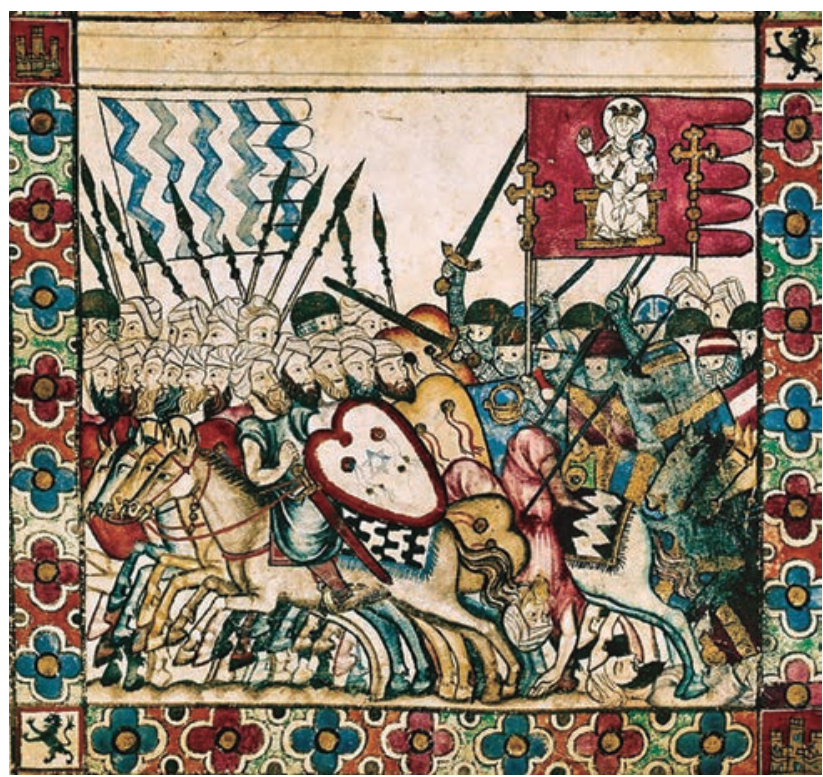

Figura 4.1. Cavaleiros muçulmanos com adargas.

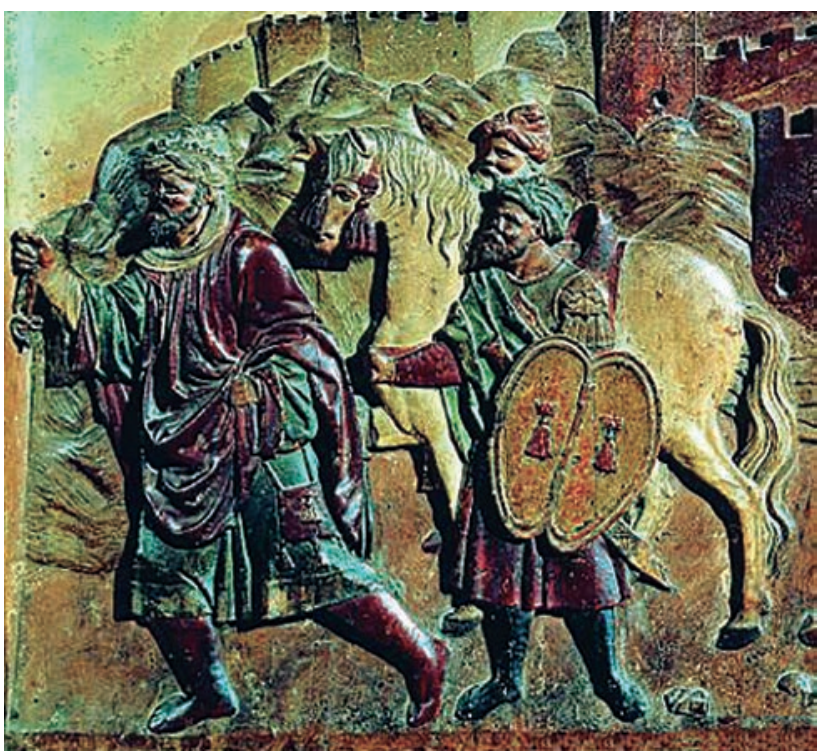

Figura 4.2. Guerreiro muçulmano com adarga. À esquerda o sultão Abū 'Abd Allāh Muhammad XII (Boabdil) entrega as chaves de Granada, em 2 de fevereiro de 1492; ao fundo, a Alhambra. Relevo na Capilla Real de Granada, 1520-1533; (f., Torres Delgado, 1988: 208 e Fernandez Puertas, 1994: 383).

première description est due à Ibn al-Faqïh. Cet incomparable bouclier, nous dit-il, doit être trempé dans du lait pendant toute une année; le sabre qui le frappe rebondit et s'il l'entame quelque peu, on ne peut l'en retirer. Le lait doit être du lait de chamelle, d'après Ibn Saïd. Al-Bakrï nous signale que les cornes de l'animal sont longues et affilées et que les meilleurs boucliers sont faits de la peau des vieilles femelles, facilement reconnaissables à ce que leurs cornes avec l'âge, sont devenues si grandes qu'elles empêchent les males d'effectuer l'accouplement; ses cornes peuvent atteindre quatre empans. L'animal et blanc mais, d'après Yäqüt, le bouclier doit sa couleur blanche à une teinture composée d'un mélange de lait et de coquille d'oeuf d'autruche; la ville de Käkudam a la spécialité de la confection de ce bouclier. Le diameter du bouclier est de dix empans. II n'existe rien de mieux pour protéger le guerrier, il est en outré très elegant et très léger à porter, ajoute Al-Idrïsi, de même qu'Abü Ḥämid, qui le décrit plat comme le pain et capable de protéger le cavalier et non cheval. Les boubliers lamțiyya font meme l'objet d'une exportation des ces regions, nous apprend Al-Himyarï. Tous les auteurs ont souligné l'impossibilité pour le fer de pénétrer ces boucliers, même Al-Qazwïnï, qui pourtant traite peu du Maghrib. Léon l'Afrcain, qui, à notre connaissance est le dernier auteur à le mentionner, signale que, sauf un projectile d'arme à feu, rien ne le traverse, raison pour laquelle il est si cher. Les boucliers lamțiyya ont été connus en Europe. Sachant que l'on ne peut se les procurer que dans son pays, Yüsüf ibn Taškin en envoie une certaine quantité, en cadeau, au roi d'Al-Andalus; plus tard, lorsque ses troupes combattront en Espagne, elles en seront équipées".

Covarrubias Orozco (1611:13), sob adarga, que descreve como "vn genero de escudo hecho de Ante, del qual vsan en Espana los ginetes de las costas, que pelean cõ lança y adarga. Y tãbien le vsan los Alarabes", acrescentou no fólio 12v que Diego de Urrea, arabista que ele frequentemente consultava, asseverava que essa palavra tinha origem no verbo "adarráq, que sinifica embraçar el escudo, y es de rais Caldea ערֶד Derah, brachium". Citou também frei Diego [sic!] de Yepes. Segundo a Historia de la muerte y glorioso martyrio del Sancto Innocente (Rodrigo de Yepes, 1583: 12-13; Capitulo tercero, De la conformidad que ay desta tierra a la de lerusalem y ludea, no solo en la figura y disposicion de algunas partes, sino en los nombres Hebreos que aca se hallan), declarou o frade:

"Y en nuestra lengua Española y Romanense, o Romance, hallamos tambien palabras Hebreas. Para que sepamos (dize San Hieronymo), que la lengua Hebrea es matriz de todas las lenguas. Para mostrar esto más claro, quise poner aqui algunos vocablos, que siendo Hebreos, se hallan en otras lenguas" (fólio 12r).

E entre esses exemplos colocou (fólio 12v):

"DARGA, significa defensa, municion: y ansi lo es en la guerra y exercicios de nobles a los de a caualo".

Como também sói acontecer, há os que fizeram provir essa palavra do latim (ou do italiano). Assim, por exemplo, encontramos em Bluteau (1712: 120): 
"ADARGA. Especie de escudo. Querem alguns, que se derve do Italiano Targa, que val o mesmo que Escudo, ou da palavra Latina Tergus, id est, as costas, porque em Africa, \& Hespanha os ginetes, que pelejão com lança, \& adarga, com a adarga se cobrem as costas. He escudo de couro, \& leve; consta de braçadeiras, \& muitos debruns. Tem miras, cavas, golpe, por onde se mette o dedo polegar, psara a segurar, \& correya, por onde se pendura. Querem alguns, que responda ao que em Latim se chama Cetra, ae. Fem. Tit. Liv.".

A origem correta do nome, do árabe, foi apresentada por Quatremère (1831: 634, nota 2):

\section{C'est du mot lamat, bل celui des boucliers appelés درق لمطية ou quoique plusieurs écrivains, tels qu'Ebn-Haukal (man. pag. 34), Ebn-Khilkan (man. 730 , fol. 486 \%. et 487 r.), et Édrisi (texte imprimé, p. 83 , man. fol. $56 \nu_{.}$) fassent venir ce nom de la province de Lamtah, $\mathrm{b}$, habitée par une tribu berbère du même nom, et qui forme la limite méridionale du royaume de Maroc. Mais comme la chose, dans Pun et l'autre cas, revient absolument au même, il est inutile d'entrex à ce sujet dans aucune discussion.}

E, como acertadamente estabeleceram Dozy \& Engelmann (1869: 41), de ad-daraca proveio adarga:

"ADARGA, darga (bouclier). Je ne m'occuperai pas ici de l'origine de targa, fr. targe, mais je crois que adarga vient directement de l'arabe ${ }^{2}$ (ad-daraca). J'ai déjà remarqué qu'on le prononçait ad-darca [...], et en outre on peut comparer le changement de daraca en darga à celui de auctoricare en otorgar, où il y a la même élision d'une voyelle brève et la même altération de $c$ en $g$. Du reste ce mot était très-usité en Espagne: non-seulement P. de Alcala traduit escudo par daraca et darca, mais il donne encore darraca (adargar), modarrac (adaragado, broquelado, escudado), et darrâc (escudero que haze escudos).

En espagnol on disait aussi adaraga; Nuñez donne cette forme et elle se trouve dans les Cortes de Leon y de Castilla, II, 84, 99, ainsi que chez Alcala sous adaragadante".

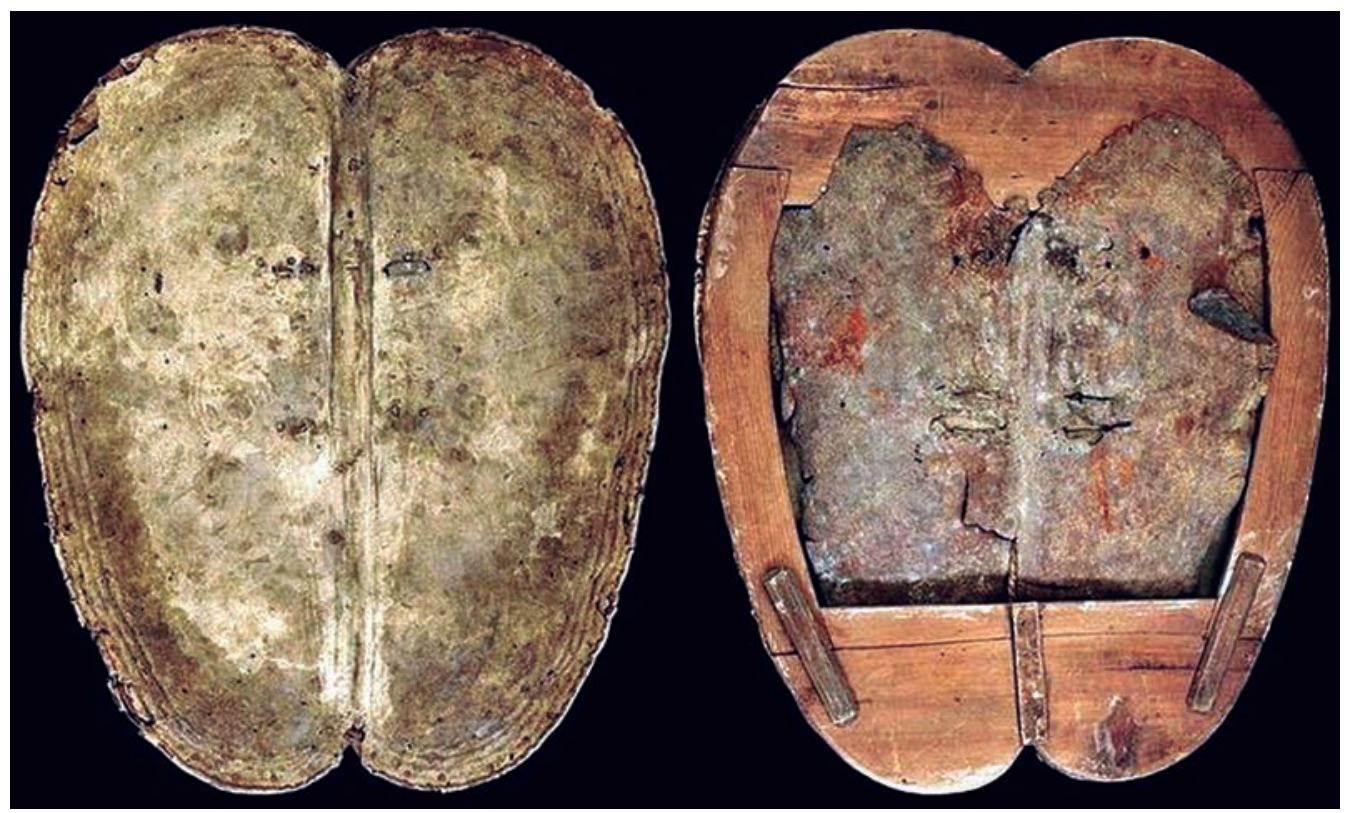




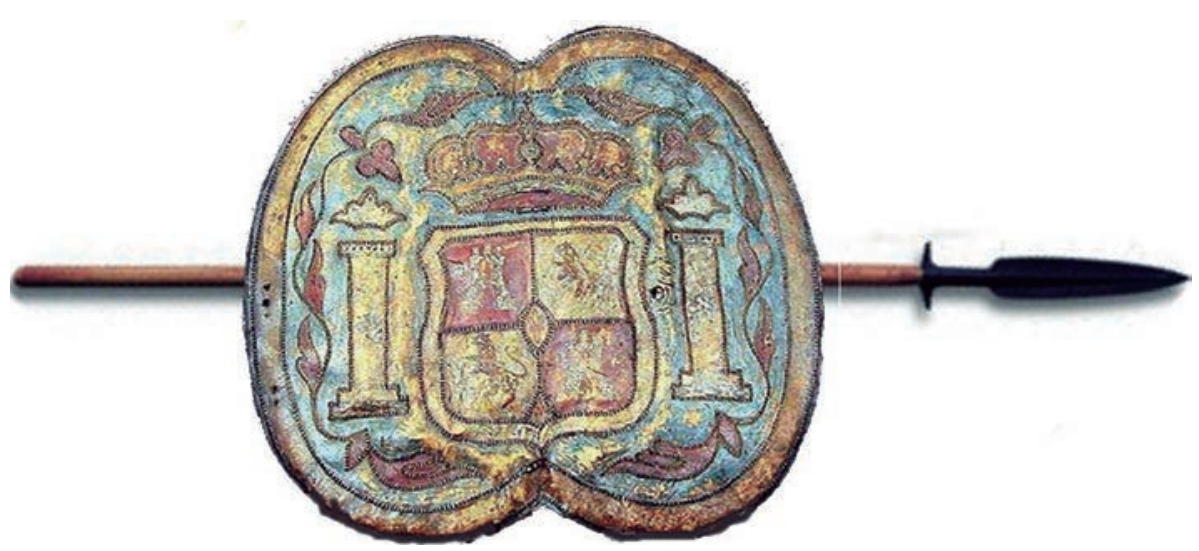

Figura 4.4. Adarga e lança.

Acrescenta a Real Academia Española (1726: 78):

"ADARGA. f. f. Cierto género de escudo compuesto de duplicados cueros, engrudados, y cosidos unos con otros, de figura quasi oval y algunos de la de un corazón [Figuras 4.3 e 4.4]: por la parte interior tiene en el medio dos alas, la priméra entra en el brazo izquierdo, y la segunda se empuãa con la mano. Usabanlas antiguamente en la guerra contra los Moros los soldádos de acaballo de lanza, y aun hasta poco tiempo à esta parte se conservaba esta milicia en Orán, Melilla, y Costa de Granada, y oy dia se conserva en la Plaza de Ceuta, aunque en menór númcro que antes. Servía la Adarga para guarnecerse de los golpes de la lanza del enemigo. Consérvase el uso de ellas (aunque menos fuertes) para las fiestas de caãas y alcancías, con la diferencia de que las que se usan para las alcancías, son de la misma hechura; pero compuestas de tablas delgadas, para que las alcancías se rompan en ellas. Es voz Arábiga, y viene de la palabra Adarraq, que vale embrazar el escudo [sic]".

\section{ALGUMAS CITAÇÕES DA ADARGA EM ESCRITOS DE AUTORES ESPANHÓIS DOS SÉCULOS XII A XVII}

A invasão islâmica da Península Ibérica, também referida como invasão muçulmana, conquista árabe ou expansão muçulmana, refere-se a uma série de deslocamentos militares e populacionais ocorridos a partir de 711, quando tropas islâmicas oriundas do Norte da África, sob o comando do general Tárique ${ }^{10}$, cruzaram o estreito de Gibraltar, penetraram na península Ibérica, e venceram Rodrigo, o último rei dos Visigodos da Hispânia, na batalha de Guadalete [Figura 5.1]. Após a vitória, termina o Reino Visigótico.

Nos séculos seguintes, os muçulmanos foram alargando as suas conquistas na Península, assenhoreando-se do território designado em língua árabe como Al-Andalus, que governaram por quase oitocentos anos [Figura 5.2].

Não admira, pois, que muito cedo (já no clássico Cantar del mio Cid, do final do século XII) a influência da língua árabe se fizesse sentir nas obras espanholas, quase todas elas tratando das lutas dos espanhóis contra os árabes de El-Andalus.

\subsection{Anôn., ca. 1200}

No poema épico Cantar del mio Cid (Anôn., 2009) há os seguintes versos:

"Tanta adarga foradar e passar,

Tanta loriga falssa desmanchar,

Tantos pendones blancos salir vermeios en sangre,

Tantos buenos cauallos sin sos duenos andar".

\subsection{Anôn., ca. 1293}

A obra La Gran Conquista de Ultramar ${ }^{11}$, que se supõe ter sido escrita por ordem do rei Don Alfonso el Sabio, teve uma primeira impressão, em dois tomos, em Salamanca. Foi editada por Gayangos (1858); nesta edição há dois trechos interessantes:

10 Tárique ibne Ziade (em árabe:دابز نب قر اط: Tārik ibn Ziyād; ca. 670-720).

11 Sobre a composição dessa obra, ver Bautista (2005). 


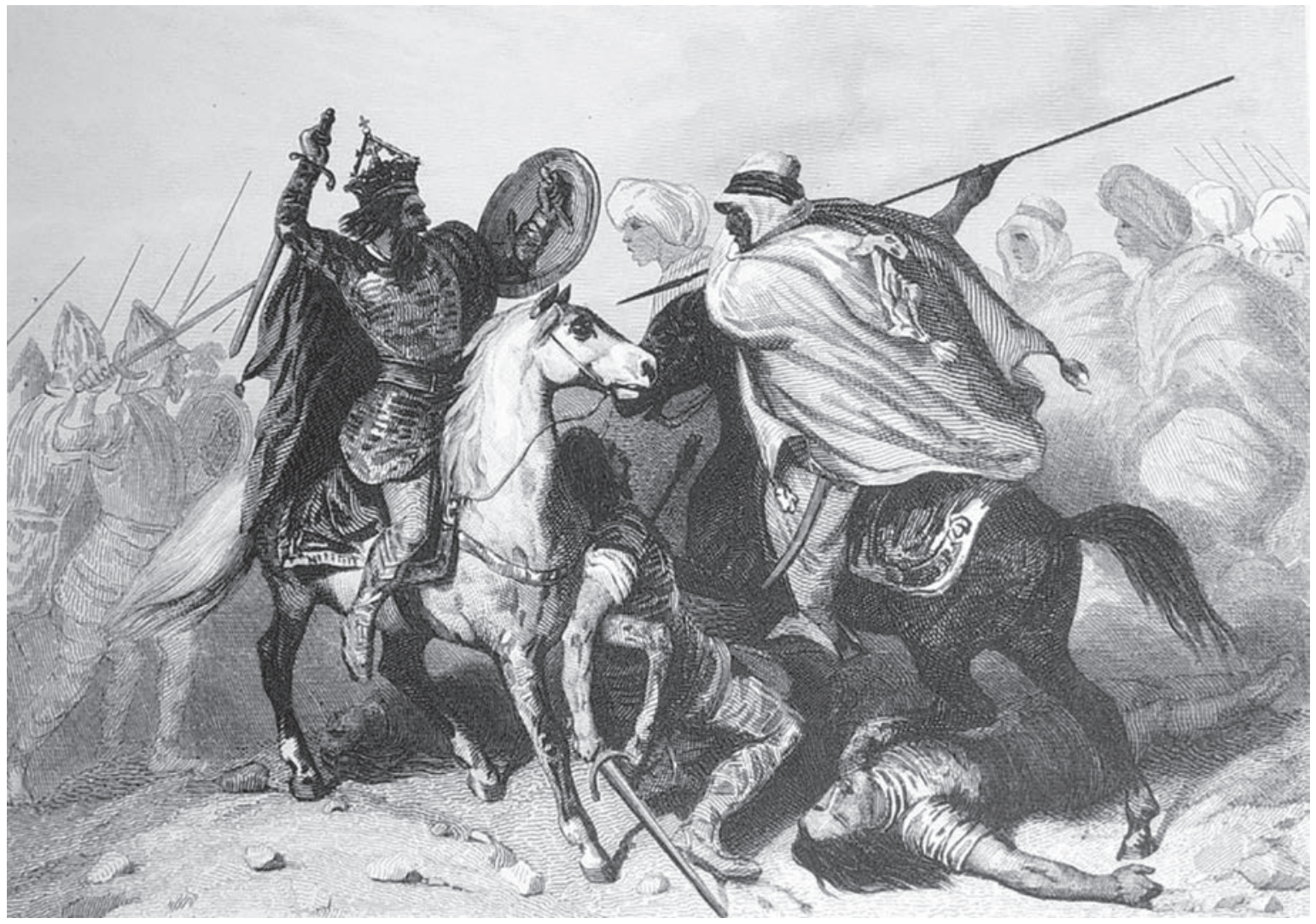

Figura 5.1. Batalha de Guadalete.

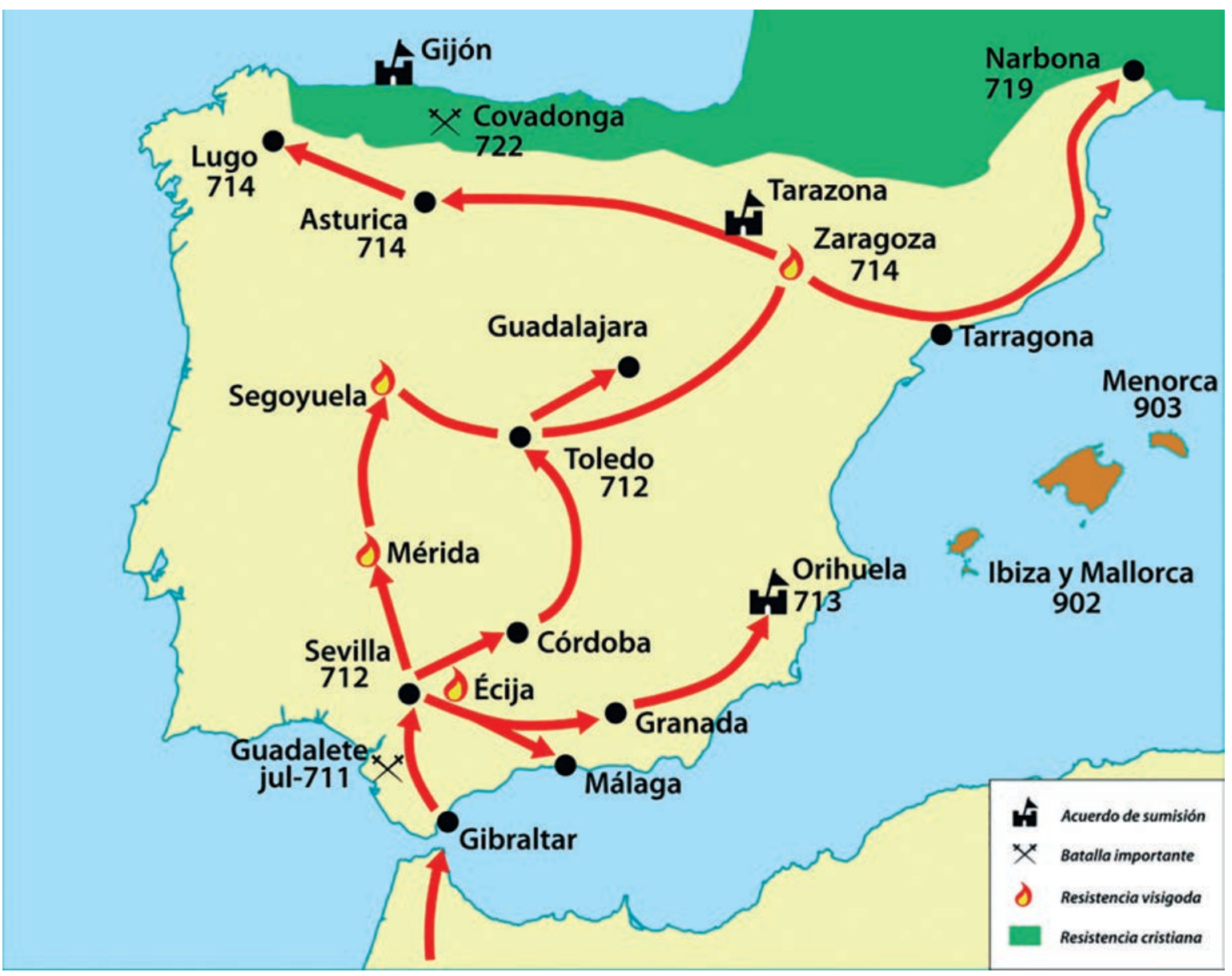

Figura 5.2. A conquista islâmica da Espanha. 
P. 171:

“El traía muy buena loriga é brasoneras, é perpunte cubierto de muy rico paño de seda, é las coberturas outrosí; é capellina de fierro traia muy buena é muy bien acecalada, é adaraga de fusta muy bien pintada á cuarterones de oro é de azul, é el espada que traia ceñida era muy buena é muy tajante, guarnida de plata muy apuestamente...."

\title{
P. 174:
}

\begin{abstract}
"adaraga traia muy luenga, cubierta de carmesí, que fuera puesto con engrudo; é estaba tan fuerte preso, que parescia el cuero mesmo de la adaraga; de parte de fuera estaba una orla en derredor, de plata entallada, en que había letras de los nombres de Dios é de loor de Mahoma, doradas muy ricamente; de dentro de aquella orla había siete cercos, todos de espejos, é eran fechos desla forma, que cada uno dellos tenia sus portezuelas de plata muy delgadillas, que se cerraban, é abrian por sí cuando corría el caballo; así que, cuando hacia sol é volvía el adaraga, parescia relámpago; de parte de dentro era cobierta de un paño de seda dorado muy rico, labrado con aljófar muy ricamente, é desa labor mesma eran los brazales, é la manera con que sufría el adaraga...."
\end{abstract}

P. 319:

"E el conde Harpin de Beorges; que estaba muy bien armado, dió al caballo de las espuelas, é firio á un turco en la adaraga de manera, que gela falsó, é metióle la lanza por el cuerpo, é dió con él muerto cerca de un sendero, é tanto firió de la lanza, fasta que la quebró; é metió mano á la espada, é dió á un turco sobre el yelmo tan de recio, que le tajó la colla é la loriga con el tiesto de la cabeza, é dió con todo en tierra...."

\subsection{Don Juan Manuel [de Castilla], 1330}

Don Juan Manuel, Infante de Castilla (1282-1349) escreveu o Libro de los Estados (cf., Tate \& Macpherson, 1974 ${ }^{12}$ ).

No Capítulo LXXV da Primeira Parte (EI LXXV capítulo fabla em cómmo Julio dixo al infante que ya le avie dicho todo lo que entendía que los emperadores devíen fazer para se parar a lla guerra que ovieren) é citada a adaraga na seguinte passagem:

"Ca la guerra guerr[i]ada fázenla ellos muy maestríamente. Ca ellos andan mucho et pasan con muy poca vianda, et nunca lievan consigo gente de pie, nin azémilas, sinon cada uno va con su cavallo, también los sennores commo qualquier de las otras gentes; que non lievan outra vianda sinon muy poco pan et figos o pasas, o alguna fructa. Et non traen armadura ninguna [sinon] adaragas de cuero. Et las sus armas son azagayas que lançan [et] espadas con que fieren".

\subsection{Anôn., ? 1483}

Na Relacion circunstanciada de lo acaecido en la prision de Rey Chico ${ }^{13}$ de Granada, año de 1483 (Anôn., [? 1483] in Lafuente y Alcántara, 1859), lê-se:

“De algunos Alfaqis moros, que salieron de los moros que se habian captivado, y de christianos que salieron de Granada, que á la sazon estavan captivos, se supo que pasaban los perdidos en aquel desbarato de los caballeros y peones, de cinco mill moros: fueron muertos y tomados más de mill cavallos y novecientas acémilas y muchas spadas ricas, y adargas de ante y otras muchas joyas, porque el despojo fue grande" (Lafuente y Alcántara, 1868: 59).

\subsection{Fernando de Rojas, 1499}

Na Comedia de Calisto \& Melibea [Figura 5.3] (Rojas, 1949; in Foulché-Delbosc, 1902: 142):

“Parmeno. Bien hablas, en mi coraçon estas, assi se haga; huyamos la muerte, que somos moços. O si me viesses, hermano, como esto, plazer haurias: a medio lado, abiertas las piernas, el pie ysquierdo adelante,

12 Transcrição do manuscrito no. 6376 da Biblioteca Nacional de Madrid.

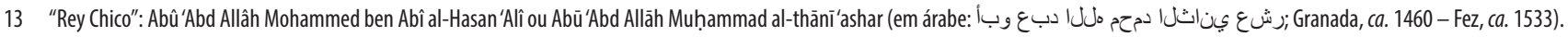


puesto en huyda, las haldas en la cinta, la adarga arrollada \& so el sobaco, porque no me enpache; que por Dios que creo corriesse como vn gamo, según el temor tengo destar aqui".

\subsection{Frei Pedro de Alcalá, 1505}

Não existem mais dados biográficos sobre Frei Pedro de Alcalá [Figura 5.4], a não ser os poucos que proporcionou no epílogo de seu Vocabulista arauigo en letra castellana (Pedro de Alcalá, 1505), onde declarou ser um "muy indigno frayle de la orden del glorioso dotor san Jerónimo, contino familiar y confessor del R. Señor don fray Fernando de Talavera".

Por seus conhecimentos da língua árabe pensou-se ser um mourisco nascido no "Reino nazarí de Granada" antes da Conquista, convertido ao cristianismo. Mas ele mesmo declarou saber pouco dessa língua, havendo-lhe custado muito esforço seu estudo e à qual não podia dedicar muito tempo por causa de suas ocupações monásticas:

“...para aprender, si pudiese alcançar de la lengua arauiga: porque sin mucha angustia de mi anima veya [...] y maguera que my ingenio sea algo y aun mucho tardinero, y no assí sotil y dispuesto para tomar nueva disciplina y sciencia, y mucho mas rudo para inventar de nuevo [...] como porque seyendo ocupado en otros servicios y officios de la sancta obediencia [...] nuna pude exercitar el estudio de las letras".

Entretanto, por seu conhecimento da língua árabe da Andaluzia, tinha boa fama entre os muçulmanos, que o chamavam de "el al-faki santo".

O Vocabulario já estava composto em 1501, mas não havia em Granada impressor que o pudesse publicar com caracteres árabes e a impressão ficou atrazada até o final de 1504, quando Juan de Varela chegou à cidade; os exemplares saíram do prelo a 5 de fevereiro de 1505.

Trata-se de uma obra para conhecer o árabe andaluz e até certo ponto sua cultura, no momento em que era completada a conquista de Granada [Figura 5.5]. Foi também o primeiro livro impresso, em todo o mundo, com caracteres arábicos gravados em madeira. Faltariam quase dez anos para a publicação na Itália do primeiro livro completo, impresso em árabe, um livro de horas (Kitāb ȘalāŤ al-sawāî), de 1514.

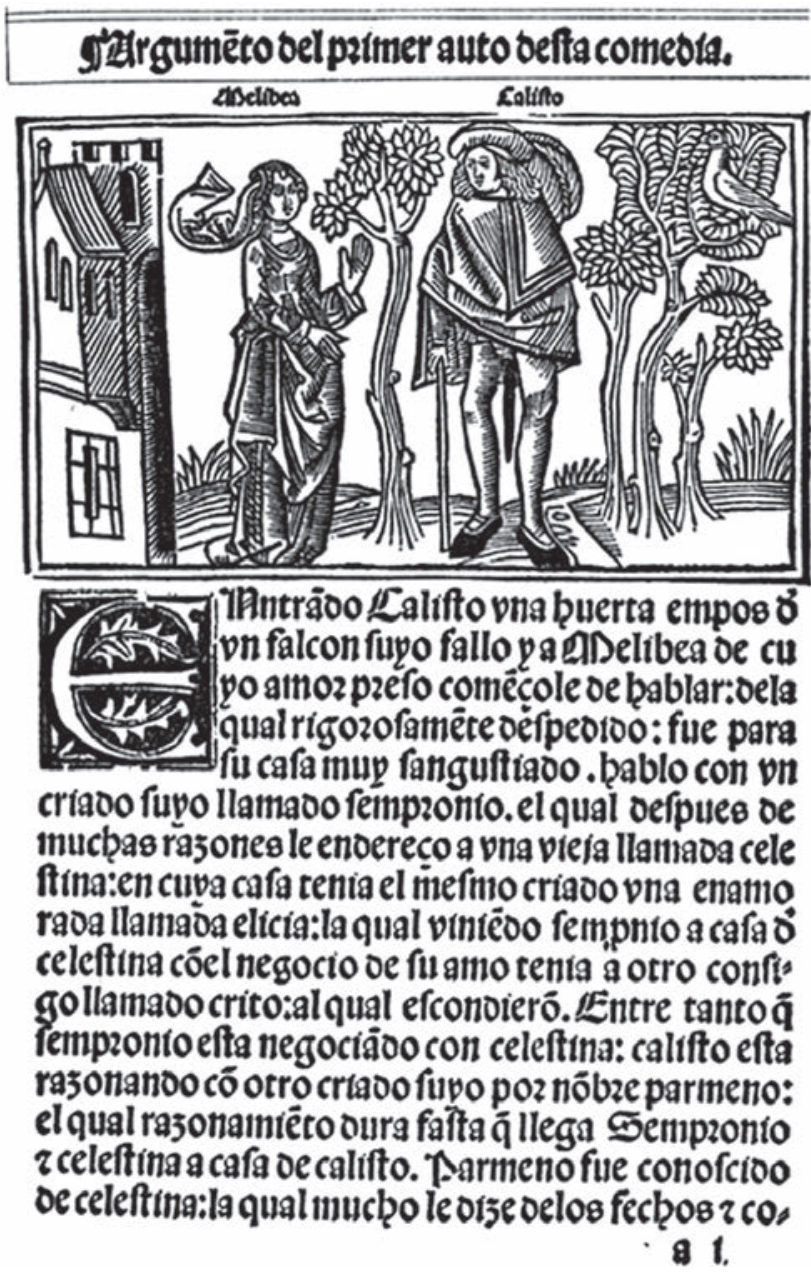

Figura 5.3. Comedia de Calisto \& Melibea (Fernando de Rojas, 1499).

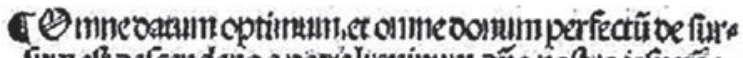

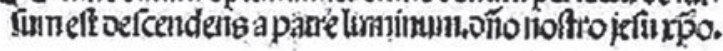

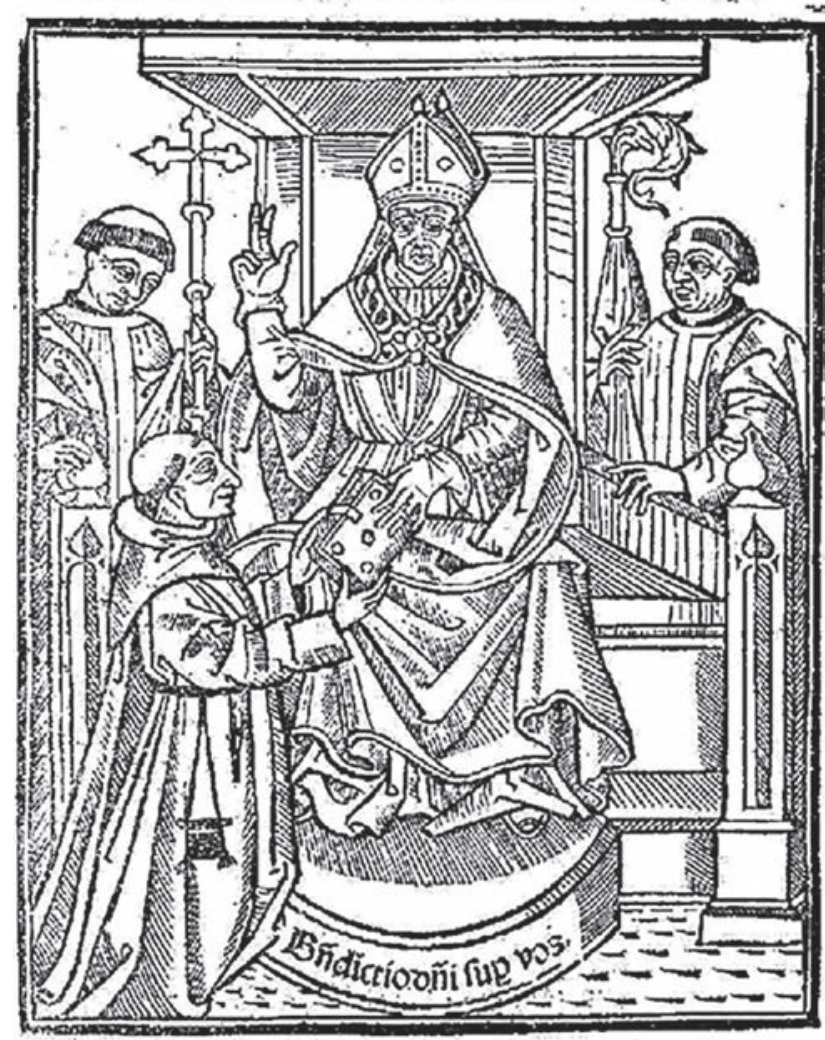

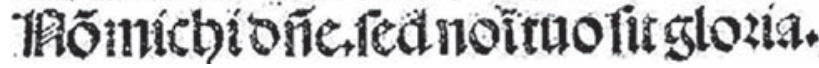

Figura 5.4. Frei Pedro de Alcalá entregando um exemplar de sua obra ao arcebispo de Granada, Frei Hernando de Talavera [Xilogravura no verso do frontispício do Vocabulista arauigo en letra castellana]. 


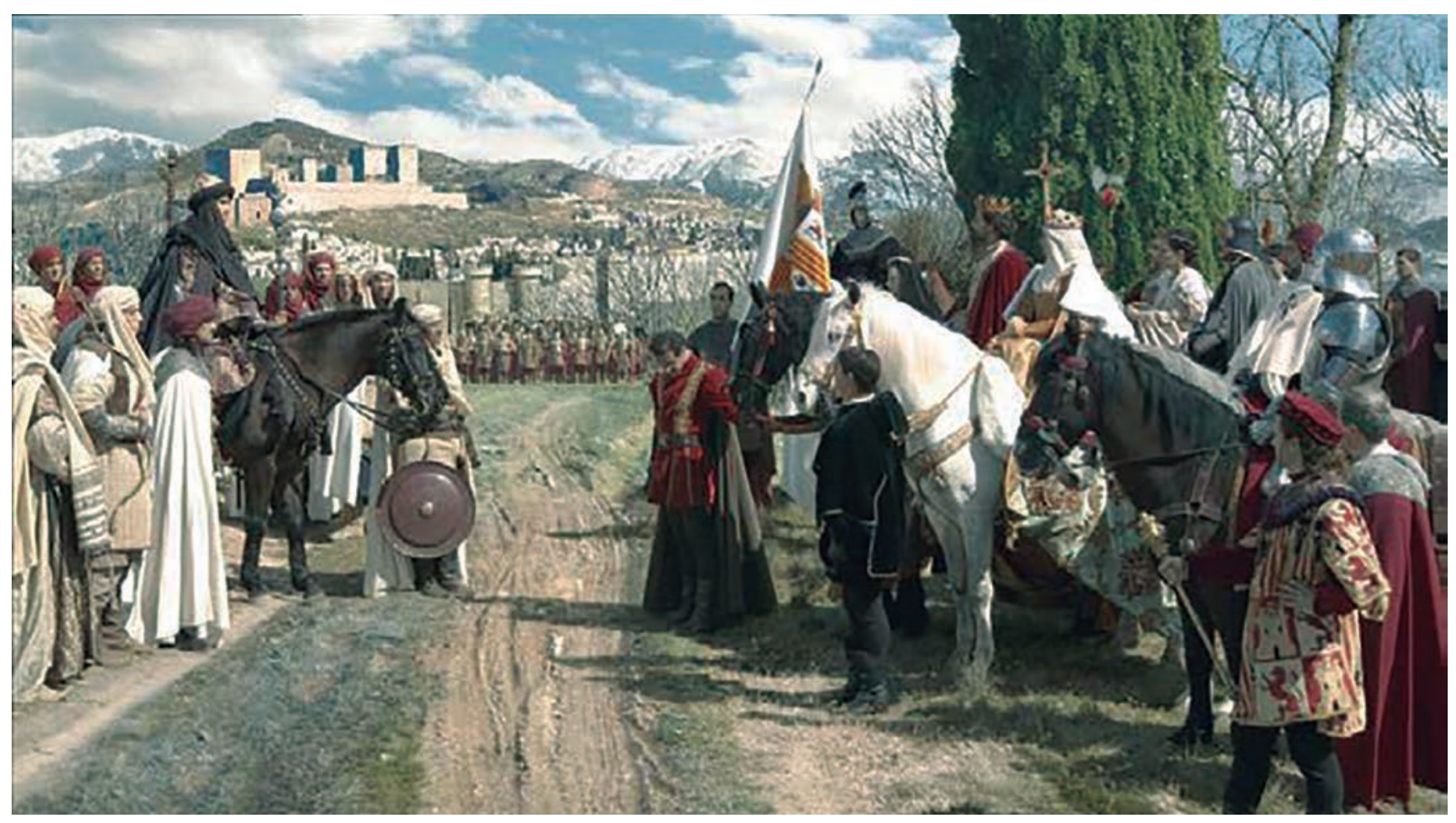

Figura 5.5. Conquista de Granada pelos Reis Católicos.

Em seu Vocabulario arauigo en letra castellana (Pedro de Alcalá, 1505; sem numeração de páginas) constam os seguintes substantivos e verbos:

[Figura 5.6]: Adaragadante. \$larăqua. darăq.

[Figura 5.7]: [Essudar. adarrăq. adarrăq̣t. adarrăq

[Figura 5.8]: Ėscuðo. darăca. darăq.

Ėscudado assí. mudărraq.

Ėscudo redondo. iŭnna muðăguara. jumnăt.mudaquarïn.

Escudado dl. mudărraq.in.

Esscudo pequeño. J田urăica. Duraíquit.

Éscudero que haze escudos. \$l

\subsection{Hernando de Vaeça, 1510}

Hernando de Vaeça [Baeza], cristão espanhol que viveu com a família real no Alhambra como intérprete, escreveu Las cosas que pasaron entre los Reyes de Granada desde el tiempo del Rrey Don Juan de Castilla, segundo de este nombre, hasta que los Catholicos Reyes ganaron el Rreyno de Granada, scripto y copilado por Hernando de Baeça, el qual se halló presente á mucha parte de lo que cuenta, y lo demas supo de los Moros de aquel Reyno y de sus corónicas. Hernando de Vaeça: de la suma que hizo estando en Granada de las cosas de aquel rreyno (Vaeça [ca. 1510] in Lafuente y Alcántara, 1868), onde citou as adargas:

“Llegados, pues, y hecha la dicha seña, el príncipe, como aquel que no dormia, acudió luego á la seña, y echó un cordelito sotíl que tênia en la mano, porque así era el concierto, y ellos en aquel cordel le ataron una soga de lana buen gruesa, la qual él ató a un marmol, y se colgó por la misma cuerda, y con él otro hermano suyo, y ambos á dos tomados por los caualleros con la reuerencia y acatamiento que deuian, les pusieron en las manos sendas espadas y sendas adargas..." (Lafuente y Alcántara, 1868: 20).

“...y alçó la manga del jubon y de la camisa, y desnudo el brazo, tomó la lança en la mano, y algunos quieren dezir que se quitó el capacete o ceruillera, y alçó el adarga, diciendo á grandes vozes; Santiago, santiago, y á ellos, que oy es nuestro dia..." (Lafuente y Alcántara, 1868: 26).

"Y dixo al rrey: señor, dios os ayude y esfuerce; y diciendo estas palabras se abaxó un poco el arroyo abajo a donde auia una tabla honda, y bajóse del cauallo, y tendió su cabeza sobre su adarga, y lançóse en el água" (Lafuente y Alcántara, 1868: 26). 
"ilonbies"

Diç

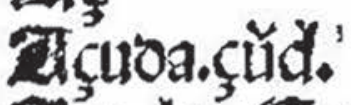

Diçuela. Eaidùm.capìdi.

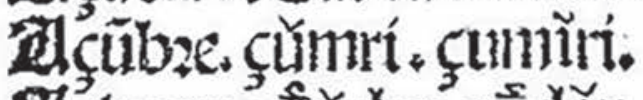

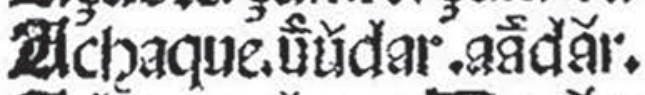
âd daragadante. oarăq.

Dldaragado.mud้ărraq.iัn. 2ldaraine oe pefo.cünen ecimiñ.

(ầm.

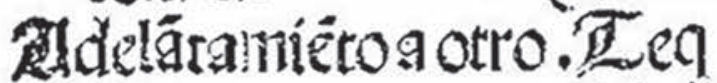
管 delantaniento oignidad Teqdìn.

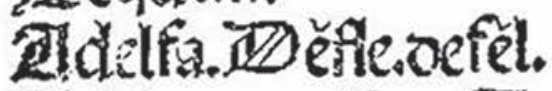

Eldelgazanivero. Taracuัn

Mdereço.Tavăr.

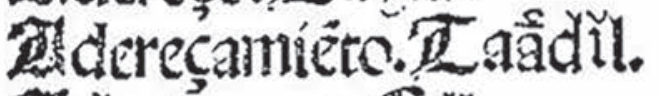

dadumanç. Sill.

Rdendade.nudium. iัt.

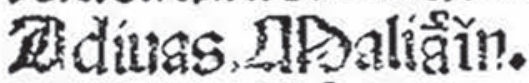

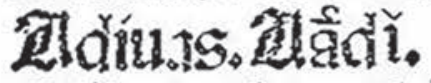

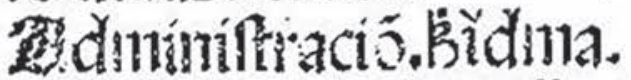

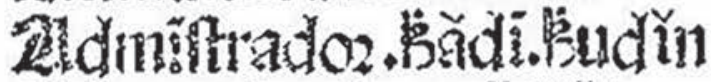

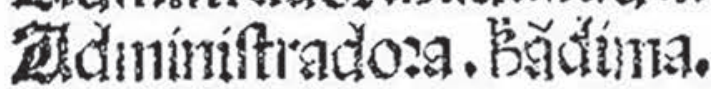
Bưdìn.

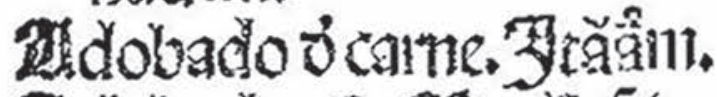

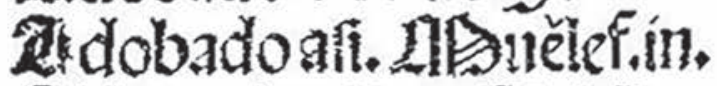
Dldobo ơmajar. Tabs. Eldobo ilgera. 'Daล์dil. Dolomda cora. muădel.in.

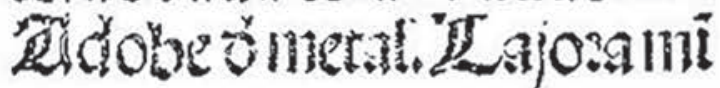

\section{ronbres.}

\section{aff}

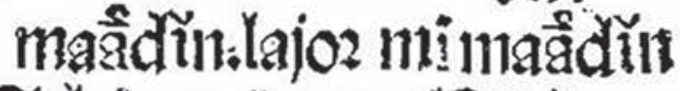
addobe oebarro. Tibèri: 20lopció. Tegnelùd. Eldoprado.2if buelled. itr. Q⿱ddoariónavios. yîběde. dedoracióalos fantos. Te guěçıl. (ūn. adomann. L ezeruัn.o.ze Dldomecidonustěrâd.ùn Adosinecímiéto iztírquèd. adradacofarara.bafifieifé

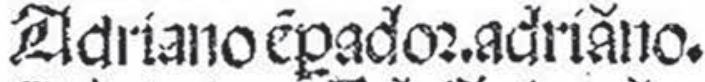

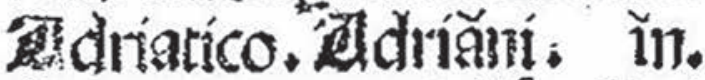

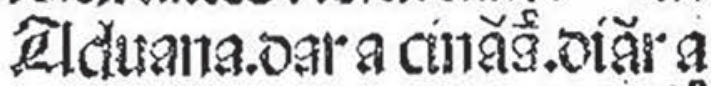

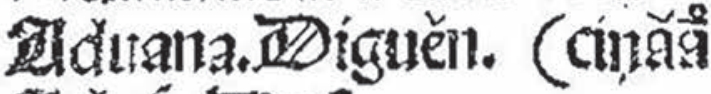

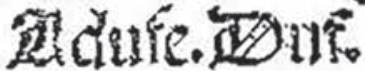
Dadufero. IDafif oafifin.

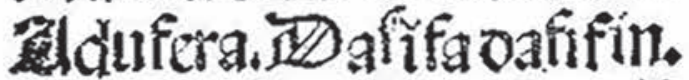
edduenedizo.13arăni. i⿱⺌兀.

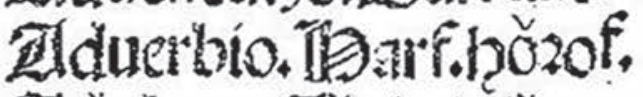

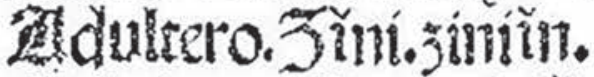
角dultera. Jinnáziniết.

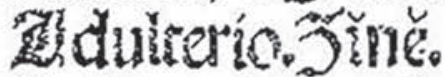

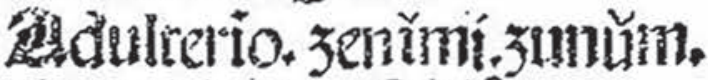

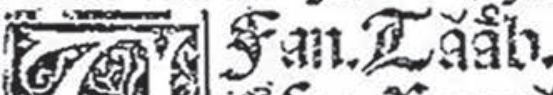
(1) 2 ,

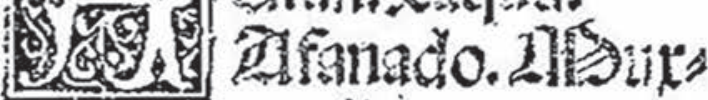
qะi.snuxquin?. alfotte. Tagadul. 焉fcitada. Masuădeda. ìn. 


\section{\$oos er. Prit. pop. Tmpati.}

这rcoplear.

rhidaffăr, oaffărt oaffăr.

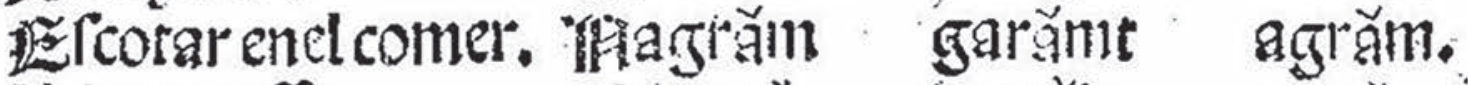

izfcotarafli.

roinexì metéit mexĭ.

记 rojer.

TParaguăt

Efcreuir como ảera.

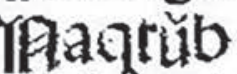

造Ccreniralfi.

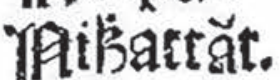

kaguătt, rağuăt.

quetěbt aqtǔb.

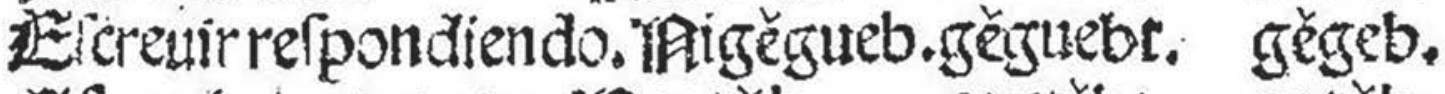

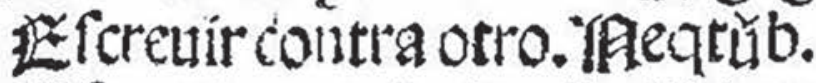

quetěbt.

equăb.

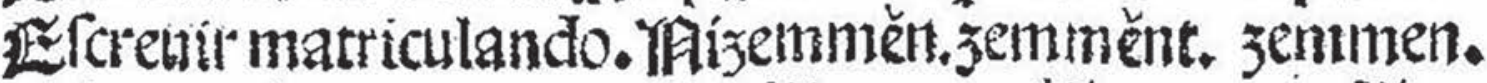

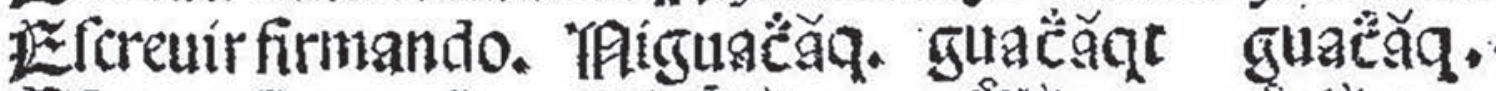

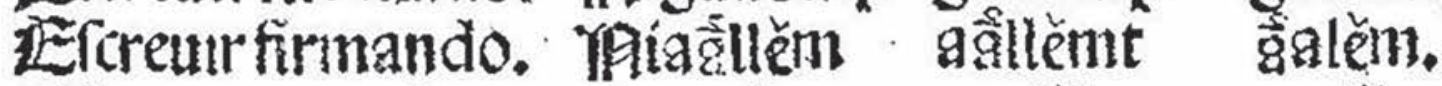

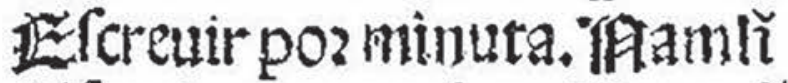

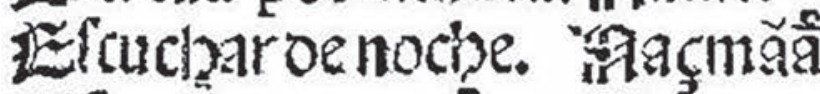

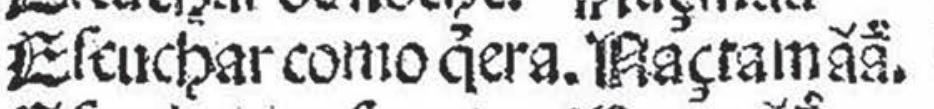

运fachar oe fecreto.

迅 fudar.

记foudaraffi。

र

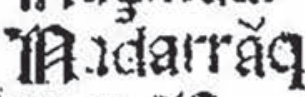

TPalcăf.

Elcudruñar.

"pqeftèt.

迅 ruitriñar.

amlěit

çamăẫt,

ainlĭ.

acramăåt

çăinăăt.

açmăẵ

açtamăẵ.

迄 falpir.

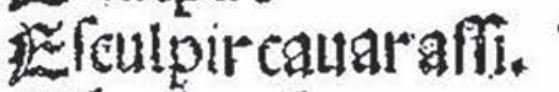

Efcurecerfe.

adarrăqut,

lacăft

açmăå̃

Efcurecer otra cola.

Eefcurriraligo.

iefurare.

feéert

adarrăqu.

alcăf

运fcufartis.

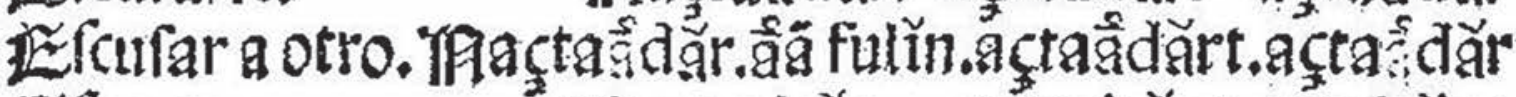

Elecutar.

Effosçare.

ìfforçar a otro.

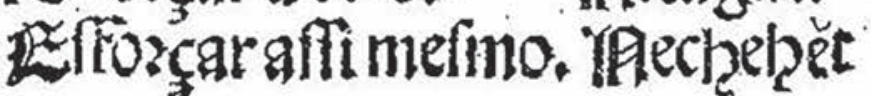

YPatcaguĭ. rificaguì. iflisarběr

rąı̉arrăm.

iflancor

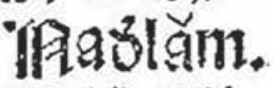

riácdallăm.

Thímaçŭă

TAabtect.

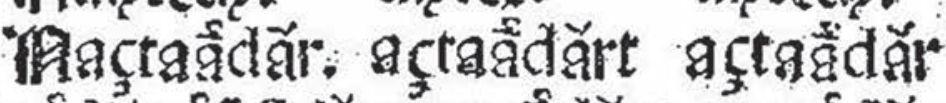

"flartarhăn

Băarbět

Bàtrămt

nacăt

adlăme

oallămt

maç̧̧ălt

apcrërt

artarbănt artąăn.

adcaguăí atcagal.

caguéit

ecbetzęret. caguĩ.

ecbatbět : 


\section{'Ronibies. ê.}

efcrinanopzincipal, cădi; cuđă.

Lếcruano oelo â otro oize.

Qutrib, cutib.

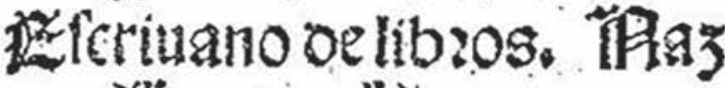

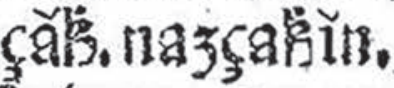

巡 forituano de contratos.

208 uăcíq. muaçiquun.

iefcriuanía publica.taveciq

eferiluanias, agaguัa.0a

$\therefore$ gutiút.

zeriuaniasani. Lereriuaniasafi. 20 Dabbă

ra.mabăbir.

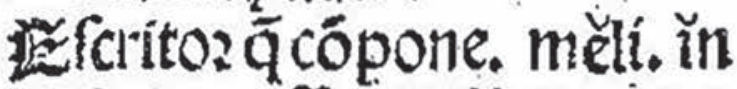

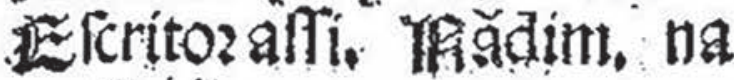
đímiัn.

Efcriturg contra otro. Taz

ğ̌l. tecě̉igl.

jefritura como äera. घut

fécritura enilas efpalăgs.

Q antbefa dăhar.

cerritura oe pzopia mano.

Q Sultbemumęzeç.

écrítoro ppímano qu tib. curtib.

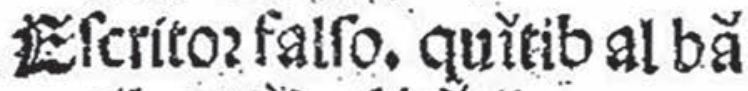
til.cuttìn al bătil.

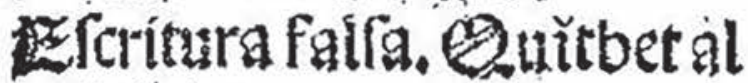
bătil.

Efrito: vodadero. Ouitib
Moniszos. er.

alpăq.cutrìb a!băq. Lefcritura vodađera. Guir betalbăa.

tecuadra de gente. 3amă 记 Couadra batalla, Janăb arnō̆p:mín B̈ăil.

E fuadra carrabon, Larta bǒncartabonur:

efuchas del campo. bitte butžt.

(î̌

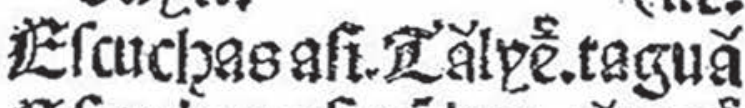

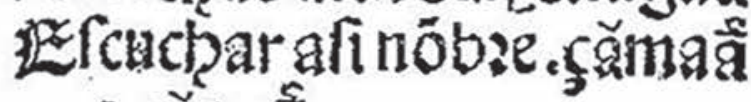
o çămè̃.

送fcudo. oarăca. oarăq. a fcudo affi, reăroua.oar quăt. efcidado fri mudu (in. fudo alfi, mudărraq. Efoudo redondo. jünna mu dăguara, junnăt , nuḋa guarìn.

迎 fudado ol.mudărraq.in 这fuco pequeño, Doră ca.ouraiquìt.

2efacteroque baje efudos Dorrăq. oarraquัn.

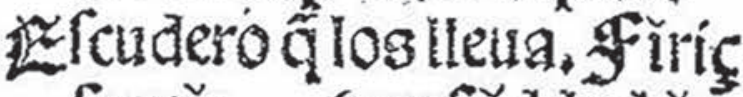
furcìn. (mufăddă zradoplateado. \$ŭmna isfoudete verua o nenǔfar. Tीễfel.

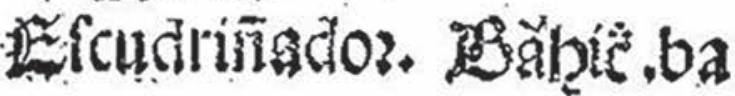




\subsection{Juan del Enzina, 1516}

No poema satírico intitulado "Almoneda"de seu Cancionero (Enzina, 1516: fólio XLVI (verso); reproduzido em Gallardo, Zarco del Valle \& Sancho Rayon, 1866: coluna 867) há os seguintes versos:

\section{Evna efpada be madero $z$ la vayna oe batnante. $\tau$ via buena oargadante se papel que nobecuero zuna cefta $\tau$ un mostero en lugar oe capacete pos purial vn majadero $z$ vilas tripas be carnero pos la falda 2 los gocetes.}

\subsection{Pedro de Salazar, 1570}

Em sua obra Hispania victrix (Salazar, 1570) há numerosas referências à adarga (fólios 6v, 7v, 11r, 14r, 18r, 19r, 27v, 28v, $32 v, 37 r, 38 v, 40 r, 42 r, 50 r, 52 r, 77 v, 78 r, 90 r, 124 r, 124 v$ e 127v), que não serão aqui transcritos.

\subsection{Pedro de Aguilar, 1572}

No Tractado de la cavaleria de la gineta ${ }^{14}$ (Aguilar, 1572) há muitas citações da adarga nos Capítulos XI (De como ha de correr el cauallero la carrra, con lança y adarga, fólios 33v-34v), XII (De como ha de andar el cauallero con lança y adarga en los galopes y en las arremetidas, fólios 34v-35r), XIIII (De la orden y manera que han de tener los caualleros, para combatir o á cauallo, con lanças y adargas, fólios 36v-39r) e XV (De como se há de jugar a las cañas, y de la orden y concierto que en ello se ha de guardar, fólios 39r-43r).

\subsection{Luís del Marmol Carvajal, 1573}

No Libro tercero y segvndo volvmen de la primera parte de la descripcion general de Affrica (Marmol Carvajal, 1573) encontramos:

14 Jineta - Arte de montar a cavalo que consiste em levar os estribos curtos e as pernas dobradas, mas em posicão vertical do joelho abaixo, como mostra o cavaleiro no canto inferior esquerdo da figura abaixo:

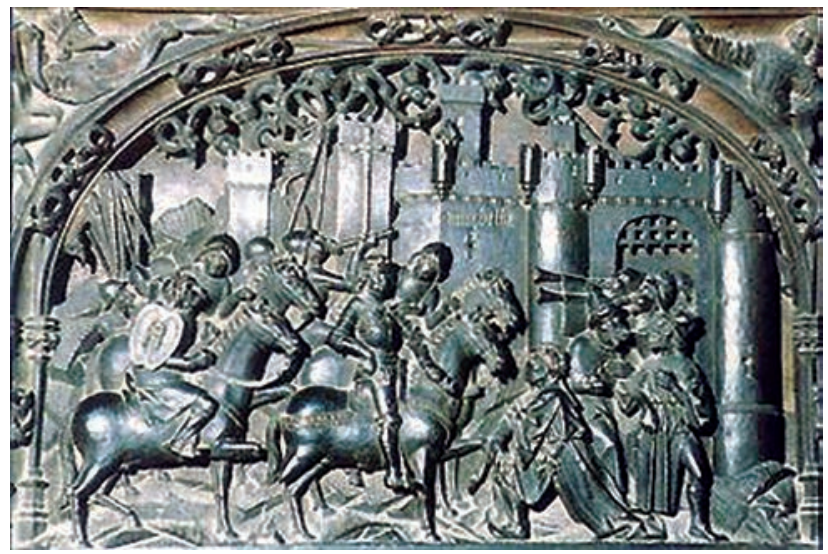




\section{Fólio 7r:}

“El qual la combatio y escalo en medio del dia, siẽdo el proprio adalid el primero que subio por el muro trepãdo por vna lança arriba: el qual embragada la adarga, y con la espada en la mano abrio el camino a su gente, matando y hiriendo muchos Moros, de los que acudian a defender la entrada".

\section{Fólio 13r:}

“Escopetas ni vallestas, no las auia entre ellos, ni sabian que cosa eran, hasta de pocos años a esta parte, que yendo a las guerras del Xerife algunos Beréberes se han hecho platicos, y tienen algunas aunque mal adereçadas. Cauallos tienen pocos, y aunque son muy pequeños, son tan ligeros,que sin herraduras suben por aquellas peñas como cabras. Los hombres de a cauallo vsan lãças cortas, y adargas de ante pequeñas y muy redondas,y vnos alfanges de la propria hechura de los puñales, y todos vsan sillas de la gineta, porque en Affrica no traẽ otras de ninguna suerte".

\section{Fólio 44r:}

"Y los dos Christianos se recogieron con harto trabajo, y peligro, a la casa fuerte porque cargaron muchos Moros sobre ellos para matarlos. Luego el mesmo dia la cercaron mas de mil Moros adargados, y entrellos algunos escopeteros,y vallesteros...".

\section{Fólio 52r:}

"Viendo se Luys de Lorero perdido porque los enemigos le tenian cercado por todas partes, poniendo la adarga delante con la lança debaxo del barco [sic] rompio por los Moros, y aunque le dierõ muchas lançadas y cuchilladas, y le cortarõ el dedo pulgar se escapo con solos siete hombres, todos los de mas fueron muertos, y captiuos".

\section{Fólio 67r:}

"Hazense tãbien en esta ciudad las adargas de Ante, porque traen muchos cueros de aquellos animales de Numidia, y de Libia donde se crian".

\section{Fólio 96v:}

"Asi mesmo les prouee de armas, como son lanças, adargas, efpadas, alfanges, cotas de malla, capacetes, y vallestas, o escopetas, procurando siempre cada vno traer su gente muy luzida...."

\section{Fólio 97r:}

"Y lanças de frexno de veynte y cinco palmos, y adargas de ante muy blancas, y en ellas ricas borlas de seda, y de hilo de oro, hazen vna hermosa vista a los que los miran".

\section{Fólio 119r:}

“...porq' luego abaxaron las lãças, y bien adargados cerraron cõ los Moros y los hizieron boluer huyendo la buelta de la ciudad, y llegando bien cerca de los muros en su seguimiẽto mataron mas de doziẽtos dellos".

\section{Fólio 154r:}

“Este dia vn escudero q' se dezia Bartholome de Soto dio vna lançada a vn Moro de a cauallo que le paso la adarga por la manija y el coginete y entrando el hierro a rayz del braço le paso vna manga de malla jazerina qu lleuaua por dos partes, y atrauesãdole el asta por el cuerpo dio cõ el muerto en tierra. $Y$ don Alonso auiendo se metido en la angostura de vn paso le cercaron los Moros, y hiriendo le el cauallo cayo y le tomo vna pierna debaxo: y como cargasen los enemigos para matarle se defendio valerosamente rescibiendo lançadas en la adarga, y en las armas hasta que fue socorrido de los soldados de apie, y saliendo malherido se retruxo a la ciudad sin perder ningun Chritiano". 


\section{Fólio 182v:}

"porque saliendo Escander con su gente dela villa, vn hijo de vn Xeque principal de los Meliones q' alli eftauan, conofciẽdo le vna adarga que lleuaua, q' la auia quitado su padre, y forçado de las mugeres, no pudiendo refrenar la yra, arremetio a el y le saco la adarga del braço, y llegando otros treynta hermanos suyos hijos del mesmo Xeque alancearõ a Escander y a todos los Turcos que alli estauan sin que bu Hamu ni Martin de Argote los pudiesaen fauorescer".

\section{Fólio 187v:}

"Llegaua vna parentela junta primero, y hablauan y abraçauan al conde los principales della, y luego escaramuçauã vn poco dando lugar depues a que llegasen los otros y desta manera llegaron mas de cinquẽta linages, entre los quales vuo algunas de ciento de a cauallo y los q' menores eran passauan de cinquenta, y todos venian cõ sus lanças y adargas ricanente enjaezados".

\section{Fólio 230v:}

"Traya este valeroso Affricano dos cotas de fina malla jazerina vestidas vna sobre otra y vna lança y vn adarga y vn rico terciado".

\section{Fólio 245v:}

“...al lado derecho yua el estafero mayor con vna lança enhieta pegado con el estribo del rey, y al yzquierdo otro con vna adarga, y detras otro con vn cauallo y vna vallesta: estos todos yuan a cauallo y alderredor dellos yuan los otros oficiales y maestros de cerimonias".

\subsection{Gonzalo Argote de Molina, 1575}

Em seu Discvurso hecho... sobre la poesia castellana (Argote de Molina, 1575: fólios 95r e 95v), transcreveu e traduziu versos do último rei árabe de Granada:

"Son versos Turquescos amor ros dedicados ala diosa de los amores que los Turcos en su lengua llaman Asich, y desta quantidad son algunos cantares lastimeros que oymos cantar a los Moriscos del reyno de Granada sobre la perdida de su tierra a manera de Endechas, como fon.

$$
\begin{aligned}
& \text { Alhambra hanina gualcoçor taphqui } \\
& \text { alamayaráli, ia Muley Vuabdeli } \\
& \text { ati ni faráci, guadárga ti albayda } \\
& \text { vix nansi nicátar, guanahod Alhambra } \\
& \text { ati ni faráci, guadárga ti didi } \\
& \text { vix nansi nicátar, guanahod aulidi } \\
& \text { aulidi fi Guadix,Vamaráti fijol alfáta } \\
& \text { ha háti di nóni, y a séti o Malfáta } \\
& \text { aulidi fi Guadix,guana fijol alfáta } \\
& \text { ha háti di nóui,y a séti o Malfáta. }
\end{aligned}
$$

Es cancion lastimosa que Muley Vuabdeli vltimo Rey Moro de Granada haze, sobre la perdida de la real casa del Alhambra guando los Catholicos reyes don Fernando y doña Ysabel conquistaron aquel reyno, la qual em Castellano dize assi.

Alhambra amorosa, lloran tus castillos O Muley Vuabdeli, que se ven perdidos dad me mi cauallo, y mi blanca adarga para pelear, y ganar la Alhambra 
dad me mi cauallo, y mi adarga azul

para pelear, y librar mis hijos

Guadix tiene mis hijos,Gibraltar mi muger

señora Malfata,heziste me perder

en Guadix mis hijos, y yo en Gibraltar

señora Malfata,heziste me errar".

\subsection{Gonzalo Argote de Molina, 1588}

Em sua obra Nobleza del Andalvzia (Argote de Molina, 1588) há as seguintes passagens:

P. 36:

“En la avanguardia puso quarenta mil Moros negros armados de lanças, espadas, y adargas, que teniẽdo hincados en tierra los cuentos de las lanças mostravan las puntas dellas azeradas a la frente de los enemigos, como en la milicia moderna yan los esquadrones de los Piqueros".

P. 134:

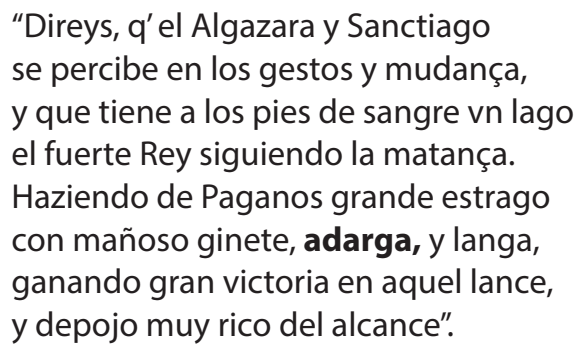

P. 273:

"Y subiendo en vn cavallo armado de adarga y lança fue a Arjonilla, y llegando ala carcel donde Macias etava, viole dende vna ventana lamentãdose del Amor".

P. 313:

“El Obipo que lo oyera, dio de espuelas al cavallo, el cavallo era ligero, saltado avia de vn vallado, mas al salir de vna cuesta, a la assomada de vn llano, vido mucha Adarga blanca, mucho Albornoz colorado, y muchos hierros de lanças, que reluzen en el campo, metidose avia por ellos, como Leon denodado, de tres batallas de Moros, la vna à desbaratado, mediante la buena ayuda, que en los suyos à hallado".

P. 332:

"Y lo mismo Alonso Gutierrez de Leon, que estãdo desarmado encima de vn cavallo e escriviendo la gente de que vio la pelea, con sola vna Adarga y vna lança en la mano se vino para don Fernando Alvarez, y estuvo siẽpre con el a muy grã peligro en lo mas fuerte dela batalla, hasta que los Moros fuerõ del todo desbatatados, y el fue herido de vn Passador en vn muslo".

\subsection{Luís del Marmol Carvajal, 1599}

Na obra Segvnda parte y libro septimo de la descripcion general de Aftica (Marmol Carvajal, 1599: fólio VIII) (verso), lê-se:

"Tafilet es vna ciudad muy grande del estado de Numidia, edificada por los antiguos Africanos, su sitio es vn llano de arena cercada de muros, y tiene vna alcaçaba al vn lado de la ciudad, enque ay mas de dos mil vezinos, esta poblada de vn pueblo de Bereberes llamados Filelis, gente rica y de grãde industria, tienen muchos palmares de datiles de los mejores de Numidia, y crian grã cantidad de ganados de toda suerte, y de camellos. Alli se labrã las ricas adargas de ante delos cueros de aquellos animales q' traen de Libia, y de los otros pueblos de Numidia". 


\subsection{Luís del Marmol-Carvajal, 1600}

Em sua Historia del rebelion y castigo de los moriscos de Reyno de Granada (Marmol Carvajal, 1600) há as seguintes citações da adarga:

\section{Fólio 5v:}

“El primero y mas alto esta junto com la Alcaçaua antigua en la parrochia de san Miguel, y alli fueron los palacios del Bedeci Aben Habuz, en las casas del Gallo, donde se vee vna torrezilla, y sobrella vn cauallero vestido a la morisca sobre vn cauallo ginete; con vna lança alta, y vna adarga embraçada todo de bronze, y vn letrero al traues dela adarga q' dezía desta manera.Calet el Bedici Aben Habuz quidateha bez Lindiluz, q' quiere dezir, Dize el Bedicí Aben Habuz, que desta manera sea de [?] Andaluz, y porque con qualquíer pequeño mouimiento de ayre buelue aquel cauallo el rostro, le llaman los Moriscos Die Reh, que quiene dezir Gallo de viento, y los Christianos Ilaman aquella casa la casa del Gallo".

\section{Fólio 29r:}

"En tanta rebolucion pasara el negocio muy adelante, i el Arçobipo de Granada, confiado mas en la misericórdia de Díos q' em la fuerça de las armas, no les apaziguara con vn eroyco hecho porq' no auíendo querido oyr al Conde de Tendílla, ní recebír su adarga, q' fse la embíaua en señal de paz...."

\section{Fólio 97r:}

"A esto acudío Gonçalo de Alcantara, y emparejando con el Moro de la vandera; le firio con la espada en eł hombro yzquierdo, y dio con el muerto en tierra, mas cargando sobre el otros que venían de tras e [?] muerto, no fuera por las armas, y por vna adarga que lleuaua embraçada, y con todo esso le dieron vna estocada em el rostro y le derribaron de espaldas en el suelo, cõ otros muchos golpes que recibio sobre las armas".

\section{Fólio 134v:}

“El conde de Tendilla fue el primero q' salio a recebir a don luan de Austria con dozíentos ginetes muy bien adereçados, ciento de la compañía de Tello Gonçalez de Aguilar, y ciento de la suya, cuyo teníente era Cõçalo Chacon, estos yuã todos vestidos a la morisca y los otros con ropetas de rafo, y de tafetan carmesi a nuestra vsança, y los vnos y los otros bien armados de coraças, capacetes, adargas, y lanças, de manera que entre gala y guerra hazían hermosa y agradable vista".

\section{Fólio 173v:}

"No por eso dexauan de acercarse los enemigos por otras partes haziendo impetuosos acometitos, y eran tantas las piedras que echaban sobre los que estauan en las tronetas, y en los traueses, que fue menester que el capitan luan Aluarez acudíese hazia aquella parte, y cubriendo los soldados con las adargas y rodelas de los escuderos, resiftio el ímpetu y furia de piedras...."

\section{Fólio 174r:}

“...donde entendian q' estauan los bastimentos y municiones, mas el capitan leuanto luego vn cauallero alto para sujetar a los trabajadores y poderlos descubrir en la obra q' hazian, y acudiendo hazia aq'lla parte, los capitanes luã Aluarez de Bohorques, y Lorenço de Leyua, fueron tambien de mucha importancia las adargas este día, porq' resistieron con ellas la furía de las piedras q' los de fuera tírauan".

\section{Fólio 174v:}

“...tomo por remedio ofender a los enemigos con sus mesmas armas, y juntando el mayor numero de soldados y moços q' pudo les mando q' boluiesen a arrojar contra las casas donde se auian metido los enemigos, las mesmas piedras que ellos tirauan, y como no tenian adargas ni celadas con que cubrir las cabeças como los Christianos...." 


\title{
5.16. Miguel de Cervantes Saavedra, 1605
}

Indubitavelmente a mais famosa referência à adarga encontra-se na imortal obra de Miguel de Cervantes Saavedra [Figura 5.9] (Alcalá de Henares, 29 de setembro de 1547 - Madrid, 22 de abril de 1616), El ingenioso hidalgo don Quixote de la Mancha [Figura 5.10]. No capítulo primeiro (Que trata de la condicion, y exercicio del famoso hidalgo don Quijote de la Mancha (Cervantes Saavedra, 1601: fólio 1r) consta a celebérrima passagem:

"Em vn lugar de la Mancha, de cuyo nombre no quiero acordarme, no ha mucho tiempo que viuia vn hidalgo de los de lança en astillero, adarga antigua, rozin flaco..... [Figura 5.11].

\subsection{Luís de Góngora y Argote, 1613}

No poema Polifemo y Galatea (cf., Pellicer de Salas y Tovar, 1630: coluna 341; tb., em Parker, 1942: 43) há a seguinte estrofe:

"Viendo el fiero layan, con passo mudo,

Correr al mar la fugitiua nieue,

(Que a tanta vista el Libico desnudo

Registra el campo de su adarga breue)

Y al jouen viendo, quãtas mouer pudo,

Celoso trieno, antiguas hayas mueue.

Tal antes que la opaca nube rompa,]

Preuiene rayo fulminante trompa".

E em Parker (1942: 14; inexistente em Pellicer de Salas y Tovar, 1630) há esta outra estrofe:

"Trescientos Cenetes eran
deste rebato la causa
que los rayos de la luna
descubrieron las adargas;
las adargas avisaron
a las mudas atalayas,
las atalayas los fuegos,
los fuegos a las campanas".

\subsection{Lope de Vega Carpio, 1624}

Em sua obra Circe con otras rimas y prosas (veja Vega Carpio, 1624), citou várias vezes a adarga:

\section{Fólio 76r:}

\author{
"Su Padre inuicto de su edad vn dia, \\ Con el vestido Arabigo de España \\ Qu nos dexò asu antigua Monarquia, \\ Marlota, capellar, adarga, y caña; \\ El zefiro del Alba desafia. \\ En el ginete que de sangre baña \\ En tal Aurora, que por justas leyes \\ Obliga tal mañana a tales Reyes".
}

\section{Fólio 145v:}

"Aurá seys dias que me ha escrito este papel (y sacòle entonces) em q' me desafia cinco a cinco, cõ lãças, adargas, y alfanjes a cauallo, como es vso nuestro: donde si fue revencedor da la palabra de cessar de la pretension: haziendo yo lo mimo si el me venciere".

"Si estoy dixo don Felis, y para que te assegures, mañana al amanecer saldremos los dos al campo, y me verás exercitar la lança, y el adarga, arremetiendo, cercando, o retirando, ya sacando el alfanje, derribando la adarga, ya sin el,tomandola por el cuento, con otras gentilezas".

"Si està V.m. diziendo, que de qual de los Moros del Romancero le he sacado, no tiene razon: porque los otros estauan en Madrid, o en Granada, y este en medio de Tunez, con vna lança de veynticinco palmos, que 


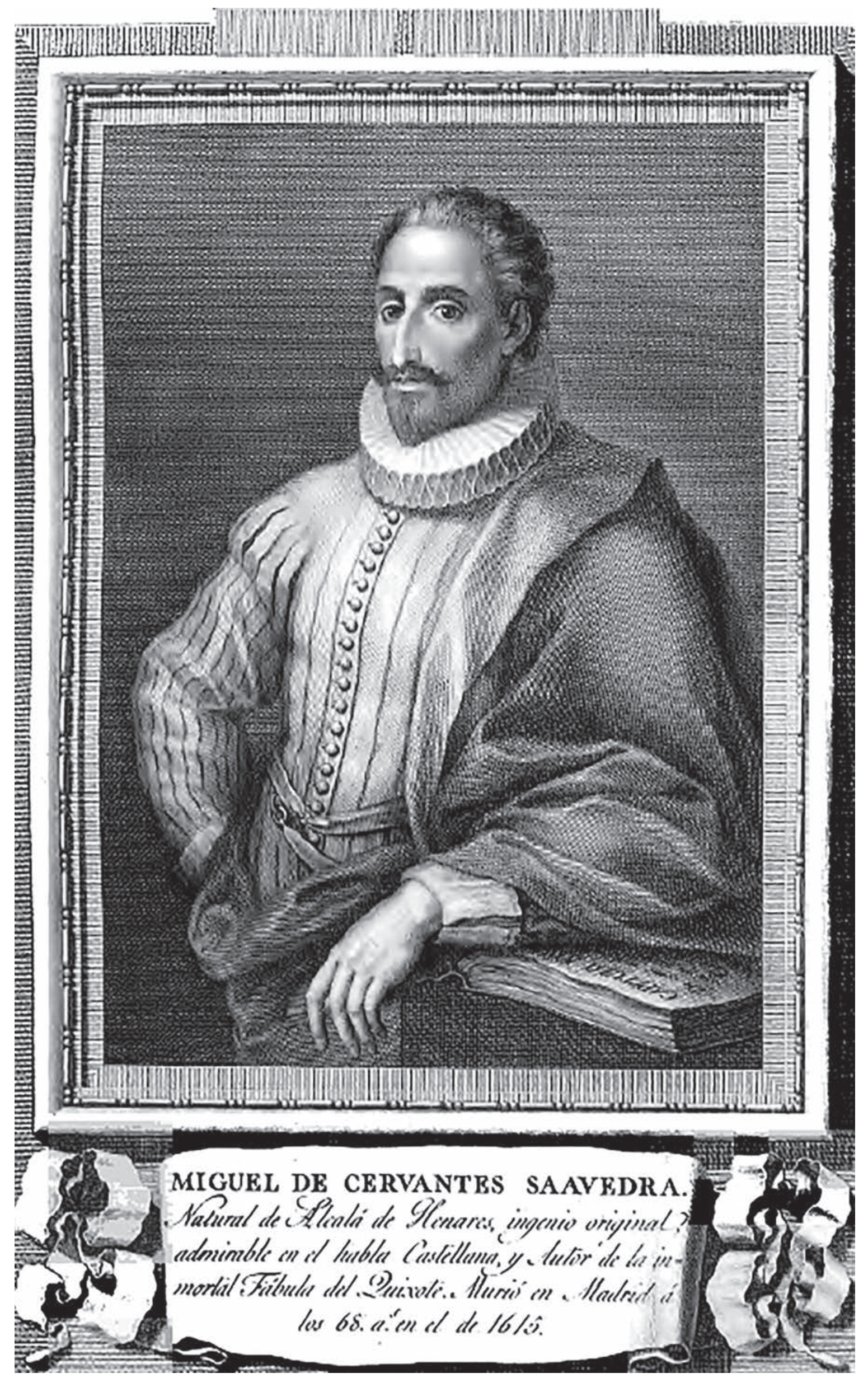

Figura 5.9. Miguel de Cervantes y Saavedra. 


\section{E L I NGE N I O S O H I D L G O DO N Q V I- XOTE DE LA MANCHA,} Compuefto por Miguel de Ceruantes Saauedra.

DIR I G ID O AL DVQVE DE BEIAR, Marques de Gibraleon, Conde de Benalcaçar, y Bañares, Vizconde de la Puebla de Alcozer, Señor de las villas de Capilla, Curiel, y Burguillos.

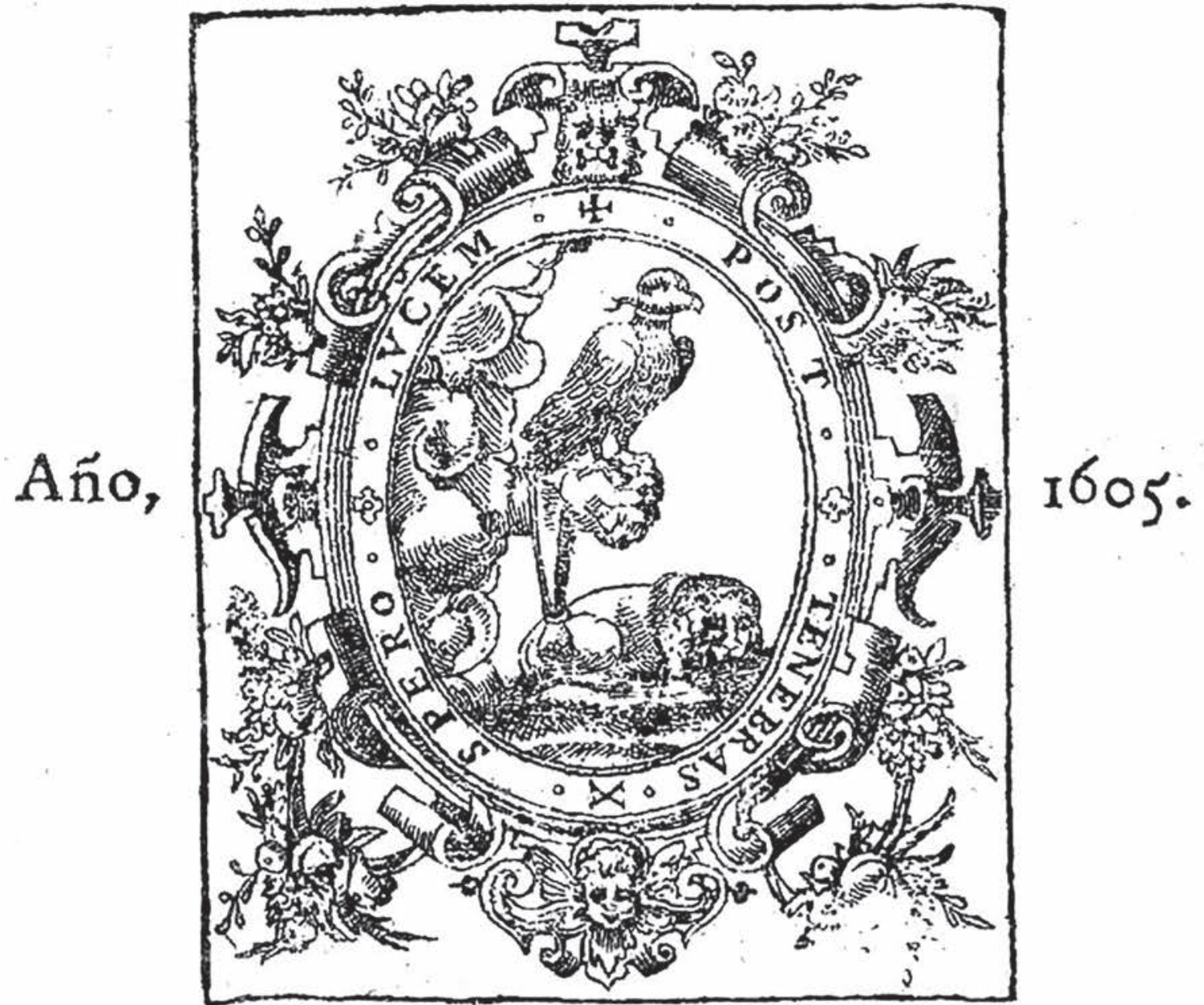

GON PRIVILEGIO, $E N x \propto D R I D$ Por luan de la Cuefta.

Vondefe en cafa deFrancifco de Robles, librero del Reynīo feñor. 


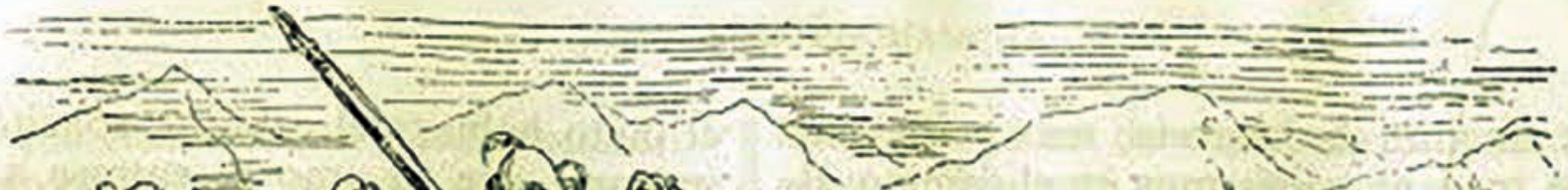

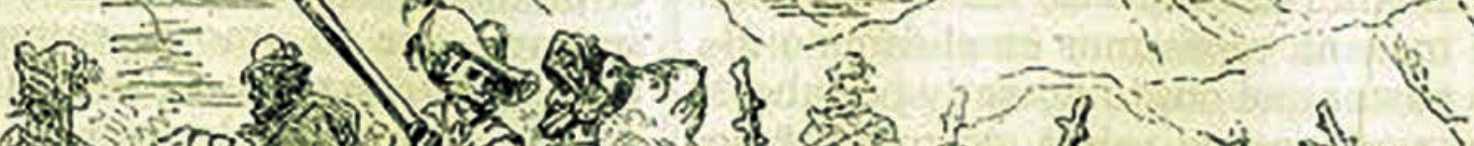
istis i) 1 (1)
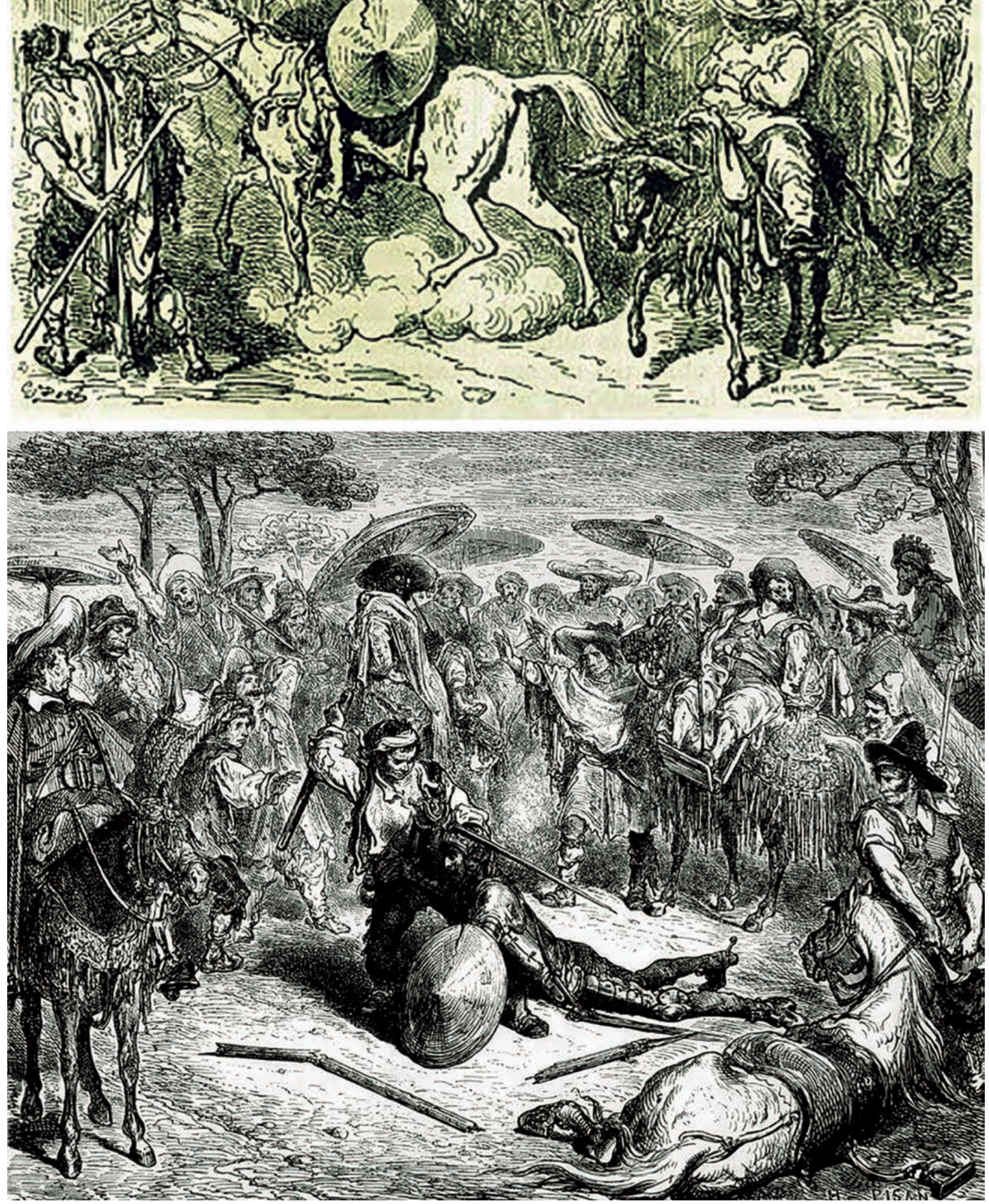

Figura 5.11. “...vn hidalgo de los de lança en astillero, adarga antigua, rozin flaco..." 
aqui no ay que quitar nada, y vna adarga de color morado, com vna F. Arabiga en medio, que a la cuenta, pues no podia dezir Francisca, diria Fatima".

\subsection{Juan Antonio de Vera y Figueroa, 1632}

Autor do poema heróico Fernando o Sevilla restaurada (Vera y Figueroa, 1632); tem três citações:

\section{Fólio 17 (Canto primero, estrofe 158):}

"Alde à Zagra ha suçedido Garsi Perez el de Vargas, De las moriscas adargas Mal buscado,y bien temido"

Fólio 81 (Canto tercero, estrofe 114):

"Asi suele con la adarga En nuestra Española fiesta

Zelarse a la caãa presta

El que reçiue la carga".

Fólio 84 (Canto tercero, estrofe 146):

"Que el çerco hauian con ynmẽso

Valor Dõ Pedro, y el Vargas,

Deshecho; bien que de Adargas

Nobles, y de Peones denso".

\subsection{Gregorio de Tapia y Salzedo, 1643}

Em seu Exercicios de la gineta Tapia y Salzedo (1643: 14) tratou das características que devia ter uma adarga [Figura 5.12]:

\subsection{Alonso Nuñez de Castro, 1658}

Consta no Libro historico político de Nuñez de Castro (1658: 470-471):

"Y otra vez jugando cañas en Seuilla, delante del señor Rey D. Fernãdo, trapasó vna adarga".

\subsection{Francisco de Quevedo Villegas, 1699}

Em seus poemas sobre as musas (Quevedo Villegas, 1699), lê-se:

P. 226:

"Adargué Cara frisona

Com una Nariz de Ganchos

Que à todos los doze Tribus

Los exó romos, y braços".

P. 234:

"La Adarga (porque le cubre)

Maldezian las mas gentes

Pareciome al adargarse

Corderito de Agnu Deies". 
EXERECIOS DELA WTETS

\section{Adidgats.}

A mas a propolico para cañas ha de Ter grado do medioariba ristray de medio abaxo blanda poroue fe paseda doblar fobre ol an a del cauallo la embraçadura en medro de ellasy ha derener dos braçales,y yna manija, y vn fiador que yengadefde el ombro cono rahali, confu euillapara acortary alargar. A g opiniones de que no es

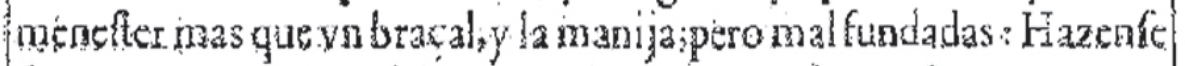
fecancones, y de junquilios, a modo de riberes, de que fe guarneceny ban de tener veinte bordes a la redondapordefuena de gaarnicion. y rambien las fuelen aformar endos antesay fe ha vifto romper el vno couv vo golpe de caña. Doran las Adargas, y las platean por de dentra; parecen mejor de fuara blancas fuelen poner en ellas vandas, motes, cifras yemprefas muy curiofas, para veras, y regocijo, y galaareria.

Figura 5.12. Página 14 dos Exercicios de la gineta de Tapia y Salzedo (1643).

\section{ALGUMAS CITAÇÕES DA ADARGA NOS ESCRITOS DE AUTORES PORTUGUESES DOS SÉCULOS XV A XVII}

\subsection{Diogo Borges, 1498 (28 de setembro)}

Numa carta à rainha D. Leonor ${ }^{15}$ (Borges, 1498; cf., Ramos-Coelho, 1892: 92; tb., em Cenival, 1934: 39-40) escreveu:

"Item, Senhora, tanto que nos este guramento tomou, cavalgou em seu cavalo, e nem levava comsygo majs de tres mours a pee desarmadis, se nom espadas e adargas, e dous christaãos no mais que com duas bestas, e bem pouquas setas; e elle soo a cavallo com hũa lança [sic] e punha [sic], e hũa adarga, sem majs outras armas".

Talvez seja o primeiro a citar a adarga na língua portuguesa.

\subsection{Anôn., in Valentim Fernandes, ca. 1507}

Cf., 8.1.2 abaixo. À página 89/36r do manuscrito consta:

"A coor de antas som como de asnos aluaçã/ da pelle de anta fazem as melhores adargas do mundo que nenhũa lança nom passa".

\subsection{Nuno Gato, 1511 (3 de janeiro)}

Escrevendo ao rei D. Manuel (Gato, 1511; cf., Ramos-Coelho, 1892: 230; tb., em Cenival, 1934: 276), comentou:

"E as gentilezas e galantarias com que se mostraram no combate da parte da porta d Almedina ate porta dos Gafos, porque eram mecejas com os alarves da parte de Zamos, com capelhares de ezcarlata, e adargas de cordões, e camisas mouriscas, e muitos corsoltes muito luzentes, e seus capacetes...."

15 Leonor de Avis ou Leonor de Portugal ou Leonor de Lencastre ou Infanta Leonor, e mais recentemente, no estrangeiro, "Leonor de Viseu", do nome do título secundário de seu pai o infante Fernando de Portugal, Duque de Viseu (Beja, 2 de maio de 1458 - Paço de Xabregas, Lisboa, 17 de novembro de 1525), foi uma princesa portuguesa da Casa de Avis, e rainha de Portugal a partir de 1481, pelo casamento com seu primo João Il de Portugal, 0 Príncipe Perfeito. Pela sua vida exemplar, pela prática constante da misericórdia, e mais virtudes cristãs, alcançou de alguns historiadores 0 epíteto de "Princesa Perfeitíssima", inspirado no cognome do rei seu marido, a cuja altura sempre se soube manter para o juízo da história. 


\subsection{Afonso de Albuquerque, 1512 (1 de abril)}

Afonso de Albuquerque (Alhandra, 1453 - Goa, 16 de dezembro de 1515), nomeado o Grande, o César do Oriente, o Leão dos Mares, o Terribil e o Marte Português, foi um fidalgo, militar e o $2^{\circ}$ Vice-Rei e Governador da Índia Portuguesa, cujas ações militares e políticas foram determinantes para o estabelecimento do Império Português no oceano Índico.

Numa extensa carta ao rei D. Manuel (Albuquerque, 1512; cf., Ramos-Coelho, 1892: 242, 246) citou adargas duas vezes:

“...el rrey de Malaca primeiro ssoube que eramod nos jtoçemtos bramcos, e crea Voss Alteza que nam arraram tres, averya hy mais duzentos malabares d espadas e adargas...".

“...e se Voss Alteza deseja de pagar os soldos a jemte, per mercadarjas ho podees muy bem fazer, e per outras coussas de que qua tems mujta neçesidade, a saber, panos chamalotes, armas, espadas. Barretes e adargas e panos de seda, e toda diversidade de mercadarja, jmda que Malaca nos dara ja d isso algũa coussa..."

\subsection{Afonso de Albuquerque, 1513 (4 de dezembro)}

Em outra carta a D. Manuel (Albuquerque, 1513; cf., Ramos-Coelho, 1892 314) contou:

"Viram s mouros a pouca jemte no muro, e vyram as nossas escadas qebradas, e acodiram rijo ao pee do sseu muro a defemder as bombaerdejras, e pelejaram bem sobre esefeito; e os nosos, porque os majs $\mathrm{d}$ eles escalaram com espadas e adargas, ssem lanças, nam poderam tolher que nam defendesem as bombardejras muy bem...."

E mais além:

"...e por alguuns dos nsos nam terem lamças, por escalarem com espadas e adargas e rreçeberam assaz de dano de pedradas e de frechadas...."

\subsection{Tomé Pires, 1515}

\section{Artigo XLI, que fala dos naires e seus custumes.}

"A gemte do Malavar hé preta e baça e parda, sam todos os reis gemtios bramenes ou de casta de seus sacerdotes. A limguajem hé toda hũa, asi como em Itália, defere se pouca cousa. E toda a terra muito pavoada. Averá neste Malavar duzemtos mill naires, homens de peleja d'espada e adarga e frecheiros. São homens que adoram o seu rei, e se por acaso o rei morre em batalha, sam hobrigados ha morrer, e se o não fazem desterram se da terra e ficam emjuriados pera sempre. Sam estes naires homens leais e nam tredos. Primeiro que hum rei do Malavar peleje com outro lho a de fazer saber, pera que se aperceba. Nenhum naire, como hé de idade pera tomar armas, não pode sair de casa sem ellas. E quando está pera morrer, sempre tem jumto consiguo a espada e adarga, tam perto que se lhe comprir que a posa tomar. Custumão todos fazer gram reveremçia aos mestres que os emsinão, em /tamta maneira que ho milhor dos nairres, se achar hum mestre que allgũa cousa lhe emsinou, faz lhe reveremçia e depois vai se lavar. E se hum naire acha em hum caminho a outro naire mais velho, adora o e dá lhe caminho. E se estiverem tres ou quatro irmãos, ho mais velho á d'estar asemtado e os outros em pee".

(via "História e Antologia da Literatura Portuguesa - Século XVI - Literatura de Viagens - II" - Fundação Calouste Gulbenkian, Boletim n²3, Dezembro de 2002 - a partir de "O Manuscrito de Lisboa da Suma Oriental" de Tomé Pires; Rui Manuel Loureiro, Lisboa, Instituto Português do Oriente, 1996).

\subsection{Ruy de Araujo, 1520 (6 de fevereiro)}

Em carta a Affonso de Albuquerque (Araujo, 1510; cf., Ramos-Coelho, 1892: 220) consta:

"Podera aquy aver quatro mjll homens de peleja, e no mais; porque todolos outros sam escravos de serviço, que nam abrangem senam a ter hŭa faca ou hŭa adaga que trazem na cynta; e as armas d estes que podem elejar, sam lanças e algũas espadas, que vem dos gores, e outras que se fazem na terra, e arcos e zaravetanas, posto que $d$ isto ha muito pouc... armaduras de seus corpos, adargas poucas, que nam abrangem... princiaes que regem". 


\subsection{Gaspar Correa (ca. 1550)}

Gaspar Correia (1492-ca. 1561) foi um historiador português, autor das Lendas da Índia, uma das mais importantes obras sobre a fase inicial da presença portuguesa na Índia e no Oriente. É referido como o Políbio português. A sua obra mais importante, Lendas da Índia, só teve edição em meados do século XIX. São escassas as informações sobre a vida deste autor, sendo escassas as informações sobre as suas origens familiares ou mesmo sobre o local e data de nascimento. Apesar dessa escassez de fontes, António Banha de Andrade situa o seu nascimento em 1492, atribuindo a paternidade a Aires Botelho, comendador de São Martinho das Feixedas, no bispado de Viseu. Sabe-se que viveu a maior parte de sua existência no Estado Português da Índia, onde terá chegado bastante jovem, por volta de 1512-1514, para servir como soldado. Foi escolhido como secretário de Afonso de Albuquerque, no que tinha bastante orgulho. Retornou a Portugal em 1529, mas retornou ao Oriente. A sua obra Lendas da Índia, embora escrita em um estilo rude, é considerada uma importante fonte coeva, sendo fruto do trabalho de 35 anos do autor na Índia, privando de fontes desconhecidas para contemporâneos como Castanheda ou João de Barros. A obra é ilustrada com os retratos dos governadores e plantas e desenhos panorâmicos de algumas fortalezas. Deve-se a ele a primeira descrição européia do cólera asiático. Uma teoria afirma que ele foi assassinado em Malaca, por ordem do governador Estevão da Gama, neto de Vasco da Gama. Embora alguns autores acreditem que existiu uma edição dessa obra em 1556, é mais provável que cópias do manuscrito desse compêndio de 3.500 páginas tenham circulado entre alguns poucos escolhidos, após ter sido trazido da Índia para Portugal por Miguel da Gama, pouco depois da morte do autor. A família conservou o manuscrito original das Lendas da Índia, que apenas viria a ser impresso, pela primeira vez, entre 1858 (início da primeira parte) e 1864 (quarta parte) por disposição da Academia Real das Ciências de Lisboa.

As numerosíssimas citações de adarga são as seguintes:

\section{Correa (in Felner, 1858: 163, sob Pedraluares Cabral, anno de 1500):}

"Então lhe apresentárão humas coiraças, e hum capacete, e adarga, e lança, que bem parecião cousas d'ElRey; e assi hum pano d'armar de figuras, com fio d'ouro muy rico, e dez peças de veludo e cetyns, e damascos de cores".

\section{Correa (in Felner, 1858: 170, sob Pedraluares Cabral, anno de 1500):}

"ElRey veo com todo seu estado, acompanhado de muyta gente, que passauão de tres mil homens Naires, que são sua gente d'armas, com espadas e adargas, e zagunchos da compridão de meas lanças, de ferros de meo couado luzentes...".

“Todas estas gentes por seu costume vem correndo com ElRey: os arcos e frechas, e zagunchos, e espadas e adargas muyto altas quanto podem sobre as cabeças, esgrimindo as espadas, batendo as adargas nos braços em que as trazem...."

\section{Correa (in Felner, 1858: 171, sob Pedraluares Cabral, anno de 1500):}

"E junto com ElRey vinha hum Page que Ihe trazia huma copa d'ouro em que elle cospe o betele, que sempre come, e tras remoendo na bocca que he seu costume, do qual betele adiante darei mais razão; e outro page, que em huma boceta d'ouro trazia a folha deste betele que lhe daua; e outro page que the trazia sua espada e adarga...."

\section{Correa (in Felner, 1858: 171-172, sob Pedraluares Cabral, anno de 1500):}

"Então o Capitão mór com os Capitães e fidalgos, e homens mais louçãos que já estauão prestes, sendo EIRey mettido na casa, sayo da bastida, deixando de dentro da porta a gente, com bom recado os Capitães e gente, e sayo fóra com sómente espadas na cinta e adargas penduradas em tiracolos aos hombros, e diante as trombetas...").

\section{Correa (in Felner, 1858: 202, sob Pedraluares Cabral, anno de 1500):}

"O que ouvido dos Mouros, derão grita, e cometterão entrar por cima das paredes por muytas partes. Ao que os nossos acodirão com lanças, adargas, e béstas que tinhão...".

\section{Correa (in Felner, 1858: 222, sob Pedraluares Cabral, anno de 1500):}

"mandou pera o Principe huma peça de téla d'ouro, e humas ricas couraças postas em brocado, e huma lança dourada, e huma adarga forrada per dentro de cetym azul, laurada de fio d'ouro com ricas broslas...." 


\section{Correa (in Felner, 1858: 231, sob Pedraluares Cabral, anno de 1501):}

"Ao outro dia, estando ElRey na guarda roupa, Pedraluarez leuou o Naire d'EIRey de Cochym, e o apresentou a EIRey; o qual hia nu, encachado com seus pannos brancos finos debaixo do embigo até mea coxa, e por cima destes panos outro de seda de cores trocido, deitado por cima dos outros ao modo de touca, e no braço da adarga, do cotouelo pera cima, tres manilhas d'ouro, grossas como hum dedo polegar, bem lauradas, e orelheiras d'ouro roliças enfiadas nas orelhas, em que tinha grandes buracos; o cabello preto corredio comprido como de molher, atado com nó dado dos mesmos cábellos: homem de dezaseis annos, de bom rosto, preto e delicado, e muyto bem desposto, e descalço; com sua adarga vermelha, e sua espada á sua usança, o qual chegando ao meo da casa, ajuntou os pés, e acostou adarga adiante das pernas, e metteo a espada sob o braço esquerdo, e ajuntou as mãos ambas como adoração, e assi juntas as aleuantou quanto pôde sobre a cabeça, e assi juntas as abaixou ante os peitos, e tornou a tomar sua adarga e espada, e andou mais até junto d'alcatifa; que ElRey folgou muyto de ver, e lhe perguntou: 'Vós sois Naire?' O moço sabia já falar muyto de nossa fala, e tomou adarga de sob o braço esquerdo, e a espada na mão esquerda, e abaixou muyto o corpo...."

\section{Correa (in Felner, 1858: 295, sob Dom Vasco da Gama, anno de 1502)}

“Era mancebo gentil homem, muy bem disposto, com sua espada e adarga nas mãos, que he seu costume sempre trazer até morte".

Correa (in Felner, 1858: 311, sob Dom Vasco da Gama, anno de 1502)

"O Capitão mór a tudo fazia a ElRey suas grandes cortesias e grandes louvores: ao que entrou o Principe, que viera de fóra a ver o Capitão mór; o qual entrado, com sua espada e adarga, se pôs ante ElRey, e ajuntou os pés, e acostou a adarga ás pernas, e metteo a espada debaxo do braço, e ajuntou as mãos, e as aleuantou muyto encima da cabeça, e juntas as abaixou até aos peitos".

\section{Correa (in Felner, 1858: 353, sob Vicente Sodré, anno de 1503)}

"Mas, que tudo ajuntara, nom era nada pera a infinidade da gente que o Rey de Calecut tinha, de gente armada d'espadas, adargas, arcos, frechas, e outros de lanças...."

\section{Correa (in Felner, 1858: 354, sob Vicente Sodré, anno de 1503)}

"Suas lanças são assi pintadas as astes de muytas cores, assentadas com alacre, que nunqua destingem por sol, nem por chuva; e suas adargas assi desta pintura, que reluzem dando-lhe o sol, que cegão os olhos como espelho, e muy leues e maneaueis, com os embraçamentos de pao".

"Os que pelejão d'espada e adarga usão destas armaduras, porque na batalha são os dianteiros, que vão muy baixos, que todos vão cubertos das adargas, e estão postos em cocoras e muy juntos huns com outros, tocando as adargas no chão, todos postos em az".

\section{Correa (in Felner, 1858: 356, sob Vicente Sodré, anno de 1503)}

“...aos quaes os discipulos tem mór obediencia e acatamento que a outra nenhuma pessoa, e se na peleja o mestre, e discipulo, se encontrarem hum ao outro nom fará mal, e se no caminho o discipulo topa seu mestre acosta a adarga ás pernas, e mete a espada debaixo do braço, e com as mãos juntas, altas sobre a cabeça, lhe faz adoração...."

\section{Correa (in Felner, 1858: 380, sob Os Alboquerques, anno de 1503)}

"A gente de Cochym apanharão quantas espadas e adargas e outras armas ficarão dos imigos mortos, e as leuarão em seus barcos, e forão apresentar a EIRey de Cochym, que esta he a sua mór honra".

\section{Correa (in Felner, 1858: 445, sob Duarte Pacheco, capitão do mar, anno de 1504)}

"O que assi ordenado, os paraos, já querendo sair o sol, aparecerão polos rios a grão remar, com grandes gritas, com muytos Mouros bem armados dos corpos com laudeis acolchoados muy fortes, como já contei, esgrimindo suas armas, e batendo as adargas, e chegando a tiro desparando muyta artelharia e grão numero de frechas, nom cessando o remar pera abalroar os bateis grandes...". 


\section{Correa (in Felner, 1858: 458, sob Duarte Pacheco, capitão do mar, anno de 1504)}

"O Capitão mór, visitando a todos, se foy a terra onde estaua o Principe, que mandou recolher do campo as adargas, e espadas, e arquos dos mortos, e os mandou pôr em hum monte no campo...."

\section{Correa (in Felner, 1858: 469, sob Duarte Pacheco, capitão do mar, anno de 1504)}

“Então os poleás tornarão a tapar seus valados, e deitando agoa pera o rio, onde tornarão a tapar seus valados como estauâo dantes, e da gente morta apanharão os panos, e muytos orelheiros d'ouro que alguns trazião, e manilhas, e as espadas, e adargas, e zagunchos, e arquos, e frechas, de que fizerão hum grande monte...".

\section{Correa (in Felner, 1859: 500, sob Lopo Soares, 1504)}

"e outro homem, com huma toalha nas mãos, leuaua uma espada, e adarga preta bordada e chapeada no meo de chapas d'ouro esmaltadas, e a espada guarneeida d'ouro de esmalte, tudo muy rico, que a espada e adarga mandara EIRey de Portugal leuar de qua pera Ihe mandar assy guarnecida...."

\section{Correa (in Felner, 1859: 501, sob Lopo Soares, 1504)}

"e Ihe mandou dizer que ElRey seu irmão Ihe mandaua aquelle dinheiro pera ajuda de seus gastos, e a espada, e adarga, e peças de seda pera o Principe, e peças de seda pera o Principe, que era homem mancebo, dar vestido aos seus fidalgos, e a peça de borcado pera almofadas em que se assentasse. Correo muyta gente a ver o presente, que sendo apresentado a ElRey, assy com os bacios de prata, que tudo Ihe derão, o recebeo com grande prazer, e ouvindo o recado que lhe os Capitães derão, disse rindo, que elle queria antes a espada e adarga, que inda tinha força como homem mancebo, e o tomou na mão, e esteue olhando, e todos seus Caimaes e Senhores que com elle estauão. Então deu a espada e adarga ao Principe...."

\section{Correa (in Felner, 1859: 553, sob Dom Francisco, Visorey, anno de 1504)}

"e com elles até vinte homens de adargas e fayns, que forão dianteiros a çarrar com os Mouros ás lançadas...".

\section{Correa (in Felner, 1859: 560, sob Dom Francisco, Visorey, anno de 1504)}

"O mouro velho, que andára com os recados, que trouxera os refrescos, o Visorey lhe deu boas peças; e Dom Lourenço per elle mandou ao Rey hum roupão de veludo carmesym auelutado, forrado de brocado raso, e nas mangas botões d'ouro esmaltados, e huma peça de brocado de pello, de que fizesse vestido ao seu costume, e quatro peças de cetym de cores, e huma adarga forrada por dentro de cetym cremesym, laurada de fio d'ouro com riquas broslas....".

\section{Correa (in Felner, 1859: 612, sob Dom Francisco, Visorey, anno de 1504)}

“Então Dom Lourenço, com toda a gente, nos batés se foy ao longo da terra, pera ver se os da terra estauão de guerra, mas toda terra era coberta de gente armada, e muytos Mouros, que se mettião n'agoa capeando com as adargas, e chamando os nossos, e soltando os panos, e lhe mostrando as trazeiras".

\section{Correa (in Felner, 1859: 682, sob Dom Francisco, Visorey, anno de 1507)}

"...e com a espada remetteo aos Mouros, que o logo derrubarão atordoado de huma pedra que lhe deu nos peitos; mas entrado Nuno Vaz com huma espada e adarga, e Dom Antonio, e outros fidalgos, fizerão arredar os Mouros, com que todos sobirão e senhorearão o terreiro, tangendo as trombetas".

\section{Correa (in Felner, 1859: 704, sob Dom Francisco, Visorey, anno de 1507)}

“...e tão desasisados hião ás vezes os Mouros que cayão nas suas couas, com que os Mouros nom querião já cometer, e estauão em suas estancias capeando aos nossos com as adargas que fossem lá". 


\section{Correa (in Felner, 1859: 721, sob Dom Francisco, Visorey, anno de 1507)}

"Todos os outros trabalhando por sobir recebião muyto mal que the os Mouros fazião, que estauão mais altos e os ferião á sua vontade, a que os nossos nom fazião mais que empararse com os capacetes e adargas, e sobre ysso acodião com panellas e artificios de fogo, que era tanto que os nossos desesperauão da tranqueira".

\section{Correa (in Felner, 1859: 723, sob Dom Francisco, Visorey, anno de 1507)}

"e nos braços da adarga manilhas d'ouro, e pera serem conhecidos todos se encacharão com panos amarellos...".

Correa (in Felner, 1859: 724, sob Dom Francisco, Visorey, anno de 1507)

“Estande neste trabalho, sayrão d'antre as mesquitas os quatorze irmãos do dezafio, todos de panos amarellos, e a saber: a seis d'espadas e adargas, e os outros de arcos e zagunchos. Os dos arcos se afastarão pera fóra, que erão grandes frecheiros, pera empregarem seus tiros á sua vontade, e mormente hum delles, que tinha grande fama de grande certeiro de arco; os das adargas, e espadas, e zagunchos cometterão Dem Lourenço muy fortemente. Dem Lourenço usou de manha, e se fey retrahindo pelos tirar pera fóra, os Naires com muyto esforço e seguindo, onde foy ferido de huma freeha no colo de huma mão, que Dom Lourenço sentio muyto, porque foy antre os neruos, com que Dom Lourenço com muyta furia remeteo com elles, fazendo roda com sua alabarda, com que alcançou dous que derrubou feridos, que se nom poderão leuantar, e tomou hum de zagunche a direito golpe de alabarda e e cortou per hum hombre em dous pedaços, e a outro d'adarga lhe cortou ambas as pernas polos joelhos...."

\section{Correa (in Felner, 1859: 817, sob Dom Francisco, Visorey, anno de 1507)}

“E assy o fizerão, que logo mandou hum mouro honrado, muyto autorisado e bem vestido, em huma barquinha, assentado em huma alcatifa, que foy ao Capitão mór, que entrando na nao o achou assentado em cadeira, e alcatifa aos pés, e derrador assentados os fidalgos em bancos, e a toldo armada de panos de figuras de Fraudes, e nelles pendurados ricos corpos d'armas, e adargas, e muytas lanças encostadas a bordo...".

Correa (in Felner, 1859: 942, sob Dom Francisco, Visorey, anno de 1509)

"...e comtudo como os Rumes entrauão na tolda os nossos sayão a elles com adargas que tinhão, e espadas, e pelejauão tão fortemente que os Rumes Ihe fogião, que já na tolda estauão oito mortos".

\section{Correa (in Felner, 1860: 16-17, sob Afonso d'Alboquerque, Segundo Gouernador, dezembro de 1509)}

"E dixe a hum homem seu que fosse onde estauão as portas e as deitasse ao mar; e então tirou o capacete da cabeça, e o deu a hum seu page, e adarga e lança, e pôs hum barrete de grã, e tomou huma cana na mão...".

\section{Correa (in Felner, 1860: 17, sob Afonso d'Alboquerque, Segundo Gouernador, dezembro de 1509)}

"O Gouernador em quanto o Marichal fallaua estaua recostado em sua lança, e adarga deitada ás costas, e toda a gente derrador, e estaua muy afrontado ouvindo as palauras do Marichal...."

\section{Correa (in Felner, 1860: 22, sob Afonso d'Alboquerque, Segundo Gouernador, dezembro de 1509)}

"O Marichal era homem grosso, e cansava muyto, e foy largando algumas armas, como todos fazião por se alyuarem e desafrontarem, e andauão quanto podião, com as adargas emparandose das frechas...."

\section{Correa (in Felner, 1860: 23, sob Afonso d'Alboquerque, Segundo Gouernador, dezembro de 1509)}

"...a que logo acodirão muytos seus que hião com elle, e mórmente hum Antonio Fernandes, homem cafre, valente caualleiro, e Jorge Coelho, Lopo Mendes Botelho, Ruy Bernaldes, que deixando as armas tomarão ao Gouernador sobre huma adarga e correrão pera a praya...." 


\section{Correa (in Felner, 1860: 35, sob Afonso d'Alboquerque, Segundo Gouernador, anno de 1510)}

"Os mouros, vendo que já os nossos andauão temorizados polo que elles Ihe dizião, e andauão recatados, e com suas armas de lança e adarga quando hião pola cidade, forão falar com ElRey...."

\section{Correa (in Felner, 1860: 58, sob Afonso d'Alboquerque, Segundo Gouernador, fevereiro de 1510)}

“...polo que o Gouernador logo se embarcou na galé de Diogo Fernandes de Beja, armado de ricas couraças, e debaixo saya de malha, e rica espada, e seu page com lança e adarga, e assy os capitães com sua gente em seus batés...".

\section{Correa (in Felner, 1860: 79, sob Afonso d'Alboquerque, Segundo Gouernador, abril de 1510)}

"Ao que logo Timoja mandou hum seu pião, que foy espiar e veo toda a gente, do que certificado o Gouernador, com o parecer dos capitães, ordenou e mandou logo Jorge da Cunha, com sessenta de cauallo e cem homens de pé portuguezes bésteiros, e Mainaique cunhado de Timoja, e Meliqeçufo capitão naique, com dozentos homens da terra, d'espadas e adargas, e frecheiros, que logo toda esta gente passou á ilha de Diuar...."

\section{Correa (in Felner, 1860: 112, sob Afonso d'Alboquerque, Segundo Gouernador, julho de 1510)}

"...onde assy estando veo o João Romão vestido em cabaya de seda, que Ihe dera o Hidalcão, a cauallo com outros arrenegados, escaramuçando e correndo, e brandindo huma lança e adarga das que ficarão dos mortos...".

\section{Correa (in Felner, 1860: 116, sob Afonso d'Alboquerque, Segundo Gouernador, julho de 1510)}

"E o meirinho foy no esquife, e o Gouernador mandou ao mestre e marinheiros que entrassem no batel, e estiuessem prestes, e a Duarte de Sousa, e outros fidalgos da nao, que tiuessem prestes suas lanças e adargas".

\section{Correa (in Felner, 1860: 117, sob Afonso d'Alboquerque, Segundo Gouernador, julho de 1510)}

"ao que logo sayo no seu esquife com lança e adarga, e com elle Simão d'Andrade, e Fernão Peres seu irmão, e Francisco de Sá, bradando todos que tal nom consentisse, ao que o meirinho deu grandes brados da parte d'ElRey...."

\section{Correa (in Felner, 1860: 146, sob Afonso d'Alboquerque, Segundo Gouernador, novembro de 1510)}

"A este tempo que o dia esclarecia, dom João de Lima, e Manuel de Lacerda com o esquadrão, tocando as trombetas, enuocando Santyago, bemauenturada santa Caterina, cometerão os mouros da ribeira, que aos nossos forão receber com muyto esforço, pelejando muy fortemente ás zagunchadas, e frechadas, e cutiladas, cubertos com suas grandes adargas...."

Correa (in Felner, 1860: 151, sob Afonso d'Alboquerque, Segundo Gouernador, novembro de 1510)

"Manuel de Lacerda, cuberta a cabeça com sua adarga, e com a espada na mão, sobio acyma, onde se descobrindo, das muytas frechadas que Ihe tirauão huma lhe deu na face da mão esquerda, e lhe entrou na queixada, a que elle lançou a mão, e a não pôde tirar, e quebrou, ficandolhe hum pedaço de cana com o ferro trancado no rostro, que o tanto atormentou que ouvera de cayr...."

\section{Correa (in Felner, 1860: 189, sob Afonso d'Alboquerque, Segundo Gouernador, março de 1511)}

"Sayo o capitão com estes corenta de cauallo, e cento e vinte homens de pé, de lanças e adargas, e muytos d'elles armados, e com seis centos piães da eapitania de Lourenço Prego, e Manuel de Sampayo, que Icuaua a bandeyra, e com boa ordem forão buscar os mouros os quaes sabendo que os nossos os hião buscar ouverão grande medo, e o Pulatecão com sua gente se foy pera Goa velha, e esperou no lugar onde ora está a casa de Nossa Senhora d'Agoa de Lupe, porque vio boa desposição na terra pera se defender, com muytos frecheiros que tinha, e zagunchos, espadas, adargas. $O$ capitão se pôs na dianteira com a gente de cauallo, e a gente de pé atrás, e a pionagem per fora d'ambas as bandas, e como os de cauallo 
hião bem armados, postos em ordem com suas lanças e adargas, que muytos mais parecião, os mouros forão em muyto medo, que tanto que os nossos derão Santyago todos se puserão em desbarato, fogindo por onde podiâo; aos quaes seguião os nossos piães, matando, e ferindo".

Correa (in Felner, 1860: 263, sob Afonso d'Alboquerque, Segundo Gouernador, outubro de 1511)

“...e então mandou Simão de Miranda d'Azeuedo, muyto bem concertado com seis homens de seu seruiço, e mandou ao Rey humas coiraças de cetym cremesym, e huma lança e adarga, e hum capacete gornicido...."

Correa (in Felner, 1860: 292, sob Afonso d'Alboquerque, Segundo Gouernador, agosto de 1512)

P. 292:

"e sayndo fóra, cada capitão se ajuntou em esquadrão com sua gente, que era fermosa cousa de vêr a riqueza das armas, lanças, adargas...".

Correa (in Felner, 1860: 303, sob Afonso d'Alboquerque, Segundo Gouernador, setembro de 1512)

"e d'ahy até Banestarim, tudo era coberto de mouros, onde estaua o Roçalcão com seiscentos de cauallo, e a gente de pé muyto em ordem, armados de suas grandes adargas, zagunchos, e muytos frecheiros".

Correa (in Felner, 1860: 304, sob Afonso d'Alboquerque, Segundo Gouernador, setembro de 1512)

“Os mouros de pé erão tantos que deixauão as adargas e arqos polo campo por embaraçar o caminho aos nossos, que lhe forão seguindo o alcanço, e lhe chegauão alguns com as lanças; com que a pressa foy tanta que nom cabendo pola porta forão fogindo derrador da cerqua, onde os nossos os alcançauão e derrubauão".

\section{Correa (in Felner, 1860: 340-341, sob Afonso d'Alboquerque, Segundo Gouernador, fevereiro de 1513)}

“Desembarcou toda a gente, e dom Gracia tomou á mão esquerda com seiscentos homens de seu esquadrão, com quatro escadas, e foy a huma porta que achou atupida por dentro com parede e aruorou as escadas, porque a gente começou a sobir com sómente adargas e espadas, porque nom podião leuar as lanças...".

\section{Correa (in Felner, 1860: 342, sob Afonso d'Alboquerque, Segundo Gouernador, fevereiro de 1513)}

"onde acodio o Miramergem com muytos mouros, que com frechas e pedras cobrião os nossos e os muyto ferião e encrauauão, a que os nossos nom tinhão mais que o emparo de suas adargas, que todos nom tinhão, e se emparauão com as costas, aguardando que a gente sobisse pera decerem abaixo e dar na cidade..."

Correa (in Felner, 1860: 343, sob Afonso d'Alboquerque, Segundo Gouernador, fevereiro de 1513)

"O que vendo os mouros acodirão abaixo á rua, onde os nossos se meterão com elles ás cutiladas e lançadas, e os fidalgos na dianteyra, onde Gracia de Sousa nom podia pelejar com a lança, porque nom podia largar adarga, que era como rodella feita como as adargas dos malauares, porque a trazia encrauada no braço com as frechas que atreuessauão, onde ally foy morto de hum zaguncho d'arremesso....".

Correa (in Felner, 1860: 378, sob Afonso d'Alboquerque, Segundo Gouernador, janeiro de 1514)

"E o embaixador Ihe disse que EIRey folgaria de vêr huma lança, e espada, e adarga com que os nossos pelejauão na guerra".

Correa (in Felner, 1860: 401, sob Afonso d'Alboquerque, Segundo Gouernador, janeiro de 1515)

“E se partio, e passou por Baticalá, d'onde mandou leuar arroz branco pera mantimento de oitocentos homens malauares, que vinhâo de Cochym com dom Gracia; homens d'espadas, adargas, lanças, arquos e frechas, por soldo de seiscentos réis cada mez...". 
Correa (in Felner, 1860: 409, sob Afonso d'Alboquerque, Segundo Gouernador, março de 1515)

"E.das bandas estauão em cyma dos pannos pendurados corpos de riqas armas, e coiraças, com seus capacetes, e fraldas, e coxotes, e espadas nas cintas, e adargas, cousa fremosa de vêr...."

Correa (in Felner, 1860: 409, sob Afonso d'Alboquerque, Segundo Gouernador, abril de 1515)

"e o Gouernador assentado em eadeira gornicida, vestido em sayo e loba de damasco preto, e seu collar, e crís d'ouro, como já disse, com sua barba grande comprida muyto branca; ao redor do estrado os capitães e fidalgos, bem atabiados de suas pessoas, com espadas na cinta, e detrás seus pages com lanças e adargas, e todos com barretes fóra".

Correa (in Felner, 1860: 432, sob Afonso d'Alboquerque, Segundo Gouernador, abril de 1515)

"E logo vestio a ElRey humas coiraças de cetym branco com suas mãos, e lhe cengio huma espada dourada, e hum punhal gornecido d'ouro, e lhe deitou ao pescoço huma cadea d'ouro de rocaes esmaltada, e junto com elle hum seu page, com huma lança e adarga com capacete..."

Correa (in Felner, 1860: 434, sob Afonso d'Alboquerque, Segundo Gouernador, abril de 1515)

"Então correo adarga polo braço, e tomou hum bacio, e meteo na caldeira do arroz e tomou hum pouqo, e encostou a lança ao hombro, e comeo hum pouqo, sómente porque ElRey visse que comia o seu comer".

Correa (in Felner, 1860: 439, sob Afonso d'Alboquerque, Segundo Gouernador, maio de 1515)

"E o dia que os capitães nom trabalhauão estauão presentes na obra, com seus pages com lanças e adargas".

Correa (in Felner, 1860: 443, sob Afonso d'Alboquerque, Segundo Gouernador, junho de 1515)

"E mandou de presente ao Xequesmael hum arnês branco enteiro, dourado por partes, e huma riqua espada esmaltada, e lança e adarga gornecida como conuinha, e huma espingarda muyto louçã de todo concertada...."

Correa (in Felner, 1861: 505, sob Lopo Soares, Terceiro Gouernador, anno de 1517)

"O doente logo ao outro dia morreo. O outro, que fiqou no chapiteo com lança e adarga se pôs em defesa...."

Correa (in Felner, 1861: 507, sob Lopo Soares, Terceiro Gouernador, agosto de 1517)

“...e se mostrauão valentes passando per junto dos portugueses, batendo as adargas e esguirmindo as espadas...".

Correa (in Felner, 1861: 511, sob Lopo Soares, Terceiro Gouernador, agosto de 1517)

"e apartados os piães da terra com seus naíques, que são seus capitães, todos d'espadas, adargas, e arqos e frechas...".

\section{Correa (in Felner, 1861: 514, sob Lopo Soares, Terceiro Gouernador, agosto de 1517)}

"Os mouros apertarão tanto aos nossos, que pelejauão sem coração, que ouve alguns que se deitauão dos cauallos e se metião fogindo pólos matos, e outros com os cauallos se lanlauão por cyma das adargas, em que cayão os cauallos, e elles hião fogindo a pé".

Correa (in Felner, 1861: 572, sob Diogo Lopes de Sequeira, Quarto Gouernador, junho de 1519)

"...e acodio muyta gente com armas, e muytros escrauos e criados dos fidalgos, que corrião a lhe leuar lanças e adargas a seus senhores que erão com o Gouernador". 


\section{Correa (in Felner, 1861: 587, sob Diogo Lopes de Sequeira, Quarto Gouernador, anno de 1520)}

"...e todos muy concertados e atabiados de vestidos e todo o que compria, e de presente para o Preste hum mapamundo, pera lhe darem a entender a redondeza da terra, e assy huma carta de marear, e huma espada e punhal d'ouro d'esmalte, e humas coiraças postas em brocado, e hum capacete e adarga...."

\section{Correa (in Felner, 1861: 649, sob Diogo Lopes de Sequeira, Quarto Gouernador, anno de 1521)}

"Antonio Correa pôs a gente em concerto, com as espingardas carregadas nas mãos, e aos pós as lanças e adargas...".

Correa (in Felner, 1861: 664, sob Diogo Lopes de Sequeira, Quarto Gouernador, anno de 1521)

“...e mandou recado a dom Aleixo que ao outro dia com a viração tornasse pera dentro; ao que outros contradixerão, dizendo que como auia d'auer no mundo nossa armada estar recolhida no rio, e as fustas batendo as adargas, e dando gritas...".

\section{Correa (in Felner, 1861: 687, sob Dom Duarte de Meneses, Quinto Gouernador, anno de 1521)}

"João de Meira foy amanhecer no porto de Calayale e logo mandou entrar no balel quinze homens com lanças e adargas, que leuauão abatidas...."

Correa (in Felner, 1861: 707, sob Dom Duarte de Meneses, Quinto Gouernador, anno de 1522)

"Tu tens traçado e cofo, e eu espada e adarga, e seja quandi quigeres".

Correa (in Felner, 1861: 713, sob Dom Duarte de Meneses, Quinto Gouernador, anno de 1522)

"Do qual recado Antonio de Brito Ihe mandou grandes agardicimentos, e pedir licença pera desembarcar e a hir vêr; do que lhe muyto aprouve, e ao outro dia desembarqou Antonio de Brito, com a gente honrada louçãos, e seus moços com lanças e adargas...".

Correa (in Felner, 1861: 758, sob Dom Duarte de Meneses, Quinto Gouernador, anno de 1523)

“Elle com boa cortezia Ihe dixe: Senhor, manday embarcar marinheiros que a nao ha mester, e sabem o que hão de trabalhar, e não os homens que o nom entendem; que eu nom sey mais que pelejar com huma lança e adarga, e a ysto me aueys de mandar".

Correa (in Felner, 1861: 927, sob Dom Anrique de Meneses, Setimo Gouernador, anno de 1525)

“Então ElRey, muy indinado de lhe nom obedecerem, se pôs no meo da estrada, deitando no chão adarga, e com grandes brados fez seu juramento por seus pagodes...".

Correa (in Felner, 1861: 949, sob Dom Anrique de Meneses, Setimo Gouernador, novembro de 1525)

“...com que se forão chegando pera Heytor da Siluelra, que andaua sua gente cercada de mouros que o metião em muyta afronta, porque usauão elles de manha de que muyto se ajudauão, que em os nossos os ferindo das lanças nas adargas lhas largauão...".

\section{Correa (in Felner, 1862: 72, sob Coisas do Preste)}

"Suas armas são azegayas, zagunchos, sayas de malha, roys espadas pouqas, largas e compridas, que Ihe vem da Turquia, e arcos, e frechas que nom tem penas, capacetes, cascos compridos, pouquos, que tambem lhe trazem por mercadaria que vem da Turquia, que lhe vendem por muyto dinheiro, e os usão depois que virão os nossos. Tem muytas adargas redondas e fortes, de coiros de alimarias forradas".

Correa (in Felner, 1862: 89, sob Pero Mascarenhas, Oitauo Gouernador, anno de 1526)

“Onde o Gouernador, por mostrar sua valentia e dar esforço á gente, se pôs na dianteyra, pelejando ás lançadas sem adarga...". 


\section{Correa (in Felner, 1862: 107, sob Pero Mascarenhas, Oitauo Gouernador, janeiro de 1527)}

"Trazia duzentos homens de sua guarda, a que daua mesa, e dormião em sua sala e a vigiauão; mostrauase fixo, poderoso, por que o temessem; a seus parentes, e amigos em que tinha confiança, fazia mercês; e se muyto acompanhaua d'elles, que todos andauão a cauallo e trazião moços com lanças e adargas".

Correa (in Felner, 1862: 120, sob Pero Mascarenhas, Oitauo Gouernador, anno de 1527)

"E mandou arrepicar o sino; ao que sayo fóra á praya todo o pouo da cidade, a cauallo e com armas, correndo toda a praya a todas partes, e Afonso Mexia diante de todos com a bandeyra da cidade diante, e elle com adarga e lança".

Correa (in Felner, 1862: 132, sob Pero Mascarenhas, Oitauo Gouernador, março de 1527)

"Caualgaua com muytos homens de cauallo, de lanças e adargas, com toda tenção de matar quem lhe offendesse".

Correa (in Felner, 1862: 151, sob Pero Mascarenhas, Oitauo Gouernador, abril de 1527)

"Polo que andaua secretamente armado com muytos de sua guarda, em que trazia espingardeiros, acompanhado com os de sua valia a cauallo, com lanças e adargas.

Correa (in Felner, 1862: 163, sob Pero Mascarenhas, Oitauo Gouernador, junho de 1527)

"O que ouvido por Lopo Vaz se deceo do cauallo, e embarçou huma adarga e tomou huma lança".

Correa (in Felner, 1862: 390, sob Nuno da Cunha, Decimo Gouernador, anno de 1530)

“Do que aprouve a ElRey, de que o Gouernador se despedio muyto amigo. E tomou a soldo seis centos malauares d'espadas, adargas, lanças, frechas, e lhe deu seis centos réis por mês, que logo lhe pagou tres meses...".

\section{Correa (in Felner, 1862: 403, sob Nuno da Cunha, Decimo Gouernador, feuereiro de 1531)}

“...onde de dentro os mouros tirauão taes frechadas que matauão ou derrubauão a quem acertauão, porque passa não coiraças e adargas e capacetes...".

\section{Correa (in Felner, 1862: 428, sob Nuno da Cunha, Decimo Gouernador, anno de 1531)}

"Ao que acordou o capitão e da genella vio a briga e bradou que acodissem, e tomou huma adarga e espada, e abrio a porta da camara pera sayr fóra, e vio o regedor e os outros com os crises arrancados, que remeterão a porta pera o matar; mas elle com adarga e espada ás estocadas se defendeo, que nunqua o puderão entrar...".

Correa (in Felner, 1863: 468, sob Nuno da Cunha, Decimo Gouernador, anno de 1533)

“...e junto d'elle dous pagens bem armados, que lhe leuauão sua lança, adarga, capacete, como compria, tudo muy loução...."

Correa (in Felner, 1863: 484, sob Nuno da Cunha, Decimo Gouernador, anno de 1533)

"Martim Afonso o conuidou que fosse ao banquete, o qual sempre trazia quatro escrauos d'espingardas e quatro com lanças e adargas...".

Correa (in Felner, 1863: 546, sob Nuno da Cunha, Decimo Gouernador, anno de 1533)

"Mas, se elle nom ouver medo de mim, eu lhe farey largar no campo o cofo e traçado. E eu só com minha adarga e espada". 


\section{Correa (in Felner, 1863: 653, sob Nuno da Cunha, Decimo Gouernador, anno de 1535)}

“...e Martim Afonso buscou humas coiraças postas em télla d'ouro, abertas polas ilhargas, e hum capacete, e lança dourada e adarga, tudo como conuinha, e se foy a casa d'ElRey...."

\section{Correa (in Felner, 1863: 654, sob Nuno da Cunha, Decimo Gouernador, anno de 1535)}

"Com que elle muyto folgou, e com o capacete, que lhe armou muyto bem, mas com a lança e adarga se achou muyto embaraçado".

"Martim Afonso deu ordem ao que todos auião de fazer, e fez os espingardeiros em huma batalha de quatro em quatro, hum após outro, que fazião áz atrauessada de vinte e cinco, muy bem ordenados, e após elles vinte de cauallo em batalha, todos a la par, e atrás elle com os outros trinta, e diante d'elle seu alferes a cauallo, com hum guião da cruz de Christus, todos em muyta ordem, com suas trombetas a cauallo, e todos adargados, que sayndo ao campo lhe daua o sol nas armas, que reluzião tudo em ouro".

Correa (in Felner, 1863: 710, sob Nuno da Cunha, Decimo Gouernador, anno de 1536)

“...e nom achando os bateis, man dou tomar os feridos ás costas dos piães canarys, e sobre suas adargas, com que caminharão legoa e mea até a passagem...."

\section{Correa (in Felner, 1863: 713, sob Nuno da Cunha, Decimo Gouernador, anno de 1536)}

"O qual recado foy soberboso, que era escusado; porque por suas leys, se estão em campo, e andando na batalha pelejando Ihe derem noua de sua mãy morta, ou seu principe herdeiro, n'aquella hora o filho da morta manda meter no chão hum zaguncho, e acosta a elle sua espada e adarga, e se afasta a fóra com suas gentes, sem mais bolir".

Correa (in Felner, 1863: 765, sob Nuno da Cunha, Decimo Gouernador, anno de 1536)

“Então tomão suas armas e se vão ao campo, que são adargas, espadas, lanças, arqos, frechas; alguns d'clles armados de laudeis de pannos de seda, e mórmente de viludo de Meca, acolchoados com algodão, muy fortes...."

“E sendo no campo, que se põy em ordem de pelejar, os adargueiros se põy em áz dereita, muyto juntos postos em cócoras, e se cobrem das adargas, que nada parecem...."

\section{Correa (in Felner, 1863: 780, sob Nuno da Cunha, Decimo Gouernador, anno de 1537)}

"Ao que ouve trouação e aluoroço, e forão á pressa, nom sabendo o que era, mas decendo as lanças do toldo, e as pondo baixas, e adargas, e bolindo com espingardas".

Correa (in Felner, 1863: 781, sob Nuno da Cunha, Decimo Gouernador, anno de 1537)

"Ao que entrou Diogo de Mesquita com huma espada e adarga, e após elle Pedraluares d'Almeida, e Antonio Correa".

Correa (in Felner, 1864: 328, sob Martim Afonso de Sousa, Dozeno Gouernador, anno de 1543)

"e a gente d'espingardas pôs nos fios de fóra de hum cabo e de outro, que com as espingardas hião varejando o campo, em que auião passante de mil espingardas, porque os mais dos homens leuauão seus escrauos que lhas leuauão ou a lança e adarga".

Correa (in Felner, 1864: 604, sob Dom João de Crasto, Trezeno Gouernador, anno de 1547)

"entrou na cidade com toda a gente armada em seus esquadrões, com suas bandeiras, e atambores e pifaros, e trombetas e charamellas, e diante as bombardinhas que tomarão do castello, e arqos e frechas, e adargas que os mouros deixarão no campo...".

Correa (in Felner, 1864: 95, sob Dom João de Crasto, Trezeno Gouernador, anno de 1547)

“E mandou a Francisco de Sequeira, que era capitão dos quinhentos malauares, (que são valentes guerreiros de lanças e adargas) em sua parelha, e com elle dom Francisco de Lima, com cincoenta homens...". 


\subsection{João de Barros, 1552}

João de Barros (ca. 1496-1570), na em sua Primeira Década da Ásia (Livro I, Capítulo VII) (Barros, 1552, 1628, 1777, 1778):

“Ouvesse maes em este resgate hŭa adarga de couro danta cru, \& muitos ouos de hema [casuar]: os quaes tornado Antão Gonçaluez a este Reyno sem fazer maes outra cousa, forão apresentados à mesa do Infante tão frescos, que os estimou elle por amilhor iguaria do mŭdo".

\subsection{Fernão Lopes de Castanheda, 1552}

Fernão Lopes de Castanheda (Santarém, ca. 1500 - Coimbra, 1559) foi um historiador português no renascimento. Em seu Terceiro liuro da historia do descobrimento \& conquista da India, polos portugueses (Castanheda, 1552: 148-149) registrou:

"E logo na entrada de laneyro do anno de mil \& quinhẽtos \& doze, despachou ho embaixadore del Rey de Sião, a quẽ fez muytas mercês, \& assi aos capitães Chĩs q' vierão coele, \& mãdou ẽ sua cõpanhia seu ẽbaixador a el Rey đ Sião, q' foy um fidalgo chamado Antonio de Miranda, a que deu hum presente pera el Rey de Sião. s. hũas couraças de veludo carmesim, \& outras armas braças muyro boas \& bem goarnecidas: hũa adarga danta com hũs cordões ricos \& hũa fũda de borcado...."

\subsection{Jorge Ferreira de Vasconcellos, 1555, 1560}

Segundo Santos (R.L.) (1996: 261-262):

"A primeira edição da Comédia Eufrósina foi editada em 1555. Nesse mesmo ano, teve outra impressão a que se seguiram mais três: 1560 [Figura 6.1], 1561, 1566. As três primeiras edições referidas foram impressas na cidade de Coimbra e as duas últimas, em Évora. A fortuna literária obtida na época está patente nas sucessivas impressões desta comédia, que cessaram, por proibição inquisitorial, pelo menos de 1581 a 1612.

Em 1616, foi recuperada por Francisco Rodrigues Lobo e o seu êxito recrudesceu, não só em Portugal mas também já em Espanha. Pouco conhecida nos séculos seguintes do público em geral, tomou-se obra de referência para dicionários, gramáticas e obras de investigação, sobretudo devido à sua riqueza lingüística.

O seu autor foi Jorge Ferreira de Vasconcelos de quem conhecemos escassos dados biográficos, inclusivamente a data do nascimento, à qual, por aproximação, se atribui o ano de 1515. Sabe-se, porém, que pertenceu a uma família originária de Montemor-o-Velho, foi criado de casa dos Duques de Aveiro e freqüentou o meio universitário de Coimbra cerca de 1540, onde se inscreveu no curso de Direito e foi contemporâneo de Camões. Jorge Ferreira de Vasconcelos foi também escrivão da Fazenda Real e da Casa da Índia, tendo morrido em 1585".

Na primeira edição da Comédia Eufrosina (Vasconcellos (J.R.), 1555: sem paginação) aparece o verbo adargar-se e o nome adarga:

"Acto primeyro. Scena primeyra

Após isso cmeçay pregoaruos por mal desposto, adargayvos sempre do sereno" [Na edição de1560, à p. 14].

"Aucto [sic] quinto. Scena primeyra

Daqui me ficou tal maginação, q' ando feyto hũa Cassandra, bradando antre meus cuydados sem me creren. Desdẽs confiados me xaqueam a vida, \& aqui vos quero auisar que me nam enganan bõs sinays, boa boca, boa carreyra, adarga em braço, \& sam loam verde aa porta..." [Na edição de 1560, à p. 261].

\subsection{Afonso de Albuquerque, 1557}

Em seus Commentarios (Albuquerque, 1557) há numerosas passagens citando adargas e uma única mencionando a adarga danta:

\section{Fólio xvij (verso):}

“Tristam da cunha com essa gente que leuaua sayo em terra, \& entrando pelo lugar achou ainda muytos mouros cõ suas azagaias \& adargas que o esperaram". 


\section{Zelotypo.Eufrofina.Siluia de Soufà.}

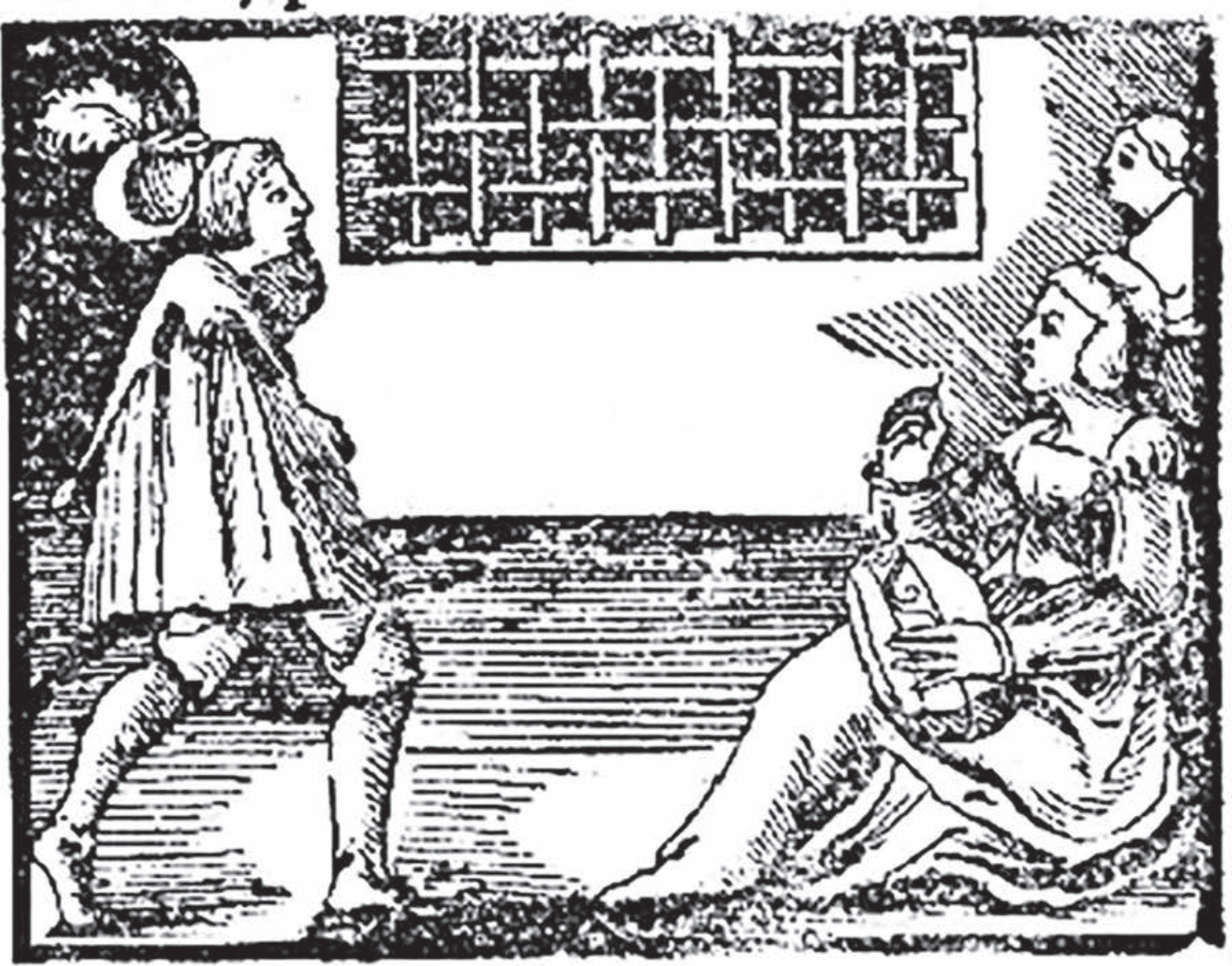

ComediaEufro

fina. De novio reuilta, \& em

partes acrecétada.Imprefla

em Coimbra.

Por loá de Barreyra Imprelsor da Vniuerlidade;

$$
\begin{gathered}
\text { Aos dez de Mayo. } \\
M_{1} D_{1} \text { LX. }
\end{gathered}
$$




\section{Fólio xviij (recto):}

"Chegado Tristam da cunha sayo em terra com toda a gente, \& deu em duas pouoações: \& os cafres nam ousandi de pelejar fogiram, q' podiam ser ate dous mil homẽs, com suas azagayas, adargas, arcos \& Frechas...."

\section{Fólio xxiiij (verso):}

"...o primeiro que cometeo entrar foy dom Antonio de noronha, que metendo a cabeça pera entrar, deçeo hum mouro com hũa espada pera lhe dar, \& ouueralhe de cortar o pescoço se nam fora Afonso Dalboquerque que vendo vir o golpe o cobrio com a sua adarga...."

\section{Fólios xxxiij (verso) e xxxiiij (recto):}

"Chegado Afomso Dalboquerque a terra soube de hum batel dos nossos que aly estaua tomando agoa, que toda aquella noyte passada ouuera grande aluoroço \& grandes gritas na cidade, \& muytos tangeres de trombetas \& atabaques, \& que toda esta festa era porq' chegara hum capitam principal com tres mil homẽs, (gente de lanças compridas, adargas, \& espadas), de socorro...."

\section{Fólio xlj (recto):}

"E estando nisto chegou Afonso dalboquerque, \& vio dom Antonio de nornha que estaua á porta, \& chegando a elle lhe disse. Aa sobrinho, que vergonha he esta, inda vos aqui estays: \& em Ihe dizendi isto cobriose com a adarga, \& entrou pólo postigo dentro ás cotiladas cõ os mouros...".

\section{Fólio xlvij (recto):}

"Vendo Afonso Dalboquerque estas mentiras, \& que tudo era a fim de dilatarem pera se fazerem mais prestes, \& todo seu brandir despadas, \& capear com as adargas...".

\section{Fólio Ixxviij (recto):}

"A gente desta terra he muy domestica, \& do cabo Guardasum ate a boca do estreito nã tem Rey, \& sam gouernados por senhores. Suas armas sam adargas, espadas mouriscas, tem grande criaçã de gados...."

\section{Fólio Ixxxvj (verso):}

"E que Cojeatar como isto soubera, mandara a todo hmem do pouo que teuesse arco, espasa, \& adarga, \& prouisam dagoa pera hum mes...".

\section{Fólio xxviij (recto):}

"Como o Marichal que ya na dianteira começou a entrar pola cidade com determinaçam de jr ás casas del Rey, vieram ter com elle obra de vinte ou trinta naires cõ suas espadas, \& adargas...."

\section{Fólio cxxv (verso):}

"Como dom Antonio jsto vio mãdou Timoja que fosse recolher a artilharia, \& tudo o mais que se achasse no baluarte, \& elle ficou ẽ Pangij recolhendo o despojo que ficou aos mouros, que eram muytas lãças, espadas, adargas, arcos \& frechas".

\section{Fólio cxxviij (verso):}

“E depois de ter mãdado lançar estes pregões andou vẽdo a fortaleza, \& os paços do çabayo, q' erão todos laurados de maçenaria, cõ jardijs \& poços dagoa dentro, \& dali foy ter a hũas terçenas grandes que o çabayo ali tinha, onde achou muytos mantimẽyos, muyta poluora, salitre, enxofre, cobertas de caualos, como as nossas, \& outras embotidas de algodam, muytas lanças, espadas, adargas, arcos, frechas, \& muytas armas domẽs de pee...." 


\section{Fólio clx (verso):}

“E como tudo foy cõçertado veo el Rey da cidade esperar ali Afonso dalbuquerq', \& em sua companhia vinha Mamallde \& o Algozil de Cananor, \& os regedores da terra, \& outros muytos mouros honrrados, \& trazia de sua guarda cinco mil Naires todos despadas \& adargas".

\section{Fólio ccxvi (verso):}

“Depois Dafonso Dalboquerque ter passado suas praticas com o embaixador del Rey de Sião, determinou de o despachar, \& mandou em sua companhia Antonio de Miranda dazeuedo com cinco homẽs que o acompanhassem de bõs corpos \& boas presenças: \& por elle mandou a el Rey de Sião de presente em nome del réu dom Manuel hũas couraças de veludo çremesim [sic], \& hum coçalate comprido de todalas peças, \& hum capaçete \& barbote muy bem guarnesçidos, \& hũa adarga dãta com seus cordões muyto ricos, metida em sua funda de brocado...".

\section{Fólio ccxlviij (recto):}

“...\& nam poderam entrar por amor do fumo que os afogaua: \& os nossos que estavam em çima do muto por nam terem lanças nam lhe poderam defender que a nam tapassem, porq' quando sobiram a elle nam leuauam se nã espadas \& adargas".

\section{Fólio ccxlix (recto):}

"Tu saluate, que eu ey de morrer aquim porque nunca Deos queyra que eu deça se nam por onde sobi, \& leuaras esta minha adarga a el Rey nosso senhor, porque seja testemunha diante delle de omo aqui morry por seu seruiço...".

\section{Fólio cclxxxvij (verso):}

"E mandou a toda a outra gente de lanças \& adargas, que tambem estiuessem ali em ordem mais chegados ao estrado, de maneyra que fizerã hũa rua muy comprida".

\subsection{Damião de Góis, 1566}

Damião de Góis (1502-1574), em Chronica do felicissimo Rei Dom Emanvel (Goes, 1566) também mencionou a adarga danta:

\section{Parte I, fólio 30v:}

"Ha gente destes barcos era baça, de bõs corpos, vinham vestidos de panos dalgodam listrados, \& nas cabeças traziam hŭas Touquas foteadas com viuos de seda, laurados đ fio douro, \& terçados mourisquos çingidos, com adargas nos braços, hos q'es em chegando a bordo das naos, entraram seguramente nellas, saudando hos nossos em lingoa Arabia que todos fallauam".

\section{Parte II, fólio 9v:}

“Dom Françisco vendo q' ho corpo da gẽte dos imigos creçia, mandou da sua a dom Lourẽço, pera que hos fosse cometter, deixandosse estar nos bateis pera defender que nam apagassem hos imigos ho fogo das naos, nem ho que andaua ja na çidade. Dõ Lourenço achou hos imigos em mui boa ordem, porque hos adargados estauã diante emparando hos frécheiros, \& dalli tirauam a seu saluo, ferindo algũs dos nossos, ho que vendo dom Lourẽço, hos esforçou, apertando tão rijo com hos imigos, que hos fez retirar pa a fralda da serra".

\section{Parte II, fólio 31v:}

"Naquelle mesmo dia se ajuntáram aho redor da fortaleza mais đ mil mouros, adargados, que com espingardas, e béstas tirauam contra hos nossos, \& vendo que isto nam fazia mossa, mandáram trazer bombardas, com que tiráram toda aq'lla noite, a qual hos nossos passaram todos armados". 


\section{Parte II, fólio 39v:}

"...\& elle vestido đ hũ laudel đ laminas cuberto de çetim cremisim, cõ hũa çellada dourada na cabeça, \& no braço hũa muito boa adarga, cõ hũa spada, çẽgida, laurada de tauxia douro, \& prata, \& na mão hũa azagaia".

\section{Parte II, fólio 39v:}

"...\& ho primeiro foi dõ Antonio de Noronha, aho qual se Afonso dalbuquerque seu tio, nã lançára hũa adarga sobello pescoço...."

\section{Parte II, fólio 40r:}

“...\& a outros q' se punhão diãte destes pera hos defender atassalharão has adargas ante hos braçaes...."

\section{Parte III, fólio 41v:}

"Com este embaixador mãdou Afonsodalbuquerque por embaixadores a elRei Antonio de mirãda dazeuedo, \& Duarte coelho bem acompanhados, per quẽ screueo a elRei, \& Ihe mandou hũas couraças de veludo cramesi, \& hũ capaçete, $\&$ barbote guarneçidos douro, \& hum arnes darmas brancas, \& hũa adarga danta muito rica, metida em hũa funda de brocado, \& outras peças de prata laurada de bestiões, \& pannos darmar douro, \& seda, \& hũa bésta muito bem obrada, com seu almazem".

\section{Parte III, fólio 81r:}

"...\& mandou abrir outra bombardera que estaua junto do cubelo; pela qual ho primeiro q' entrou foi um homem, que trazia ho guião de Emanuel de laçerda, com spada, \& adarga, deixando o guião de fora...."

\section{Parte III, fólio 91v:}

"Com tudo hauia na borda delle hum magote, de quasi trezentos villãos adargados, que todos jũtos fezeram rosto ahos nossos, hos quaes dom Bernardo cometteo com ha sua gente, porque loão da sylua passara hũa ponta đ rochedo, que entra no rio, pera dar em outra companhia de Mouros, que por aquella banda se saluaram a nado. Nestes adargados deu dom Bernardo, indo em sua companhia Afonso telez zeu primo, loão dornelas, Rui Miranda, George rodriguez pinto, Antam tellez, \& Duarte do quintal...."

\section{Parte III, fólio 95v:}

"Dos Mouros (segundo se depois soube, \& ho Nuno fernãdez per suas cartas afirmou a ElRei) morreram mais de dous mil, \& seis çentos, entre hos quaes foi hum dos alcaides del Rei đ Féz, \& outro foi derrbado, q' se saluou dreixando há lança, adarga, \& cauallo...."

\section{Parte III, fólio 122v:}

"Raix nordim quomo a pessoa a que tocaua ho cargo, por ser Guazil da çidade, mandou tambem perá praia ha gente delRei, \& algũa da çidade, toda armada, em q' entrauam duzẽtos soldados de Raix hamed, q' traziã saias de malha, capaçetes, \& adargas...."

\section{Parte IV, fólio 62v:}

"...hos mouros vendo recolhidos aquelles vinte de cauallo, \& que dom loam era já fora da Villa, voltaram, leuando ho despojo que Ihes ficara no rio doçe, de redes, adargas, selas, cabeçadas, \& freos, com outras meudezas da calidade...".

\section{Parte IV, fólio 65r:}

"... aho q' loam coelho, \& Aires coelho armados de couraças, capaçetes, \& adargas acodirã cõ lanças nas mãos..."

"...ho que fezerão cõ muito animo, dos q'es, ẽ inuestindo ha carauela saltarão pela proa quĩze, ou dezaseis dẽtro, cõ capaçetes lãças, rodelas, \& adargas...". 


\section{Parte IV, fólio 79r:}

"Com esta frota partio Antonio Correa de Ormuz no começo de lunho, de Mil quinhentos, \& vinte hum, \& em sua companhia Raix xarafo com ha armada delRei, que passaua de çento, e çinquoenta terradas, em que hiam tres mil mouros frecheiros, \& spingardeiros, de lãça, \& adarga...."

\section{Parte IV, fólio 83v:}

"...na qual saida ganharam hũa tranqueira que elRei mandara fazer entre ho porto, \& ha çidade com sós hos de lanças, \& adargas...."

\section{Parte IV, fólio 99r:}

"...\& assi se veo muito de vagar recolhendo ho despojo que hos mouros deixaram no campo de lanças, adargas, marlotas, \& outras cousas que alargaram por fogirem mais a sua vontade...."

\section{Parte IV, fólio 107r:}

"...\& na guarda dos ginetes hauia duzẽtos caualeiros, todos de boa casta, \& conheçidos por valentes homẽs, q' ho acompaanhauão quãdo caminhaua, cõ lanças, \& adargas, \& erão obrigados a ter armas prestes, \& cauallos pera quãdo se delles quisesse seruir".

\subsection{Luís Vaz de Camões, 1572}

Há duas menções de adargas nos Lusiadas (Camões, 1572):

\section{Fölio 15v [Canto I, LXXXVII]:}

"Andão pela ribeira alua arenosa,

Os belicosos Mouros acenando,

Com a adarga, \& co a astea perigosa,

Os fortes Portugueses incitando:

Nam soffre muito a gente generosa,

Andarlhe os cães os dentes amostrando.

Qualquer em terra salta, tam ligeiro,

Que nenhm dizer pode que he primeiro".

\section{Fólio 119v [Canto VII, XXXIX]:}

"Desta sorte o ludaico pouo antigo

Nam tocaua na gente de Samaria,

Mais estranheza inda das que digo

Nesta terra vereis de vsança varia,

Os Naires sos san dados ao perigo

Das armas, sos se defendem da contraria

Banda o seu Rei, trazendo sempre vsada

Pela ezquerda a adarga, e na dereita a espada".

\subsection{Diogo do Couto, 1602, 1612}

Na Decada qvarta da Asia (Couto, 1602: fólios 30v-39r):

"E decẽdose do caualo embraçou hũa adarga, \& tomando hũa lança nas maõs foi cometendo a escada, bradandolhes que se dessem à prisão...." 


\section{Fólio 88v:}

" \& como ele estaua com aquelle animo \&furor, naõ fazendo caso da ferida, nem lha entendendo os que etauaõ de tras delle, por que estaua diante de todos mudou cõ muita presteza hũa adarga q' tinha pera aquelle braço, \& tomando a epada com a maõ esquerda, fez com ela taes cousas,que se lhe naõ sintio o defeito do outro braço, que ele trabalhaua por encobrir, acodindo de quando em quãdo com a maõ efquerda a aleuantalo pera cima, porque tinha os osos quebrados, \& com o pezo da adarga lhe caya ao longo da perna...".

\section{Fólio 167r}

"Aqui socedeo hũa cousa mũy dina de memoria a vm foaõ Trãcoso, irmaõ do Doutor Antonio Trancofo Defembargador da casa do Cluel (homens mũy nobres que eu conheci mũy bem). Era este Trancofo vm homem agigantado \& muito forçoso, andando aceso na batalha, (e mãtinha mũy bem pelejado \& mostrado o valor de sua pesoa) alcãçou com a maõ esquerda vm Mouro, \& metendolhe o braço pelo singidouro (que era vm camarabando de muitas voltas) o aleuantou no ár, fazendo delle adarga: \& remetendo com os Mouros lançouse no meyo delles como vm liaõ matando, \& derribando muitos, naõ ouzando os Mouros a descarregar nelle seus golpes, por naõ matarem o companheiro...."

\section{OTAPIR ${ }^{16}$}

\subsection{As espécies de Tapirus na região neotropical}

Quatro espécies de Tapirus (Perissodactyla, Tapiridae) existem na América Latina.

O Tapirus terrestris (Linnaeus, 1758) [Figuras 7.1 e 7.2] ocorre a leste da Cordilhera dos Andes, desde o sul da Venezuela até o norte da Argentina [Figura 7.4], em áreas abertas ou florestas próximas a cursos d'água. É o maior mamífero terrestre do Brasil e o segundo da América do Sul, tendo até $300 \mathrm{~kg}$ de peso e $242 \mathrm{~cm}$ de comprimento. Possui uma dieta frugívora e tem um papel importante na dispersão de sementes, principalmente de palmeiras. Seus predadores são grandes felinos como a onça-pintada (Panthera onca) e a onça-parda (Puma concolor). É um animal solitário e vive em territórios de $5 \mathrm{~km}^{2}$ de área, em média. A anta tem reprodução lenta, com uma gestação que pode durar mais de 400 dias e parem apenas um filhote por vez, que pesa entre 3,2 e 5,8 kg. Podem viver até 35 anos de idade.

O jovem apresenta listras e manchas claras e coloração parda avermelhada [Figura 7.3]. À medida que envelhece, sua coloração vai ficando marrom escura e uniforme pelo corpo.

O Tapirus pinchaque (Roulin, 1829) [Figura 7.5] habita principalmente as florestas de altitude do Andes da Colômbia e Equador e talvez no oeste da Veneziela e norte do Peru. É a segunda menor espécie existente de anta, maior somente que o recentemente descrito Tapirus kabomani. É também a única espécie existente de sua família a viver fora das florestas tropicais na natureza. É encontrada nas florestas de altitude e nos páramos das montanhas nas cordilheiras orientais e centrais da Colômbia, Equador e no extremo norte do Peru. No passado seu alcance pode ter sido prolongado até o oeste da Venezuela, mas já foi extinta nessa região. Normalmente vive em altitudes entre 2.000 e 4.300 metros, e nessas altitudes as temperaturas rotineiramente caem para abaixo de zero, e a pelagem da anta da montanha, maior do que nas demais espécies de antas, é provavelmente uma adaptação para viver nessas condições. Durante a estação das chuvas tendem a habitar as florestas temperadas dos Andes, enquanto durante os meses mais secos deslocam-se mais para o pé das montanhas, onde não sofrem tanto com as picadas de insetos.

Tapirus bairdii (Gill, 1865) [Figura 7.6] ocorre ao leste do Istmo de Tehuantepec, no México, através de todos os países da América Central, até a Colômbia a oeste do rio Cauca e o Equador a oeste dos Andes até o Golfo de Guayaquil. Possui uma distinta marcação de cor creme no rosto e garganta e um ponto escuro em cada bochecha, atrás e abaixo do olho. A cor da pelagem varia de castanho escuro a castanho acinzentado. Vive principalmente em áreas próximas a cursos d'água e em florestas, sendo um animal extremamente associado a presença de água, na qual pode repousar durante horas, principalmente nas partes mais quentes do dia.É o maior e mais pesado mamífero terrestre existente nas Américas centra e do sul, tendo até $400 \mathrm{~kg}$ de peso 2,50 $\mathrm{m}$ de comprimento total e 1,20 $\mathrm{m}$ de altura no ombro, o que a torna também a maior das quatro espécies existentes de antas no continente americano.

Tapirus kabomani Cozzuol, Clozato, Holanda, Rodrigues, Nienow, de Thoisy, Redondo, \& Santos, 2013 tem o peso estimado em até 110 quilogramas. É a menor espécie vivente do gênero Tapirus. Para comparação, Tapirus pinchaque pesa entre 150 e 225 quilogramas. Tapirus kabomani possui cerca de 130 centímetros de comprimento e 90 centímetros na altura dos ombros. A pelagem varia do cinza-escuro ao marrom-escuro e as pernas são curtas. Os machos são menores que as fêmeas, que possuem uma mancha branca que vai do queixo ao pescoço até a base da orelhas. Tapirus kabomani ocorre na América do Sul. Foi coletado no sul do Amazonas, em Rondônia e Mato Grosso. A espécie também deve ocorrer no departamento do Amazonas na Colômbia e no Amapá e sul da Guiana Francesa. Embora não tenha sido descrita for-

16 Dennler de la Tour (1971) publicou um artigo sobre a origem das palavras tapir e anta, ao qual não tive acesso. 


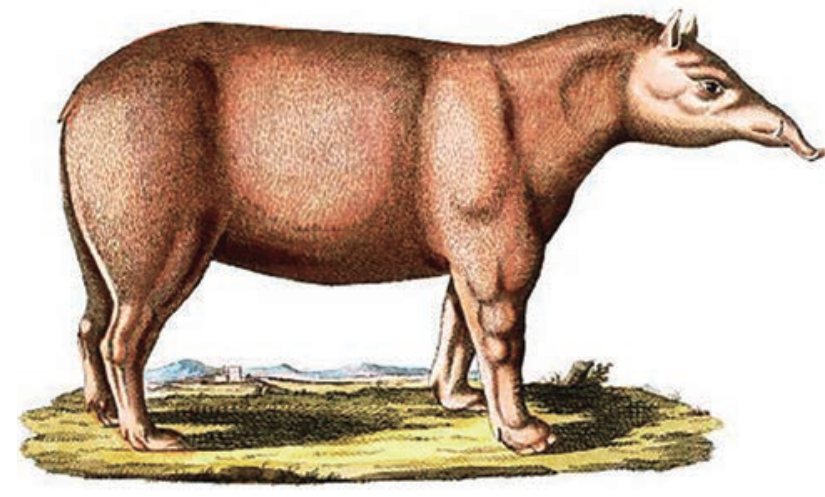

Figura 7.1. Tapir (Tapirus terrestris (Linnaeus 1758)) (Spalowsky, 1795: pl. 47).

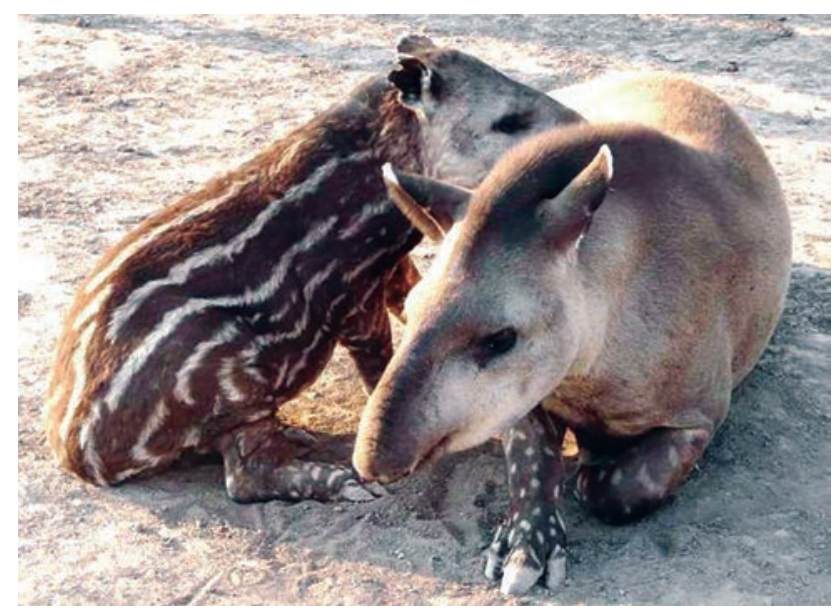

Figura 7.3. Filhote de anta com listras brancas.

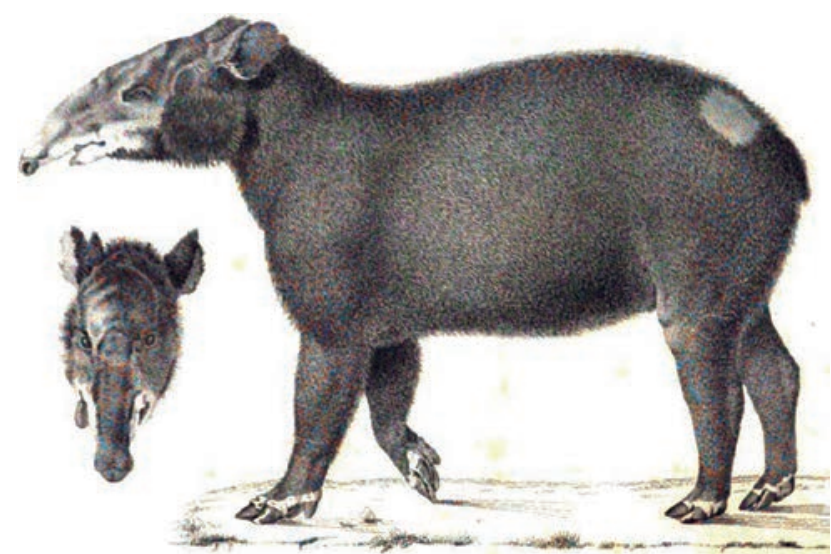

Figura 7.5. Tapirus pinchaque (Roulin, 1835: pl. I).

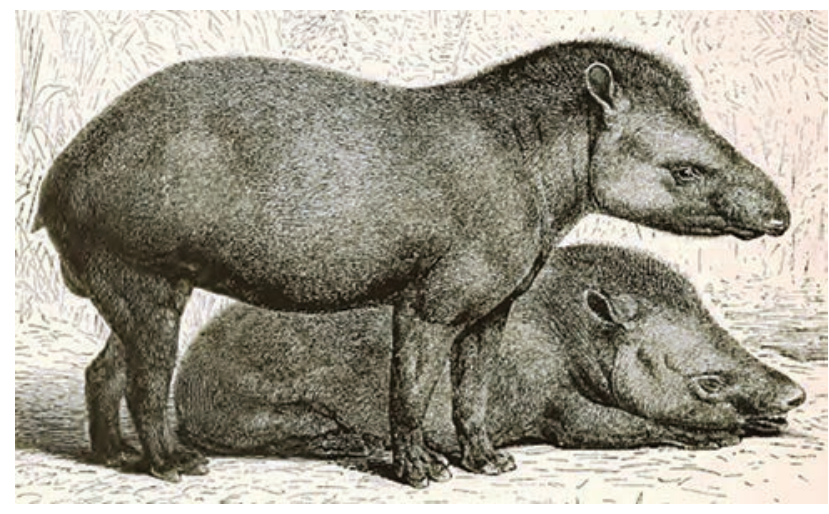

Figura 7.2. Tapir (Tapirus terrestris (Linnaeus, 1758)) (Lydekker, 1894: 460).

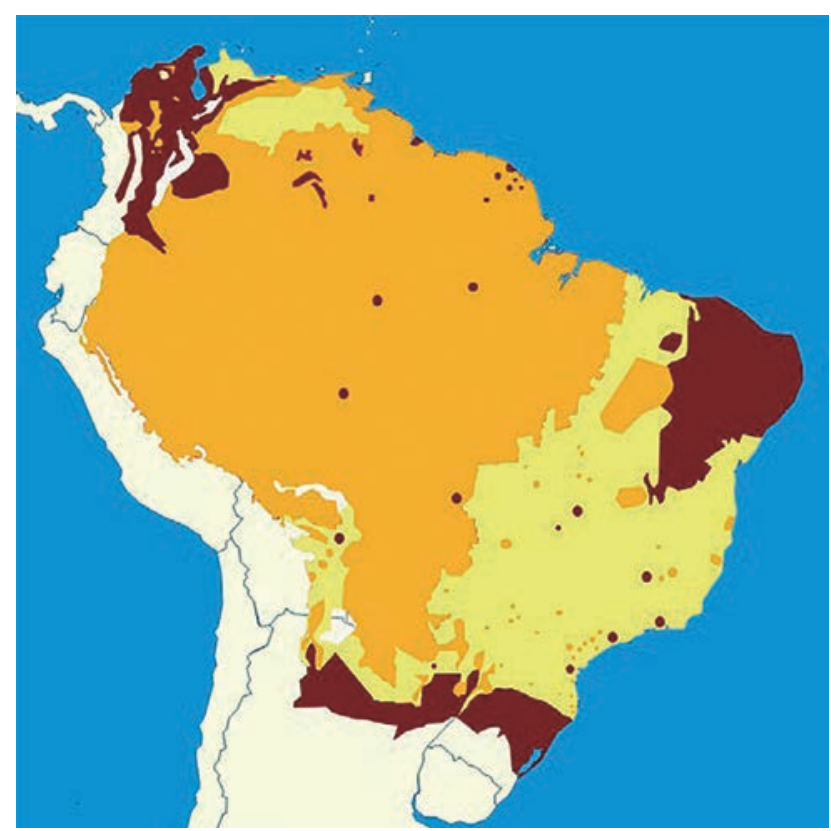

Figura 7.4. Distribuição geográfica do Tapirus terrestris (Vermelho: extinto; laranja: presente; amarelo: provavelmente presente).

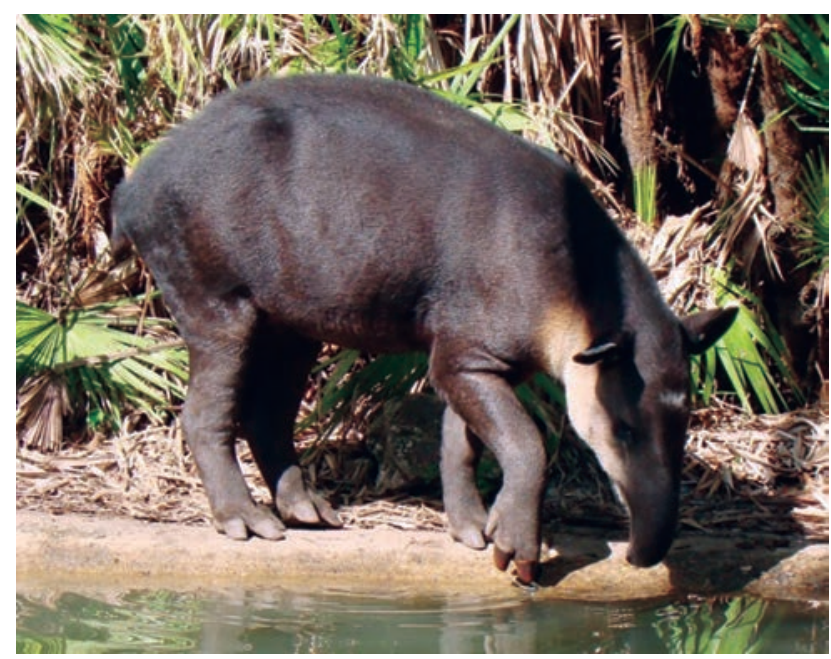

Figura 7.6. Tapirus bairdii. 
malmente até 2013, a possibilidade de T. kabomani ser uma espécie distinta já havia sido sugerida 100 anos antes. O primeiro espécime reconhecido como um membro desta espécie foi coletado pela Expedição Científica Rondon-Roosevelt. Roosevelt (1914) acreditava ter coletado uma nova espécie, já que caçadores locais reconheciam dois tipos de anta na região (Roosevelt, 1914); outro membro da expedição, Leo E. Miller, sugeriu que havia duas espécies. Entretanto, embora observada por especialistas, todas as antas foram classificadas como Tapirus terrestris, incluindo o exemplar AMNH 36661, identificado como T. kabomani. A espécie só foi descrita formalmente em dezembro de 2013 e foi a primeira espécie de anta a ser descoberta desde 1865. O epíteto específico deriva de Arabo kabomani, a palavra para anta no idioma Paumarí.

\subsection{Citações do nome tapir (e variantes) por autores dos séculos XVI a XX}

Tappire Jehan Lamy, 1540: fól. 54r (in Dalby \& Hair, 1966) (“Tappire - ung chacal [sic]") ${ }^{17}$. É o primeiro registro do nome tupi.

Tapihire Thevet; 1558a: 96r, 1558b: 94r, 1561: 210 ('Il se trouue d'auantage en l'Amerique grande quantité de ces bestes, qu'ils nommẽt Tapihire, desirées \& recommandables pour leur deformité. Aussi les Sauuages les poursuyuent à la chasse, non seulement pour la chair qui en est tresbonne, mais aussi pour les peaux, dont ces Sauuages font boucliers, desquels ils vsent en guerre. Et est la peau de cete beste si forte, qu'à grande difficulté vn trait d'arbalette la pourra percer. Ils les prennent ainsi que le cerf \& le sanglier (...). Ces bestes sont de la grãdeur d'vn grand asne, mais le col plus gros, \& la teste comme celle d'vn taureau d'vn an: les dents trenchãtes \& agues: toutesfois elle n'est dãgereuse. Quan on la pourchasse, elle ne fait autre resistẽce que la fuite, cherchant lieu propre à se cacher, courant plus legerement que le cerf. Elle n"a point de queuë, sinon bien peu, de la longueur de trois ou quatre doigts, laquelle est sans poil, cõme celle de l'Agoutin. Et de telles bestes sans queuë se trouue grande multitude par delà. Elle 'a le pié forchu, auec vne corne forte longue, autant presque deuant comme derriere. Son poil est rougeatre, comme celuy d'aucunes mules, ou vache de par deça: \& voila pourquoy les Chrestiens qui sont par delà, nomment telles bestes vaches, non differentes d'autre chose à vne vache, hors-mis qu'elle ne porte point de cornes: \& à la verité, elle me semble paticiper autãt de l'asne que de la vache: car il se trouue peu de bestes d'especes diuerses, qui se ressemblent entierement sans quelque grande difference'), 1575: fól. 937v ('Il s'y trouue encor là, grande quantité de bestes, appellees Tapihires, desirees \& recommandees à cause de leur deformité. Aussi les Sauuages les poursuyuẽt, tant pour en auoir la chair qui en estfort sauoureuse \& saine, que pour les peaux, desquelles ils en font des rondelles fort larges, desquelles ils vsent \& portent à la gerre, à cause qu'elles sont si dures \& fortes, que à grand peine vn trait d'arbaleste les purroit percer. Et vsent de pareille ruse à prendre le Tapihire, que à tromper les Sangliers, Cerfs \& Biches. Ceste beste est de la grandeur d'vn Asne, ayant le col plus gros, \& la teste cõme celle d'vn Taureau, les dents trenchantes \& aigues, non que pour cela elle en soit plus dangereuse: car estãt chassee, toute sa fedense ne consiste qu'á la fuitte, \& à checher sa retraite, laquelle court plus vistement que ne fait le Cerf. Elle n'a point de queuë, sinon bien peu, \& icelle sans poil, tout aussi celle de l'Agoutin, cy dessus descrit. Aussi le pied fourchu, \& cornue, \& le pil rougeastre cõme celuy d'vne vache. Qui a causé, que plusieurs des nostres, estant de par delà, appelloient le Tapihire, vache Sauuage: mais il e sembre autant participer de l'Asne que de la vache, veu que la difference y est aussi grande de l'vne espece que de I'autre'), 1587-1588: 89r-89v; in Laborie \& Lestringant, 2006: 229-230): 'Et quant à celle que l'on appelle Tapihires, desirées, et recommandées, à cause de leurdite deformiré. Elles sont aussy poursuivies des Sauvages, tant pour en avoir la chair, qui en est tres bonne, et saine, que pour les peaux, desquelles is font des rondelles fort larges, desquelles ils usent, et portent en guerre, à cause qu'elles sont si dures, et fortes, qu'à grand'peine un trait d'arbaleste les pourroit percer, et usent de pareilles ruses à prendre le Tapihiri, qu'á tromper les sangliers, cerfs, et biches. Cette beste est de a grandeur d'un asne, ayant le col plus gros, et la teste comme celle d'un taureau. Les dents trenchantes, et aiguës, non que pour cela elles soient plus dangereuses. Car cette beste estant chassée, toute sa defense ne consiste qu'à fuïr, et à chercher sa retraitte. Je me doubterois que c'est cét animal, que Léry dit estre une vache. En quoy il se trompe grandement, attendu la grosseur, et grandeur, del'une, et l'autre. Elle n'a que bien pu de queuë san poil, tout ainsy que la beste Agoutin cy dessus descrite, ayant le poil rougeastre, comme celuy d'une vache').

Tapiíra Anchieta, [1560] 1812: 150 ('Est aliud animal satis frequens esui aptum, ab Indis Tapiíra, ab Hispanis vero Anta dicitur, ea credo, quae Latinis Alce nominatur: Mulae similis bestia, cruribus aliquanto brevior, pedes habet trifidos, superius labrum prominentissimum, colore est inter Camelum et Cervum medio in nigro declinante: $n$ tissim vidierigit se jubarum loco per cervicem torus ab armis ad caput, in quo erectior aliquantulo totam frontem armat, et viam sibi per nemorum condensa discretis hinc inde lignis aperit: brevissima est cauda nullis munita jubis: sibilum ingentem vice vocis emittit: die dormit et quiescit, nocte huc illuc discurrens diversos arborum fructus pascit, et cum hi defuerint, cortices: cum a Canibus lacessitur, morsibus resistit et calcibus, aut in flumina prosilit, diuque latitat sub aqua, quam ob rem juxta fluvios frequentius versatur; ad quorum oras solet etiam terram effodere et argillam mandere. Hujus ex tergore faciunt Indi cetras, duratas solummodo

17 Alguns aventureiros normandos aprendiam alguns vocábulos da língua Tupi, ou passavam a residir entre as tribos da costa brasileira, adquirindo um conhecimento bastante razoável da língua indígena. Eram os chamados truchemans, palavra originalmente provinda do árabe, que significa 'intérprete'. Esses truchemans (turgimão em português; também conhecidos na época como 'os línguas'; serviam portanto de intérpretes e intermedários entre os navegantes franceses e os índios. Um raro documento dessa época é a Langaige du Bresil. Dalby \& Hair (1966) publicaram essa lista de nomes tupis com 0 correspondente significado em francês constantes desse documento, compilado por um certo Jehan Lamy por volta de 1540 , encontrado nos fólios $53 \mathrm{r}-54 \mathrm{r}$ de uma coleção de três escritos sobre náutica ou navegações (MS 24269 da Biblioteca Nacional da França [0 original está disponível; procurar em 'Gallica', sob Regyme pour congnoistre la latitude de la region... ]. 
ad solem, sagittis omnino impervias' (Há outro animal, bastante frequente, próprio para se comer, chamado pelos Índios tapiira e pelos espanhóis 'anta'; julgo que é o que em latim se chama 'alce'. É uma fera semelhante à mula, um pouco mais curta de pernas; tem os pés divididos em três partes; a parte superior do beiço é muito proeminente; de cor entre a do camelo e a do veado, tendendo para o preto. Levanta-se-lhe, pelo pescoço, em vez de crinas, um músculo desde as cruzes até a cabeça, com o qual, como é um tanto mais alto, arma toda a fronte e abre caminho por espessos bosques, separando os ramos daqui e dali. Tem a cauda muito curta, desprovida de crinas; dá um grande assobio em vezde grito; de dia dorme e descansa; de noite, corre de um lado para outro; nutre-se de diversos frutos, e, quando não os há, come as cascas das árvores. Quando perseguida dos cães, faz-lhes frente a dentadas e coices, ou lança-se ao rio e fica por muito tempo debaixo d'água; por isso vive quase sempre perto dos rios, em cujas ribanceiras costuma cavar a terra e comer barro. Do seu couro, endurecido, apenas pelo sol, os Índios fabricam broquéis completamente impenetráveis)).

Tapirovssov Léry, 1578: 137 ("Au retour d'vn voyage que ie feis en la terre du BresiL dicte Amerique,en l'an 1558. ayans demeurez \& brãslez cinq mois sur mer sans mettre pied à terre, \& durãt la famine que nous eusmes d'vn mois, nous fusmes contraincts de mãger des rondaches de cuir sec, faictes de la peau d'vn animal gros comme vn taureau d'vn an, que les Sauuages appelent TAPIROVSSOV, mais nous les mettions seulement rostir sur les charbons par petis morceaux: \& ne peusmes trouuer l'inuention de les amollir comme nous auõs faict les peaux seiches à Sancerre").

Tapirousou Thevet, 1575: fóls. 910v, 929v ('vne beste, qu'il nõmẽt Tapirousou, que est vne espece d'Asne sauuage, de la grãdeur d'vn Taureau, farouche \& hideux, \& difficile à attaquer').

Apiroupsou Thevet, 1575: fól. 919v) ('en vn moment changez en diverses formes hideuses \& figures de plusieurs animaux terrestres, si comme sont Loups, Chiens \& Chats sauuages, \& autres semblables, lesquels sont appellez en leur langue, larnare: \& en y a de plusieurs sortes, sçauoir est larnare-este, Iarnarh-bouten, Pau, Apiroupsou, laona Tonapech, Marga, lonacsou, Margata, Miry, Cirat, \& plusieurs autres especes de bestes, qui se voyent en ladite terre').

Apyropsou Thevet, 1575: fól. 913r: ('lesquels [Sauuages] nous aporterẽt vne beste grosse cõme vne vache, nõmee Apyrousou, cuicte \& boquonee à leur façon'), fól. 919v.

Tapijrete Cardim [1583] (in Purchas, 1625: 1301, 1906: 450) ('The Tapijrete are the Elkes, of whose skinne the leather Targets are made, they are like Kine, much more like a Mule, the tayle is of a finger length, they have no hornes, they have a snout of a quarter long, which he shrinketh up and putteth forth. They swimme and dive very much, but when they dive they take ground presently under water, and going on it they come out in another place, where there are great store of them in this Countrie'. Cardim (1925: 37): 'Tapyretê - Estas são as antas, de cuja pelle se fazem as adargas; parecem-se com vaccas e muito mais com mullas, o rabo he de um dedo, não têm cornos, têm huma tromba de comrimento de hum palmo que encolhe e estende. Nadão e mergulhão muito, mas em mergulhando logo tomão fundo, e andando por elle saem em outra parte. Ha grande copia dellas nesta terra').

Tapiruçú Souza (G.S. de), [1587] 1851: 243 ('E comecemos das antas (a que os indios chamam tapiruçú) por ser a maior alimaria que esta terra cria; as quaes são pardas, com o cabello assentado, do tamanho de uma mulla, mas mais baixas das pernas; e tem as unhas fendidas como vacca, e o rabo muito curto, sem mais cabello que nas ancas; e tem o focinho como mulla, e o beiço de cima mais comprido que o debaixo, em que tem muita força. Não correm muito, e são pezadas para saltar; defendem-se estas alimarias no mato, com as mãos, das outras alimarias, com o que fazem damno aonde chegam; comem frutas silvestres e hervas; parem uma só criança; e emquanto são pequenas são raiadas de preto e amarello tostado ao comprido do corpo, e são muito formosas; mas depois de grandes tornam-se pardas: e emquanto os filhos não andam, estão os machos por elles emquanto a femea vai buscar de comer. Matam-nas em fojos, em que cahem, ás flexadas. A carne é muito gostosa, como a de vacca, mas não tem sebo; e quer-se bem cozida, porque é dura; e tem o cacho como maçã do peito de vacca; e no peito não tem nada. Os ossos d'estas alimarias queimados e dados a beber são bons para estancar camaras; as suas pelles são muito rijas, e em muitas partes as não passa flexa ainda que seja de bom braço, as quaes os Indios comem cozidas pegadas com a carne. D'estas pelles, se são bem cortidas, se fazem mui boas couraças, que as não passa estocada. Se tomam estas antas pequenas, criam-se em casa, onde se fazem muito domesticas, e tão mansas que comem as espinhas, e os ossos com os cahhorros e gatos de mistura; e brincam todos juntos'), 127 (nota 1, de Pirajá da Silva: “Tapiruçu - anta - Tapirus terrestris L. 1785 [sic]. ("Tapirus americanus Gem [sic] 1788). Tapira - anta - Dic. Bras. Tapira-etê - também significa anta, o tapir").

Tapiraçu Souza (G.S. de), [1587, ca. 94] 1971: 243.

Taparuçu Souza (G.S. de), [1589] 1825: 215.

Taperuçu Souza (G.S. de), [1587, ca. 94].

Tapihiri Thevet, 1587-1588: 89r; in Laborie \& Lestringant, 2006: 229.

Tapira Monteiro (J.), [1610] (in Leite (S.), 1949:417) ("Há muitas antas, a que chamam tapira. A carne difere pouco da nossa vaca, no sabor, posto que me pareceu de ventagem uma vez que dela no mato nos fiseram seu presente os Aimurés, trazendo-no-la já assada a seu modo, de moquém, que se faz nesta forma: fazem uma cova no chão; enchem-na de brasas, sobre elas botam uma camada de folhas de bananas, que são mais altas que um homem, e de largura de dous ou três palmos; e depois de a cobrirem com outra camada lhe lançam terra, de modo que tapam a cova. A carne se vai ali assando com tal têmpera, que leva vantagem a toda a mais invenção de assado, na limpeza e na tenrura e sabor. Tem no focinho um palmo de tromba, que lhe serve de mão com que apanha o que come. Tem os olhos pequenos e envovados. Será de altura de um jumento, mas mui envolta em carmes. Tem as pernas grossas. Peleja com os dentes, 
que serão como de mula, mas leva todo o que alcança. Nadam sobremaneira, e muito mais mergulham, porque passam rios mui largos de banda a banda, e andando debaixo da água. Em pequenas são mui lindas e pintadas, depois crescem e aborrecem, mas fazem-se mui caseiras e mansas. Sustentam-se das frutas dos matos. Criam nas entranhas pedras bazuares, que os Franceses regatavam aos Índios em igual preço que o do ambre").

Tapyyre-été Claude d'Abbeville, 1614: fól. 250r (cap. xli) ('L'on y voit les Tapiyre-été Vaches braues ou Vaches sauuages, lesquelles sont assez semblables aux Vaches de par deçà, sinon qu'elles ont les oreilles plus longues, la queuë \& les iambes plus courtes \& les dents plus aiguës, \& n'ont aucunes cornes. Ordinairement l'on trouue de Bezouard en icelles'), 1975: 200; Garcia, 1923: 76 ("Tapira-etê a anta (Tapirus americanus, Briss.). - O nome é susceptivel de várias explicações, mas nenhuma satisfactoria; o suffixo eté verdadeiro, legitimo, serve para differençar aquelle ungulado dos bovinos, que os tupis só conheceram depois do contacto europeu").

Tapyrete Laet, 1633: 551.

Tapiyie-ete Laet, 1633: 618.

Tapiyré-été d'Avity, 1637: 120.

Tapié Montoya, [1639] 1876: 355r ("Tapié - Anta").

Tapií Montoya, 1639a: 355r (1876: 355r) ("Tapií, anta, animal conocido"), 1640(1): 168 (sob anta).

Tapijerete Marcgrave, 1648: 228.

Tapiierete Marcgrave, 1648: 229 ("TAPIIERETE Brasiliensibus, Lusitanis Anta, animal quadrupes, magnitudine juvenci semestris: figura corporis quodammodo ad porcum accedens, capite etiam tali, verum crassiore, oblongo, superius in acumen desinente, promuscide super os praeminente, quam validissimo nervo contrahere \& extendere potest: in promuscide autem sunt fissurae oblongae. Inferior: oris pars brevior est superiore. maxillae ambae anterius fastigiatae, \& in qualibet decem dentes incisorii superne et inferne, hinc per certum spatium, utraque maxilla caret dentibus, sequuntur dein molares, grandes omnes in quolibet latere quinque, ita ut habear viginti molares \& viginti incisores. Oculos habet parvos porcinos: aures obrotundas majusculas, quas versus anteriora surrigi: crura vix longiora porcinis, at crassiuscula: in anterioribus pedibus quatuor ungulas, in posterioribus tres; media inter eas major est in omnibus pedibus; in prioribus pedibus, tribus quarta parvula exterius est adjuncta; sunt autem ungulae nigricantes non solidae sed cave, \& quae detrahi possunt. Caret cauda, \& ejus loco processum habet nudum pilis, conicum, parvum, more Curian. Mas membum genitale longe exserere potest instar Cercpitheci. Incedit dorso incurvato ut Capybara. Cutem solidam habet instar Alcis; pilos breves. Color pilorum in junioribus est umbrae lucidae, maculis variegatus albicantibus ut capreolus: in adultus fuscus sive nigricans sine maculis; animal interdiu dormit in opacis silvis latitans; noctu aut mane egreditur pabuli causa. Optime potest natare. Vescitur gramine, arundines Saccharifera, brassica, \&c. Caro ejus comeditur sed ingrati saporis est".

Tapiiereté Piso, 1658: 101, fig. [Figura 7.7].

Tápiíereté Theatr., Anim. [1660] in Teixeira, 1993: 39 [Figura 7.8].

Tapiicreté, Lufitanis Anta, mirum afpectu animal, magnitudine Iuvencifemeftris; dorfoincurvato, figura corporis quodammodo ad Porcum accedens, imprimis oculis, capite \& pedibus. Promufcide eft fuper os praeminente, quam validiflimo nervo contrahere \& extendere poteft. Ore dentato in utraque maxilla. Loco caudx exiguum proceffum habet depilem. Cute eft folida inftar Alcis, brevibus pilis, umbræ \& fufci coloris. Salax eft beftia \& noctambula, qux arborum fructus, arundines facchareas, depopulatur. Inter amphibia non recenfetur : fluvios tamen tranfnatat rapidiffimos. Cxterum iners \& $<$ focor's apparet, adeoque lucifuga, ut in denfis mediterraneis filvis interdiu dormire amet: Ita ut, fi detur animal aliquod quod noctu tantum, nunquam vero de die vene-

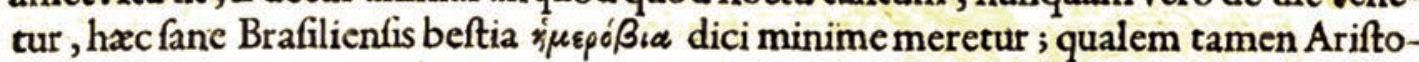
teles \& Scaliger exterreftrium genere in Afia non dari autumant. Caro ejus vefca,fi juvenis, \&rite præparetur, bubulamque æmulatur, eaque mediterraneis ac maris accolis in frequenti ufu exiftit.

Figura 7.7. Piso (1658: 101). 


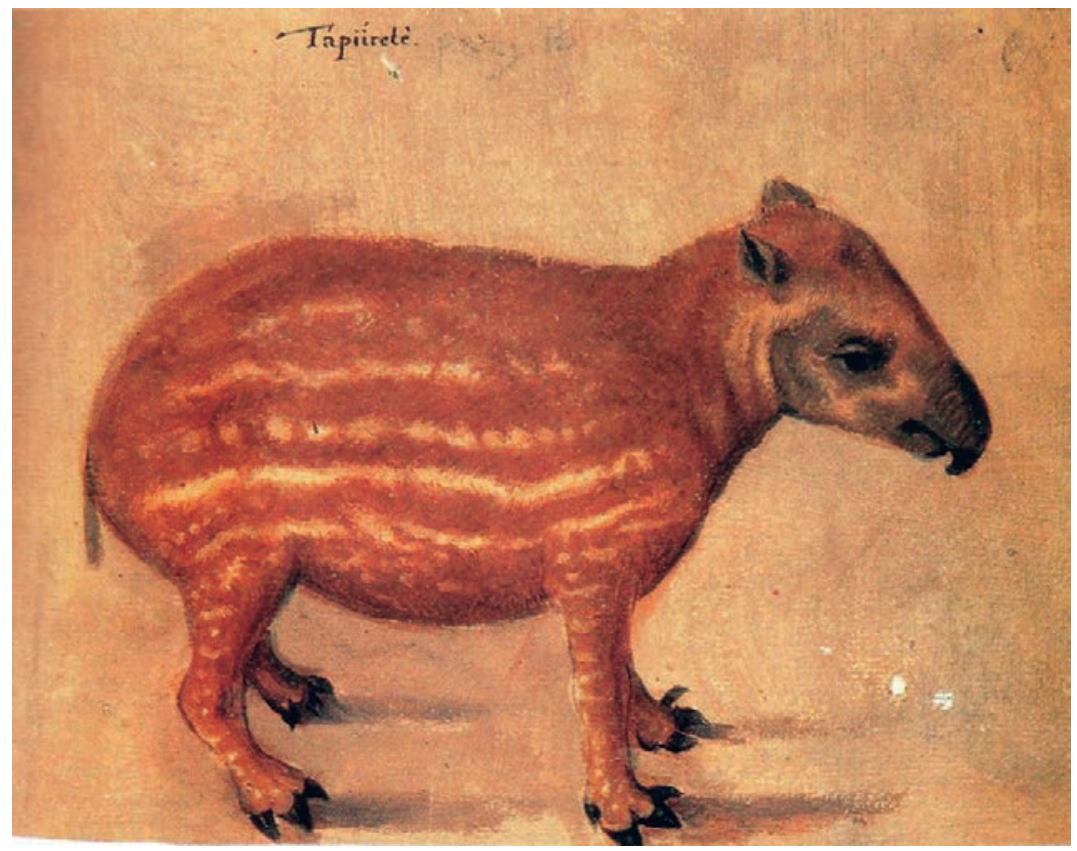

Figura 7.8. Anta jovem (Theatr., Anim. [1660] in Teixeira, 1993: 39).

Tapierete Jonstonus, 1652: 108.

Tapiroussu [Erro por tapiroussou de Léry] Jonstonus, 1652: 212.

Tapiyre-ete Montanus, 1671: 396 ("De tapiyre-ete verscheelen weinig van wilde koeyen, alleen dat langer ooren, korter beenen en staert en scherper tanden hebben; doch geen hoornen. Men vind in haer koppen bezoar").

Tapyi Restivo [1722] 1893: 318 (sob gran bestia, anta).

Tapyira Frei João de Arronches [1739] in Ayrosa, 1935: 51 (sob anta), 1937: 99 (sob anta).

Tapiýra Frei João de Arronches, 1739: 6 (sob anta).

Tapiïra Anôn., ${ }^{2}$ [Século XVIII] (2): fól. 17v, coluna 1 (sob boi sylvestre).

Tapir Brisson, 1756: 119.

Tapirierete [Erro por tapiierete de Marcgrave, 1648: 229]. Linnaeus, 1758: 74 (sob Hippopotamus terrestris).

Tapiïra Prévost, 1758: 441, 1773: 414.

Tapiirete Pennant, 1771: 82, 1793: 163.

Tapyrete Leiste, 1780: 149.

Tapirete Zimmermann, 1780: 154; Donndorff, 1793: 169; Chermont de Miranda (1906), 1968: 85.; Teschauer, 1912 : 124 ("tapir pequeno"[sic]); Freire (L.), 1954: 4841; Tierno, 1954: 719; Rocque, 1968: 1643.

Tapì Clavigero, 1781: 155.

Tapiìra Clavigero, 1781: 155.

Tapii Ray (P.A.F.), [1788] 1804: 586.

Tapí-reté Ferreira (A.R.), 1790, 1972: 190; Bueno, 1998: 335.

Tapiier-eté Azara, 1802: 7.

Tapiruzú Azara, 1802: 7.

Tapiro Casti, 1802a: 230, 1802b: 254, 1802c: 21.

Tapirassou Ashe, 1812: 72.

Tapiiára Lara e Ordonhes, 1812: 173.

Tapijirete Henderson, 1821:501 ("The ANTA, which the Aborigines call Tapira, and Tapijerete, is the largest of the Brazilian quadrupeds, and does not belong to any known species, constituting of itself a distinct one in the history of animals. It is the size of a small heifer, and very similar to a hog in the figure of its body as well as in the shape of the ears, which are proportioned to its size. The hair is short and sleek; the legs are very thick and short; the hind feet have three hoofs and the front feet four; the tail is of a tapering form, with little more than three inches in length; the head is large and long; the eyes small; the upper lip is a musculous appendage, which the animal extends four inches beyond the lower one, or draws it in to the same length; the mouth is furnished with eight pointed teeth in each jaw, ten grinders in the lower, and fourteen in the upper. It pastures like a horse; and, although heavy, has considerable velocity iu its career. It is timid and harmless, doing no injury even to the dog which pursues it. Being amphibious, it swims and dives in an extraordinary manner, and proceeds along the bottom of deep pools for a great distance, remaining for a long time under water without respiring. Its flesh differs from that of the ox only in taste and smell, and is eaten generally. It is of all colours").

Tapiirété Wied-Neuwied, 1826: 549 (Tapirus americanus). 
Tapirosú Costa e Silva (J.M. da), 1844: 197.

Tapiroussú Costa \& Silva (J.M. da), 1844b: 302.

Tapyr Gonçalves Dias, 1851: 49.

Tapüra Wallace, 1853, 1972: 334.

Tapiereté Burmeister, 1854: 331 (Tapirus suillius).

Tapy'ra Gonçalves Dias, 1858: 65.

Tapyra Martius, 1860: 531, 1863: 479 (sob tapira), 479 ("Tapyra, Tapira - in genere animal mammale et in species Tapirus et Taurus").

Tapirussú Baril, 1862: 118.

Tapirassu Liais, 1872: 397 ("il paraît dériver de tapy, épais, profond, et provient sans nul doute de l'épaisseur de leur cuir").

Tapyra-assu Liais, 1872: 397.

Tapiieretê Amorim (F.G. de), 1873: 119.

Tapiyra Amorim (F.G. de), 1874: 141.

Tapiiruçu Nogueira (B.C. de A.), 1880: 482 ("Tapiiruçu anta grande, vacca, boi, gado bovino").

Tapiera Barbosa-Rodrigues, 1881: 44.

Tapyreté Barbosa-Rodrigues, 1881: 44, 1882: 124.

Tapiy Barbosa-Rodrigues, 1881: 45, 1882: 125 ("O nome indigena que tem este animal não é tapiyra, mas sim tapiy, que vem de taba aldeia e piy o que frequenta, isto é: o que facilmente de domestica e mora na aldeia. Póde ter outra etymologia que não deixa de ter algum fundamento, póde derivar-se de tapy grosso, e pira corpo, que por euphonia fazem synalepha no $p$, accentuam fortenente o $i$ e pronuciam tapiyra. Este nome, depois da introducção do gado no Brazil, estendeu-se tambem ao boi, e para differença um animal do outro, ajuntam a palavra eté, verdadeiro e assim denominam á anta tapiyreté e ao boi tapiyra").

Tapyira-eté Barbosa-Rodrigues, 1881: 46.

Tapyre-eté Barbosa-Rodrigues, 1881: 46, 1882: 126.

Tapiyreté Barbosa-Rodrigues, 1882: 125.

Tapikira Luccock, 1881: 6.

Tapikra [sic] Luccock, 1881: 2, 6.

Tapiir Smith (H.H.), 1884: 582.

Tapii-r-a Adam, 1896: 133.

Tapirête Chermont de Miranda, 1906: 97.

Tapiretê Ihering (R. von), 1938: 243, 1940: 770; Sampaio (A.J. de), 1944: 319; Cunha (A.G. da), 1978 : 282 (“< T. tapiiire'te < tapi'ira 'tapir' + e'te 'verdadeiro"); Ferreira (A.B. de H.), 1999: 1926.

Tapirêtê Matta, 1938: 304.

Tapyretê Garcia (R.), in Cardim, 1980: 61 ("Tapyretê, ou anta, ungulado perissodáctilo da família dos tapirídeos (Tapirus americanus, Briss.), o maior animal terrestre da nossa fauna. Tapiireté em Piso e Marcgrav. O nome tupi é suscetível de várias explicações, mas nenhuma satisfatória; o sufixo etê, verdadeiro, legítimo, serviu para diferençar o ungulado do bovino, que os Tupi só conheceram depois do contato europeu, e ao qual chamaram tapyra").

\subsection{Nomes compostos}

\section{Tapir-americano}

Tapir americano Amorim (F.G. de), 1873: 119.

Tapirapoã

Tapirapoã Bueno, 1998: 335 ("a anta adulta, corpulenta").

Tapir-caiuara

Tapiéra-caiuara Gonçalves Dias, 1854: 555 (sob anta).

Tapiira-caiwara Tastevin, 1923: 737 ("Tapiira-caiwara - Anta brava, para differencial-a do boi").

Tapira-caaiuara Couto de Magalhães, 1939: 301 ("Os tupis chamavam a anta de tapira-caaiuara, ou tapira-caapora, o que significa boi do mato").

Tapira-caaiúra Rocque, 1968: 1643.

Tapiyra-cauara Barbosa-Rodrigues, 1881: 45, 1882: 125 ("Mais commumente, porém, a anta é denominada tapiyra-cauara, que significa, o boi mateiro ou natural do matto, de caá, matto e uara que é uma dicção que denota naturalidade, habitação, etc.").

Tapyra-caiuara Pennafort, 1901: 234.

Tapyra-caiura Pennafort, 1901: 134, nota (6).

Kaiwara Grenand \& Ferreira, 1989: 65 (L.G.).

Tapira-uborim

Tapira-uborim Silva (H.), [1913]: 115.

Tapir-caapora 
Tapiira-caapoara Goeldi, 1893: 99.

Tapiî́ra-cäápóra Eckart, [Séc. XVIII]': 37 (sob boy silvestre).

Tapi'ira-ka'apura Grenand \& Ferreira, 1989: 159 (L.G. Tapirus terrestris; "tapi'ira = boi/ ka'á = mata/ pura = morador").

Tapira-caapora Prazeres, [1819-1820] 1891: 267.

Tapira-caapóra Silva (H.), [1913]: 115.

Tapiryra-caapóra Silva (H.), [1913]: 115.

Tapyira-caapoara Martius, 1860: 531, 1863: 479 (sob taperuçú).

Tapyîra-caápoára Anôn., 1795: 12 (sob anta).

Tapyirá-caapóra Stradelli, 1926: 665 ("Tapyirá-caapóra - Anta do matto, que mora no matto. Usado quando há necessidade de distingui-la do boi").

Tapyíra-caapóra Anôn., 1750 (sob anta, animal); Martius, 1863: 88 ("tapyíra caapora - wörtlich: Ochs im Walde, anta, Tapirus americanus").

Tapyira-cäó-pora França, 1859: 15 (sob anta).

Tapyira-capora Anôn., 1771: fól. 21r (sob anta).

Tapyra-caapora Martius, 1860: 531, 1863: 479 ("Tapyra-caapora i.e., animal silvestre Tapirus americanus (suillus)").

Tapy'ra-caapóra Gonçalves Dias, 1858: 65.

Tapyra-sabetyra Wappaeus, 1884: 302.

\subsection{Outras denominações do tapir}

\section{Assobio}

Assobio Boiteux, 1957: 106 ("variedade de anta").

Boi-silvestre

Boy-sylvestre Eckart, [Séc. XVIII]: 37 ("Boy silvestre: Tapiîra cä/ápóra”).

\section{Capoava}

Capoava Taunay, 1914a: 54 ("Nome que em certas regiões do Brazil central dão á anta (Tapirus americanus)").

Cauara-tapyira Barbosa-Rodrigues, 1881: 46.

Icuré

Icuré Anôn., 1750: 256 (sob anta, animal).

Öaçurê Marcos Antonio (Pe.), 1757: fól. 9r (sob antâ).

Icurê Gonçalves Dias, 1858: 32 ("Icurê, anta, animal").

Acuré Magalhães (A.C. de), 1898: ii-iii; Taunay, 1914a: 18; Freire (L.), 1954: 213; Ferreira (A.B. de H.), 1999: 47; Houaiss et al., 2001: 76 ("Do tupi ou língua geral, prov. regressivo de antacuré, com depreensão de anta (arabismo); acuré, meio obscuro, parece ser'verdadeiro"').

Açurê [sic]. França, 1859: 15 (sob anta).

Içuré [sic] Liais, 1872: 397.

Acuré Magalhães (A.C. de), 1898: ii-iii.

Iguré [sic] Sampaio (T.), 1914: 224 (sob icuré).

Acuraua [sic] Anôn., 1961.

Curé [F. red. de antacuré]. Tastevin, 1923: 709 ("Curé - variedade de anta").

Mborebi [Guarani].

Mbore [Mbyá-guarani]. Dooley, 1998: Ixxi.

Mborebi Restivo [1722] 1893: 318 (sob gran bestia, anta); Dobrizhoffer, 1784: 294; Azara, 1802: 1, 1809: 246; (F. Cuvier) in Plusieurs Professeurs du Jardin du Roi, 1823: 374; Fischer (J.B.), 1829: 409, 733 (Tapirus americanus); Burmeister, 1854: 331 (Tapirus suillius); Martius, 1860: 506 (sob icuré), 531 (sob taperuçú), 1863: 453 (sob icuré), 478 (sob taperuçú); Nogueira (B.C. de A.), 1880: 255 ("mborebi um dos nomes dados á anta, cuja explicação é difficil"); Castro, 1936: 69; Hershkovitz, 1987: 59 (mamíferos citados por Azara).

Mborebí Montoya, 1639: 216r (1876: 216r) ("Mborebí. Anta"); Restivo [1722] 1893: 80 (sob anta), 130 (sob anta), 318 (sob gran bestia, anta); Azara, 1802: 1; Obelar, 191?: 9.

Mbórebi Montoya, 1640(1): 168 (sob anta).

Mborepi Matta, 1938: 52 (sob anta).

Mborevi Burton, 1870(2003): 394; Goeldi, 1893: 99; Guasch, 1961: 605 ("Mborevi: tapir, anta"); Tibiriçá, 1989: 109; Assis (C.F. de), 2000: 91; Trinidad Sanabria, 2007: 157, 651 (sob tapir) (Avañe'ê).

Mboreví Vera, 1903: 42; Bertoni (A. de W.), 1914: 70 (Tapirus terrestris); Dennler, 1939: 231; Simpson, 1941: 16; Gatti, 1985: 197; Sampaio (M.A.), 1986: 30, 217.

Mboreví-hovíh Dennler, 1939: 231 (Tapirus terrestris var. obscura).

Mboreví-jovî Gatti, 1985: 197 ("nombre que se aplica a los ejemplares más obscuros de mborevi").

Vaca-do-mato

Uaca-do-mato Valle (L. do), [1585], in Ayrosa, 1938: 420; in Drumond, 1952(II): 140 ("Uaca-do-mato - uide Anta"). 


\title{
8. A ANTA OU DANTE DA ÁFRICA E A ANTA (ANTE, DANTA, DANTE) SUL-AMERICANA
}

\author{
Roulin (1835: 610-613):
}

"Les mots de Danta et Anta, auxquels il faut joindre celui d'Ante, existaient dans les langues espagnole et portugaise à une époque où l'existence de l'Amérique n'était pas même soupçonnée. Ils s'employaient indifféremment tous les trois en parlant de divers animaux, tels que le buffle, l'élan et d'autres grands ruminans de la côte d'Afrique dont on ne connaissait que les dépouilles qui étaient fournies par le commerce avec la côte de Guinée. Chacun de ces noms s'appliquait à tous ces quadrupèdes indistinctement, soit qu'on les trouvât dans les pays tempérés, soit qu'ils vécussent dans les régions voisines du tropique ou dans celles qui touchent le cercle polaire; mais il ne leur était donné que lorsqu'on le considérait sous un certain point de vue, c'est-à-dire comme fournissant des cuirs épais que l'art du chamoiseur transformait en buffle ou, comme disaient les Espagnols, en Ante. L'art de donner aux grosses peaux la souplesse nécessaire pour les usages de la buffleterie ne fut long-temps pratiqué que dans les pays du Nord. En Suède, en Norwège et dans certaines parties de la Pologne, on préparait de cette manière des peaux d'élan qui se répandaient ensuite dans tout le reste de l'Europe, où elles se vendaient fort cher. On disait alors de l'élan, comme on a dit plus tard du buffle, lorsque les Italiens, s'étant approprié ce genre d'industrie, y employèrent comme matière première la peau de buffle. Au quinzième siècle, la Péninsule tirait encore ce produit du nord et le recevait par l'intermédiaire des Flamands, qui le nommaient dans leur langue Eelendt, Elandt et Elant. Les Espagnols, prenant la première syllabe du mot pour un article, dirent: El Ant, et, en mettant à la fin une voyelle, conformément au génie de la langue, el ante. Le féminin Anta devint quelquefois Danta par l'adhésion du signe du génitif. Comme le mot flamand s'écrivait aussi avec le double l, on en eût pu faire el lent ou el lant, cependant je n'ai jamais vu cette forme employée par les auteurs espagnols. A l'époque de la conquête du Nouveau-Monde, une partie nécessaire de l'équipement d'un homme de guerre était la cuera ou coleto de ante, ce qu'en français on nommait collet de buffle, bien que ce fût un pourpoint complet, et que par abréviation on nommait encore plus souvent un buffle. Quand les Espagnols pénétrèrent dans l'intérieur de l'Amérique du sud, en s'écartant du rivage de l'Atlantique, ils n'y trouvèrent plus des peuples doux et inoffensifs comme les insulaires de Guanahani, mais des hordes vaillantes exercées à la guerre, et dont quelques-unes connaissaient jusqu'à l'art des fortifications. Dans plusieurs de ces tribus les guerriers faisaient usage d'armes défensives. Ils employaient le cuir du Tapir, au Brésil, pour faire des boucliers comme on en avait déjà vu parmi les nègres du Sénégal et au Paraguay, pour faire des heaumes; enfin dans certaines provinces de la Nouvelle-Grenade ils fabriquaient avec cette peau une sorte de dalmatique à l'épreuve des flèches et des javelots; c'était là leur buffle, et il fut naturel de donner à l'animal dont la peau était ainsi employée, le nom d'Ante ou Danta".

\subsection{A anta ou dante da África}

8.1.1. Gomes Eanes de Zurara, 1453. Sua Chronica do descobrimento e conquista de Guiné, escrita por mandado de El Rey D. Affonso V só foi publicada pelo Visconde da Carreira (1841), baseado no manuscrito original da então Biblioteca Real de Paris. À página 370 dessa edição lê-se:

"E diz que teem cativos Negros, e os honrados abasto douro, que trazem daquella terra donde os Negros vivem; e que ha naquella terra muytas emas, e antas, e gazellas, e muytas perdizes, e muytas lebres; e que das andorinhas que de ca partem no veraão, que ally vaão invernar sobre aquel las areas, creo que seja por razom da queentura; e assy vaão la outros passaros pequenos; mas que as cegonhas passam aa terra dos Negros, onde manteem o inverno".

Talvez seja a mais antiga referência ao nome anta na língua portuguesa, conferido aos órixes africanos.

8.1.2. Anônimo, in Valentim Fernandes, 1507. Incluído no códice Valentim Fernandes ${ }^{18}$, há um relato anônimo intitulado Cepta e sua costa (Ceuta e sua costa); como assinalado por Mucig (2014: 96): "Descrive la costa africana, non limitandosi

18 Uma personagem que se destacou na disseminação internacional de notícias sobre os Descobrimentos Portugueses foi Valentim Fernandes, oriundo da Morávia, que viveu em Portugal a partir dos anos 90 do século XV até à sua morte, ocorrida ou em 1518 ou no ano seguinte. Valentim Fernandes não se notabilizou apenas pelas suas obras tipográficas, mas também pela colecção de escritos e notícias acerca das viagens dos Descobrimentos e pela sua transmissão a eruditos e mercadores situados em Nuremberga e Augsburgo no Sul do Sacro Império Romano-Germânico. Aí, Conrad Peutinger foi um dos principais receptores das novas. 0 afamado humanista e conselheiro de Maximiliano I possuía uma colectânea notável de documentos referentes à Expansão Portuguesa, da qual fazia parte 0 denominado "Manuscrito Valentim Fernandes". Trata-se de um volume que inclui vários textos; foi encontrado, em meados do século XIX, em Munique (Bayerische Staatsbibliothek, Codex hispanicus, 27). Esta preciosa colecção, composta pelo famoso impressor, provavelmente no segundo quinquénio do século XVI, contém documentos redigidos em latim e em português. Os escritos - parcialmente textos fragmentários - não estão organizados por ordem cronológica o que dificultou uma classificação exata das fontes. Os documentos podenm ser divididos em dois blocos temáticos relacionados com aspectos geográficos das navegações portuguesas, ou seja, numa série "africana" e outra "oriental".

Em conformidade com este esquema, a série oriental inclui: 
però alla costa mediterranea di Ceuta, come suggerisce ingannevolmente il titolo, ma continuando la descrizione anche della costa occidentale d'Africa fino all'attuale regione della Sierra Leone".

Há duas citações da anta (órix).

Na primeira, à página $66 \mathrm{v} / 23 \mathrm{v}$ do manuscrito [Figura 8.1, segundo parágrafo] consta:

"As mercaderias q' trazẽ os mouros da t'ra firme/ som escrauos p'tos de guynee/ ouro pelles dantas/ goma arauiga/ gatas dalgalia ouos demas...."

E logo abaixo repete "pelle data [sic]".

A segunda, à página 89/36r do manuscrito [Figura 8.2, segundo parágrafo], é a seguinte:

"A carne danta hã na por melhor carne de todas outras animalias /ca toda he çumorenta e de sabor de lombo de vaca/ As antas som tammanhas como hũu bezerro de dous annos /E andam em manadas como vacas $E$ ho seu correr he maior que de hũu veado/ berra como boy e tem pees e cabeça como boy / saluo que tem cornos dalgados e muy compridos de mea braça e dentro cheo de noos em alto hũu pouco pera torto e muy agudos A coor de antas som como de asnos aluaçã/ da pelle de anta fazem as melhores adargas do mundo que nenhũa lança nom passa".

Pela descrição dada do animal, parece ser realmente o Oryx dammah do norte da África.

8.1.3. Em 1589 Duarte Lopes ${ }^{19}$, que morava há doze anos no Congo, chegou a Roma como embaixador do rei congolês Dom Álvaro II junto ao papa Sixto V e relatou tudo o que sabia sobre o Congo para o italiano Filippo Pigafetta (1533-1604), que em 1591 publicou a obra Relatione del Reame di Congo et delle circonvicine contrade. Deve-se a Duarte Lopes o emprego da palavra danta para um artiodáctilo africano. Entretanto, segundo se lê em Pigafetta \& Lopes (1591), certamente não se aplicava ao Oryx dammah e também designava o alce na Alemanha (!). Os textos dessa obra são os seguintes:

\section{P. 14 (Cap. V. Del lato della Tramontana del Regno del Congo \& de suoi confini):}

"Il Re di Loango ${ }^{20}$ è amico del Re di Congo, \& è fama che gia tempo fu di lui vasallo, \& i popoli si circoncidono all'vsanza degl'Ebrei si come han' per costume di fare tutti li gentili di quelle contrade, \& communicano insieme, \& guerreggiano alcuna fiata con li vicini, \& in tutto sono della natura stessa con quelli di Congo. Le armi loro sono targhe lunghe, che gli cuoprono la persona quase tutta, composte di pelle dure, \& grosse di certo animale chiamato Empachas, minore de vn bue, con le corna à guisa di capro, il qual animale nasce anco in Lamagna ${ }^{21}$, \& nominasi Dante, \& di quei paesi, \& di Congo si conducono le pelli in Portugallo, \& d'indi in Flãdra, oue si acconciano, \& fansi li colletti da corsaletto, \& corazza, che chiamano di Dante"22

— o relato do alemão Hans Mayr sobre a expedição à Índia em 1505/06, relato este provavelmente ditado por Fernão Soares, capitão da nau em que Mayr fez a viagem ("Da viagem de dom francisco dalmeida primeyro visorey de India. E este quaderno foy trelladado da nao sam raffael em q hia hansz mayr por escriuam da feytoria. E capitam fernam suarez. Viagem e cousas de dom francisco viso rey de India escrito na nao sam raffael do porto, capitam fernam suarez");

— uma descrição de um autor anônimo acerca da "India" e"Das ylhas de Dyue [= Maldivas]".

A série africana contém:

- uma descrição da costa africana, de Ceuta à Serra Leoa, elaborada com base nos testemunhos de navegadores portugueses ("Çepta cidade em ho estreito herculeo em frõnte de Gybraltar");

— uma relação histórico-geográfica de diversos arquipélagos e ilhas atlânticas (Canárias, Madeira e Porto Santo, Açores, Cabo Verde, São Tomé e Ano Bom) com mapas desenhados pelo próprio Valentim Fernandes ("Das Ylhas do mar oceano");

- um sumário da Crónica de Gomes Eanes de Zurara ("Cronica da Guiné");

- o relato do navegador Diogo Gomes de Sintra sobre o descobrimento da Guiné, também designado por "Relato Behaim-Gomes" ("De prima inuentione Guinee");

- um roteiro para a navegação da Galiza a São Jorge da Mina ("Este liuro he de rotear...").

Não se sabe ao certo quando os documentos do "Manuscrito Valentim Fernandes" chegaram às mãos de Conrad Peutinger. Supõe-se que os textos desta colecção foram enviados, de forma solta, ao humanista alemão que os deixou encadernar. No início dos anos 40 de Quinhentos, Damião de Góis viu o valioso volume na biblioteca de Peutinger, afirmando que este o cuidava como um tesouro, não o querendo emprestar a ninguém, apesar de não entender a língua portuguesa.

0 códice pertencente a Peutinger, como já dito, foi descoberto na Bayerische Staatsbibliothek de München (Codex monacensis hispanicus no. 27) e descrito (em alemão) por Schmeller (1847). Edições na língua portuguesa foram feitas por Baião (1940) e Costa (1997).

19 Duarte Lopes (natural da Vila de Benavente do Arcebispado de Évora, segundo Machado (1741: 733)) foi um comerciante português que deixou Portugal para ir ao Congo em abril de 1578, a bordo do navio mercante $S$. Antônio, pertencente a seu tio. Após uma estada de vários anos, tendo acumulado alguma riqueza, foi nomeado pelo rei do Congo, D. Álvaro II, convertido ao catolicismo, como embaixador junto ao Papa e a Filipe II (nessa época rei da Espanha e Portugal). Essa missão havia sido antes confiada a um certo Sebastião da Costa, que fora enviado ao Congo em 1580 para anunciar a ascenção de Filipe Il e obter do D. Álvaro a permissão para explorar umas pretensas minas de prata; Costa embarcou para Portugal levando uma carta de D. Álvaro, mas morreu durante a viagem. Duarte Lopes foi então nomeado em seu lugar. Como embaixador junto a Felipe II, Duarte Lopes deveria oferecer espécimes de minerais locais e abrir a região para o livre comércio com Portugal e Espanha, além de informar ao Papa da necessidade de enviar para aquele país africano mais missionários. Duarte Lopes regressou ao Congo em 1589 e depois disso nada mais se soube dele.

200 Reino de Loango (Nsi ya Luangu, na língua quicongo) foi um estado pré-colonial africano, entre os séculos XV e XIX, situado no que é hoje a República do Congo. No seu auge no século XVII o reino expandiu-se de Mayombe, no norte, até Cabinda, em Angola, quase à foz do rio Congo.

21 Lamagna = Alemanha. Provável referência ao alce.

22 Na tradução inglesa: "The king of Loango is at amity with the King of Congo, but it is said was formerly his vassal. The people use the rite of circumcision like the Hebrews, as is the custom of all heathen in those countries. They are friendly amongst themselves, but fight with the neighbouring tribes at times, resembling the people of Congo in every particular. Their weapons are long shields, which 


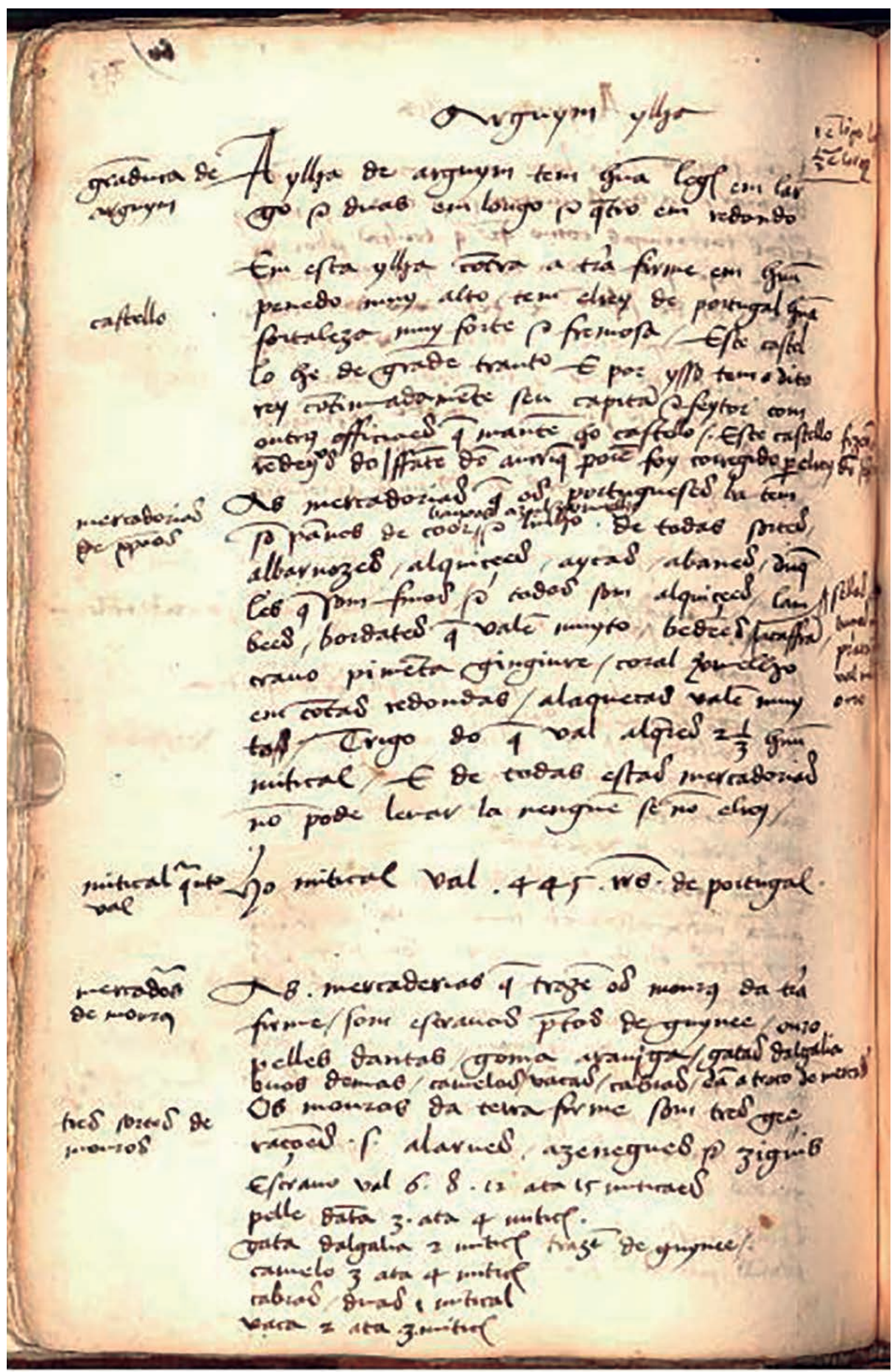

Figura 8.1. Página 66v/23v do MS Valentim Fernandes (Bayerische Staatabibliothek, München, Cod. hisp. 27). No último parágrado o texto sobre a anta (órix).). 


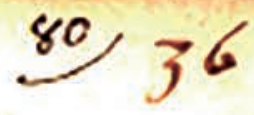

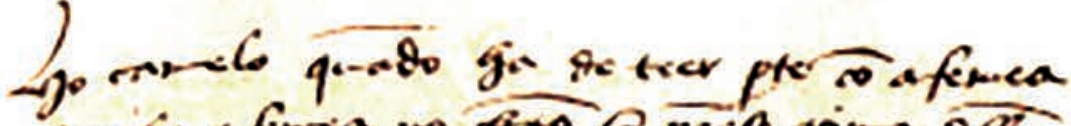

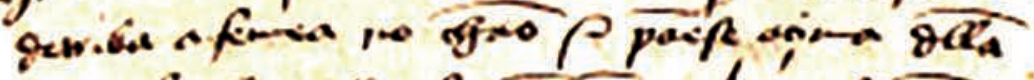

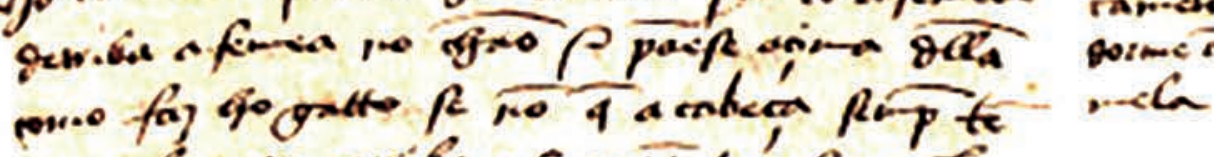

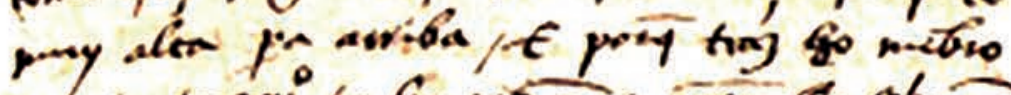

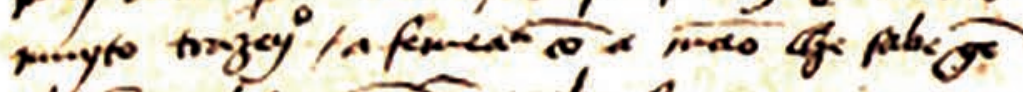

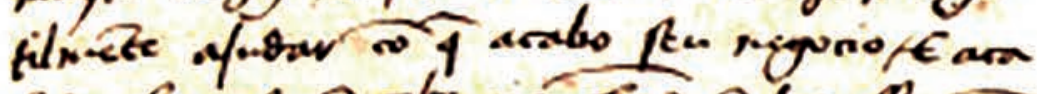

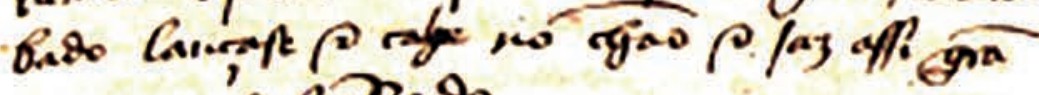

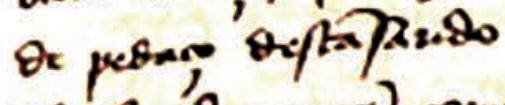

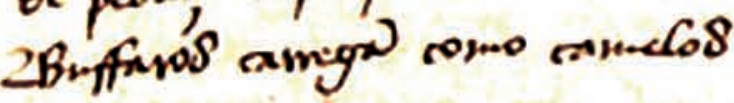

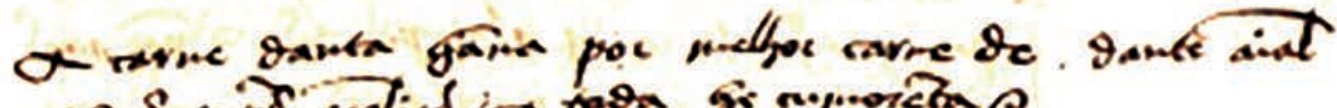

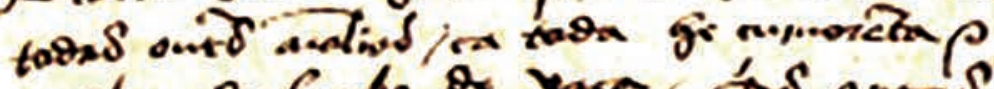

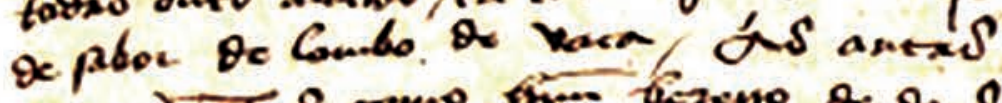

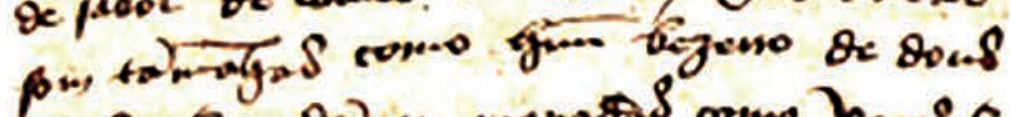

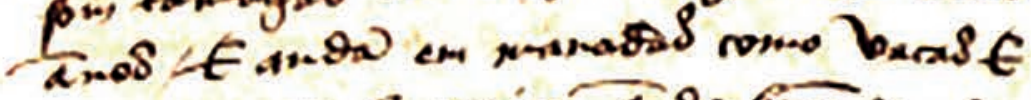

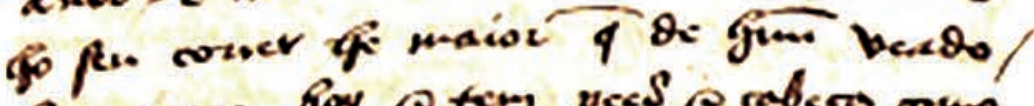

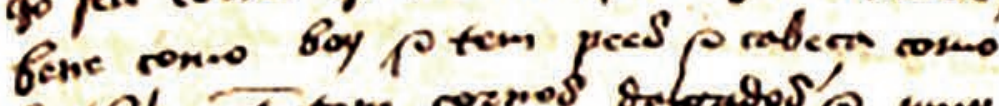

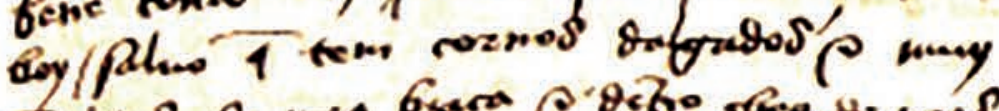

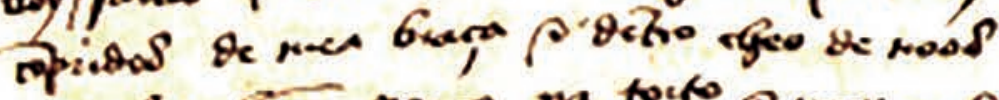

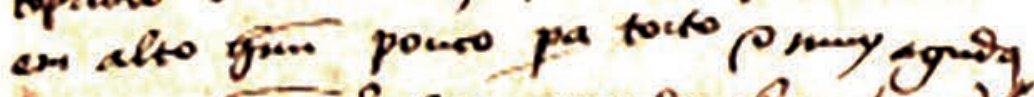

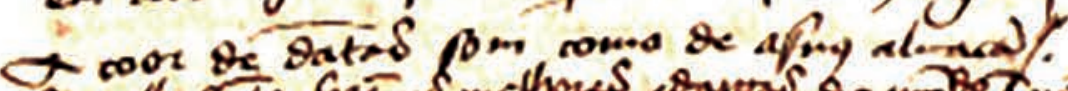

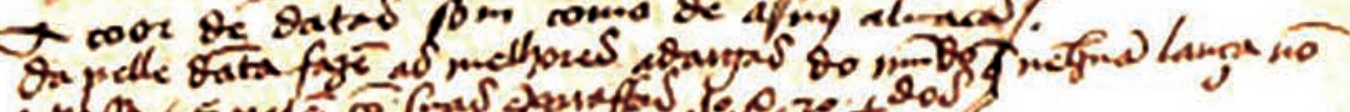

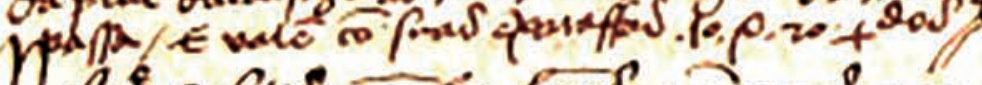
Theptes ocptos mo ga lyoes in onges nem

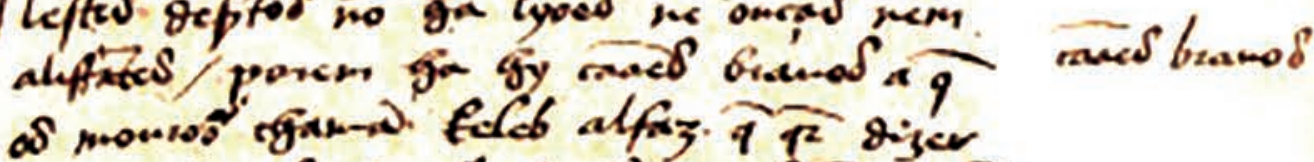

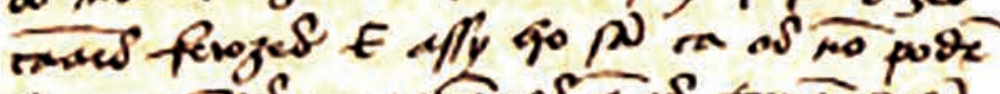

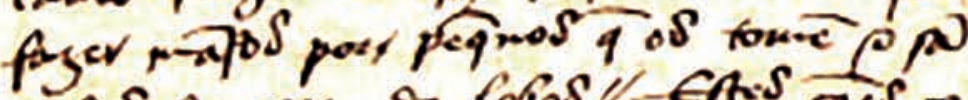

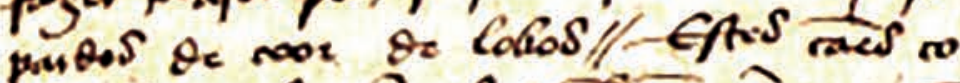

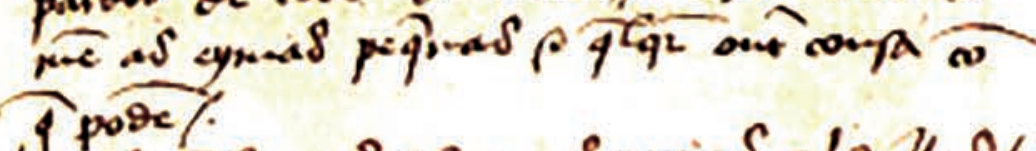

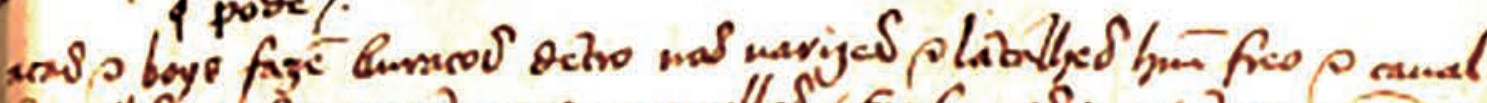

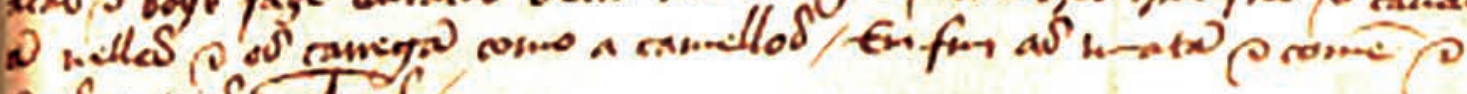
ons ontais rastods 


\section{P. 38 (Cap. XIII. Animali della contrada di Pamba):}

"Altre bestie si trouan da 4. piedi alquanto minori del bue, rosse con le corna à guisa d'vn caprone, liscie, \& splendenti in nero di cui fanno lauori diuersi, come di quelle de' bufali. Hanno le capi, \& li crini come buoi, \& le pelli loro sono molto pregiate, peroche si portano in Portogallo, \& d'indi in Lamagna per accõciarsi \& l'appellano Dãte. Desidererebbe il Re di Cõgo d'hauer huomini che le sapessero purgare, \& ridurle in vso à fine di farne armi da difesa vsandole non dimeno quelle nationi per scudi, \& targhe resistendo esse à colpi dell'armi, \& massimamente alle tratte delle saette.

Gli amazzano con gl'archibugi, \& con le saete, ma se del cacciatore si auedono, l'assaltano, \& essendo feroci, \& animose lo pistano, \& rompono col piedi, \& col muso, non potendo far danno loro con le corna, lasciandolo mezzo morto, ouero affato vcciso"23.

Na edição latina (Pigafetta \& Lopes, 1598: 11, 22) [Figura 8.3] consta:

"Reges eius, qui olim vasalli Regis Congiani videntur fuisse, Regis se amicos nominant. Incolae, vt \& caeteri ferè omnes huius plagae habitatores, ludaerorum more circumciduntur; caeterum tam bello quam pace, vt \& statura, colore \& complexione Congianis símiles. Armatura est magnus clypeus, qui totum fere tegit hominem, quem è magnis durisque coriis animalium Empachas dictorum, Germaniae Bubulis haud absimilium ${ }^{24}$, consuunt".

"Est \& aliud animal quadrupes, Dante dictum, boue paulo minus, forma tamen \& capitis \& reliqui corporis non multum absimili, colore subrufo, cornua caprina habens in capite, polita tamen \& nigra, ex quibus vt \& ex bubalorum varia conficiuntur instrumenta. Pellis ad multa vtilis, vnde in Lusitaniam, \& inde in Germaniam defertur, et vt bubalorum, ceruorum, aliorumque animalium ad vsus humanos, praecipuè ad conficiendas vestes durabiles praeparatur. Haberet quidem rex Congi libenter qui eas praeparandi nosset artificium, sed cum voti non possit fieri compos, crudis vtuntur incolae, parmas \& scuta sua contra telorum vim, iis contegentes. Ferum admodum est animal, \& venatorem suum, nisi dexterrimus \& celerrimus sit, facile pessundat, absque vllo enim timore visum insequitur, \& si adipiscitur, cum cornubus nocere non possit, ore dilacerat, \& pedibus vsque ad mortem concultat. Arcu tamen \& sagittis, aut nun sclopeto occiditur".

\subsection{A anta (ante, danta, dante) da região neotropical}

Antonio Pigafetta (Antonio Lombardo) (Vicenza, 1491 - Vicenza, 1534) foi um marinheiro, geógrafo e escritor italiano. Pagou de seu próprio bolso uma expressiva quantia para acompanhar e auxiliar o capitão português a serviço da Espanha, Fernão de Magalhães em sua viagem ao redor do mundo. Pigafetta chegou à costa brasileira, entre os Cabos de S. Roque e S. Agostinho em fins de novembro de 1519 e na Baía de Guanabara a 13 de dezembro desse ano, deixando-o aos 27 do mesmo mês. Manteve um registro acurado da viagem, o qual mais tarde lhe foi valioso na tradução de uma das línguas filipinas, o Cebuano, sendo considerado o primeiro documento a registrar esta linguagem. Dos duzentos e sessenta homens que partiram na expedição em 1519. Durante o confronto em que Magalhães foi morto em Mactan, nas Filipinas, Pigafetta foi um dos feridos. Entretanto, conseguiu se recuperar e encontrava-se entre os dezoito sobreviventes, a bordo do Victoria, que retornaram à Espanha, três anos após a partida. Tendo aportado a Sanlúcar de Barrameda (Província de Cadiz) em setembro de 1522, Pigafetta retornou à Itália, onde relatou as suas experiências na obra Relazione del Primo Viaggio Intorno Al Mondo, composta em italiano, mas publicada pela primeira em francês ${ }^{25}$ (Anôn., ca. 1526).

almost entirely cover the body, and are made from the frough skins of a certain animal called Empachas, which is smaller than the ox, with horns like a goat, and is still found in Germany, where it is called Dant" (Pigafetta (F.), 1881: 15).

23 Na tradução inglesa:"Other animals are found in these regions standing about four feet less than oxen, with red-coloured skins, and horns like a goat, black, smooth, and glistening, of which they make pretty ornaments, such as are made also from buffalo horns. Their heads and hairs resemble those of an ox, and their skins are much prized, being taken to Portugal and from thence to Germany to be dressed, and are called Dants. The King of Congo was desirous of having workmen skilled in the art of dressing and cleansing these skins, so as to make them into weapons of defence. Nevertheless, these people use them as weapons, and especially against arrows. These animals are killed both with guns and arrows, but if they espy the hunter they attack him, and, being fierce and courageous, will injure him with their feet and muzzle, not being able to do so with their horns, and leave him almost, or indeed altogether dead" (Pigafetta (F.), 1881: 51).

\section{$\mathbb{C} \mathbb{E p}$ finit Peptraict busict fiute/ tranflate de Gtalien en firancoib.}




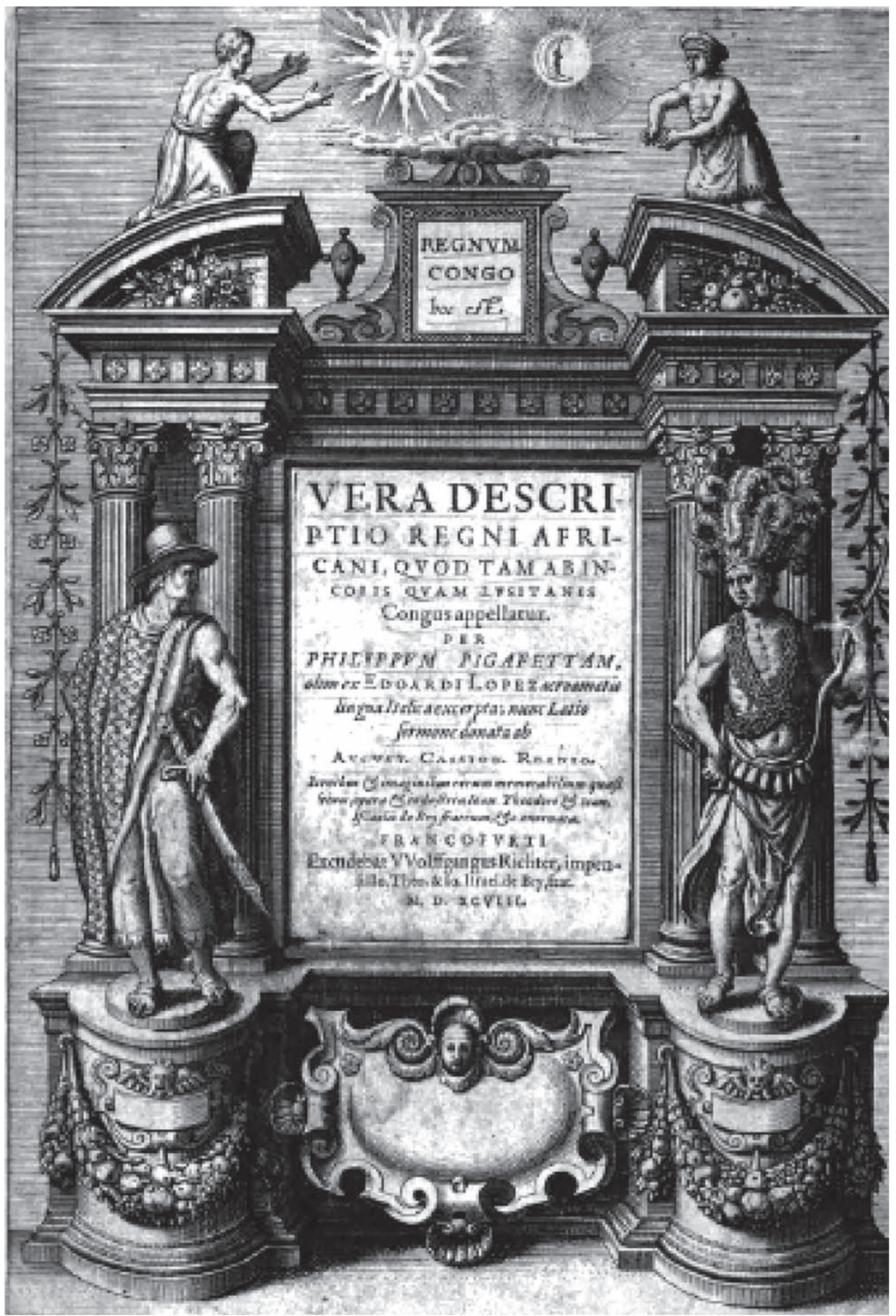

Figura 8.3. Frontispício da edição latina de De Bry (1598). 


\section{更e bopatye $\mathfrak{t} \mathfrak{n a}$} uigation/faictpar (es [E fpaignof; cs Gfredeg-arfurques.des ilfer quilj ont troille ausict bopage/ des R2ops dicelfes/oe leur gomuernentent \& inta: niere oc Dinte/ ouecplufieuto anftes çofer.

\section{toumpziutlegín,}

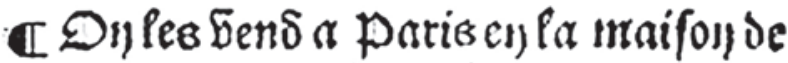

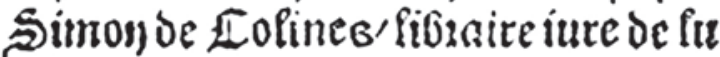 nimer fite de parioidentoutit en fa tue faiutct Gefand de Deanfuaio/a lenfria gne ou Solsil 20 \%.}

Iffap. Fi.

- 'D Bffe fa figne equmoctiate persis rent la tanfoncontaigne, ceftadice

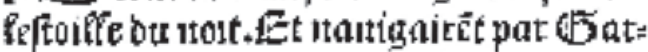

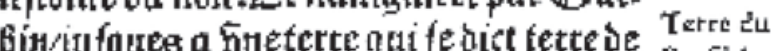

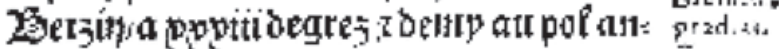

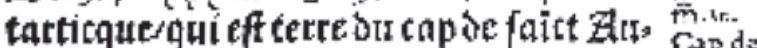

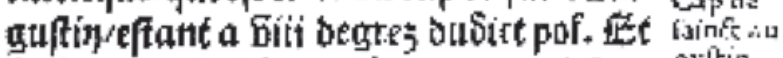
fa feate $\bar{e} t$ tefref

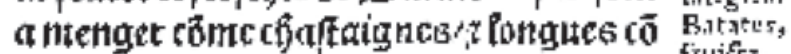

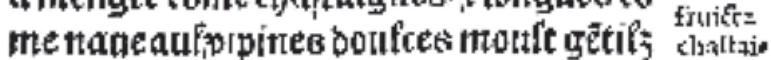

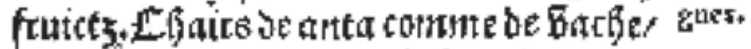
carnedoufte/et auftere chofe infinte/qute

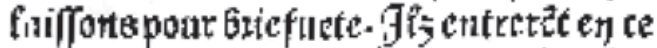

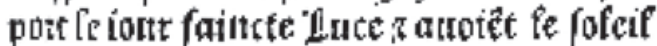

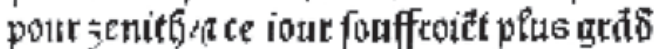

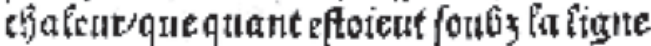
equttoctiafe.

Figura 8.5. Fólio $4 r$ da primeira edição da viagem de Antonio Pigafetta (Anôn., ca. 1526), com a citação de "Chairs de anta".

Figura 8.4. Frontispício da primeira edição da viagem de Antonio Pigafetta (Anôn., ca. 1526).

Nessa obra (Anôn. [Pigafetta], 1526) [Figuras 8.4 e 8.5] apareceu por primeira vez o nome anta, aplicado ao tapir brasileiro. Pigafetta muito provavelmente conheceu essa denominação através da tripulação espanhola de Fernão de Magalhães.

Como atestou Oviedo y Valdez, em sua De la natural hystoria de Indias [Figura 8.6] (1526: fólios XXr e XXv) [Figura 8.7], o nome danta foi dado ao animal por ter ele o couro muito grosso; mas Oviedo judiciosamente acrescentou "pero no son Dãtas"; o nome foi conferido ao animal impropriamente.

Ramusio (1550: 380r) publicou a primeira versão em italiano:

"Passata la linea dell'equinottiale si perdè la tramontana, \& nauigãmo per gherbin sino ad una terra, che si chiama terra di Bressil, xxij gradi \& mezzo uerso il Polo Antartico, la qual terra è continuata col capo di santo Agustino, il qual è otto gradi lontano dall'equinottiale. In questa terra fummo rinfrescati con molti frutti, \& tra gli altri Battates, che nel mangiar s'assomigliano al sapor delle castagne, sono lũghi come nauoni, n'hauẽmo anchora alcuni che chiamã Pines dolci, molto gẽtil frutti: mãgiãmo della carne di uno animale detto Anta [Figura 8.8], la qualè come una uacca"26. [Cf., tb., Amoretti, 1800: 16; Pigafetta, 1999: 6].

Uma provavel figura de anta, com probóscida desproporcional, foi representada no Atlante Veneto de Vincenzo Maria Coronelli (Coronelli, 1691; mapa entre as páginas 134 e 135) [Figuras 8.9 e 8.10]:

\subsection{Citações do nome "anta" (e variações) por autores dos séculos XVI a XVIII}

Daí em diante, muitos autores dos séculos XVI a XVIII passaram a empregar essa denominação:

26 Na tradução de Robertson (1906: 37): "After we had passed the equinoctial line going south, we lost the North star, and hence we sailed south south-west until ]we reached] a land called the land of Verzin [pau-brasil] which lies in 23 1 12 degrees of the Antarctic Pole [i.e., south latitude]. It is the land extending from the cape of Santo Augustino, which lies in 8 degrees of the same pole. There we got a plentiful refreshment of fowls, potatoes [batate], many sweet pine-apples - in truth the most delicious fruit that can be found - the flesh of the anta, which resembles beef, sugarcane, and innumerable other things, which I shall not mention in order not to be prolix". 


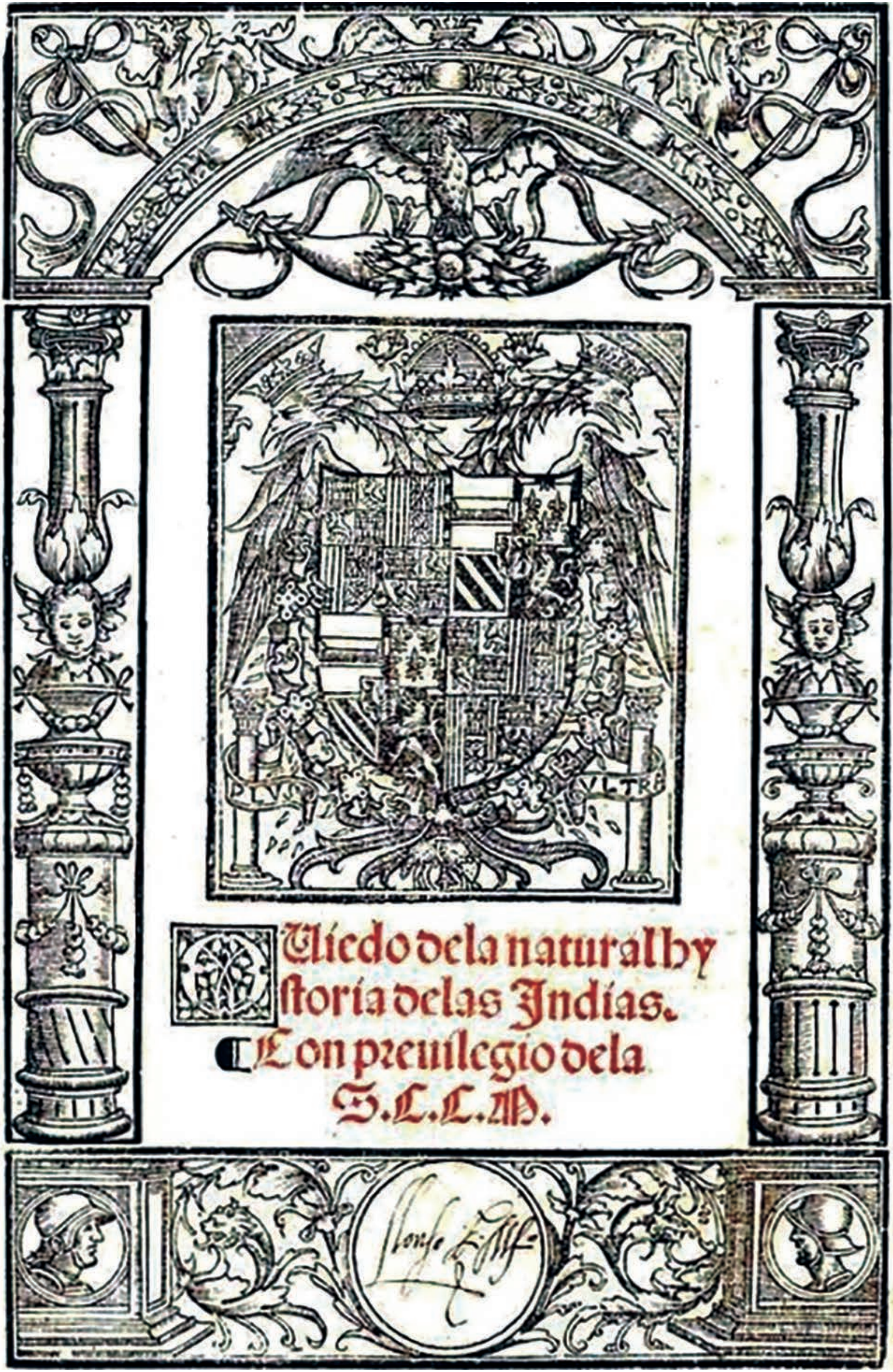

Figura 8.6. Frontispício da De la natural hystoria de las Indias de Oviedo y Valdez (1526). 
Amta Diogo Nunes, [1538] 1840: 377 ("Ay carnes montezes nesta tra. veados amtas porcos momtezes patos. E outras castas muytas").

Danta Gaspar de Carvajal, [1545] in Díaz Maderuelo, 1986: 94 (“...y fue así, que undía sobre tarde apareció que vênia Poe el rio uma danta muerta, tamaña como uma mula, y visto por el Capitán mando a ciertos compañeros que se la trujesen y tomasen uma canoa para traerla, y la trujeron y se repartió por todos los compañeros de manera que a cada uno le cupo de comer para cinco o seus días, que no fue poco sino mucho remedio para ellos. Esta danta vênia recién muerta, porque estaba caliente y no traía ninguna herida".

Anta Anchieta, [1560] 1988: 128.

Anta Gândavo, ca. 1571a: fól. 128r, linhas 760-764 (cf., Pereira Filho, 1965: 161) ("Há muitas Antas q' quase saõ tamañas como vacas sua carne tem o sabor como de vaca. A pelle deste animal he mui grossa e Rija"), ca. 1571b: fól. 26r, 1576: 20v-21r ("sam da feiçcam de mulas, mas nam tam grandes, \& tem o focinho mais delgado \& hũ beiço cõprido á maneia de trõba. As orelhas sam redondas \& o rabo nam muito delgado comprido: \& sam cinzentas pelo corpo, \& brãcas pela barriga. Estas Antas nam saem a pascer senam denoite, \& tanto q' amanhece, metemse em algũs bréjos, ou na parte mais secreta que acham, \& ali estam o dia todo, escondidas como aues noturnas, a que a luz do dia he odiosa, ate que anoitecendo, tornam outra vez a sair \& apascer por onde querem como he seu costume. A carne destes animaes, tẽ o sabor como de vaca, da qual parece que se nam diferença cousa algũa"), 1858: 357.

Anta Souza (G.S. de), [1587, ca. 94] 1971: 243.

Anta Soares (F.), 1590: fól. 1023v, linhas 330-331 (cf., Cunha, 1966: 7) ("Antas mªs saõ ao modo de mullas nadaõ também quando as seguem cõ os cães e mordem nos e arrementẽ a gente cõ os dentes"), 1591: 37, linhas $950-955$ (cf., Cunha,
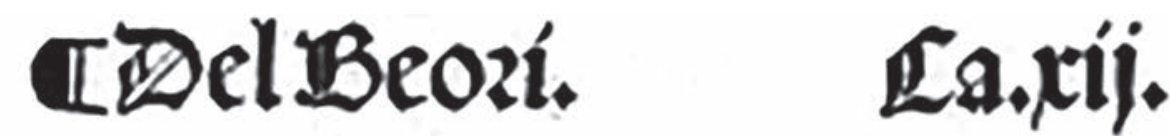

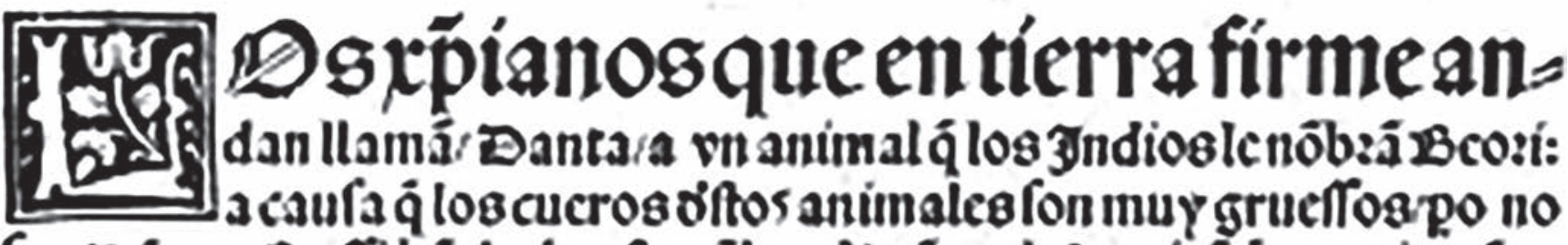

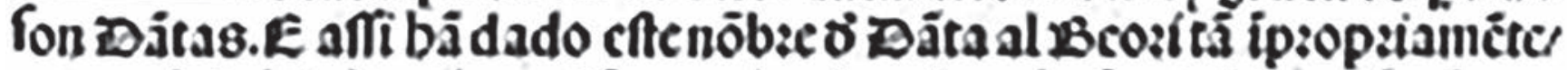
como al orbicl octigre.Eftosanimsles becosics fon ocltamaño sona

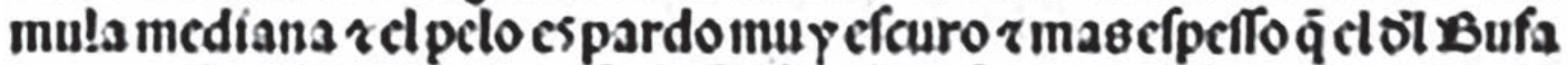
no znotiene cuernog/avná algüoslos llamä vacas. sō mup buenacar

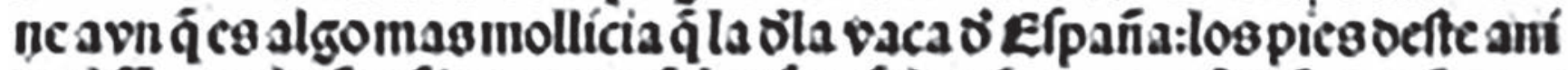

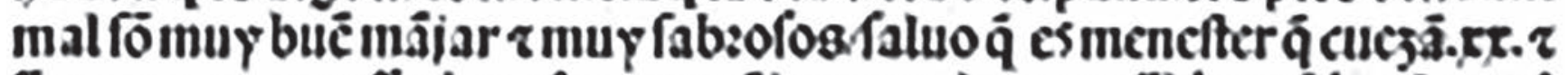

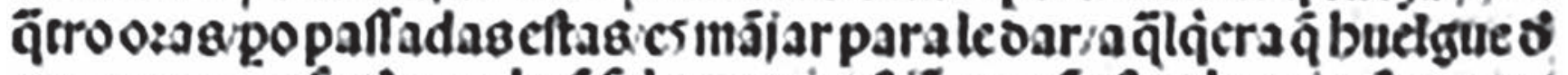
comer vua cofa ò muy buéfaboz/zoigeftiō. matäeftos beo:iscó perros

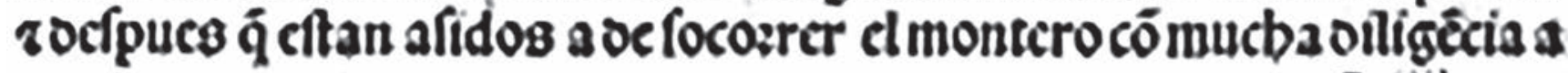
E iiij

släce ar efte animal antce ä fe entre enel agua fipoz allicerea la aypot:-

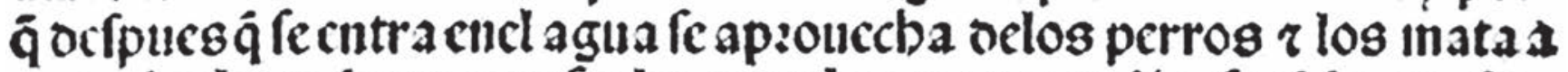
grandes bocados/z acacfec letiar vn bzaço con incdia épalda ccrcé de vn bocado a vnl lebicl: $z$ a otro quitarle vn palmo o do soi pellcio affic co mofilo oeffollafien/ $\tau$ yobe vifto lo vno z lo otro. lo qual no bazen tan a Fin falto fucra oel agua. Fasta agoza los cucros deftos antinalcs no ios faben adobar nife apzonecban oclloslogchziftianos/po:que no losfa ben tratar/perofon tan grueffos/o masquelosdel bufano.

Figura 8.7. Fólios XXr e XXv de Oviedo y Valdez (1526). 


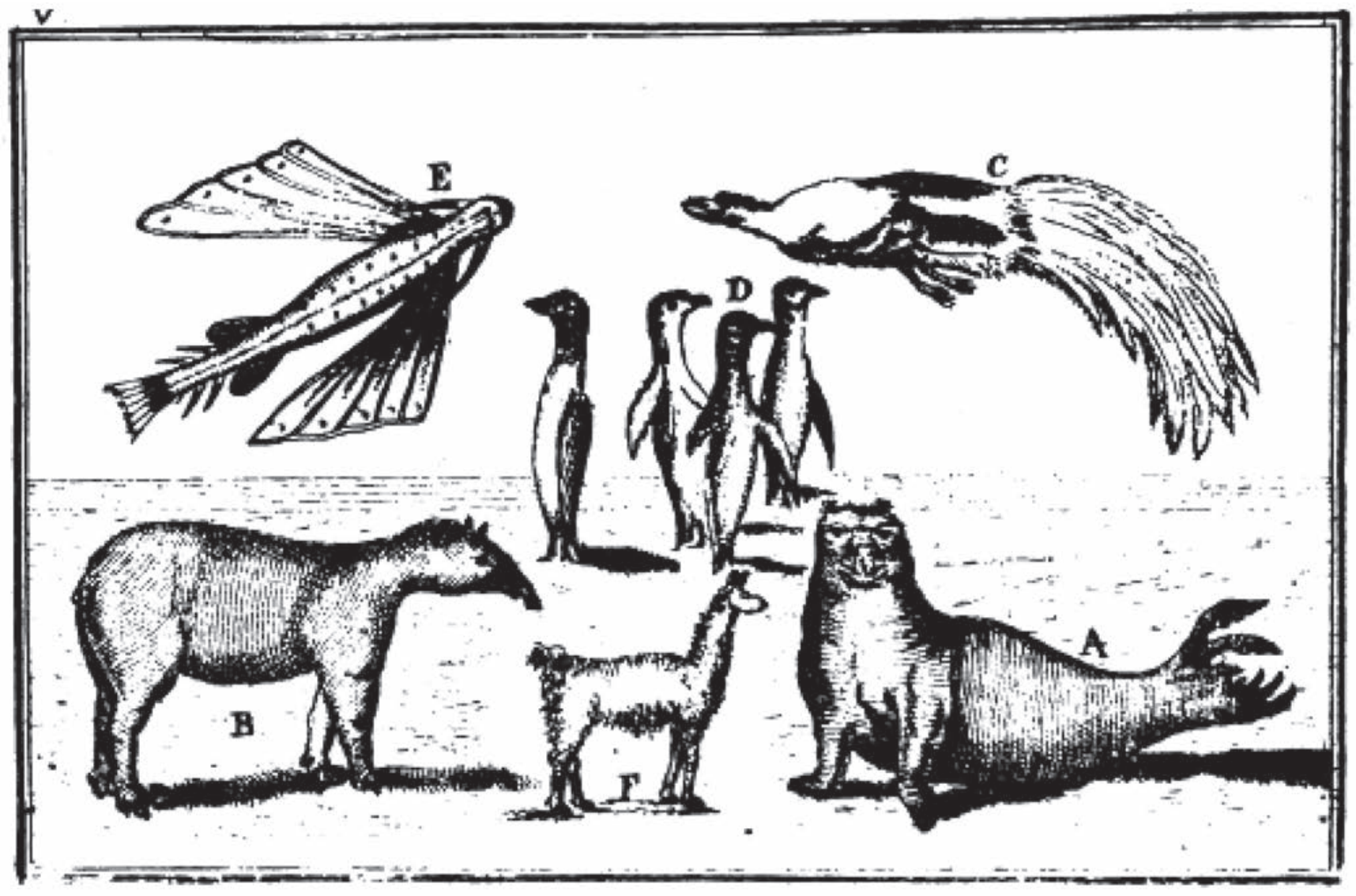

Figura 8.8. Desenho de anta (B) em vinheta à página 105 da edução da obra de Pigafetta por Amoretti (1800).

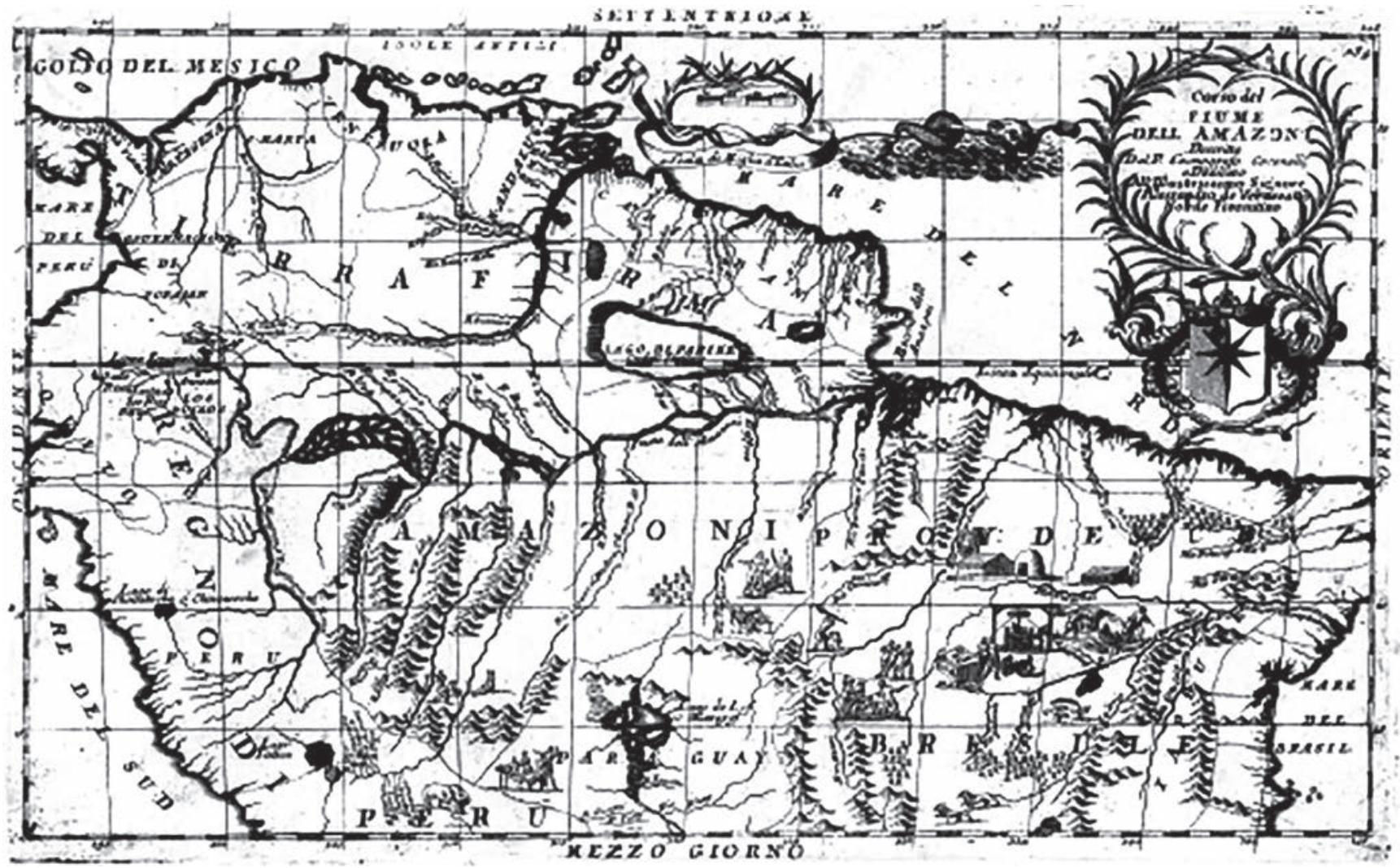

Figura 8.9. Mapa do norte da América do Sul (Coronelli, 1691: entre as páginas 134 e 135). No canto inferior esquerdo, entre as letras de PERU, uma provável figura de anta. 
1966: 103) ("Antas. Há mªs antas hũas nadaõ mto e tẽ o fosinho como trõba e fazẽ mal cõ os dentes as orelhas como mula sẽ rabo e do tamanho de hũ asno grande as pernas grossas o esterco tẽ como de caualo e serue ẽ fresco $\mathrm{p}^{\text {a }}$ corrim ${ }^{\text {tos" }}$ ).

Ante Magini, 1598: fólio 209v ("L'Ante così detto da' paesani sono animali simili alla Mula, ma minori d'essa, con vn becco sottile, ma nel labro di sotto lũgo come vna tromba, con l'orecchie ritonde, con la coda corta, \& in tutto'l rimanente del corpo bigi. Questi fuggono la luce, onde non escono a' pascoli se non di notte, e nel mattino si nascondono nelle secrete lor tane. Le carni di queste bestie paiono al gusto carni di bufalo").

Anta Maffei, 1605: 45 ("Antae sunt etiam, gentis vocabulo, ad mulae similitudinem; sed minores, \& rostro tenuiore, inferiore autem labro tubae instar oblongo, rotundis auribus, breui cauda, reliquum cinereae corpus. eaedem lucifigae sunt, non nisi noctu ad pabulum prodeunt: vbi diluxit, in sua sese condunt latibula. Huius belluae carnes gustatu planè bubulas referunt").

Anta Rodrigues (J.), [1605-1607] in Leite (S.), 1940: 231 ("Os dias passados indo à caça pelo campo, mataram duas antas; e logo lá, cada um por onde pode corta; e pedindo-lhe um índio um pedaço para nós, respondeu o senhor da carne - Também eu tenho boca como os Padres. E não-na deu").

Anta Guerreiro (F.), 1609: 199v: "Ha nestes cãpos muitas \& grades alagoas \& bẽ prouidas de pexe, ha outeiros mui altos, mas de area, todos cubertos de aruoredo, porẽ temos pera nos q' daraõ tudo quãto lhe semeacẽ, ha muitos veados do reyno, Emas, Antas, ha muitas Onças, \& animais feros".
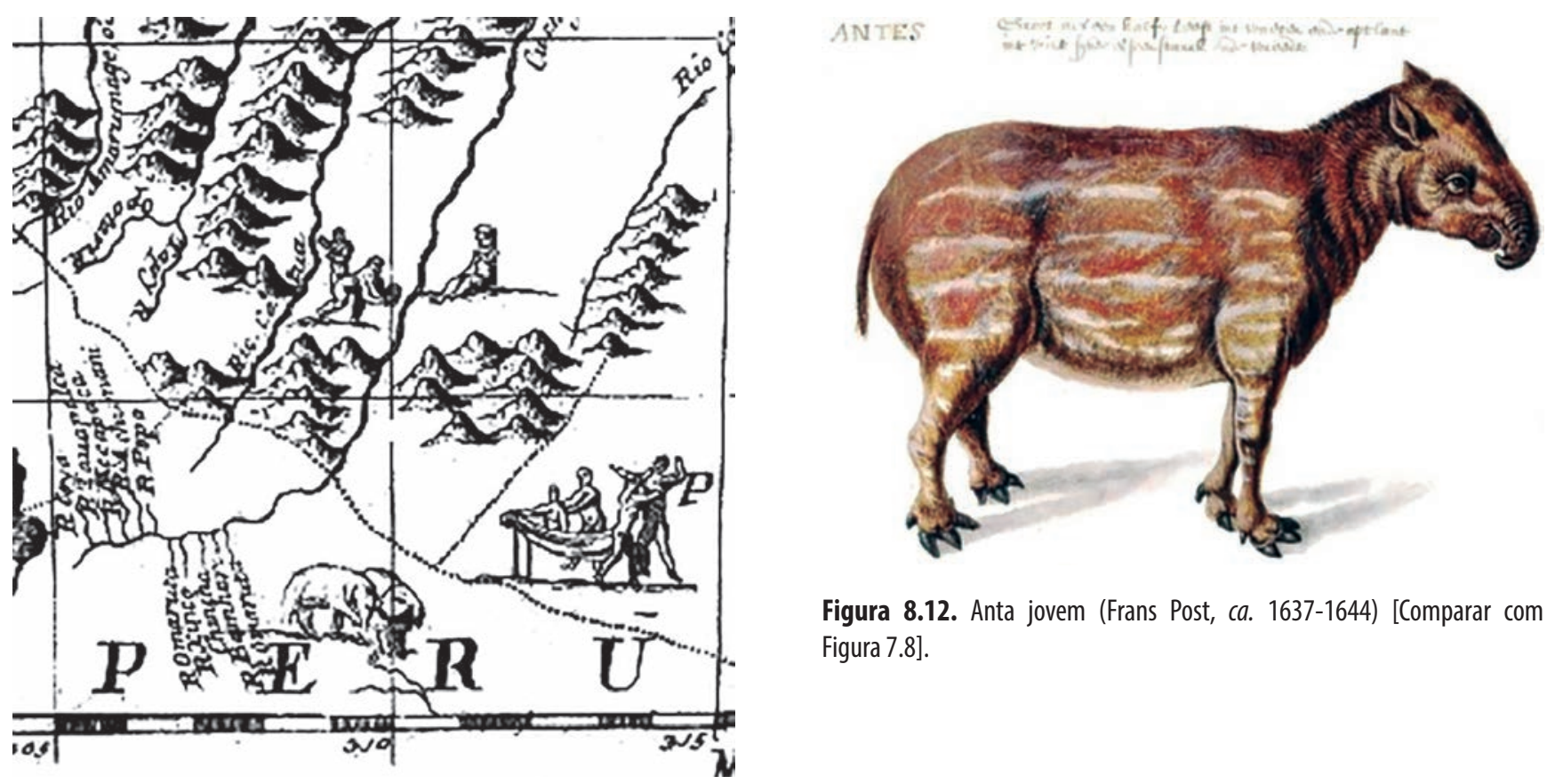

Figura 8.12. Anta jovem (Frans Post, ca. 1637-1644) [Comparar com Figura 7.8].

Figura 8.10. Detalhe da figura anterior.

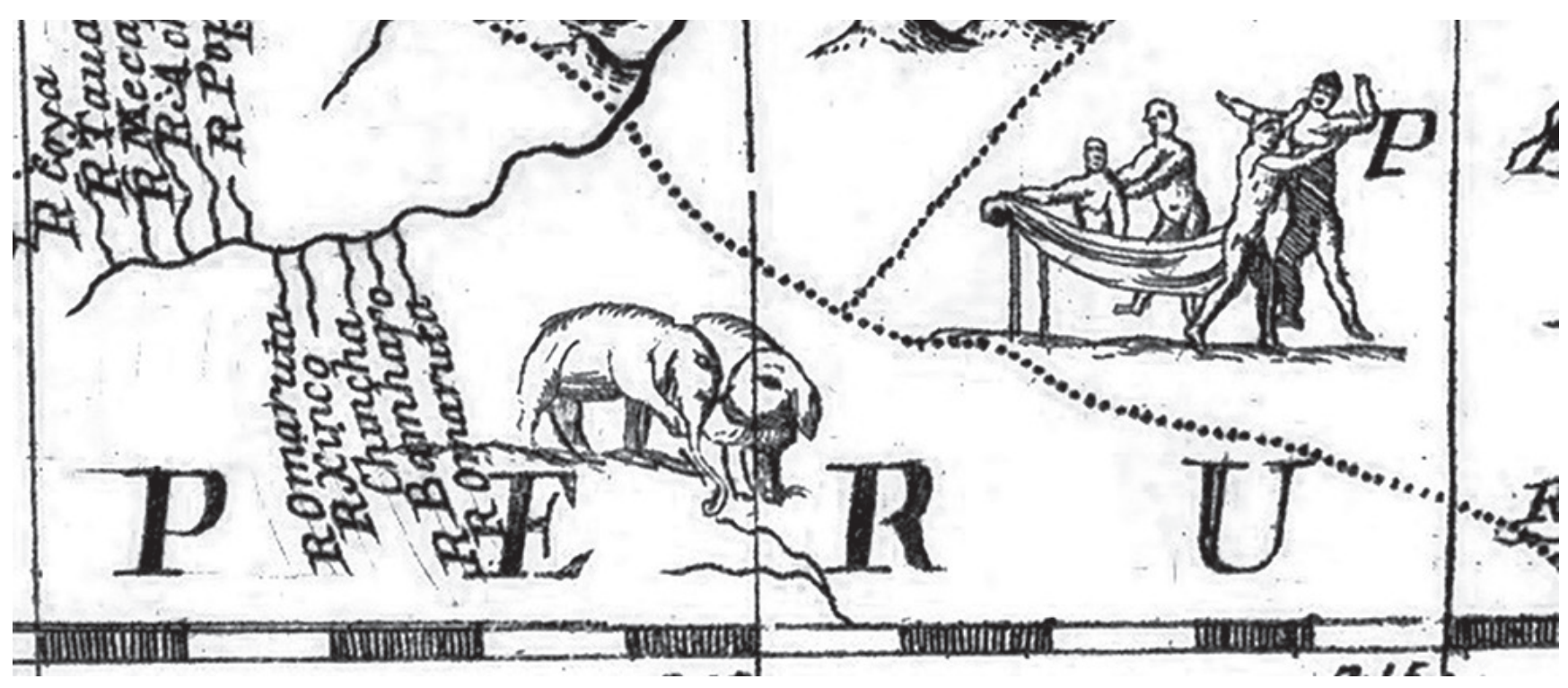

Figura 8.11. Detalhe da Figura 8.10. 
Anta Monteiro (J.), [1610] (in Leite (S.), 1949: 417) ("Há muitas antas, a que chamam tapira. A carne difere pouco da nossa vaca, no sabor, posto que me pareceu de ventagem uma vez que dela no mato nos fiseram seu presente os Aimurés, trazendo-no-la já assada a seu modo, de moquém, que se faz nesta forma: fazem uma cova no chão; enchem-na de brasas, sobre elas botam uma camada de folhas de bananas, que são mais altas que um homem, e de largura de dous ou três palmos; e depois de a cobrirem com outra camada lhe lançam terra, de modo que tapam a cova. A carne se vai ali assando com tal têmpera, que leva vantagem a toda a mais invenção de assado, na limpeza e na tenrura e sabor. Tem no focinho um palmo de tromba, que lhe serve de mão com que apanha o que come. Tem os olhos pequenos e envovados. Será de altura de um jumento, mas mui envolta em carmes. Tem as pernas grossas. Peleja com os dentes, que serão como de mula, mas leva todo o que alcança. Nadam sobremaneira, e muito mais mergulham, porque passam rios mui largos de banda a banda, e andando debaixo da água. Em pequenas são mui lindas e pintadas, depois crescem e aborrecem, mas fazem-se mui caseiras e mansas. Sustentam-se das frutas dos matos. Criam nas entranhas pedras bazuares, que os Franceses regatavam aos Índios em igual preço que o do ambre").

Anta Sylveira, 1618: 204.

Anta Brandão, [1618] 1887: 107, 1977: 225.

Anta Soares (F.) [Séc. XVI], 1966: 17, 103.

Anta Moreno, [1618] 1967: 185.

Anta Herrera, 1622: fól. 10v.

Anta Sylveira, [1624] 1979: 45.

Anta Vicente do Salvador, 1627: fól. 16v (in Oliveira (M.L.), 2008: [107]), 1965: 75.

Dante Nieremberg, 1635: 187.

Anta Montoya, 1639: 3v.

Danta Acuña, [1641, cap. xxviii] 1986: 54.

Dantes Frans Post, ca. 1637-1644, aquarela e guache, Noord-Hollands Archief, Haarlem [Figura 8.11].

Anta Barlaeus, 1647: 132 ("Antae mulas referunt, licet minores magnitudine sint. bucca illis gracilior, labrum inferius tubae similitudine oblongum, aures rotundae, brevis cauda, corpus reliquum coloris cinerei. lucem fugiunt, nec nisi noctu ad pastum vagantur. ubi diluculum adventat, in latebris sese abdunt. Carnes ejusdem ferè cum bubulis saporis sunt").

Anta Marcgrave, 1648: 229, fig. (sob tapiierete).

Anta Piso, 1648: 10 ("Antae etiam lucifugae (mira aspecty animália) carnes gustatu bubulas plane referunt").

Anta Jonstonus, 1652: 108.

Anta Piso, 1658: 101, fig.

Anta Vasconcellos (S. de), 1658: 54 ("Nas paragens de Mattos ha grande abundancia de Caça; de Antas, Veados, Pòrcos Monteses, Coelhos do Mato, Emas Voadoras [sic], \& outras diuersas Castas de Féras, \& Aues"), 55 ("Ha grandes, \& fermozas Alagoas; nestas se criam Còbras tam Monstruosas em grandeza, que se conta por certo, que da carne d'huma sò dellas, comeo hum Exercito inteiro, \& nam parece grande o espanto aos que sabem a disforme grandeza daquellas Bichas, a que chamam Giboïas vulgarmente. Succedeo neste mesmo Sertam o caso seguinte. Andando à Càça certo Soldado d'huma destas Tropas, por nome Fulano Luis Grou; desuiouse do corpo da Gente com sua Espingarda a certa Matta, aguardar algum Lanço; \& estando à Espera, ao reboliço que ouuio entre a Rama, acodio a ver o que serìa: o que vio, foi huma briga extraordinária entre huma Cóbra Giboïa, \& huma Anta; a Còbra que de grandesa era descomedida, tinha a cauda enroscada em hum Tronco d'huma Aruore, \& os dentes empolgados na Anta do tamanho quasi d'huma Mula: forcejáua a coitada Anta por fugir, \& arrancar consigo a Cobra, mas esta firmada com a cauda, hïa preualecendo, \& despedaçando o triste Animal: porem nenhum dos dous ficou com a vitoria, porque ficàram ambos mòrtos no Campo; nam a vnhas, \& dentes, mas a continuas pelouradas da Espingarda do destro Grou Soldado; cujo Estrondo, \& Lezam nam foi bastante a que desaferrassem, \& fugissem estes dous Animais: tam embebidos, assanhados, \& fora dos senridos estauam em luta").

Anta Barlaeus, 1660: 619 ("Antae etiam lucifugae, mira visu animalia, carnes bubulas referunt").

Anta Heriarte, 1662 (cf., Varnhagen, 1874 e Nowotny, 1964: 30, 52, 82).

Ante Maffei, 1665: 69 ("Il y a vn animal appellé sur le lieu Ante, qui a quelque chose d'vne Mule, lorsqu'il est plus bas, il a la bouche plus petite, la levre d'en bas longue, \& avancée, comme vne espece de trimpe; les oreilles rondes, la queuë courte, \& le reste du corps cendré. II hait le jour \& ne va paistre que de nuit, \& se retire au premier rayon de lumiere qui paroist. Sa chaur a le goust de celle du boeuf").

Anta Schott, 1667: 916 [Figura 8.12] ("CAPUT IV. De Anta Brasiliae animali. Mirum ac foedum aspectu animal in Brasilia reperiri, quod Brasilienses Tapiiereté, Lusitani, Anta vocent, auctor est Gulielmus Piso lib. 3 Hist. Nat. \& Med. sect. 3. Est magnitudine juvenci semestris; dorso incurvato, figurâ corporis quodammodò ad porcum accedens, imprimis oculis, capite, \& pedibus. Promuscide est super os praeminente, quam validissimo nervo contrahere, \& extendere potest. Ore dentato in utraque maxilla. Loco cauda exiguum processum depilem. Cute est solidâ instar Alcis, brevibus pilis, umbra \& fusci coloris. Salex est bestia, \& noctambula, quae arborum fructus, arundines sacchareas, depopulatur. Inter amphibia non recensetur; fluvios tamen transnatat rapidissimos. Caeterùm iners \& secors apparet, adeoq' lucifugae, ut in densis mediterraneis silvis interdiu dormiret amet; ita ut si detur animal quod nocyu tantùm, nunquam verò de

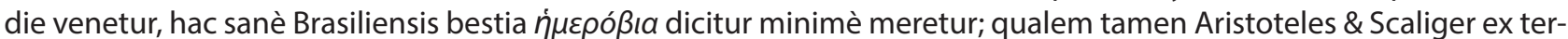
restrium genere in Asia non dari autumant. Caro eius vesca, si juvenis, \& ritè praeparetur, bubulamq' aemulatur, eaque mediterraneis ac maris accolis in frequenti usu existit. Haec Piso. Vide Icon. XXVII. En typum animalis"). 
Anta Vasconcellos (S. de), 1668: 289.

Anta Ferreira (J. de S.), [1693] 1894: 45, 1918: 303.

Danta Montanus, 1671: 272 (" $\mathrm{t}$ 'Voornaemste dier is danta. Het sweemt eenigzints na een muil-ezel: heeft heen hoornen; maer rosactig lang hair, korte hals, hangende ooren, dunne beenen met drie klaeuwen voor en twee achter, lang hoofd, smal voor-hoofd, keinen oopgen, een snuit hangende over den bek, geringe slaert, scherpe tanden en een huid ses vingeren dik, door welke geen geweer lichtelijk treft. $t^{\prime}$ Word gevangen in vallenm of kuilen, of met honden. Indien de kanr van water krijgt, bijt vibbig van sich: en vernielt meenigen dog, Anderzints vluchr het, zoo lang t' hard onder te voeten heeft. Men segt, dat de danta den mensch geleerd heeft t' ader-laeten; want overlasing van bloed, quetsts $t^{\prime}$ lichaem met scherp ried, en stopt de wonde voorzichtig toe. $t^{\prime}$ Vleesch is smaeklijk: gelijk oog der rosse leeuwen, die by dag op hooge boomen slaepen; waer ui by meenigte geschooten worden").

Anta Bluteau, 1712: 395 ("Anta. Animal quadrupede, a que o Gentio do Brasil chama Tapijerete. He do tamanho de hum bezerro de seis mezes, a figura he de porco, mas com cabeça mais grossa. Tem olhos pequenos; naõ tem rabo, sô tem em lugar de rabo huns poucos de cabelos, que vê cahindo. Em cada mão tem quatro unhas, naõ solidas, mas ocas; nos pês tem tres, \& como um principio da quarta...").

Danta Lemery, 1716: 189 ("Les ongles de ses pieds rapez \& pulverisez sont estimez sudorifiques, propres pour l'epilepsie, pour resister au venin; cet effet provient du sel volatile qu'ils contiennent; la dose en est depuis un scrupule jusqu'à une dragme").

Ante Gumilla, 1741: 200-201 ("La Nación Achagua gasta menos días en bolver con mucha carne de Ante assada: salen los antes del Rio à comer paja tierna: los Achaguas estàn sentados entre la misma paja, y saben remedar bien el ecco del Ante: al tal ecco responde la Anta (es. lo que llamamos la gran Bestia) y ambos juntos vienen al reclamo del Achagua: este dispara à cada uno su flecha de veneno, llamado Curare, y ambos caen muertos luego al punto; de modo, que si hai fortuna, en un dia se matan. En el dia siguiente se assan, y al tercero, ó quarto dia yà estàn en sus casas cargados de carne assada, y no despreciable, porque sabe la carne de Ante à muy rica ternera, aunque su figura es la mas rara, que se pueda pensar: su cuerpo es del tamaño de un jumento, ò de un muleto de un año; los quatro pies cortos, que no corresponden al cuerpo, rematan no en dos pesuñas, como las de la ternera, sino en tres; y estas son las uñas afamadas, y tan apreciables, que vulgarmente se llaman las uñas de la gran Bestia, por haverse experimentado admirables contra la gota coral, tomando de sus polvos, y colgando una de aquellas uñas al cuello del doliente. La cabeza del Ante tiene alguna semejanza, aunque poca, à la de un cebon, y tiene entre ceja, y ceja un huesso tan fuerte, que con èl rompe quanta maleza, y palos halla por delante en las selvas; de modo, que el tygre se esconde junto al pasto, que vè trillado de los Antes, salta encima del primero, que passa, y le aferra con sus quatro garras: si el paraje es limpio, perece el Ante; pero si hai maleza cerca, y arboleda, recae el daño sobre el tygre, porque corre furiosamente el Ante, mete la cabeza por lo mas escabroso de la selva, con tal impetu, y fuerza, que si el tygre no se há desprendido antes, perece despedazado entre los palos, y los abrojos.

La cola del Ante tampoco dice, ni corresponde à su cuerpo, porque es corta, delgada, y retorcida, ni mas, ni menos, que la de un cebon. Tambien tiene clin, que le dà algun ayre; pero no excede de la clin de un jumento: de tan buena gana vive en el profundo del Rio, ù de la laguna, como en tierra. Es verdad, que para pacer la yerva de su regalo especial, que se llama Gamalote, siempre sale à tierra. En fin, ella se llama comunmente la gran Bestia: no se por què; tal vez

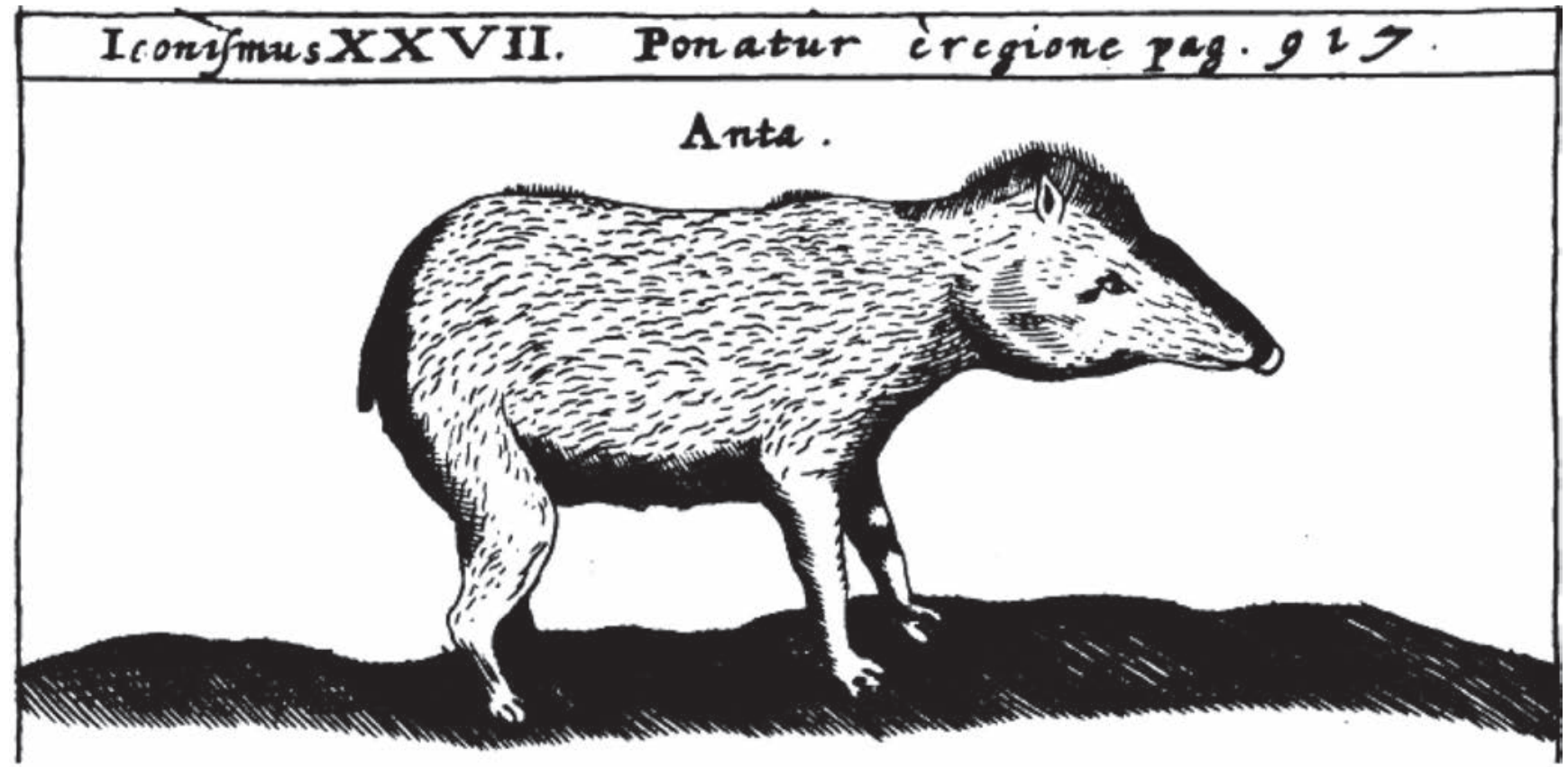

Figura 8.13. Anta (Schott, 1667: 917, pl. XXVII (parte)). 
será, porque es un animal irregular, que viene à resultar de varias partes de otros animales, sin que el todo se parezca à alguno de ellos.

Pues què dirè de sus dientes, y de la facilidad, y destreza con que despelleja de alto abaxo à los perros, quando se vè rodeado, y perseguido de ellos el Ante? No dexa su puesto, por mas que le acometan; y es tal su habilidad, tenacidad de dientes, y fierza con que arroja al perro que acertò à morder, que quedandose con la mayor parte del cuero del perro, le arroja bien lejos despellejado, y dando terribles ahullidos, con lo qual huyen los otros perros, espantados de la desdicha de su compañero: Como hace el Ante este daño tal, y tan instantaneamente? Ni los mismos Espñoles, que gustan de cazar los Antes, por la diversion, y por el interès de la piel, y de las uñas, que vèn morir em cueros, y sin piel todos los dias à sus perros, no saben decir como es, ni explicar la destreza con que lo hacen. Um Ante, que nos traxeron los Achaguas à la Colonia de Guanapalo, tenia de largo dos varas y quarta").

Anta Moreira (A.), post. 1753: 4r ("Antas, aq' os Indios chamão Boy do matto, são huns animaes da grandeza de bezerros, mas $\mathrm{m}^{\circ}$ grossos, e as pernas Curtas, a pata he rachada, e do mesmo feitio, $\mathrm{q}^{\prime}$ de boy; Correm $\mathrm{m}^{\circ}$ e Com tanta Violencia, q' deyxão o mato quebrado por onde vão Correndo; a Carne he propriam ${ }^{\text {tq }}$ em tudo, como a de vaca, e he Comer $\mathrm{m}^{\circ}$ gostozo de todos: sua unha he aq' vay $\mathrm{p}^{\mathrm{a}}$ as boticas $\mathrm{p}^{\mathrm{a}}$ varios remedios, aq' chamão unha de Grão Besta, sua banha he singular remedio $\mathrm{p}^{\mathrm{a}}$ Curar obstrucções, dores, e humores Coagulados interiorm ${ }^{\text {te }}$ e exteriorm ${ }^{\mathrm{e}}$ untandose repetidas vezes Com ella q ${ }^{\text {te }}$ o Cancro. He bem celebrado em todo o mundo, deq' se fazem vestidos $\mathrm{p}^{\mathrm{a}}$ a guerra, porq' o não passa bala nẽ ferro penetre sendo bem curtido") [cf., Papavero \& Teixeira, 2011: 120].

Danta Llano Zapata, [1757] 2005: 520-521 ("Hállase en el Paraguay y montañas del Perú la bestia que vulgarmente los españoles Ilaman danta. Esta nuestra difiere en algo a las demás de su género. Su figura es de mula aunque pequeña, a excepción de tener las uñas y orejas de vaca. Su color es blanco, pardo o castaño, con la piel tan dura que creen resiste seca a la penetracón del fierrom sus carnes son delicadas y mayormente la de las hembras. Se aposenta de hierbas. Y según escribe el padre Antonio Ruiz de noche come barro y salitre. Cuentan los indios que cuando este animal se siente cargado de sangre se evacua de ella fregando sus piernas en los cañaverales hasta que destilando aquel fluido la cantidad com que reconocen el alivio de sus vasos, los cierran resvolviéndose en el barro. De aquí ha venido que el oidor Palacio y el cronista Herrera lahayan tenido por el hipopótamo y Pedro de Cieza por espécie de zebra. En el Reino de Tierra Firme le nombran pan, en chiapa y verapai, veon y según el padre Juan Eusebio que parece copio a Juan Lerio, le daban también en los nombres de capani tapirouson, doucana. En mi juicio este animal no es outro que el que los naturalistas llaman alca, voz griega derivada de alka palabra dórica que según Cornelio Schevelio en su lexicón Greco-Latino y el padre Jacobo Bayer en el Latino-Greco, significa fuerza. Pero más se ajustan a las cualidades que atribuyen al Alce, la interpretación de auxilio que da Federico Hoffman sobre la clave de Schrodero, derivando de ella Erociano el adjetivo analkes, cosa que no auxilia. Pretenden, las uñas de este animal, en particular las del pie izquierdo sean contra el veneno, epilepsia, y mal caduco. Para precaverse de estos males traen los indios colgados al cuello unas ruedecillas de estas uñas, que también usan como sortijas. No me admiro que estas gentes poco instruídas se crean de semejantes amuletos, cuando muchos médicos las prescriben en polvos, como remedios anti epilépticos siendo estos peniaptos verdaderamente un engaño por no decir superstición, que de los gentiles se ha propagado a la república Cristiana. Y Savary por las siguientes palabras nos desengaña de este abuso: 'Pomet da las señales por cuyo medio se deben reconocer los verdaderos pies del alec pero, como su virtud es muy equivoca, por no decir absolutamente fabulosa, poco importa el engañarse, la opinión basta em defecto de la verdad'. Y Lemery ya había dicho: 'estos amuletos nada producen de provecho', expresando lo mismo Dudithio y Castelli. Me parece que esto sobrará para desengañar al vulgo de los nuestros de este error, estampándolo algunos autores regnícolas en sus libros, como se lee en el citado padre Antonio Ruiz hablando del Paraguay donde es más común este animal, que los indios de la Canadá nombran orignac u orignat de cuyas pieles hacen un grande comercio con los de la Francia que transportan a la Europa y emplean en varios usos y manufacturas").

Ánta Vieyra, [1773] 1833 ("a beast in the West Indies, like a little cow, but without horns. (...). The same beast is called Tapijerete by the natives of Brazil").

\subsection{Nomes compostos}

Anta-batupeva lhering (R. von), 1940: 88 ('Anta 'gamelleira', anta 'xuré,' 'batupeva'e 'batuvira' são nomes que os caçadores dão aoo que supõem ser variedades").

Anta-batuvira Silva (H.), [1913]: 116.

Anta-caá-pororoca Boiteux, 1957: 99 ("i.e., que faz barulho no mato").

Anta-cinzenta Quadros, 1892: 246.

Anta-commum Silva (H.), 1922.

Anta-das-ordinarias Meneses (J.C. de), 1776.

Anta-do-matto Brandenburger, 1923: 88.

Anta-gameleira Neiva \& Penna, 1916(1999): 107.

Anta-gamelleira Ihering (R. von), 1940: 88 ("Anta 'gamelleira', anta 'xuré', 'batupeva' e 'batuvira' são nomes que os caçadores dão ao que supõem ser variedades"). 
Anta-nambi-tinga Ferreira (A.R.), 1790 ("differe [...] em ter as pontas das orelhas brancas").

Anta-negra Quadros, 1892: 246.

Anta-pororoca Quadros, 1892: 246.

Anta-preta Paranaguá, 1905: 153.

Anta-rosilha Paranaguá, 1905: 153.

Anta-rosia Almeida (M.B. de), Smith, Lima, Mendes, Piyãko, Aquino \& Andrade, 2002: 455.

Anta-verdadeira Sylveira, 1624: [19] ("saõ como vacas piquenas cõ o rosto como ellas: mas sẽ cornos, \& o beiço de baixo muy cõprido, e naõ sahẽ se naõ denoite").

\section{UMA QUESTÃO EM ABERTO: ANTA-SAPATEIRA E ANTA-XURÉ: DUAS ESPÉCIES DISTINTAS?}

\subsection{A anta-sapateira (ou anta-batupeva, caapora, gameleira, lubuna, tapira-caapora, tapirassu)}

Spix (in Spix \& Martius, 1823: 326, nota *i), em nota discreta, diferenciou o Tapir maior, que chamou de Sapateira, do Tapir minor, que chamou de Xurés.

Martius (in Spix \& Martius, 1828: 542, nota 3.III) forneceu algumas características da "anta xuré" e comentou: "Von der gewöhnlichen Anta, Anta Sapateira, Tapirus americanus, L., glaubte Dr. Spix die sogennante Anta Xuré als Art unterscheiden zu können. Dieses Thier, von niedrigerer Statur und gleichfarbigen, nicht an der Spitze weissen, Ohrkappen, ist jedoch wahrscheinlich nur eier Varietät, oder das jüngere Individuum” ["Da anta-sapateira (Tapirus americanus, L.) julgou o Dr. Spix separar, como espécie, a chamada anta-xuré. Êste animal, de estatura baixa, orelhas de côr uniforme, não brancas na extremidade, é, provavelmente, apenas uma variedade ou indivíduo mais novo" (Spix \& Martius, s/d: 102)].

Liais (1872), com seus costumeiros delírios etimológicos e inexatitudes, endossou a hipótese de Spix e escreveu longamente sobre a questão:

"Nous commencerons dans les Pachydermes par le genre Tapir, dont il existe seulement trois espèces vivantes, dont l'une appartient à l'Indo-Chine et à la Malaisie. Les deux autres espèces sont de l'Amérique. On croyait que le Brésil en possédait une seule. Dans mon dernier voyage, j'ai pu m'assurer de la présence de deux espèces sur son territoire.

La tapir, le plus anciennement connu au Brési, le Tapirus americanus de Gmelin, porte dans l'Empire, conjointement avec l'autre espèce, le nom d'Anta, et il en est distingué dans le val du San-Francisco par l'epithète de Sapateira, tandis que l'autre espèce porte de nom d'Anta Churé. Le nom de Sapateira est portugais et ne s'expliquerait nullement, como qualification distinctive de l'une des espèces, puisque l'une et l'autre ont la peau épaisse et propre à faire des selles et des souliers ${ }^{27}$, si ce n'est qu'il est la corruption du nom indien Çaba-tyra, poils redressés [sic], lequel represente en effet l'un des caractères par lesquels cette espèce se distingue de l'autre, en ce que les longs poils du cou sont plus redressés" (p. 394).

Mais adiante (pp. 396, 397) acrescentou:

“Le plus grand et le plus commun des deux tapirs du Brésil est le Tapirus americanus des auteurs, l'Anta sapateira du pays. As hauteur mesure au train de derrière peut attendre jusqu'à $I^{m}$, 10 , et même $I^{m}, 15$, e dans ce cas as longueur totale, corps er tête reunis, est de Im ,80 environ. La peau est extrêment épaisse, dure et couverte de poils peu fournis et courts, excepté sur le cou, où ils sont plus long et formenr uma petite crinière dressée. La couleur est d'un brun foncé assez uniforme, plus clair toutefois sur le cou et les côtés de la tête, et il y a à la base de l'oreille des poils blancs se prolongeant sur les bords de cet organe. En 1553, Gomora [sic] signal ace tapir dans les regions de l'Orénoque sous le nom de Guarani [sic] de Çaba, poilu [sic]. Il est facile [sic] d'y reconnaître l'abbréciation du mot Çaba-tyra dont les Portugais on fait Sapateira, et cela confirme l'origine que j'ai indique pour ce dernier nom.

(...).

Toutefois, il serait plus exact et plus conforme à l'origine du nom d'appeler l'espèce dont nous parlons en ce moment Tapyra americama, plutôt que Tapyrus americanus, et comme il y a une seconde espèce en Amérique, il serair mieux encore de l'appeler Tapyra sabatyra. Ce tapir a des plis transversauz sur la trompe".

Na realidade, Lopez de Gómara (1554: 103v, Cap. LXXX. La caça y pesca de Cumaneses), grafou Capa e não Çaba, como fantasiou Liais, e disse simplesmente:

27 A hipótese de que sapateira se refere à utilização do couro para a fabricação de sapatos é ridícula, pois o epíteto é também conferido à lagosta-sapateira... Para Couto de Magalhães (1939: 304): “Uma dessas espécies é conhecida pelos caçadores sob o nome de'sapateira', por que tem os cascos mais alongados e em fórma de bico de sapato". A mesma explicação foi dada por Fonseca (F. da), 1940: 43 ("Os protozoarios descritos na presente nota provêm de material colhido de um exemplar de Tapirus da especie clara, de tamanho medio, provavelmente Tapirus raulinus [sic; Tapirus roulini, ident. err.], conhecida pelo nome vulgar de'anta sapateira', denominação esta que lhe dão os caçadores devido à conformação alongada dos dedos, em oposição à fórma curta observada na especie negra e maior, o Tapirus americanus. Esta anta, capturada muito jovem em S. Romão, Pirapora, Estado de Minas Gerais, foi-nos remetida pelo missionário Frei Bertholdo von Mee, ao qual somos muito grato, tendo chegado a Butantan com cerca de tres meses de idade"). 
"Toman vn animal que llaman Capa, mayor que asno, velloso, negro y brauo, aunque huye del hombre. Tiene la pata como çapato frances, aguda por detras, ancha por adelante, y algo redonda. Persigue los perros de aca, y vna capa mata tres, y quatro dellos juntos".

Como bem assinalou Roulin (1835: 10-11) Lopez de Gómara fez uma grande confusão com este animal:

"L'auteur, Lopez de Gomara, en parle même en trois endroits de son ouvrage, mais il en fait trois animaux différens. D'abord il le place dans la province du Darien et il en donne une description qui ne diffère presque de celle de P. Martyr ${ }^{28}$ qu'en ce qui concerne la forme du pied; du reste, de même que l'auteur des Décades, il oublie de lui assigner um nom ${ }^{29}$. Il le compte ensuite parmi les animaux de la province de Cumana, et, sous le nom de Capa, il le décrit un peu mieux. Enfin, à l'occasion du Voyage de Magellan [Cap. XCII], il le fait reparaître sous le nom plus connu d'Anta, le représentant ici comme un animal qui a quelque resemblance avec la vache, et qui habite les environs de Rio-Janeiro. Dans le même chapitre, le nom d'Anta est encore deux fois employé: I'une pour un quadrupède commun aux environs du port SaintJulien (côte des Patagons), l'autre pour un animal qui se trouve sur les bords du détroit de Magellan, et dont la fiente sert aux indigènes pour calfeutrer leurs canots d'écorce. Le premier animal est comparé pour Gomara à un âne sauvage; mais on sait par d'autres historiens que c'est du Guanaco qu'il s'agit. Quant au second, c'est probablement un grand quadrupède qui a été vu plusieurs fois aux environs du détroit, mais que les naturalistes ne connaissaint point encore; peut-être est-ce celui que Molina a désigné sous le nom de Huemul (equus bisulcus) [atualmente Hippocamelus bisulcus (Molina, 1782)]".

É interessante notar que no Tarih-i Hind-i garbi (Anôn., 1730 (ano da Hégira de 1142), fólio 46v), o primeiro livro turco sobre a fauna americana, que se aproveitou de textos de Lopez de Gómera, há a figura de dois tapires com a tromba desmesuradamente longa, como a de um elefante [Figura 9.1].

Segundo Senna (1924: 213):

"A anta-sapateira dos caçadores (é a mesma Tapira-caapóra dos selvagens, já classificada de Tapirus americanus) é a especie maior e mais comum do nosso paiz".

\author{
Anta-batupeva \\ Anta-batupeva Ihering (H. von), 1894: 13. \\ Lubuna \\ Lubuna Ihering (H. von), 1894: 13. \\ Caapora \\ Caá-pora Marcos Antonio (Pe.), 1757: fól. 9r (sob antâ). \\ Caâpoára Anôn., [1795] in Ayrosa, 1934: 58 (sob anta). \\ Caapoára Martius, 1860: 488, 1863: 436 (sob anta;"caapoára - dominus herbae vel silvae"). \\ icanum Indi celebrant"). \\ Caápoára d'Oliveira (J.J.M. de), 1936: 134 (cf. Leite (F.R.), 2013: 154). \\ Caapóra Martius, 1860: 492, 1863: 441 (sob caapora).

\subsection{A anta-xuré (ou anta-batuvira, cambacica, anta-chure, antacuré, anta-mirim, anta-pequena, anta-pororoca, anta-uborim, tapir-xuré, xuré)}

Caapora Martius, 1860: 492, 1863: 441 ("Caapora vel caapóra i.e., dominus vel habitator sylvae, nomen quo Tapirum amer-

Saint-Hilaire (1830: 337) citou "deux espèces ou varietiés d'ANTA (tapir), dont une plus petite porte le nom de XURÉ* (*M. Spix considérait le xuré comme une espèce distincte".

Liais (1872: 397-398) tratou da anta-xuré, propondo-Ihe o nome de Tapirus pinchaque brasiliensis:

"La seconde espèce de tapir est l'Anta churé, du val du San-Francisco. Ce nom paraît une altération du nom icuré ou içuré [sic], donné par les Indiens pour qualificatif d'un des tapirs et qui nous a été conservé. Cette espèce est un peu plus petite et beacoup plus rare que l'espèce prédédente. Jusqu'ici elle n'a été signalée au Brésil dans aucun ouvrage [sic; Liais ignorou os dados de Spix e de Saint-Hilaire], quoique cependant tous les habitants de l'intérieur la connaissent parfaitement et la distinguent fort bien de l'Anta sapateira. Au reste, on a longtemps ignoré l'existence de plus d'une sorte de tapir dans l'Amérique, et on

28 Em Martyr (1530: fólio xxxiijr), lê-se: "Sed animal vnum praecipue procreat, in quo natura studuit sese mirã artificem ostendere. Id est corpore bouem aequans, promuscide armartum est elephantina non elephas. Bouino colore nn bos, equinis vngulis non equus, auriculis etiam elephantinis sed minus patentibus \& demissis, quçã caeterorũ tamen animalium patẽtioribus".

29 Lopez de Gómara (1554, Cap. LXVII. Frvtas y otras cosas que ay enel Darien, p. 87): "Vacas mochas, y que siendo patihendidas [sic], parecen mulas con grandes orejas, y tienen alo [sic] q' dizen uma trõpilla como elefante. Son pardas, y buena carne". 


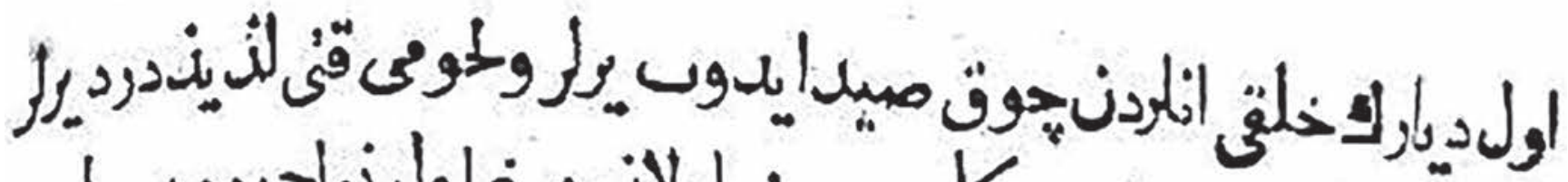

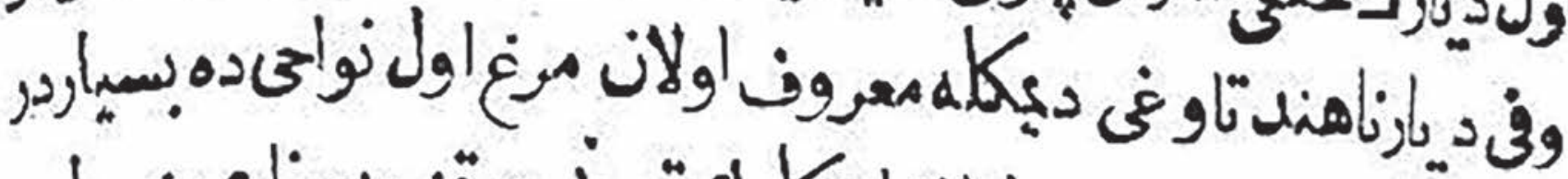

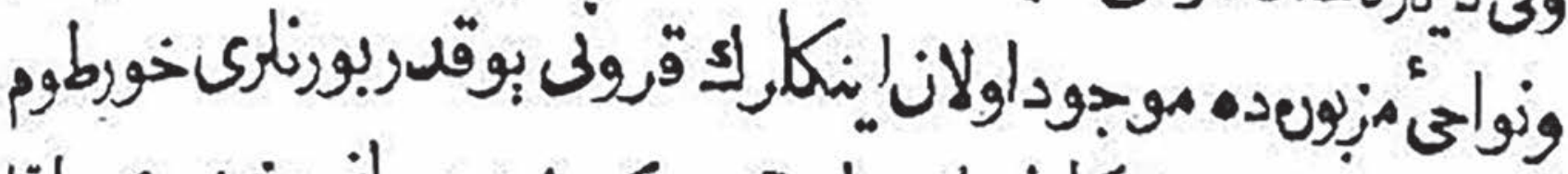

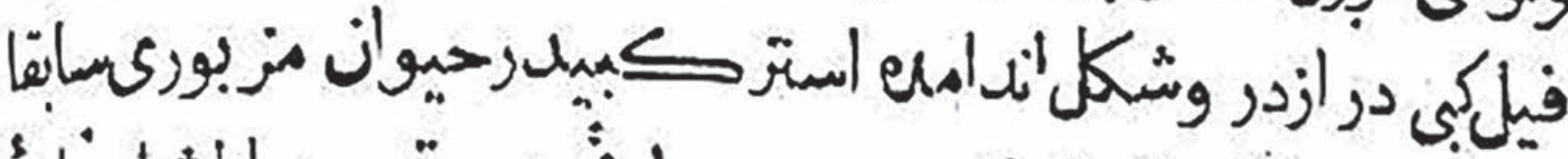

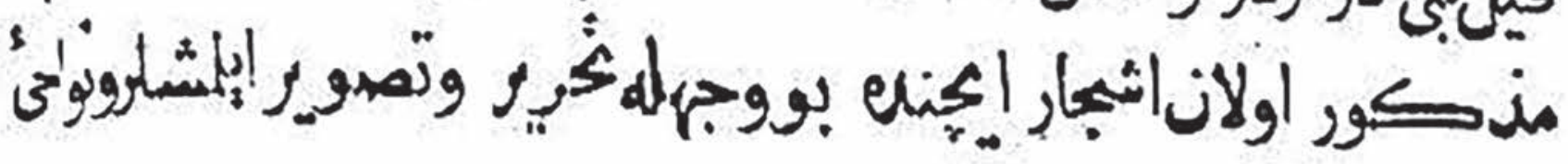

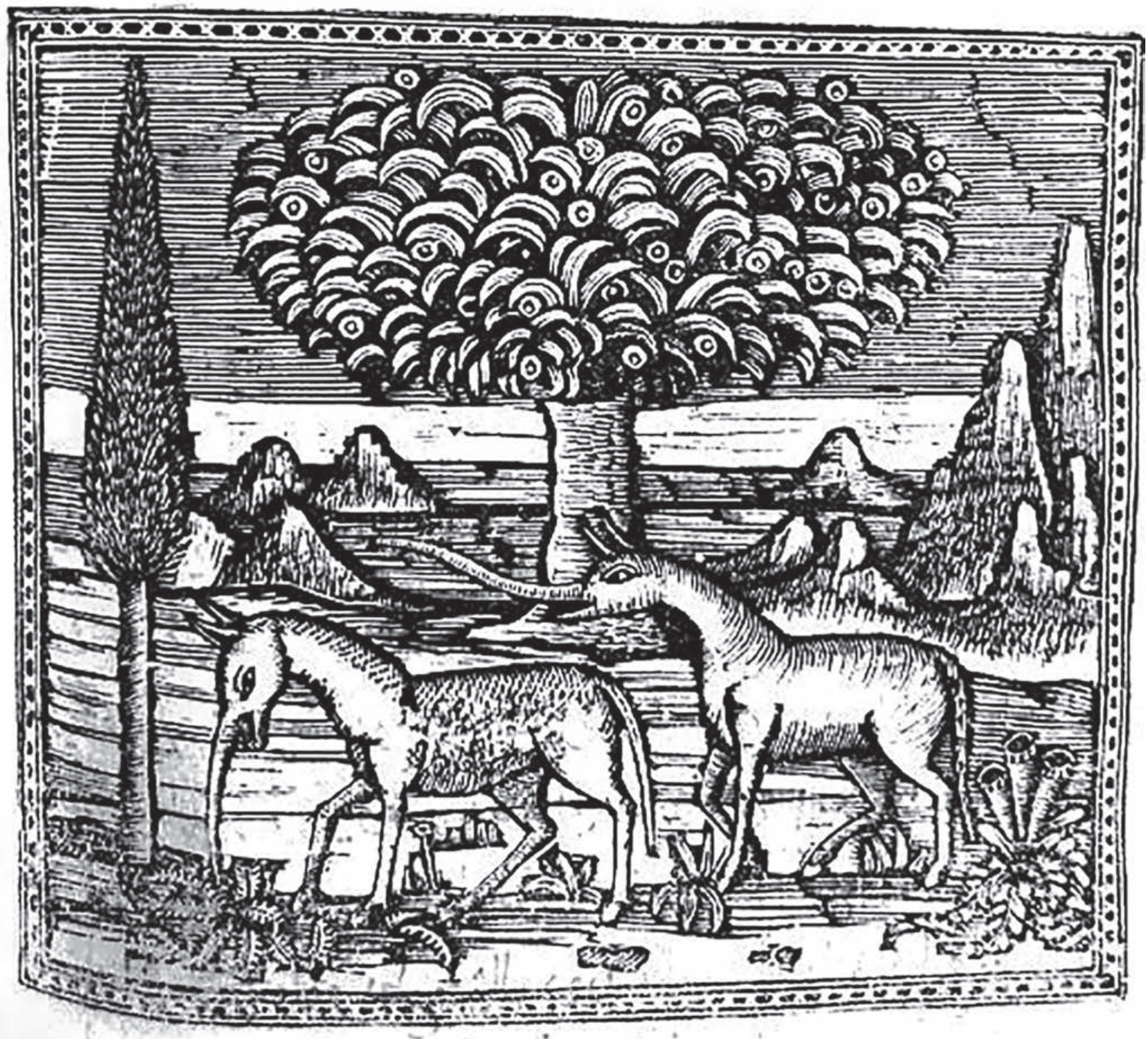

Figura 9.1. Tapires representados no Tarih-i Hind-i garbi (Anôn., 1730 (ano da Hégira de 1142), fólio 46v). 
doit à $M$. Roulin la première description de la seconde espèce trouvée, conjointement avec la première, dans les Andes-Colombiennes, où elles habitent les mêmes localités. II en est de même au Brésil, et j'ajouterai que, dans ce dernier pays, la seconde espèce présente l'ensemble des caractères par lesquels la description en question la différencie de la première. Ces caractères sont particulièrement l'absence de raies transversales sur la trompe, les poils plus longs sur les flancs, mais ne formant pas crinière sur le cou; beaucoup moins de blanc aux oreilles, taille plus petite et couleur un peu plus sombre en avant. La seule diffèrence que je voie dans la description du tapir de la Colombie, Tapirus Pinchaque de Roulin ou Tapirus Roulinii de Fischer, et l'espèce du Brésil, est l'absence d'une sorte de petite tache blanchâtre a l'extrémité de la mâchoire inférieure dans l'espèce du Brésil et qui, paraît-il, existerait dans l'autre. Cette petite différence ne pourrait servir en tous cas à justifier une distinction spécifique. Tout au plus peut-on constituer une variété du Tapirus Pinchaque et non une espèce distincte. La seconde espèce de tapir du Brésil est donc bien le Tapirus Pinchaque ou Roulinii. J'ose à peine faire une variété Brasiliensis pour l'espèce du Brésil, à cause du manque de blanc sous le bord de la lèvre inférieure, car ce caractère dépend peut-être de l'âge. Je n'ai pu voir les jeunes, et ceux-ci, d'après M. Roulin, ont des piquetures blanches comme les jeunes de l'autre espèce. Or, l'individu d'après lequel la description du Tapirus Pinchaque a été donnée, me paraît avoir été un fort adulte et non un individu vieux, car je trouve dans la descripion du crâne le défaut de saillie de la crète bipariétale, et, chez le tapir comme chez beaucoup d'animaux, cette crâne augmente avec l'âge; le seul individu que j'aie pu voir de cette espèce, au contraire, était évidemment un vieux. Cette espèce a les membres à proportion légèrement plus gros que l'autre".

Wappaeus (1884: 303) declarou: "A segunda especie de Tapirus é a Anta Chure de Minas Geraes. É menor e mais rara que a precedente. Caracterisa-se pela ausência de raias transversaes na trompa, pêllos mais longos sobre os flancos e que não formam crina no pescoço".

Taunay (1914a-b: 25) escreveu: “Anta xuré, s. f. Especie de anta (Minas) (Tapirus Roulinii)”).

Segundo Neiva \& Penna (1916: 107): “Somente em Goyaz, podemos alcançar material proveniente de antas, que naquele Estado ainda são muito abundantes; a carne só é aproveitada para os cãis, sendo o couro muito procurado para varios misteres. Os naturais distinguem duas especies, uma denominada 'gameleira' é maior e mais clara, possuindo desde ao nacer a ponta da orelha branca em ambos os sexos; a outra, denominada de 'xuré' é menor, de côr mais escura, sendo mais valente; todavia as informações nem sempre concordavam quanto á côr da 'anta xuré' que para alguns é de coloração mais amarela que a 'gameleira'. A este tipo pertencia o exemplar que matamos, possuindo dimensões dignas de rejistro: comprimento Im 25, altura Im 05; circumferencia toracia [sic] Im 25, peso 170 quilogramas. O peso deve ser tomada [sic] aproximadamente, para mais ou para menos, porquanto a balança, de que nos servimos, de propriedade dum fazendeiro tinha por peso pedaços de ferro não aferidos e que faziam suspeitar da sua exatidão. A ciencia até hoje só rejistrou uma espécie de anta para o Brazil, o Tapirus americanus BRISSON, mas na Colombia, Equador e Perú existe o Tapiras pinchaque ROULIN e na America Central um subgenero com duas especies: Tapirus (Tapirclla) bairdi GILL e Tapirus (Tapirella) dowi GILL. Estudos mais pormenorizados a respeito, talvez venham dar razão á observação, já de ha muito tempo rejistrada pelos caçadores, da existencia de outra especie de anta em territorio brazileiro. De Petrolina aos gerais bahianos a anta é animal completamente desconhecido. Dos gerais em diante é muito abundante").

Para Senna, 1924: 212: "Ha a 'anta-mirim ou anta-pequena', que é o tapir-xuré dos nossos caçadores, menos estimada que o tapirassú (anta grande)"), 213 (“...e anta-uborim, tambem conhecida por anta-Xuré, no Brasil Central, e por anta-batuvira ou anta-pororóca noutros pontos do Brasil, é de menor porte e corpo"; Anôn., 1927: 6 (apenas repete a a frase de Senna (1924: 212).

Outras citações:

Anta-xurê Matta, 1938: 52 (sob anta); Couto de Magalhães, 1939: 304 ("Ha duas espécies bem distintas desses tapirideos brasileiros: uma, escura, com orelhas de bordas brancas, e outra, de pelagem cinzenta, bem menor do que a precedente"); Carvalho (C.T.), 1969: 10 ("idêntica à anterior, porém mais pelada na nuca e de côr bruno-fusca, com raias transversais na tromba").

Antacuré Ferreira (A.B. de H.), 1999: 147.

Anta-batuvira ou Batuvira [F. red. de anta-batuvira] e variantes Ihering (H. von), 1894: 13 (12.,TAPIRUS AMERICANU3, LIN. T. suillus Blumenb. Anta. Os caçadores distinguem uma anta maior, preta, (?) de mais de oitoarrobas, que chamam batupéva e outra menor que chamam batuvira, que é um tanto russa, com as pontas das orelhas brancas. Não temos por ora material no Museu para estudar a questão. No Rio Grande do Sul me disseram que a variedale menor é a preta, sendo a outra de côr parda tratada de lubuna. O que é certo é que na America Central existe uma espécie differente no craneo, e na região andina da America do Sul ha uma terceira espécie (Tapirus Roulinii) que é preta com pellagem espessa, mas sem crinas. Será esta a nossa anta batuvira? Será idêntica á que no Estado de Minas tratam de anta Xuré? Os caçadores daquelle Estado nos têm de ajudar a decidir a questão e recommendo-lhes que nos guardem ao menos o craneo junto com algumas notas indicando o comprimento total, sexo, côr, etc, do respectivo animal"; Senna, 1924: 213 (batuvira); Ihering (R. von), 1932: 218, 1940: 135 (batuvira); Bueno, 1998: 73 (batovi, sob batuvira); Bueno, 1998: 73 (batuvi, sob batuvira). 
Capororoca ou Pororoca [F. red. de anta-caá-pororoca] Rosa (J.V. da), 1905: 367, 368 ("[variedade] menor, quase preta").

Cambacica Santos (A.V. dos), [1850] 1952: 105 (cambassica, anta pequena).

Tapir-xuré Anôn., 1927: 6 (“He a'anta-mirim ou anta-pequena', que é o TAPIR-XURÉ dos nossos caçadores, menos estimada que o TAPIRASSÚ anta grande").

Xuré Silva (H.), [1913]: 117.

Xurê Saint-Hilaire, 1830: 337 (nota 3).

\section{O TAPIR COMO ALCE OU GRÃ-BESTA}

\subsection{O alce}

$\mathrm{O}$ alce $^{30}$ (Alces alces (Linnaeus, 1758) [Figuras 10.1 e 10.2] é o maior dos cervos, podendo atingir mais de 2 metros de altura ao nível das escápulas e pesar mais de 700 kg (no caso dos machos; as fêmeas são menores). Distingue-se dos restantes membros da família pelo tipo particular de galhadas: geralmente presentes apenas nos machos, têm secção cilíndrica e formato de taça e podem atingir 1,60 m de amplitude. $O$ alce é um animal típico das regiões circumpolares [Figura 10.3]. Na Europa, ocorre essencialmente na Finlândia, na Suécia e na Noruega. Ao contrário do que se possa pensar, as suas longas hastes servem para amenizar a temperatura corporal no verão. A longevidade do alce é, em média, de cerca de 20 anos.

O alce foi chamado por vários autores de magna bellua, gram besta, gran bestia, grand animal, grande beste, magna bestia, magno animal; uns poucos exemplos são os seguintes:

Menabeni, 1581: 1 (magnum animal).

Menabeni, 1584: 1 (grand'animale, gran bestia).

Anguisola, 1587: 186 (magna bellua, gran bestia, magna bestia).

Bacci, 1587.

Goebel, 1595 (gran bestia) [Figura 10.3].

Bacci, 1598a, 1958b (magna bestia).

Ambrosini, 1642.

Roma, [1664] 1753: 477 (granbesta).

Margeret, 1669: 8 (grande beste).

Anônimo, 1675 (gran bestia) [Figura 10.4].

Heins, 1681: [16] ('Idem volunt Galli appellatione suâ, efferunt enim Alcem per la grande beste, sic Scoti etiam eam insigniunt suo great beast. Nec non Itali cum Curonis in cognominatione ferae, quam vocant magno animali, proceritatis rationem habentes conspirant').

Cyprianus, 1688: 248 (grande beste).

Dale 1693: 623.

Pomet, 1694: 24 (grand animal).

Dale, 1696: 567

Palacios, 1706.

Caetano de Santo Antonio 1711: 80, 305-310, 323 (gram besta).

Vigier, 1714: 201.

Valentini (M.B.), 1720: 57 (grande beste).

Palacios, 1792.

Grossinger, 1793: 508.

Nemnich, 1793: colunas 960 e 961 [Figura 10.5].

Hernandez de Gregorio, 1803.

Jimenez, 1826: 285.

Jourdan, 1829: 342.

Henry \& Guibourg, 1830: 153, 275 (gran bestia).

Roulin, 1835: 617 (grande bête, gran bestia, animal magnum).

Jimenez, 1838: 21.

\subsection{A unha de alce como materia medica}

Desde tempos imemoriais a unha do alce (ungula alcis) foi parte integrante de várias composições farmacêuticas, notadamente para a cura da epilepsia.

Segundo Ambrosini (1642: 129):

30 Alce - do protoindoeuropeu *hxólkis - Lat. Alcēs (Mallory \& Adams, 2006: 487) 

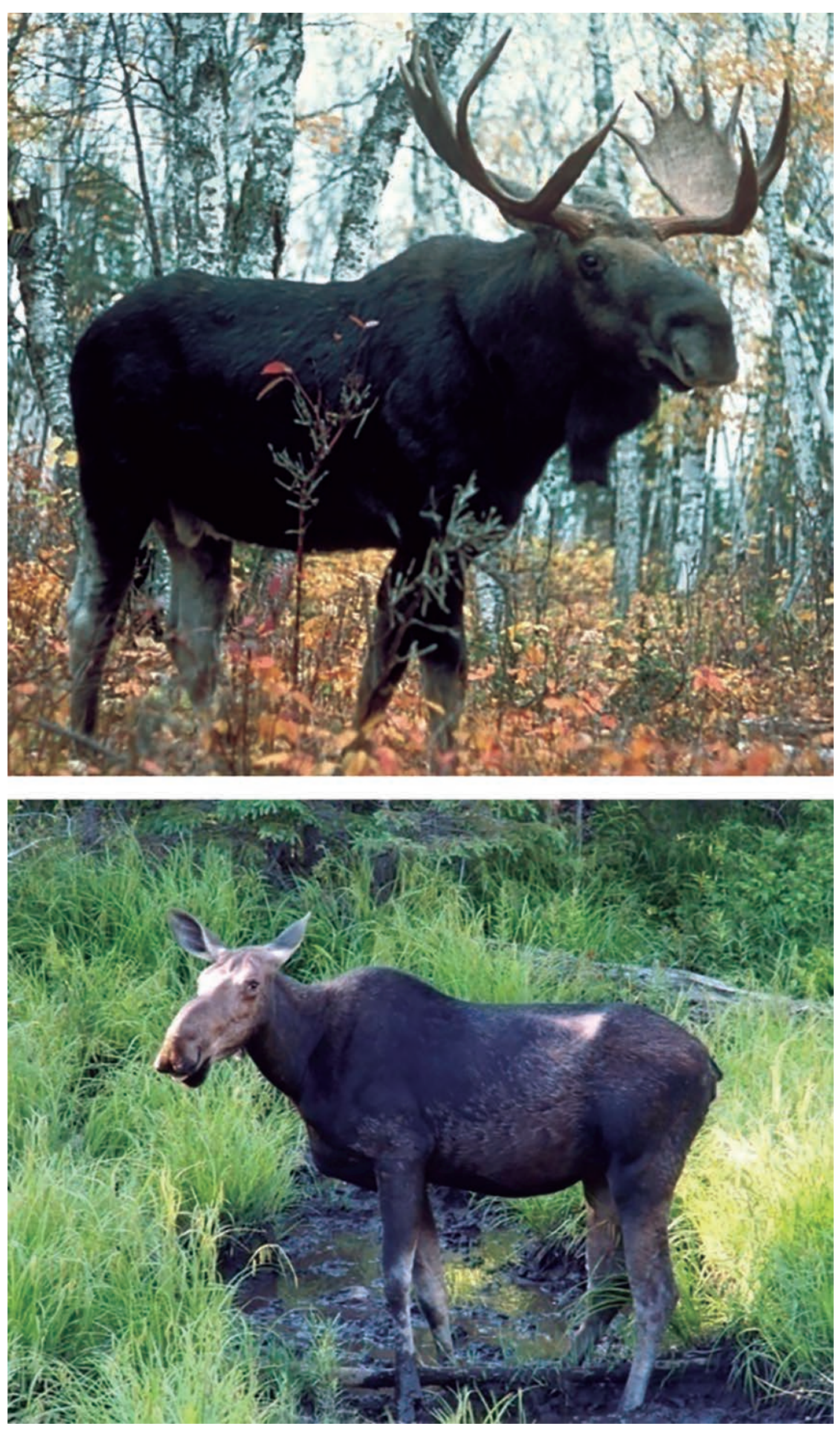

Figura 10.1. 0 alce (Alces alces (Linnaeus, 1758)). Macho (acima) e fêmea. 


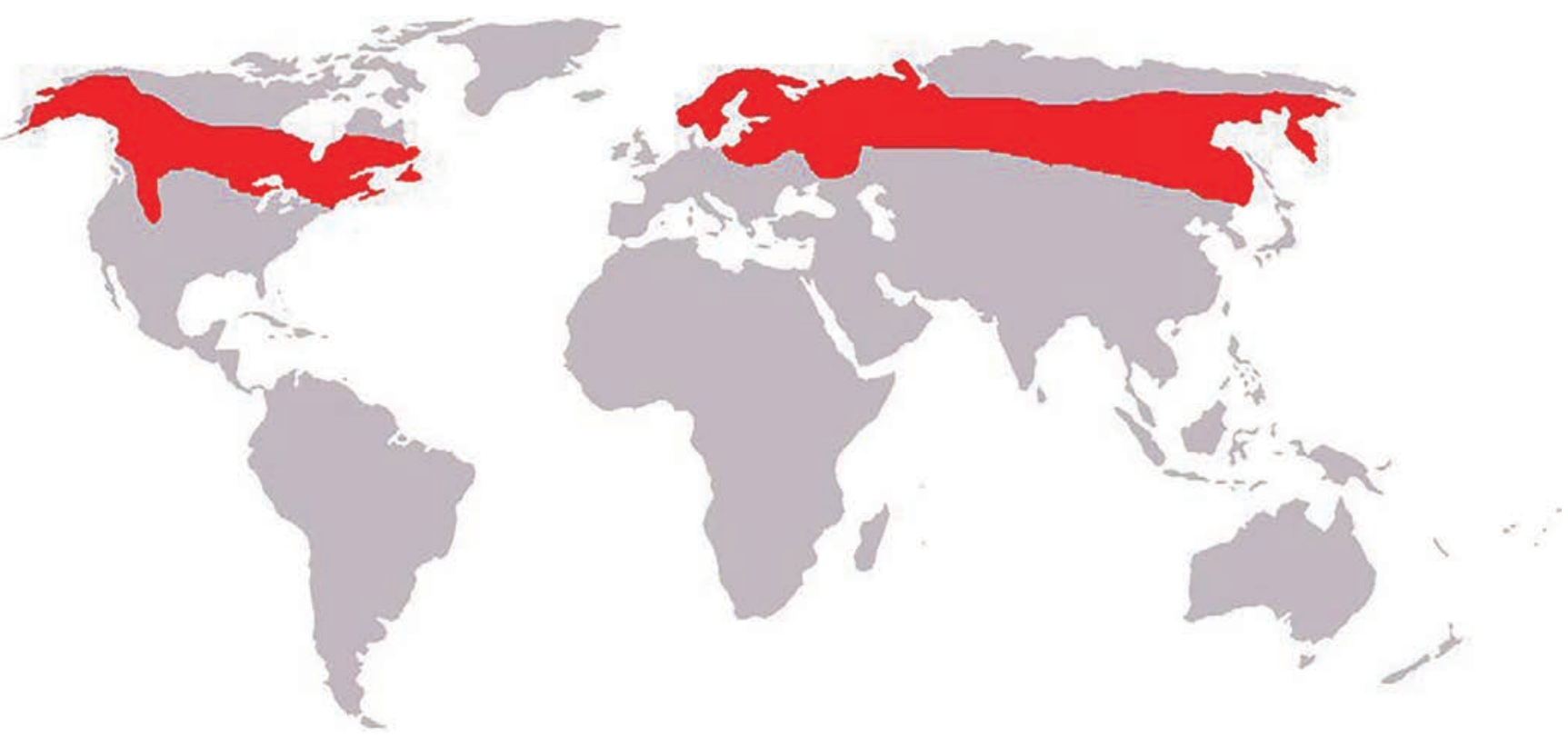

Figura 10.2. Distribuição geográfica do alce.

“Praetera vngues huius magni Animalis in Epilepsia magis commẽdantur, illudq' magna admiratione dignum est, hunc vnguem non tantùm terapeuticum, sed etiã prphylacticum esse: enim solum factam iam epilepsiam curat, sed impendentẽ etiam probibet. Na verò omnis vnguis huius animalis eadem potiatur facultate, variae sunt apud Authores sententiae. Non desunt, qui sinistro vngui posteriori plus tribuunt, quàm aliis, quia hunc bestia auri apponẽs morbum propellst. Nos verò dextro potius, quàm sinistro posteriori primas tribuendas esse censemus: siquidemsi vsum vtriusq' espiciamus, Dexter facilius, quàm sinister auti apponitur, aut vtrũq' vnguiculum indiferiminatim eadem pollere facultate pronunciamus, com vterq' auri sine difficultate iuxta animalis appetitum, \& opportunitatem loci, \& situs, applicari possit. Nihilominus in praeferentia genuinam iconem vnguicoli posterioris dextri pedis exhibemus spectandam [Figura 10.6]".

Pomet (1694: 23-24) explicou os cuidados que se deveria ter para utilizar esse símplice:

“...je diray seulement que le nom d'Eland ou Elan, luy a esté donné par les Allemands, qui signifie Misere, tant à cause qu'il ne vit que dans des lieux inhabitez, comme les bois, ou autres endroits, que parce qu'il est extremement sujet à tomber du haut mal; \& aussi-tôt qu'il en est attaqué, il ne manque pas de se mettre le pied gauche dans son oreille gauche pour se guerir de cette maladie: ce qui a donné sujet aux anciens de croire, que l'ongle ou la corne du pied gauche de cet animal, estoit un remede specifique pour se garantir de l'Epilepsie, du haut mal, ou mal caduc, que nous appellons ordinairement, Mal de Saint, ou de S. Jean. De tout cet animal, on se sert en Medecine que du pied gauche de derriere, tant à cause qu'il est estimé, comme j'ay déja dit, fort convenable pour soulager ceux qui sont attaquez des maladies cy-dessus nommées; c'est le sujet pour lequel ceux qui auront besoin de pied d'Elan, auront le soin qu'il soit veritable, \& que ce ne soit le pied de qualque autre animal semblable, ce qui est assez difficile à connoître, à moins que la jambe ou la peau ne soit avec le pied, tant pour le reconnoître à son poil, que pour voir si c'est le pied gauche de derriere. On prendra garde aussi qu'il ne soit mangé des vers, ce qui arrive assez souvent, lors qu'il est vieux; qu'au contraire, la corne en soit pesante, noire, luisante \& fort unie. Quelques-uns veulent que son nerf, ou priape, ait les mêmes proprietez que son pied, à qui les latins ont donné le nom d'Ungula Alces, qui signifie, ongle ou pied d'Elan. D'autres ont donné à l'Elan le nom de Grand animal, non pas que ce soit le plus haut de tous les animaux; mais parce qu'il est un des plus vistes à la course, \& parce qu'il est d'une force presque indomptable, \& qu'il tuë ou brise tout ce qu'il rencontre. Enfin de la peau de cet animal, on en fait plusieurs ouvrages, conmme de Gands, \& autres semblables".

João Curvo Semmedo, médico da família real portuguesa, também advertiu seus leitores sobre o mesmo assunto (Semmedo, 1718: 10):

"Unha do grão besta, \& suas virtudes.

O Grão besta he hum animal, que na lingua dos Ethiopes Mouros se chama Nhumbo, \& na lingua Portugueza val o mesmo que animal fermoso. A suafórma he de hum perfeyto cavallo em tudo menos: 

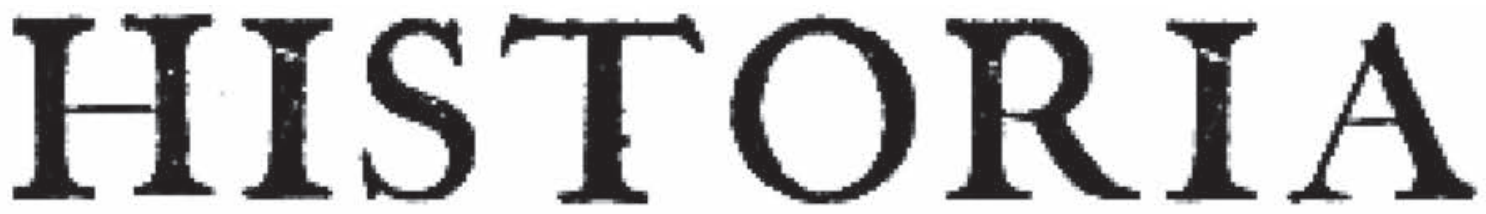

S E V B R E V I S

DESCR I P T IO

A NIMALIS ALCIS QVODVVLGO vocant $G$ ran beftia, deque illius partium,facultatibus, in literatorum \& prafertim occulte natura indagatorum gratiam, edita.

PER SEVERINVM GOEBELIVM SEVERINIF, BORYSSVM.

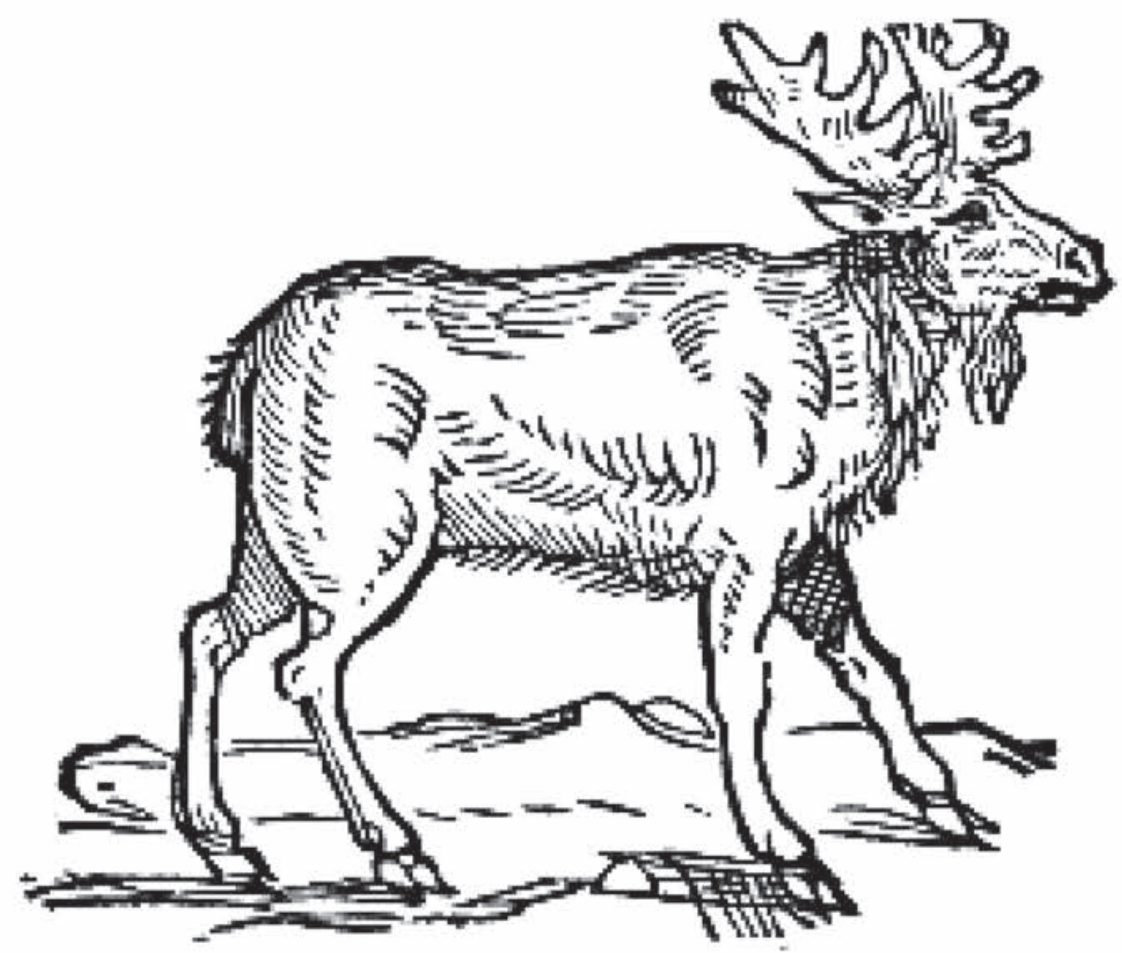

VENET IIS, Apud Ioannem de Albertis. $\mathrm{M} \mathrm{D} \mathrm{XCV}$. 


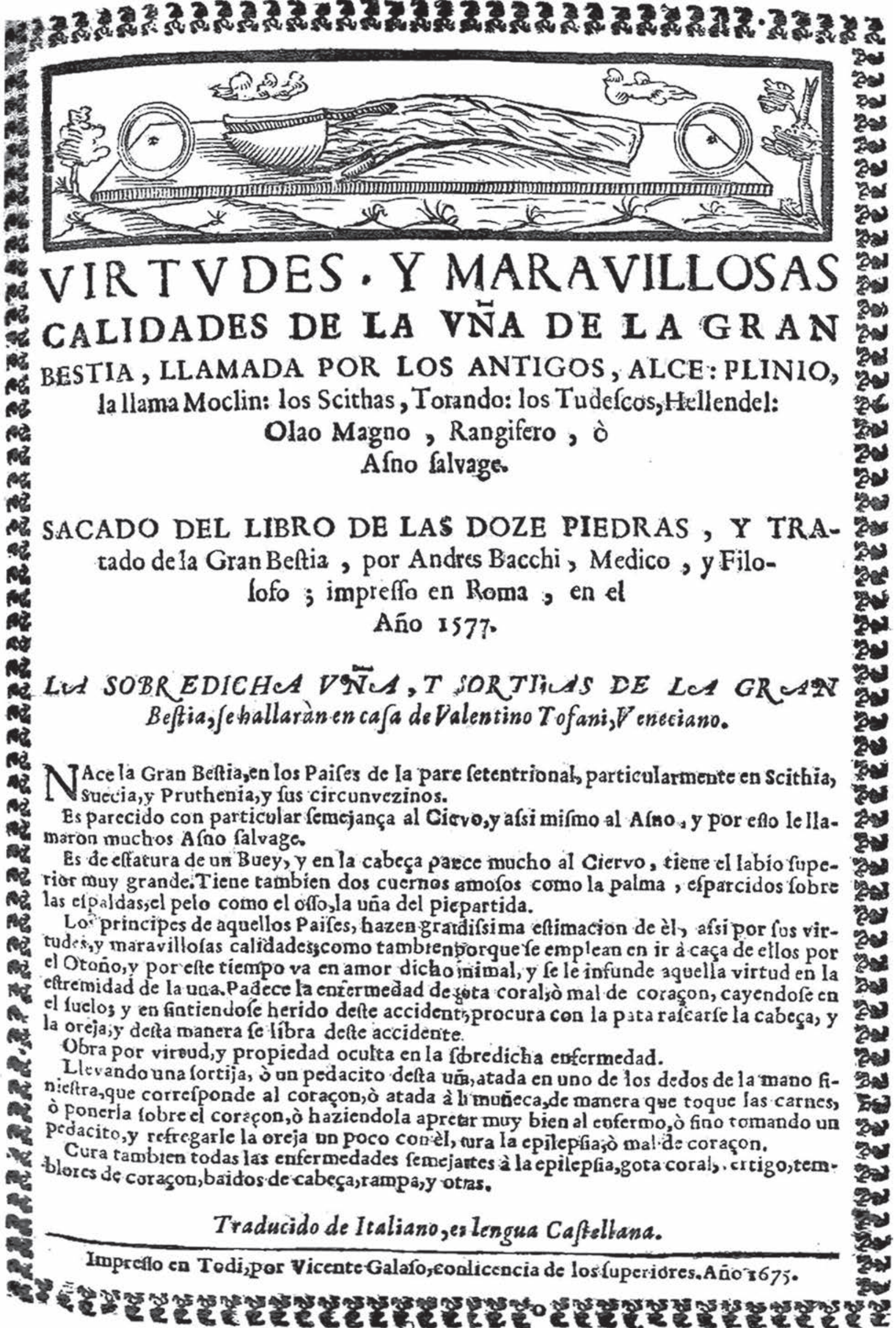

Figura 10.4. Folheto publicado por Anôn. (1675). 


\section{CER}

dretan, slandes cervicales: - eervicales matcall.

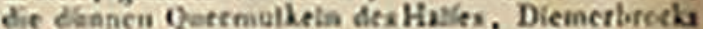
notere Nackenmuthel. Ies cervicaux defiendans of Diemcrbreek ; - cervicolis vena a) extecos, b) ia. teris; - servieslesvertebrae. die llalswibelfeine. les vertebres cervirates; es find fiebre rain Halle cebürige Keochen, die mit den zwîlf Rtickenuir. Eelu und den fas Leudenwirbelo dea RUcken zas. machen. - Cervicales apertincae, weus fich die

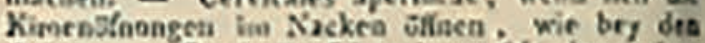
Aslen. - Cerrkalia fpiracula verfabickeuec Ats. phibien.

CERVUS. [Marmat.]

a) Cervus alces.

Deutikh. Das Bleodthier, Elenntlice, Ellend. thie: das Elen, Elenn, Elent, Ekend. Elendt; der Elendhirfch, die Elendkuh; die grotie Beftie ; das Musthier, Mufechier: das Orignal; Alt Elk; Tetrow. Elach.

Holl. Eland, Elanddier; Alt Allańt, Be lande.

Däu. Elsdyr; Nono. Elg, Ellgur, Elsdyr; Islasd Elgur. Elgsdyr; At Yllgur.

Silered. Elg, älg; Dalek. Brind, Brines; Ginel. Dyr.

hlas Elghjort. Elgoxe; fon. Blgko.

Engl. The elk; in Anmisa the moofeder, mose-decr.

Aluglf. Elch.

Franz. Is clan. (cland; ellend); in Ancrits

l.orignal. orignac.

Itat. Ia grandbeftia; grand-animale; alce.

Span. Gran-beftia; alce; clan.

Port. . Gram.bota; alce.

$R=$ ff. Los. Snchatoi; Halbjährig Wolin;

Sibur. Soriat.

Polv. łos.

Böhra. Las, Elegen.

INyr. Los.

Ungr. Jávor.

I.til. Boreedis.

Eh/\%. Pödder.

Fint:l. Hirwi.

lappl. Sarw.

Tstar. Bulan.

Bakhtir. Bulan.

Tilext. Bulan.

Kingi). Bulan.

Baras. Bulan.

Txshucrasth. Bnlan.

sc Ofjak. Pianga.

An Öruj/ry. Chhaja.

\section{$96 r$}

\section{CER}

No/nask. Chondugai.

Txuícress. Tschōrdz.

Wowjas. Pufche, Koje.

II'oget. Tout, Schōrbur.

Bachar. Chowos, Kuk.

Chiviny. Sugun.

Szinjin: 1.üss, Lola, Jüra.

Burizt. Bogu.

Alisguf. Took.

Allancmf. Altechangsel.

Ginf. Iremi.

(Dis Hostcstott. Tkanna, Tkumma.)

Das Elendelier leve in Baropa. Aien und Amerike. corminntich nact Nonden $x 2$ OS die alke oder

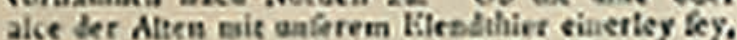

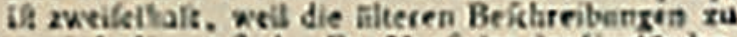
wraic betcimmt fins. Dus Moofeler der Einglinder. nod Jus Origlasl Ler Framzosin in Nondamerike

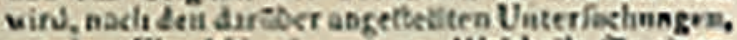

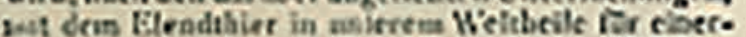
Ioy gehalten. Anch wollen bosige in deu Wrsuern vonSudiatrika klendibiete zefunden baben: dahin ceibüre der Danta der Spanier na Portezike, we. cher in Peru Pogra, in Brafities Tagima und in Gelana Waiporsi getsunte wird. Rs wird inseh ven elnem afrikanilcken Biend, Nimenx Dave oder Lante, Deldasg gethan, velctes, vie der Nateio im Kleigrvicbe Conre, vielen Zocilel ibtis Inist Von der earopkiftien Besensang Elowa ismt fics nit Grwifhetr hein Uripreng angreen.

Dic Gefohiche des Biendeklera in betanst eenog. Rs

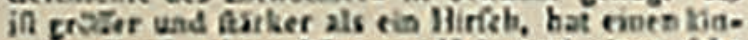
seren Kog?, einen kirseren His and eines fele Klelicn Sthwanz. Es tiebs die nirdrizen, fouchiea sind fehattittell Gegendea. tebe methess in den dichteten Waldern send Whidniffen, daber die Jagd Flir bektivertich in. In der Jugend Lint es bich gut zatren maclica. Soise Friffe. befonders die Bincerea, lind fo Aark, dals es mit ciucn tinzigen Schlage riats Wolf Noder kann. Seis Gaug in ein leblafter, anhaliender Trott. Scistell in dick und widerficbt volt einer rintenhugel. Sein Gr-

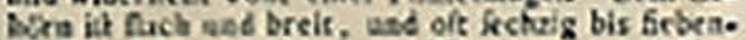
zig Pfund fotwer: das ghute Tater wirgt zuwellen Dis awtahiendert Pfand. Bs nxhet Kxh vos Bume. nobe, Labb, Noos wud allerley andern Venetz. ballen. Sein Fleiks in eftsor und Ehinackhaft. socuders rthimt man die Zunge und bi Nafe. Mit dem Rennthire fuhrs ex faf ciliertey Labensurt. Es vird ron den Rabehirren, bekanderx Lra WJUten, four verfolgt.

Die Fuedsklaten wurden ehemuls zis ein fpecifebes bituel gezen dis Folioglie entweder imertics, oder Eufferlics, als Anutet. fehr eropshtien. Nan lat

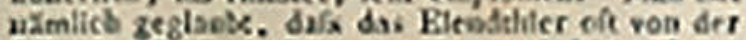
fillendera Suckt befallen urtbe, wod foine Cene. fung dadarch bewirke, dais es firb mit felnen

- Kaiea binter die Oliten Aratoe. Heatizes Tages whirdigt tuas dife alteSace keiarz writesen Widerlegrog. 
a sua cauda tem muy pouco pelo, \& o casco he fendido como unha de cabra; ordinariamente naquelles contornos saõ manchados como Tigres; alguns, que saõ raros, de cor castanho claro.

Só as unhas do pé esquerdo saõ as que tem virtude; as outras, sendo do mesmoanimal, não tem serventia; \& muytas vezes se dà qualquer das ditas unhas, ou vende, \& sendo do mesmo animal não tem prestimo; $\&$ tem a circunstancia de que hade ser tirada a unha sem ser metida no fogo, nem em agua quente, porque perde a virtude.

O animal he sugeyto a accidentes repetidos, \& tem tal instincto, que assim como se vè ameaçado do accidente, mete a unha do pé esquerdo no ouvido, \& assim lhe passa logo a força delle.

Serve a unha do grão besta, trazendoa juntoà carne no musculo do braço esquerdo, ou ao pescoço, \& ainda sobre o peyto, ou no dedo da mão esquerda, engastoada em ouro, de sorte que a unha toque na carne; serve contra os accidentes de gotta coral, \& vágados, \& contra o ar. Preparada em água, \& bebida serve contra o veneno, \& contra as fabres intermitentes.

Nos accidentes de asthma se darà hum escropulo de pó da dita unha misturado com huma chicara de agua de cereijas negras, por quanto a asthma he hũ accidente de gotta coral do bofe, como diz Vanelmoncio: Asthma est caducum pulmonis").

Em sua Polyanthea medicinal (Semmedo, 1704; 68, 77 e 84) descreveu algumas preparações incluindo a unha da grão-besta:

"O ouro potavel he grande remedio contra os Vágados, dando delle cinco, ou seis gottas em agua cozida com hyssopo; em falta de ouro potavel pòde servir a prata potavel, ou a mesma prata preparada filosoficamente, \& misturada com dobrada quantidade de esterco de pavaõ femea, se for molher, ou de pavaõ macho, se for homem, continuando este remedio muitos dias. Polverizar a cabeça, rapada à navalha, com pó dos bichos da seda, tem especial virtude neste caso. Dar cinco, ou seis dias nove gottas de oleo de pao de buxo feito por defectum, untando tambem com elle as fontes da cabeça, \& as arterias que estaõ detraz das orelhas, he grande remedio. O electuario que se faz de huma oitava de ambar branco, outra de pò de unha da gram besta, hum escropulo de almiscar fino, meya onça de pò de pao de Aguila, com hum escropulo de cardamomo menor, outro de noz noscada, misturando tudo com assucar; \& humas gottas de oleo de cravo, se forme electuario, de que daráõ ao doente meya oitava cada dia. Serve tambem para as apoplexias, \& gotta coral".

"O terceiro remedio he dar dar nove dias ao doente tres onças de agua cozida com raiz de pionia negra, que he a melhor, deitando nesta agua oito gottas de fel de cachorrnho de mama, morto daquelle instante, \& em lugar do fel do cachorrnho, podem dar vinte grãos da unha da gram besta, calcinada filosoficamente: quero dizer, calcinada por vapor de agua fervente, \& de nenhuma sorte seja queimada no fogo, como erradamente fazem ao margim, \& ao osso de veado; porque como a virtude desta unha, \& do osso de veado, \& marfim consiste no sal volatil, facilmente se perde, quando se queimaõ; donde se segue hum grande absurdo, porque quando os doentes cuidaõ que compraõ remedio para sua saude, ficaõ enganados, porque só compraõ huma pouca de cinza inutil, \& sobre perderem o dinheiro, perdem o tempo, que poderiaõ aproveitar tomando outras medicinas, de que colhessem mayores frutos".

"A decimaoitava advertencia he, que se o accidente de Gotta Coral for procedido da madre, a que ordinariamente chamamos Gotta Coral Uterina, daremos a beber à mulher meyo quartilho de Oxicrato, que he presentaneo remedio, como tenho experimentado muitas vezes; mas nunca dou este remedio, sem estar certo que o accidente procede da madre. Nem he menos admiravel medicamento, assim para as mulheres, como para os homens, defunallos com aparas de unhas de burro, por quanto a dita unha, na opinião de muitos Authores, tem a mesma virtude que a unha da gram besta. Alguns dam huma oitava do pò da unha direita do burro, desatada em quatro onças de agua de Cardo Santo, continuando este remedio oito, ou nove dias, \& observaõ grande utilidade. Trazer no braço huma manilha da unha do pè direito do burro, ou no dedo hum anel da mesma unha, tem taõ grande virtude contra os accidentes de Gotta Coral, como tem a unha da gram besta: assim o refere Abraham Ecchellense 30. As fumaças de tabaco de fumo deitadas pelos ouvidos, obraõ prodigios em alguns doentes".

Entre muitos outros, escreveram sobre o uso em medicina da unha do alce os seguintes autores: Cordus, 1592: 3731 , 1598: 35; Bacci, 1598b; Du Chesne, 1606: 226; Renou, 1608: 7, 18; Untzer, 1616: 213; Du Chesne, 1617: 226, 488; Genath,

31 Como curiosidade, aqui vai a formulação prescrita por Cordus (1592: 37): "PVLVIS EPILEPTICVS, APVD NOS DICTVS MARCHIONIS.

Radicum Paeonia maris suo tempore effossi (si haberes potest) unciã dimidiam

Visciquercini

Limatura ungulae alcis

selecta

Eboris

Spodij

Corall. rubeorum

Vnicornus, vel eig loco probati Ceruini

Corall. rubeorum 
1618: obs. XXIX; Aldrovandi, 1621: 358; Velez de Arciniega, 1613: 177-178; Cordus, 1627: 621; Schröder, 1648: 44; Johnson, 1652: 193; Panaroli, 1654: 89-90; Bartholin, 1658: 23, 238, 245, 279; Lovell, 1661: 466; Bartholin, 1662: 44, 53, 61; Cordus, 1666: 37, 198; Grüling, 1670: 41; Zwelfer, 1675: 80, 105, 116; Deckers, 1678: 8, 10, 17, 226; Burnet, 1678: 452, 457; Deckers, 1678: 8, 10, 17, 226; Harris, 1683: 312; Gockel, 1683: 135; Manget, 1683: 68, 93, 108, 131, 159, 588, 687, 719; Anôn., 1686: 32; Rolfinck, 1686: 621; Burrh, 1690: 23; Wolff, 1690: 216; Dale, 1693: 623; Paullini, 1695: 223; Dale, 1696: 567; Potier, 1698: 500, 687; Sommerhoff, 1701: 402; Dolaeus, 1703: 77; Valentini (M.B.), 1704: 439; Helmont, 1707: 709; Caetano de Santo Antonio 1711: 80, 305-310, 323; Shipton, 1711: 62, 81, 85; Ludovicus, 1712: 698; Valentini (M.B.), 1716: 297, 304; Hoffmann, 1719: 208; Rzączynski, 1721: 212; Suarez de Ribera, 1721; Baron, 1732: iij, cxxv, 61; Lemery, 1735: 138, 139, 145, 165, 298, 387, 473; Lanzoni, 1738: 88, 284; Hoffmann, 1739: 70; Tralles, 1740: 2, 5, 9, 26, 110, 113, 124, 129, 130, 138, 140, 152, 154, 155, 157; Farvacques, 1741: 76; Rieger, 1743: 353-354; Parenti, 1745: 9, 122, 194, 237; Roncalli, 1747: 45, 175, 244, 398; Milàns \& Rossell, 1749: 40; Wecker, 1750: 132; Andree, 1753: 32, 260; Anôn., 1753: 70; Swaab, 1756: 9; Triller, 1764: 114, 124, 389, 521, 524, 527, 535, 536, 537, 538, 539, 540, 541, 549, 550, $559,560$. 578, 628, 666, 790, 848; Alston, 1770: 40; Anôn., 1770: 66, 105, 107, 116, 118, 119, 121, 123, 134, 142, 187, 193, 200; Haller, 1788: 39, 173; Tissot, 1789: 230, 305, 355, 256, 357; Fuller, 1790: 11, 17, 39, 69, 92, 105, 205; Parenti, 1792: 2, 79, 113, 184, 227; Gray, 1818: 104; Frank, 1821: 395, 396; Marx, 1827: 212; Fenzl, 1834: 103, 121; Frank, 1841: 503, 504; Valentini (M.B.), 1843: 330; 193.

Mas, finalmente, a ungula alcis caiu em desuso; segundo Jimenez (1838: 21):

\section{“DE LA UÑA DE LA GRAN BESTIA.}

Ungula Alcis off. Pezuña del Cervus Alcis Linn., rumiante muy comum en el norte de los continentes.

Esta sustancia ha hecho en algun tiempo, pues se hacian com ella collares para combatir la epilepsia, y entraba en varias composiciones de la antigua polifarmacia (...). Se daba entonces la preferencia á la que provenia del pie izaquierdo, pero en el dia no tiene ningun uso y debe considerarse como un medicamento ridículo".

\subsection{O alce e o tapir}

\section{Como assinalou Roulin (1835: 616):}

“En appliquant le nom d'Anta ou Danta au Tapir, les Espagnols et les Portugais voulurent assimiler cet animal, non à l'Antilope africaine, mais à l'Anta qui leur était le premier connu, à l'Elan. Ce qui le prouve sans réplique, c'est que lorsqu'ils ont écrit en latin, c'est sous le nom d'Alce qu'ils ont désigné le Tapir (Laet (Novus orbis, lib. XV, cap. V)"

Sobre este tema, ver o excelente artigo de Podgorny (2018):

O parco conhecimento da fauna americana, a utilização do couro do alce e do tapir para a fabricação de escudos e o emprego de certas partes desses animais como materia medica explicam a confusão feita pelos autores europeus. Acrescente-se que, para o olhar leigo, as figuras do alce (fêmea; sem galhada) e do tapir [cf., Figuras 10.7 e 10.8] pareciam representar o mesmo animal.

Alce, Anta Anchieta ([1560] 1812: 150) foi o primeiro a associar, no Brasil, o tapir ao alce: "Est aliud animal satis frequens esui aptum, ab Indis Tapiíra, ab Hispanis vero Anta dicitur, ea credo, quae Latinis Alce nominatur: Mulae similis bestia, cruribus aliquanto brevior, pedes habet trifidos, superius labrum prominentissimum, colore est inter Camelum et Cervum medio in nigro declinante: nitissim vidierigit se jubarum loco per cervicem torus ab armis ad caput, in quo erectior aliquantulo totam frontem armata, et viam sibi per nemorum condensa discretis hinc inde lignis aperit: brevissima est cauda nullis munita jubis: sibilum ingentem vice vocis emittit: die dormit et quiescit, nocte huc illuc discurrens diversos arborum fructus pascit, et cum hi defuerint, cortices: cum a Canibus lacessitur, morsibus resistit et calcibus, aut in flumina prosilit, diuque latitat sub aqua, quam ob rem juxta fluvios frequentius versatur; ad quorum oras solet etiam terram effodere et argillam mandere. Hujus ex tergore faciunt Indi cetras, duratas solummodo ad solem, sagittis omnino impervias (Há outro animal, bastante frequente, próprio para se comer, chamado pelos Índios tapiira e pelos espanhóis 'anta'; julgo que é o que em latim se chama 'alce'. É uma fera semelhante à mula, um pouco mais curta de pernas; tem os pés divididos em três partes; a parte superior do beiço é muito proeminente; de cor entre a do camelo e a do veado, tendendo para o preto. Levanta-se-lhe, pelo pescoço, em vez de crinas, um músculo desde as cruzes até a cabeça, com o qual, como é um tanto mais alto, arma toda a fronte e abre caminho por espessos bosques, separando os ramos daqui e dali. Tem a cauda muito curta, desprovida de crinas; dá um grande assobio em vez de grito; de dia dorme e descansa; de noite,

\section{alborum}

Margaritar. prepar. an. drach. unam

Folior. auri puri numero viginti. fiat pulvs.

In catarrhis, intemperie humida \& frigida cerebri, terrorib. nocturnis, in metu apoplexiae \& epilepsia admodū creber apud nos vsus est huius pulueris". 


\section{Alcis vnguiculus pofterior dextri pedis,}

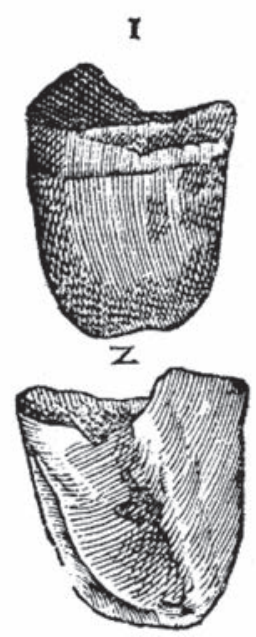

Figura 10.6. Unha do pé posterior direito do alce (Ambrosini, 1642: 130).

corre de um lado para outro; nutre-se de diversos frutos, e, quando não os há, come as cascas das árvores. Quando perseguida dos cães, faz-lhes frente a dentadas e coices, ou lança-se ao rio e fica por muito tempo debaixo d'água; por isso vive quase sempre perto dos rios, em cujas ribanceiras costuma cavar a terra e comer barro. Do seu couro, endurecido, apenas pelo sol, os Índios fabricam broqueis impenetráveis)".

Alce, Tapyrete Laet, 1633: 551:"Alces Tapyrete a barbaris appellari scribit Author Lusitanus, Larius Tapiroussou, Thevetus Tapihire; sunt autem mulis non absimiles, proboscide oblongiore, quam aut contrahunt aut promittunt, sine cornubus, auriculis longioribus et pendulis, colo contractiore, cauda brevíssima, auribus gracilibus, solidis ungulis, carne pene accedente ad bubulam. Natandi atque urinandi peritissimum est anmal, statim petit fundum, et ubi longius processerit, emergit rursus: magna morum in hisce provinciis est copia, ita ut tergoribus illorum barbari clypeos suos obducant aut eadem in ordem distenda et ad solem siccata conforment in parmulas" (Chiquieri, Papavero \& Teixeira, 2011: 69: "O autor lusitano escreve que os selvagens chamam os alces [sic] Tapiretê. Lérty, Tapiroussou e Thevet Tapihire, são bastante parecidos com mulas, têm um focinho longo que retraem e alongam, sem chifres, orelhas longas e pendentes, o pescoço curto, rabo curto, orelhas esguias, unhas duras e sólidas; a carne se aproxima da do boi. É um animal que nada e mergulha muito bem, alcançando o fundo e indo bem longe sob a água, antes de vir à tona; há muitos nessas províncias, de modo que os selvagens cobrem seus escudos com sua pele ou estendem-na em círculo e secando-a ao sol dão-lhe o formato de pequenos escudos").

Ante, Anta ${ }^{32}$, gran Bestia Gumilla 1745: 200-202: "La Nacion Achagua gasta menos dias em bolver com mucha carne de Ante assada: salen los antes del Rio à comer paja tierna: los Achaguas estàn sentados entre la misma paja, y saben remedar bien el ecco del Ante: al tal ecco responde la Anta (es lo que llamamos la gran Bestia) y ambos juntos vienen al reclamo del Achagua: este dispara à cada uno su flecha de veneno, llamada Curare, y ambos caen muertos

32 Gumilla distinguiu o macho como Ante e a fêmea como Anta.

\section{CONRADI GESNERI TI" \\ GVRINI HISTORIAF. ANIMALIVM

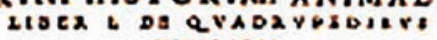 \\ viviresis. \\ DE ALCE.}

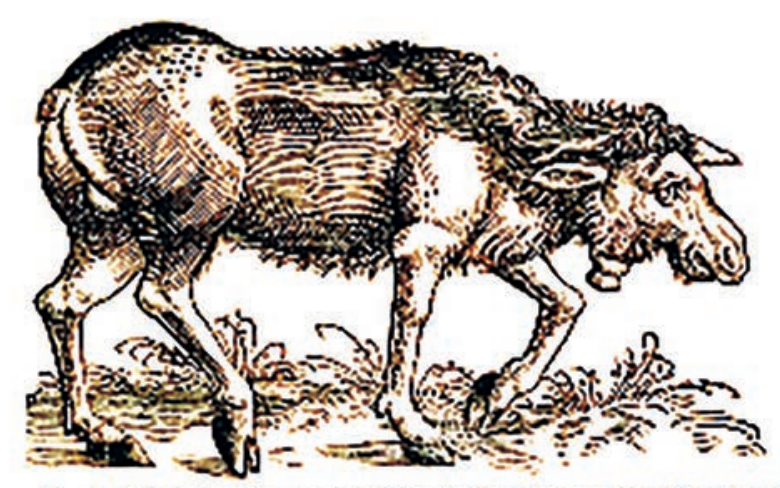

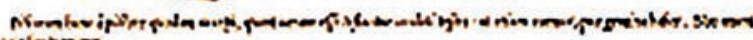

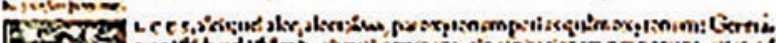
F.

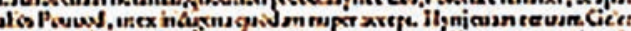

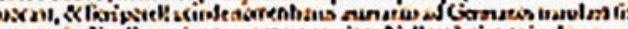

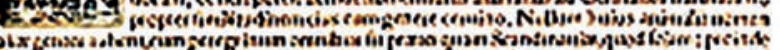

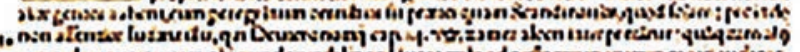

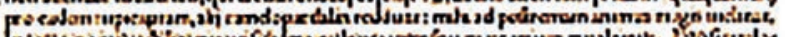

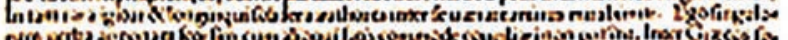

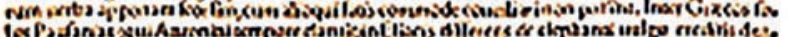

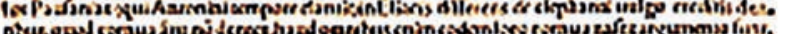

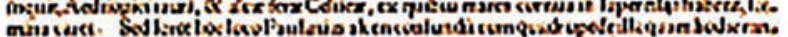

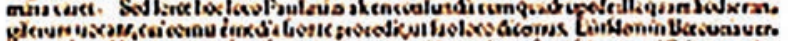

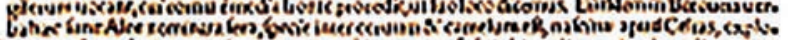

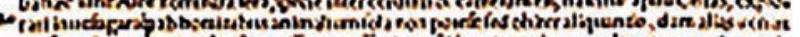

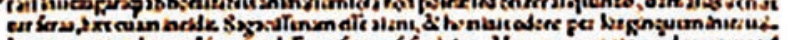

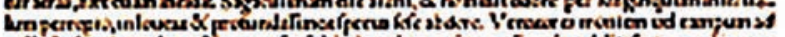

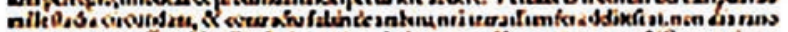

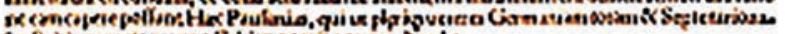

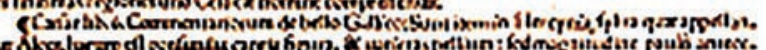

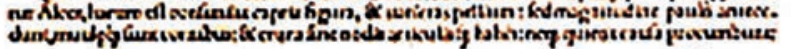

Figura 10.7. Fêmea de Alce (Gesner, 1551: 1).

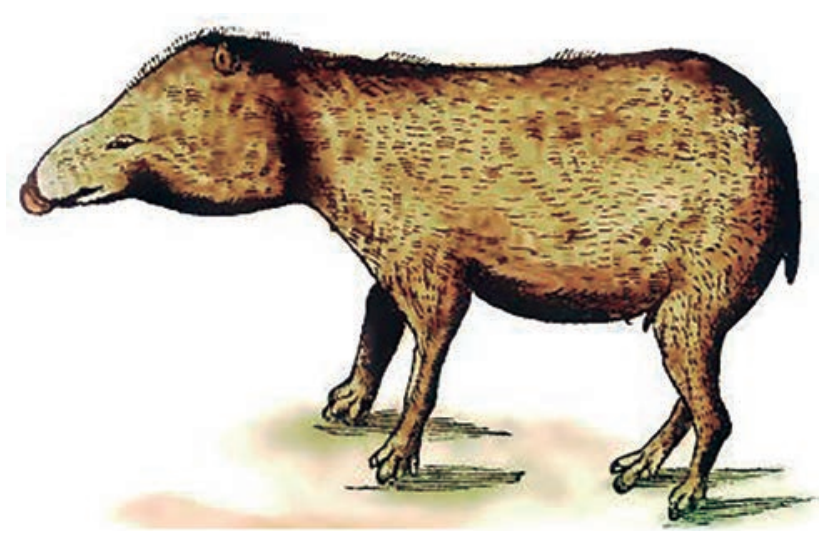

Figura 10.8. Tapiierete (Marcgrave, 1648: 229).

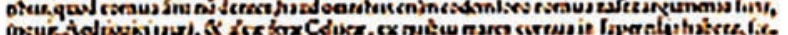

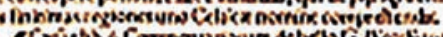

\section{I}

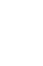

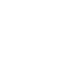


luego al punto; de modo, aque si hai fortuna, en un dia se matan. En el dia siguiente se assan, y al tercero, ò quarto dia yà estàn en sus casas cargados de carne assada, y no despreciable, porque sabe la carne de Ante à muy rica ternera, aunque su figura es la mas rara, que se pueda pensar: su cuerpo es del tamaño de un jumento, ò de un muleto de un año; los quatro pies cortos, que no corresponden al cuerpo, rematan, no en dos pesuñas, como las de la ternera, sino en tres; y estas son las iñas afamadas, y tan apreciables, que vulgarmente se llaman las uñas de la gran Bestia, por haverse experimentado admirables contra la gota coral, tomando de sus polvos, y colgando una de aquellas uñas al cuellio del doliente ${ }^{33}$. La cabeza del Ante tiene alguna semejanza, aunque poca, à la de un cebon, y tiene entre ceja, y ceja um hueso tan fuerte, que con èl rompe quanta maleza, y palos halla por delante en las selvas; de modo, que el tygre se esconde junto al pasto, que vè trillado de los Antes, salta encima del primero, que passa, y le aferra con sus quatro garras: si el parage es limpio, perece el Ante; pero si hai maleza cerca, y arboleda, recae el daño sobre el tygre, porque corre furiosamente el Ante, mete la cabeza por lo mas escabroso de la selva, con tal impetu, y fuerza, aque si el tygre no se ha desprendido antes, perece despedazadi entre los palos, y los abrojos. La cola del Ante tampoco dice, ni corresponded à su cuerpo, porque es costa, delgada, y retrorcida, ni mas, ni menos, quela de um cebon. Tambien tiene clin, que le dà algun ayre; pero no excede de la clin de un jumento: de tan buena gana vive en el prifundo del Rio, ù de la laguna, como en tierra. Es verdad, que para pacer la yerva de su regalo especial, que se llama Gamalote, siempre sale à tierra. Em fin, ella se llama comunmente la gran Besia: no se por què; tal vez será, poraquê es un animal irregular, que viene à resultar de varias partes de otros animales, sin que el todo se parezca à algumo de ellos. Pues què dirè de sus dientes, y de la facilidad, y destreza com que despelleja de alto abaxo à los perros, quando se vê rodeado, y perseguido de ellos el Ante? No dexa su puestyo, por mas que le acometan; y es tal su habilidad, tenacidad de dientes, y fuerza con que arroja al perro que acerto à morder, que quedandose com la mayor parte del cuero del perro, le arroja bien lexos despellejado, y dando terribles ahuliidos, con lo qual huyen los otros perros, espantados de la desdicha de su compañero: Como hace em Ante este daño tal, y tan instantaneamente? Ni los mismos Españoles, que gustan de cazar los Antes, por la diversion, y por el interes de la piel, y de las uãs, que vèn morir em cueros, y sin piel todos los dias à sus perros, so saben decir como es, ni explicae la destreza con que lo hacen. Um Ante, que nos traxeron los Axhaguas à laColonia de Guanapalo, tênia de largo dos varas y quarta".

Tapir, Anta, Danta, Granbestia Clavigero 1781: 155: "TAPIR, quadr. grande dell'Amer. appellato dagli Spagnuoli, Anta, Danta, e Granbestia, e in diverse lingue americane: Tapiè, Tapiìra, Beori, Tlacaxolotl, Huariari, Ssacha-Vacca. \&c.". E na nota (o), na mesma página, acresentou: "lo adopro volentoieri il nome Tapie; perchè è già in uso presso i Zoologisti moderni, e peraltro non è equivoco. Quello di Granbestia è próprio dell'Alce, o Danta si dà ancora al Zebù, quadr... dell'Afica assai diverso del Tapir".

Alce, seu grandis Bestia Dobrizhoffer, 1784: 294-297: "Abstrusiora ad Boream nemora Alce pervagatur, quam Hispani Anta, vel la gran bestia, Itali Dante, Galli Elan, Quaranii Mborebĭ, Abipones Akalèk, Germani das elendthier appellant. Magnitudine asinum adultum, figura, si óculos, caput, pedesque ejus species, porcum exprimit. Aures habet breviores, frontem versus arrectas, dentes peracutos, labia propermodum vitulinae, quorum superius quadam proboscidis specie tumescit, quam irascens protendere consurvit. Pedes anteriores, si rite memini, in duas cavas ungulas, posteriores in tres finduntur. Appendicula glabra, \& depilis, caudam supplet. Pellis fusci coloris est, \& insigniter crassa; Hinc aere siccata ab Abiponibus, Hispanisque pro thorace militari adhibetur ad ensium, sagittarumque ictus retundendos, globis tamen plumbeis, ac hastis, penetrabili. Humanum refugit conspectum bestia, viribus etsi polleat tantis, ut fune cariaceo illaqueata equitem, equumque raptet fugiens. Interdiu fere dormitat, noctu sylvarum latebras obiens herbis pascitur; Arborum, fruticumque ramis cum strepitu confractis ultro, citroque nemus perambulans sui indicium facit. Unam sub vesperum a puteo redeuntem sclopo armatus insectatus sum aliquandiu, sed solo admodum palustri prohibitus assequi haud poteram, Indi sylvicolae jam decipulas e stipitibus paratas alcibus capiendis statuunt, jam sub dumeto latentes earum vocem dexterrime imitantur, \& accurrentes bestias sagittis configunt; Earum siquidem caro seu recens, seu are durata quotidianus prope Barbarorum est cibus, etsi ob duritiem palato haudquaquam jucundissimus. Alcium stomacho, escae receptáculo, marsupium adjacet, in quo lapilli Bezoardici complures, avellana nx vix majores, figura nec teretes, neque ovati sedpolygoni, cinerei, vel plumbei coloris frequentissime reperiuntur. Hos caeteris, quos aliae ferae suppediant, Bezoar lapillis medici preastantiores opinantur, luculentiorisque in medicina efficacitatis. Arapotiyu Indus asolescens, a me praeter alios e sulvis Mbaeverà, quas Mborebǐretâ alcium patriam Barbari vocant, ad S. Joachimi oppidum adductus, ejusmodi lapillorum Bezoàr acervum mihi porrexerat: Cape, mi Pater, ajebat, saluberrimos hos lapillos, quos ex alcibus a me trucidatis collegi. Rogatus a me: Qualem demum virtutem his lapillis ipsi tribuerent, qua ratione iis uterentur in sylva? Nos, respondit, maligno quoties calore corripimur, his lapillis alcium ad focum calefactis artus refricamus nostros, \& convalescimus subinde. Hunc Bezoardici lapidis usum medicis arbitrandum lubens permitto; Fateor equidem, me istius medicaminis nullum unquam cepisse experimentum. Alcium quoque ungulae, céu valetudinis adminicula, \& adversus noxios aeres amuleta magni fiunt ab Hispanis; Quid quod \& in phasmacopolis Europaeis venales prostare dicuntur in varios medicorum usus, máxime ad epilepticos, e variolis, morbillisque laborantes, ut refert Woyts in suo Gazophylacio medico-physico, qui cum aliis, vel ex aliorum relatione affirmat, alces epilepsia, seu morbo comitiali identidem cruciari, \& ad doloris levamentum ungula pedis posterioris sinistram aurem refricare. Num ita sit, viderint

33 Gumilla transfere para 0 tapir as pretensas propriedades da unha do alce. 
illi, qui id affirmarunt, ausique sunt afferere: Alcem a Germanis Elendthier, bestiam miserabilem dici, quod epilepsiae obnoxia sit. Re tamen ipsa a priscis Germanis Elck dicebartur a Graecis ád $k \eta$ a latinis Alx, vel Alce. Cum ex historicis omnibus mihi constet: Alces in Borealibus Eupropae provinciis cornutas esse, viderimque ipsus Paraquarienses cornibus destitui, dubitare caepi, num hae ab illis toto genere differant, \& ob aliquam duntaxat similitudinem eodem nomine insigniantor. Mirabar profecto pleraque, quae de Alcibus Julius Caesar scripsit. Nam libro sexto belli Gallici de Germaniae feris exoticis agens ait: Sunt item, quae appellantur, Alces. Harum est consimilis capris figura, \& varietas pellium, sed magnitudine paulo amtecedum mutilaque sunt cornibus \&c. Inaudita haec, incredibiliaque, quippe authorum caeterorum testimoniis omnio contraria. Alcem vel eminus a caesare visam vix mihi persuadeo, qui eam capris quaecunque demum ratione consimilem affirmÇarit, fors vagis rumoribus deceptus, fors tantis belli negotiis oppressus, ut peregrinus bellicosissimae tum Germaniae feras contemplari nec vacaverit illi, nuc lubuerit. Ad illam provinciam veniens eo animum oculosque convertit unice, ut gentes, quas sibi contrarias viderat, vinceret, expugnaretque de ferarum figura parum solicitus. Nil mirum adeo, illum in Alcibus, aliisque minoris momenti rebus describendis fuisse hallucinatum. Non anderem profecto tanto imperatori, tanto histórico refragari, bisi haec, quae subjicio, apud suetonium [sic] Tranquillum ex recensione Georgii Graevii in vita Julii Caesaris folio mihi 29 legissem: Commentarios de bello Gallico Pollio Asinius parym diligenter, parumque integra veritate a caesare compósitos putas: cum Caesar pleraque, \& qua per alios erant gesta, temere credideris, \& quae per se, vel consulso, vel etiam memória lapsus, perperam edideris: Existimatque rescripturum, \& correcturum fuisse. Haec Pollionis Asinii Augusto Caesari familiaris, \& a Quintiliano magnopere laudati de Caesaris historia opinio erat. Neque illis assentior, qui Alces Equicervos, ac proin hybridas appellant, veluti ex cervo, \& equa prognatos. Id de Alcibus saltem Paraquariensibus ne cogitari quidem prudenter potest; Asperrima equidem \& salebrosa nemora, Alcium stativa, equis perinde ac cervis non ignota modo sunt, sed prorsus inacessa. Centum facile leucarum intervallo Alces campum, ubi cum cervis, equisve convenire possent, nusquam deprehendent. Quodquid sit, illis fidem adhibendam suadeo, qui haec aetate de rebus naturalibus ex instituto copiosus scripserunt" ${ }^{\prime 34}$.

Grande-besta Eckart, [Séc. XVIII]: 21 (sob anta).

Anta, Grão-besta Moreira (A.), ca. 1750: fólio 4r (cf., Papavero \& Teixeira, 2011: 120): "Antas, aq' os Indios chamão Boy do matto, são huns animaes da grandeza de bezerros, mas mo grossos, e as perna Curtas, a pata he rachada, e do mesmo feitio, q' de boy; Correm mo e Com tanta Violencia, q' deyxão o mato quebrado por onde vão Correndo; a Carne he propriamte em tudo, como a de vaca, e he Comer mo gostozo de todos: sua unha he aq' vay pa as boticas pa varios remedios, aq' chamão unha de Grão Besta, sua banha ${ }^{35}$ he singular remedio $\mathrm{p}^{\text {a }}$ Curar obstrucções, dores, e humores Coagulados interiorm ${ }^{\text {te }}$ e exteriorm ${ }^{\text {e }}$ untandose repetidas vezes Com ella $\mathrm{q}^{\text {te }}$ o Cancro. He bem celebrado em todo o mundo, deq' se fazem vestidos pa a guerra, porq' o não passa bala nẽ ferro penetre sendo bem curtido", "Não eram menos supersticiosos a respeito das mulheres em estado de prenhez. Eram condemnadas a um jejum severo em quanto se achavam n'este estado, e deviam se abster de tudo quanto julgavam poder ser nocivo a criança. Assim se bem que em geral ellas como todos os indios fossem mui golosos da carne da grão besta (anta), era-lhes prohibido proval-a com receio de que a criança nascesse com o nariz disforme").

34 Na tradução de Coleridge (1822: 262-265): "THE ANTA, or THE GREAT BEAST. The more secluded Woods towards the North are the haunts of this animal, which the Spanirds call the Anta, or La gran bestia. In size it resembles a full gown ass: in shape, if you except his eyes, head, and feet, a pig. It has rather short ears, inclining towards the forehead, very sharp teeth and lips, like those of a calf, the upper part of which somewhat resembles a proboscis, and is thrust forward by the animal when he is angry. The fore feet are cloven into two hollow nails, the hind feet into three. A smooth unhairy appendage supplies the place of a tail. The skin is of a tawny colour and extremely thick, on which account it is dried in the air by the Spaniards and Abipones, and used for a breat-plate to ward off the blows of swords and arrows, but is penetrable to shot and to spears. This beast flies the sight of man, though possessed of such extraordinary strength as, when caught with a rope, to drag along with him in his flight both horse and rider. It generally sleeps in the day-time, and by night, wandering up and downs the recesses of the woods, feeds upon herbs; it frequently betrays itself by the rustling noise it makes in breaking the branches of shrubs and trees as it walks about the woods. The Indians who inhabit the woods lay traps, made of stakes, to catch the antas, or concealing themselves in some thicket, imitate the sound of their voices, and pierce the beasts on their arrival with arrows; for their flesh, either fresh or hardened by the air, is continually eaten by the savages, though its toughness renders it rather unpalatable. In the stomach of the anta lie a pouch, which is often found to contain a number of bezoar stones, scarce bigger than a hazle-nut, not oblong or oval, but polygonous, and of the colour of ashes or lead. These are thought by physicians superior to the bezoar stones supplied by other beasts, and more efficacious as medicine. Arapotiyu, the young Indian whom I brought from the woods of Mbaeverà, which the savage call the country of the antas, gave me a heap of these bezoar stones: - 'Take, afther', said he,'these most salutaey little stones, which I have collected from the antas I have killed.' On my enquiring what virtue they attributed to them, and how they were used in the woods, he replied - 'Whenever we are seized with a malignant heat, we rub our limbs with these antas' stones, after warming them at the fire, and receive immediate relief'. This use of the bezoar stone I submit to the judgment of physicians, for it must be confessed I never made trial of its virtues. The nails of antas are much esteemed by the Spaiards, as remedies for ill-health, and worn by them as amulets, to defend them from noxious airs: they are said to be sold in the driggists' shops in Eurpe, for various medicinal purposes, especially for persons afflicted with epilepsy, small-pox, and measles, as is related by Woytz in the Medico-physical Thesaurus, where he affirms that antas are often afflicted with epilepsy or the falling-sickness, and that, to relieve the pain, they rub the ear with the nail of the fore-foot. The truth of the fact must be looked to by those who have affirmed it, and have hazarded the assertion that he anta is called by the Germans elendthier, the miserable beast, because it is subject to epilepsy. But in reality it was called by he old Germand elck, by the Greeks å̀ $\kappa_{\eta}$, and by the Latins alx ou alce. As it appears from all writhers, that elks are horned in the northern countries of Europe, and as I myself saw, that those in Paraguay have no horns, I began to doubt whether they were not a different animal altogether, and only bore the same name on account of some similitude.

I do not agree with those who call the elks equicervi, mongrel creatures born of a stag and a mare. This cannot be imagined for a moment of the Paraguayrian antas, which inhabit the roughesr and most rugged forests, not only unknown but almost inaccessible both to horses and stags. The antas choose plains full one hundred leagues distant, where they can never meet with either of those animals. However this may be, I advise giving credit to those who, in the present age, have written more fully on natural history from authority".

35 Nos tempos atuais, entre as populações ribeirinhas do rio Negro, no Amazonas, "A anta (Tapirus terrestris) e a capivara (Hydrochaerus hidrochaerys) foram os mamíferos terrestres mais citados pelos entrevistados (20 citações cada). A gordura de ambas é utilizada na cura de problemas respiratórios (ex. asma, gripe, pneumonia) e inflamrtórios (ex. ferimentos, golpes etc.). 0 pênis ('vergalhão') da anta é desidratado e guardado por longo tempo, sendo preparado em infusões (chás) para tratar de inflamações, hemorragias puerperais e outros problemas uterinos (doenças da 'mãe do corpo')" (Silva, A.L. da, 2008: 351). A "gordura das costas" da anta é conhecida na região como "quilina" (Silva, A.L. da, 2008: 355, tabela 4). Senna (1924: 213) constatou: "A parte mais apreciada da carne da anta é a que se chama pacuera ou paquera; e vem a ser a'fressura' [Conjunto das vísceras - coração, fígado, bofes; de certos animais] que se prepara moqueada logo depois de ser abatido e espostejado 0 animal pelos caçadores sertanejos. Na medicina popular, tem grande voga entre nós a gordura ou banha do chamado 'cacho d'anta' (que se extráe do pescoço ou 'cachaço' deste gordo pachiderme e tem larga applicação para cura das dôres rheumaticas e de algumas outras enfermidades". 
Anta, Grambesta Sáa (J.B. de), 1769: fól. 31r (cf., Papavero, Teixeira, Figueiredo, Barros-Cordeiro \& Pujol-Luz, 2012: 86): "Anta - Hé Animal, q' se acha em $\mathrm{m}^{\text {tas }} \mathrm{p}^{\text {tes }}$ da America, e hé o $\mathrm{q}^{\prime}$ nas Indias Orientaes chamão Grambesta. Cresce athé 5 palmos de alto, 7 de comprido, e 10 de grosura; há de 2 castasm brancas e sinzentas; sustenta-se de ervas, e frutas; hé $\mathrm{m}^{\text {to }}$ feroz $\mathrm{q}^{\text {do }}$ corre fugitivo, arrebenta troncos e páos grosos, e leva adiante de si; hé tão cobarde, $\mathrm{q}^{\prime}$ de $\mathrm{q}^{\prime} \mathrm{q}^{\mathrm{r}}$ sombra se-espanta, e foge; tem o fel por todo o figado, espalhado $p^{r}$ hũas veias $m^{\text {to }}$ sutis; pode estar de bx ${ }^{\circ} d^{\prime}$ agua 1 hora sem respirar engorda este animal $\mathrm{m}^{\text {to; }}$ a carne hé saboroza; o coiro hé $\mathrm{m}^{\text {to }}$ duro, e rijo; pare hũa vez no anno; athé a ide de 1 anno são pintadas de brco, e dali em de vão perdendo esa côr".

Gran Bestia, Danta Julian 1787: 200: "Hay Salvages, que realmente no son otra cosa que monos, pero como son de diferentes colores, que no se ven en los micos, ni monos ordinarios, y por otra parte, remedan las acciones del hombre, los llaman Salvages, pero clarisimamente son monos. De éstos he visto uno en Roma, traido de un forastero entre otros animales, que eran: un Tigre, una Pantéra, un Leopardo, la Gran Bestia, (que no es mas que la Danta de la América) y algunos otros".

Danta, gran bestia Veigl, 1798: 210.

\section{REFERÊNCIAS BIBLIOGRÁFICAS}

Academia Real das Sciencias. 1812. Collecção de noticias para a historia e geografia das nações ultramarinas que vivem nos dominios portuguezes ou lhes são visinhas. Tomo I. Lisboa, Typografia da Academia.

Acuña, C. de. 1641. Nuevo descubrimiento del gran Rio de las Amazonas. Por el Padre Christoval de Acuña, Religioso de la Compañía de lesus, y Calificador de la Suprema General Inquisicion. Al qual fue, y se hizo por orden de su Magestad, el año de 1639. Por la Provincia de Quito en los Reynos del Perú. Al Excellentisimo Señor Conde Duque de Olivares. Madrid, Imprenta del Reyno.

Acuña, C. de. 1986. Nuevo descubrimiento del Gran Rio del Amazonas, en el Año 1639. In: Figueroa, F. de et al. Informes de jesuitas en el Amazonas, 1660-1684. Iquitos, Monumenta Amazonica. p. 25-107.

Adam, L. 1896. Matériaux pour servir à l'établissement d'une grammaire comparée des dialectes de la famille Tupl. J. Paris, Maisonneuve, Libraire-Éditeur. (Bibliothèque Linguistique Américaine, Tome XVIII).

Aguilar, P. de. 1572. Tractado de la cavalleria de la gineta cõpuesto y ordenado, por el Capitã Pedro de Aguilar vezino de Malaga, natural de la ciudad de Antequera. Dirigido à la S.C.R.M. del rey don Philippe nuestro señor, segũdo deste nombre. Acabose de cõponer por el mes de março de 1570. Siendo, el autor, de edad de cinquẽta y cinco años. Contiene diversos avisos y documẽtos, y otras muchas reglas vtiles y necessarias, assi para lo que toca a la doctrina y entrenamiento de los cauallos, como para la perfection y destreza que en esta facultad conuiene q' tengan, en cosas de paz y de guerra los caualleros. Seuilla, En casa de Hernando Diaz impressor de libros, a costa del auctor.

Aharoni, J. 1930. Die Säugethiere Palestinas. Zeitschrift für Säugeterkunde, 5: 327-343.

Albuquerque, A. de. 1512 (1 de abril). Carta de Affonso de Albuquerqyue a El-Rei D. Manuel. Dá cona do estado da armada que deixou na India, quando foi para Malaca; das desordens de Cochim; do desleixo nas fortalezas; das malfeitorias do vigario de Goa; do damno que fazem os boatos da vinda de rumes e de outro governador; pondera a necessidade de segurar a India; pede gente, armas e petrechos de guerra. Como se poderá conservar a amisade dos reis e senhores da India. Inconsiderado auxilio prestado pelo capitão de Goa a Rustalcão. Prividencias de Cormandel para Malaca. Pede mercadorias para negocio e pagamento de soldos. Informa da sucessão do reino de Onor. Contenda com Timoja por haver tomado duas naus de Chaul. Vassallagem offerecida pelo rei das Maldivas. Navios e provimentos que mandou a Malaca; commercio que ali se póde fazer; boas condições d'aquella cidade. Necessidade de proteger os casados de Goa. Presentes do rei de Siam, salvos do naufragio da Flor de la Mar que se enviam para o reino. Remette amostras da moeda que mandou cunhar em Malaca e do ouro da mina de Menencabo. Manda uns mappas da ilha de Goa, de Dio, e de uma ilha do canal de Cambaia, e copia de parte de uma importante carta nautica de um piloto de Java. Inconvenientes do peso novo mandado usar na India, etc. (Corpo Chron., parte 1a., maço 11, no. 50). in Ramos-Coelho, q.v. p. 232-261.

Albuquerque, A. de. 1513 (4 de dezembro). Carta de Affonso de Albuquerque a El-Rei D. Manuel. Relata as obras que se estão fazendo na armada e para fortificar a cidade de Goa, a maneira favoravel por que recebeu os mercadores, capitães e mestres das naus de Ormuz que ali chegaram. Quaes as obras a que estaa procedendo em Banestarim; como despachou embaixadores ao Sabaio, e aos reis de Cambaya, Narsinga e Vengapur; as obras que fazia em Pangim; 0 conselho que tomou com os capitães sobre ir tomar Adem e entrar no mar Roxo; os sucessos da viagem; os assaltos áquella cidade; a entrada do dito mar, com muitas noticias d'elle e d'ella; e como voltou á India (Corpo Chron., parte 1a., maço 14, no. 15). in Ramos-Coelho, q.v. p. 304-339.

Albuquerque, A. de. 1557. Commentarios de Afonso Dalboquerque capitão geral \& gouernador da India, collegidos por seu filho Afonso Dalboquerque das proprias cartas que elle escreuia ao muyto poderoso Rey dõ Manuel o primeyro deste nome, em cujo tempo gouernou a India. Vam repartidos em quatro partes segũdo os tempos de seus trabalhos. Lixboa, loam de Barreyra jmpressor del Rey nosso Senhor. [0utras edições em 1576 e 1774].

Aldrovandi, U. 1621. Vlyssis Aldrovandi patricii bononiensis Quadrvpedvm omniū bisvlcorū historia, Joannes Cornelivs Vterverius belga colligere incaepit. Thomas Dempstervs baro a Mvresk scotus perfectè absoluit. Hieronymvs Tambvrinvs in lucem edidit. Ad illustrissimvm, et reverendissimvm D. Paridem Lodroniū comitem archiepiscopum et principem salisbvrgensem sedis apostolicae legatvm natvm. Cum indice copiosissimo. Bononiae, Apud Sebastianum Bonhommium.

Almeida, M.B. de; Smith, M.; Lima, E.C. de; Mendes, M.K.; Piyãko, M.; Aquino, T.V. de \& Andrade, A.G. de. 2002. Bichos de cabelo. In: Cunha, M.C. da \& Almeida, M.B. de (Orgs.). q.v. p. $455-509$.

Alston, C. 1770. Lectures on the materia medica: Containing the natural history of drugs, their virtues and doses: Also directions for the study of the materia medica; and an appendix on the method of prescribing. Published from the manuscript of the late Dr. Charles Alston, Professor of Botany and the Materia Medica in the University of Edinburgh by John Hope, M.D. Professor of Medicine and Botany at the University. In two volumes. Vol. I. Edinburgh, Edward and Charles Dilly, London \& A. Kincaid and J. Bell. 
Ambrosini, B. 1642. Paralipomena accuratissima historiae omnivm animalivm, quae in voluminibus Aldrouandi desiderantur. Bartholomaevs Ambrosinvs in patrio bononiensi Archigymnasio simpl. med. Professor ordinarius, musaei illustriss. senatus bonon. Horti publ. Praefectus summo labore collegit. Marcvs Antonivs Bernia bibliopolae bononienss proprijs sumptibus in lucem edidit. Bononiae, Typis Nicolai Tebaldini.

Amoretti, C. 1800. Primo viaggio intorno al globo terracqueo ossia Ragguaglio della navigazione alle Indie Orientali per la via d'Occidente fatta dal cavaliere Antonio Pigafetta, patrizio vicentino, sulla squadra del Capit. Magaglianes negli anni 1519-1522. Ora pubblicato per la prima volta, tratto da un Codice MS. della Biblioteca Ambrosiana di Milano e corredato di note da Carlo Amoretti, dottore del Collegio Ambrosiano. Con un transunto del Trattato di Navigazione dello stesso autore. Milano, Nella Stamperia di Giuseppe Galeazzi.

Amorim, F.G. de. 1873. Viagens pelo interior do Brazil. Nova terra da promoção. - Expedição ao rio Tucurií. - A Jutahycica. - Indias domesticas. - 0 portuguez Ferrugem. - Caçada. - Viagem através da floresta virgem. - As onças. - A picada perdida. - Chegada à aldeia dos índios jurunos. - Usos e costumes d'estes selvagens. - Descida pelo Xingú e salto da cachoeira grande. Artes e Letras, Lisboa, 2: 75-76, 87-89 (maio), 98-100 (julho), 118-121 (agosto), 133-136 (setembro), 150-153 (outubro), 170-173 (novembro), 183-185 (dezembro).

Amorim, F.G. de. 1874. Theatro de Francisco Gomes de Amorim. Socio da Academia real das sciencias de Lisboa. 0 Cedro Vermelho, Vol. II [Notas e esclarecimentos]. Lisboa, Imprensa Nacional.

Anchieta, J. de, Pe. 1988. Cartas, informações, fragmentos históricos e sermões. São Paulo, Editora Itatiaia \& Editora da Universidade de São Paulo. [A carta de Anchieta de 1560, Epistola quam plurimarum rerum naturalium quae S. Vicentii (nunc S. Pauli) provinciam incolunt sistens descriptionem, traduzida, está às pp. 113-139].

Anchieta, J. de, Pe., S.J. [1560] 1812. Epistola quam plurimarum rervm naturalium, quae S. Vicentii (nunc S. Pauli) provinciam incolunt, sistens descriptionem. In: Collecção de notícias para a história e geografia das nações ultramarinas. Lisboa, Academia Real das Sciencias, 1812. q.v. p. 127-178.

Andree, J. 1753. Cases of the epilepsy, hysteric fits, and St. Vitus's dance, with the process of cure: Inperspersed with practical observations. To which are added cases of the bite of a mad dog, an a method that has been found successful. The second edition. With emendations and additions in the introduction, and some new cases and inspections of dead bodies. By John Andree M.D. Of the College of Physicians in London. London, Printed for W. Meadows and J. Clarke.

Anguisola, A. 1587. Compendivm simplicivm et compositorvm medicamentorum quorum est frequens vsus apud medicos \& pharmacopolas, ab Antonio Anguisola Art. \& Med. Doctore Comite atq' Equite Palatini ex peritorum philosophorum \& medicorum monumentis collectum; in quo nomina, natura, loca, \& integritatis notae simplicium \& substitutorun, vnà cum medicamentorum compositorum descriptione, \& numero pro vsu idoneo, breuibus, fidissimèq' explicantur; ad philosophia medicinaeq' studiosorum gratiam, pharmacopolarum commodum, \& vtilitatem publicam editum. His annectitur VNICORNIS celeberrimi quadrupedia historia, antehac a nemine ita diffusè, lucide, \& fideliter exarata; cuius occasione omnia cornigera nominatim recensentur, \& nonnulla scitu digna, iucunda, \& vtilia enarrantur de natura orygis, bisontis, asini indici; rhinocerotis; equi indici; bouis indici; camphure; \& bruti, quod vulgo dicitur la gran bestia; rangiferi; semptentrionalis tricornis. Placentiae, Ex Typis lo. Bazachij.

Anôn. [? 1483]. Relacion curcunstaciada de lo acaecido en la prision del Rey Chico de Granada, año de 1483. In: Lafuente y Alcántara, E. (0rg.). q.v. p. 47-67.

Anôn., ca. 1526. Le voyage et nauigation, faict par les Espaignols es Isles dez Mollucques. des isles quilz ont trouue audict voyage, des Roys dicelles, de leur gouuernement \& maniere de viure, auec plusieurs autres choses. Paris, En la Maison de Simon de Colines, libraire iure de luniversite de Paris.

Anôn. 1675. Virtudes, y maravillosas calidades de la vña de la gran bestia, Ilamada por los antiguos, alce: Plinio, la llama Moclin: Ios Scithas, Torando; Ilos Tudescos, Hellendel: Olao Magno, Rangifero, ó asno salvaje. Sacado del Libro de las Doce Piedras, y Tratado de la Gran Bestia, por Andres Bacchi, medicom y filosofo, impresso en Roma, en el año 1577. Todi, Vicente Galafo. [Folheto].

Anôn. 1771. Diccionario da lingua geral do Brasil que se falla em todas as villas, lugares e aldeas deste vastissimo Estado. Escrito na Cidade do Pará. Anno 1771. Biblioteca da Universidade de Coimbra.

Anôn. 1795. Diccionario portuguez, e brasiliano. Obra necessaria aos ministros do altar que emprehenderem a conversão de tantos milhares de Almas que ainda se achão dispersas pelos vastos certões do Brasil, sem o lume da Fé, e Baptismo. Aos que Parocheão Missões antigas, pelo embaraço com que nellas se falla a Língua Portugueza, para melhor poder conhecer o estado interior de suas consciências. A todos os que se empregam no estudo da Historia natural, e Geographia daquelle paiz; pois conserva constantemente os seus nomes originarios e primitivos. Primeira Parte. Lisboa, Officina Patriarchal.

Anôn. [ca. 1200] 2009. Cantar del mio Cid. Barcelona, Linkgua Ediciones S.L.

Anôn. [Séc. XVIII] (2). Prosodia da lingoa [dos Indios], fólios 2r-84v, in Anôn., [Séc. XVIII] (1), q.v.

Anôn. 1686. Pharmacopaea amstelredamensis, of d'amsterdammer apothek, in welke allerlei medicamenten, zijnde tot Amsterdam in't gebruik, konstiglijk bereid worden, also ok des selfs krachten en manier van ingeven. Den derden druk naukeurigh oversien. By Jan ten Hoorn, Boekverkoper, t'Amsterdam.

Anôn. 1730 [Ano da Hégira de 1142]. Tarih-i Hind-i garbi [Descrição da Índia do Oeste]. Constantinopla, Ibrahim Mütefferrika. [cf., Goodrich, 1968, q.v.].

Anôn. 1750. Gramatica da Lingua Geral do Brazil. Com hum Diccionario dos vocabulos mais uzuaes para a intelligencia da dita lingua. Pará. Biblioteca da Universidade de Coimbra, MS. 69.

Anôn. 1753. The new dispensatory: Containing I. The theory and practice of pharmacy. II. A distribution of medicinal simples, according to their virtues and sensible qualities. The description, use, and dose of each article. III. A full translation of the London and Edinburgh Pharmacopoeias; with the use, dose, \&c., of the several medicines. IV. Directions for extemporaneous prescription; with a select number of elegant forms. V. A collection of cheap remedies for the use of the poor. The whole interspersed with practicak cautions and observations. Intended as a correction, and improvement of Quincy. London, Printed for J. Nourse.

Anôn. 1770. Dispensatorium pharmaceuticum austríaco-viennense, in uo hodierna die usualiora medicamenta secundum artis regulas componenda visuntur. Typis Joannis Thomae nobilis de Trattnern, Caes. Reg. Aulae Typographi et Bibliopolae.

Anôn. 1927. Anta. Careta, Rio de Janeiro, 20(974): 6.

Anôn. 1961. Dicionário para estudantes e curiosos do reino animal. Fauna, 20(10): 40-43.

Anôn. ca. 1526. Le voyage et nauigation, faict par les Espaignols es Isles dez Mollucques. des isles quilz ont trouue audict voyage, des Roys dicelles, de leur gouuernement \& maniere de viure, auec plusieurs autres choses. Paris, En la Maison de Simon de Colines, libraire iure de luniversite de Paris.

Araujo, R. de. 1510 (6 de fevereiro). Carta de um portuguez captivo (provavelmente Ruy de Araujo, feitor de Malaca), escripta, segundo parece, ao gobernador da India, Affonso de Albuquerque, dando muitas noticias d'aquella terra, do seu comercio, forças e navegação; referindo-se á traição que o rei de Malaca Ihe fez e 
a seus companheiros (na expedção de Diego Lopes de Sequeira), e instando para que uma armada mostre o nosso poder n'aquellas parte e os solte (gaveta 14a maço 8, no. 21). In: Ramos-Coelho, q.v. p. 219-225.

Argote de Molina, G. 1575. Discvrso hecho por Gonçalo de Argote y de Molina, sobre la poesía castelana contenida en este libro, fólios 93r-97r, in Juan Manuel [de Castilla], q.v.

Argote de Molina, G. 1588. Nobleza del Andalvzia, Al catolico don Philipe n.s. rey de las Españas de las Dos Sicilias de Hiervsalem de las Indias Orientales i Occidentales arhcidvque de Avstria dvque de Borgoña de Bravante i de Milan cõde de Hapsbvrg de Flandes i de Tirol hiio de Carlos I nieto de Philipe padre de la patria piadoso felice avgusto i vencedor, Gonçalo Argote de Molina dedico i ofrecio esta historia. Seuilla, Fernando Diaz.

Arronches, J. de, Frei. 1739. Caderno da língua. MS no Museu Paulista, Universidade de São Palo, São Paulo. [cf., Ayrosa, 1935, 1937].

Ashe, T. 1812. A commercial view, and geographical sketch, of the Brasils in South America, and of the island of Madeira; being a description of the Portuguese colonies, islands, cities, chief towns, harbours, Rivers, \&c. \&c. together with their climate, soil, and produce; trade, religion, manners, custom, \&c. Serving as a guide to the coomercial world, and pointinh out to the manufacturing towns of Sheffield, Birmingham, Manchester, Stockport, Leeds, Northampton, Nottingham, Coventry, Stroud, Dursley, Wooton, Painswick, \&. New Sources of wealth and springs of industry, by directing their attention to the formation of such goods as are consumed in the New World. Allen \& Co., London.

Assis, C.F. de. 2000. Neêe ryru avañe'ë. Dicionário guarani-português. São Paulo, Edição da Autora.

d'Avity, P. 1637. Description generale de l'Ameriqve, troisiesme partie dv monde. Avec tovs ses empires, royaumes, estats, et repvbliqves. Où sont deduicts \& traictés par ordre leurs noms, assiette, confins, moeurs, richesses, forces, gouuernements, \& religion: Ensemble la genealogie des empereurs, roys, \& princes souuerains lesquels y ont dominé iusques à nostre temps. Paris, Clauvde Sonnivs.

Ayrosa, P.M. da S. 1934. Diccionario portuguez-brasiliano e brasiliano-portuguez. Reimpressão total da edição de 1795, seguida da 2a parte, até hoje inédita, ordenado e prefaciado por P.M. da S. Ayrosa. Revista do Museu Paulista, São Paulo, 18: 17-322.

Ayrosa, P.M. da S. 1935. 0 Caderno da Lingua ou Vocabulario Portuguez-Tupi de Frei João de Arronches, 1739. Notas e commentarios à margem de um manuscripto do Séc. XVIII. São Paulo, Imprensa Official do Estado.

Ayrosa, P.M. da S. 1937.0 caderno da lingua ou vocabulario portuguez-tupi de Frei João de Arronches - 1789. Notas e commentarios á margem de um manuscripto do Séc. XVIII. Revista do Museu Paulista, São Paulo, 21: 49-322.

Ayrosa, P.M. da S. 1938. Vocabulario na lingua brasilica. Manuscrito português-tupí do seculo XVII, coordenado e prefaciado por Plinio Ayrosa. São Paulo, Departamento de Cultura (Coleção Departamento de Cultura, Vol. XX).

Azara, F. de. 1802. Apuntamientos para la historia natural de los quadrúpedos del Paragüay y Rio de La Plata. Tomo primero. Madrid, Imprenta de la Viuda de Ibarra.

Azara, F. de. 1809. Voyages dans l'Amérique méridionale par Don Félix de Azara, depuis 1781 jusqu'en 1801; contenant la description géographique, politique et civile du Paraguay et de la rivière de La Plata; I'histoire de la découverte et de la conquête de ces contrées; des détails nombreux sur leur histoire naturelle, et sur les peuples sauvages qui les habitent; le récit des moyens employés par les Jésuites pour assujetir et civiliser les indigènes, etc. Publiés d'après les manuscrits de l'auteur avec une notice sur sa vie et ses écrits, par C.A. Walckenaer; enrichis de notes par G. Cuvier... Suivis de I'histoire naturelle des Oiseaux du Paraguay et de la Plata, par le même auteur, traduite, d'après l'original espagnol, et augmentée de notes par M. Sonnini.Accompagné d'un atlas de vingt-cinq plances. Tome premier. Paris, Dentu, Imprimeur-Libraire.

Bacci, A. 1587. Le XII. pietre pretiose le qvali per ordine di Dio nella santa legge, adornauano i vestimenti del sommo sacerdote. Aggivntevi il diamante, le margarite, el'oro, poste da S. Giouanni nell'Apocalipse, in figura della celeste Gierusalemme: Con vn sommario dell'altre pietre pretiose. Discorso dell'alicorno, et delle sve singolarissime virtù. Et della gran bestia detta alce da gli antichi. Di Andrea Bacci medico et filosofo. All'illustriss. et reuerendiss. S. Alessandro Peretti cardinal Mont'Alto. Roma, Appresso Giovanni Maryinelli.

Bacci, A. 1598a. De monocerote sev vnicornv, eivsqve admirandis viribvs et vsu, tractatus, per excelentissimum \& clarissimum D. Andreas Baccivm, philosophum, medicum, \& ciuem romanum, italica lingua conscriptus, nunc vero publicae vilitatis gratia. A Wolfgango Gabelchover, artivm et medicinae doctoris, latiné redditus. Cvi ob argvmento ferè similitudinem, accessit alius, de magna bestia, ab antiquis alce, germani Ellend, vocato, eiusq' vngulae pro epilepsia \& consimilibus morbis abigendis, viribus \& vsu, libellos ab eodem D. Andrea Baccio italicé conscriptus, \& à Wolfg. Gabelchouer in latinam linguam conversus. Stvtgardiae Imprimebat Marcus Fürsterus.

Bacci, A. 1598b. De magna bestia, a nonnvllis alce, germanis Ellend, appelata, eiusq' occultis proprietatibus, epilepsiae resistentibus. Varijs ítem diuersorum animalium generibus. Tractatus Andreae Baccii, medici et philosophi romani, in itaica lingua conscriptus, nunc verò publicae vtilitatis gratia, in latinum sermonem cinuersus, a Wolfgango Gabelchover, artium \& medicinae doctore. Ecudebat Marcus Fürsterus, Stvtgardiae.

Baião, A. 1940. 0 manuscrito Valentim Fernandes oferecido à Academia por Joaquim Bensade. Leitura e revisão das provas pelo académico titular fundador António Baião. Lisboa, Academia Portuguesa da História.

Barbier de Meynard, C. \& Courteville, P. de. 1869. Maçoudi. Les Prairies d'Or. Texte et traduction par C. Barbier de Meynard et Pavet Courteville. Paris, A l'Imprimerie Royale. v. 3.

Barbosa-Rodrigues, J. 1881. Lista de arvores, animaes, etc. [Notas a Luccock, 1881, q.v.]. Revista trimensal do Instituto Historico, Geographico e Ethnographico do Brasil, Rio de Janeiro, 44(1): 35-130.

Barbosa-Rodrigues, J. 1882. Notas a Luccok sobre a flora e fauna do Brazil. Rio de Janeiro, Typ. Universal de H. Laemmert \& C.

Baril, V.L., Comte. de La Hure. 1862. L'Empire du Brésil. Monographie complète de l'empire sud-américain. Ouvrage dedié à S.M.I. Dom Pedro Il et orné d'un magnifique portrait de ce souverain. Paris, Ferdinand Sartorius, Libraire-Éditeur.

Barlaeus, G. 1647. Gasparis Barlaei Rervm per octennivm in Brasilia et alibi gestarum, sub praefectura illustrissimi Comitis I. Mavritii, Nassoviae, \&c Comitis, nunc Vesaliae Gubernatoris \& Equitatus Foederatorum Belgii ordd. sub Avriaco Ductoris, Historia. Amstelodami, Ex Typographeio loannis Blaev.

Barlaeus, G. 1660. Gasparis Barlaei Rerum per octennium in Brasilia et alibi gestarum, sub praefectura illustrissimi Comitis I. Mauritii, Nassauiae, etc., Comitis, Historia. Editio secunda. Cui accesserunt Gulielmi Pisonis medici Tractatus 1. De aeribus, aquis \& locis in Brasilia. 2. De arundine sccharifera. 3. De melle silvestri. 4. De radice altili Mandihoca. Clevis, T. Silberling.

Baron, H.T. 1732. Codex medicamentarius, seu Pharmacopoea parisiensis, ex mandato Facultatis Medicinae Parisiensis in lucem edita, M. Hyacintho Theodoro Baron, decano. Parisiis, Apud Guillielmum Cavelier. 
Barros, J. de. 1552. Asia de Joam de Barros/dos fectos que os Portugueses fizeram no descobrimento e conquista dos mares e terras do Oriente [Decada primeira]. Lisboa, Officina de Germão Galharde.

Barros, J. de. 1628. Decada primeira da Asia de loão de Barros dos feitos que os portvgueses fezerão no descobrimento \& conquista dos mares \& terras do Oriente. Dirigida ao Senado da Camara desta cidade de Lisboa. Lisboa, Impressa per lorge Rodriguez.

Barros, J. de. 1777. Da Asia de João de Barros. Dos feitos, que os Portuguzes fizeram na conquista, e desbravamento das terras, e mares do Oriente. Decada primeira, parte primeira. [Tomo I de] Da Asia de João de Barros e de Diogo de Couto. Nova edição offerecida a sua Magestade D. Maria I. Rainhja Fidelissima. Lisboa, Regia Officina Typographica.

Barros, J. de. 1778. Da Asia de João de Barros e de Diogo de Couto. Nova edição offerecida a sua Magestade D. Maria I, Rainha Fidelissima. Lisboa, Regia Officina Typografica.

Bartholin, T. 1658. Dispensatorium hafniense jussu superiorum à medicis hafniensibus adornatum Thomas Bartholinus publicis juris fecit. Hafniae, Prostat apud Danielem Paulli Regium Bibliopolam.

Bartholin, T. 1662. Th. Bartholini Domus anatomica hafniensis brevissime descripta. Hafniae, Literis Henrici Gödiani, Reg. et Acad. Typogr., sumptibus P. Hauboldi.

Bautista, F. 2005. La composición de la Gran Conquista de Ultramar. Revista de Literatura Medieval, 17: 33-70.

Beaumier, A. 1860. Roufh el-Kartas. Histoire des souverains du Maghrec (Espagne et Maroc) et Annales de la Ville de Fès. Traduit de l'arabe par A. Beaumier, agent viceconsul de France à Rabat et Salé (Maroc), Chevalier de la Légion d'Honneur, etc. Paris, A l'Imprimerie Impériale.

Beaussier, M. 1887. * للــــ Dictionnaire pratique arabe-français contenant tous les mots employés dans l'arabe parlé en Algérie et en Tunisie, ainsi que dans le style épistolaire, les pièces usuelles et les actes judiciaires. Alger, Librairie Adolphe Jourdan, Imprimeur-Éditeur.

Bertoni, A. de W. ca. 1914. Fauna paraguaya: Catálogos sistemáticos de los vertebrados del Paraguay. Asunción, Gráfico M. Brossa.

Bluteau, R., Pe. 1712. Vocabulario portuguez, elatino, aulico, anatomico, architectonico, bellico, botanico, brasilico, comico, critico, chimico, dogmatico, dialectico, dendrologico, ecclesiatico, etymologico, economico, florifero, forense, fructifero, geographico, geometrico, gnomonico, hydrographico, homonymico, hierologico, ichthyologico, indico, isagogico, laconico, liturgico, lithologico, medico, musico, meteorologico, nautico, numerico, neoterico, orthographico, optico, ornithologico, poetico, philologico, pharmaceutico, quidditativo, qualitativo, quantitativo, rethorico, rustico, romano, symbolico, synonymico, syllabico, theologico, terapeutico, technologico, uranologico, xenophonico, zoologico, autorizado com exemplos dos melhores escritores portuguezes, $e$ latinos, e offerecido a El Rey de Portugal, D. Joaõ V pelo padre D. Raphael Bluteau, clerigo regular, doutor na Sagrada Theologia, Prègador da Raynha de Inglaterra, Henriqueta Maria de França \& Calificador no sagrado Tribunal de Inquisiçaõ de Lisboa, [Vol. 1A]. Coimbra, Collegio das Artes da Companhia de Jesus.

Boiteux, L.A. 1957. Poranduba catarinense. Florianópolis, Comissão Catarinense de Folclore.

Borges, D. 1498 (28 de setembro). Carta de Diego Borges á rainha D. Leonor, acerca da sua chegada a Çafim, das perurbações que ali houve e do proveito que resultou d'ellas ao serviço de Sua Alteza e do rein, com o triumpho de Cid Abderam sobre seu tio, cujos partidarios determinavam dar a dita cidade e el-rei D. Fernando de Castella (Corpo Chron., parte 1'a, maço 2, no. 123). In: Ramos-Coelho, q.v. pp. 91-95

Brandão, A.F. [1618] 1887. [Dialogo das grandezas do Brasil] Dialogo Quinto. Revista do Instituto Archeologico e Geographico de Pernambuco, Recife, 33: 83-120.

Brandenburger, C. 1923. Lendas dos nossos indios. Leituras brasileiras. Prefacio de Afranio Peixoto. Rio de Janeiro, Livraria Francisco Alves.

Brisson, A.D. 1756. Regnum animale in classes IX distributum. Sive synopsis methodica sistens generalem animalium distributiones in classes IX, \& duarum primarum classium, Quadrupedum scilicet \& Cetaceorum, particularem divisionem in ordines, sectiones, genera \& species, Cum brevi cujusque speciei descriptione, citationibus auctorum de iis tractantium, nominibus eis ab ipsis \& nationibus impositis, nominibusque vulgaribus. Cum figuris aeneis. Classis I. Quadrupeda/Le regne animal divisé en IX classes, ou méthode contenant la division generale des Animaux en IX classes, \& Ia division particuliere des deux premieres classes, sçavoir de celle des Quadrupedes \& celle des Cetacées, en ordre, sections, genres \& espéces. Aux quelles on a joint une courte description de chaque espéce, avec les citations des auteurs qui en ont traité, les noms quills leurs ont donnés, ceux que leurs ont donnés les différentes nations, \& les noms vulgaires. Avec figures en taille douce. Classe l. Les quadrupedes. Paris, Cl. Jean-Baptiste Bauche.

Brown, R. 1896a. The History and Description of Africa and of the notable things therein contained, written by Al-Hassan ibn-Mohammed al-Wezaz al-Fasi, a Moor, baptized as Giovanni Leone, but better known as Leo Africanus. Done into English in the year 1600, by John Pory, and now edited, with an introduction and notes, by Dr. Robert Brown. In three volumes - Vol. II. London, Printed for the Hakluyt Sociey.

Brown, R. 1896b. The History and Description of Africa and of the notable things therein contained, written by Al-Hassan ibn-Mohammed al-Wezaz al-Fasi, a Moor, baptized as Giovanni Leone, but better known as Leo Africanus. Done into English in the year 1600, by John Pory, and now edited, with an introduction and notes, by Dr. Robert Brown. In three volumes - Vol. III. Printed for the Hakluyt Sociey, London.

Bueno, F. da S. 1998. Vocabulário tupi-guarani português. $6^{a}$ edição revista e aumentada. São Paulo, Éfeta Editora.

Burmeister, H. 1854. Systematische Uebersicht der Thiere Brasiliens. Welche während einer Reise durch die Provinzen von Rio de Janeiro und Minas geraës gesammelt oder beobachtet wurden. Erster Theil. Säugethiere (Mammalia). Berlin, Druck und Verlag von Georg Reimer.

Burnet, T. 1678. Thesavrvs medicinae practicae, ex prestantissimorum medicorvm observationibus, consiliis, \& epistolis, summa diligentia collectus, ordineque alphabetico dispositus, et Daniele Pverario M.D. \& in celebri Academia Genevensi philosophoae professore ord. auctus observationibvs selectissimis. Tomvs prior. Genevae, Sumptinus Joh. Herm. Widerhold.

Burrh, F.J. 1690. Hypocrates chymicus seu specimina quinque chimiae hyppocraticae a Francisco Josepho Burrho recognita, et utriusque facultatis medicae professori maximo, Olao Borrichio dedicata. Accessit brevis quaestio de circulationis sanguinis. Bruxellis, Typis Petri van den Dyck, Coloniae \& Philippi a Vleggaart.

Burton, R.F. 1870. Letters from the battle-fields of Paraguay. London.

Burton, R.F. 2003. Letters from the battle-fields of Paraguay. Hawaii, University Press of the Pacific.

Camões, L. 1572. Os Lvsiadas de Luis de Camoẽs. Lisboa, Antonio Gõçalues Impressor.

Cardim, F. 1915. Tratados da terra e gente do Brasil. Introdução e notas de Baptista Caetano, Capistrano de Abreu e Rodolpho Garcia. Rio de Janeiro, Editores - J. Leite \& Cia. 
Cardim, F. 1980. Tratados da Terra e Gente do Brasil Belo Horizonte, Editora Itatiaia Limitada \& Editora da Universidade de São Paulo.

Carvalho, C.T. de. 1969. Dicionário dos mamíferos do Brasil. São Paulo, Fundação Parque Zoológico.

Casiri, M. 1770. Bibliotheca Arabico-Hispana Escurialensis sive librorum omnium mss. quos arabice ab auctoribus magnam partem arabo-hispanis compositos Bibliothecae Coenobii Escurialensis complectitur, recensio \& explanatio opera \& studio Michaelis Casiri Syro-Maronitae, Presbyteri, S. Theologiae Doctoris, Regis à Bibliotheca, linguarumque orientaliun interpretatione: Carolus III. regis opt. max. Auctoritate atque auspiciis edita. Tomus posterior. Matriti, Antonius Perez de Soto imprimeat.

Castanheda, F.L. de. 1552. Ho terceiro liuro da historia do descobrimento \& conquista da India, polos Portugueses feito por Fernão lopes de Castanheda. Coimbra, loão de Barreira, \& loão Aluarez empressores delrey na mesma vniuersidade.

Casti, G. 1802a. Gli animali parlanti. Poema epico. Tomo primo. Milano, Della Stamperia di S. Zeno.

Casti, G. 1802b. Gli animali parlanti. Poema epico. Tomo secondo. Milano, Della Stamperia di S. Zeno.

Casti, G. 1802c. Gli animali parlanti. Poema epico. Tomo terzo. Milano, Della Stamperia di S. Zeno.

Castro, B. de. 1936. Vocabulario tupy-guarany. (Collectanea dos principaes elementos com que contribuiu a "lingua geral" para a formação das palavras do portuguezamericano). Rio de Janeiro, Ariel Editora Limitada.

Cenival, P. de. 1934. Les sources inédites de I'histoire du Maroc publiées par Pierre de Cenival. Première séreie - Dynastie Sa'dienne. Archives et bibliothèques de Portugal. Tome I. Juillet 1486 - Avril 1516. Paris, Paul Geuthner. (Publications de la Section Historique du Maroc).

Chermont de Miranda, V. 1906. Glossário paraense, ou, Collecção de vocabulos peculiares á Amazônia e especialmente á ilha de Marajó. Pará [= Belém], Livraria Maranhense," 1905 ".

Chiquieri, A.; Papavero, N. \& Teixeira, D.M. 2011. O livro XV (Brasil) do Novus Orbis seu descriptionis Indiae Occidentalis Libri XVIII de Joannes de Laet (1633). Transcriç̧a0, tradução e comentários sobre as partes relativas à História Natural. Seropédica, Editora da Universidade Federal Rural do Rio de Janeiro.

Claude d'Abbeville. 1614. Histoire de la Mission des Peres Capvcins en I'Isle de Maragnan et terres circonuoisines ov est traicte des singularitez admirables \& des Meurs merueilleuses des Indiens habitants de ce pais. Auec les missiues et aduis qui ont este envoyez de nouneau. Par le R.P. Claude d'Abbeville Predicateur Capucin. Paris, Imprimerie de François Hvby.

Claude d'Abbeville. 1975. História da missão dos padres capuchinhos na llha do Maranhão e terras circunvizinhas. [Notas de Rodolfo Garcia]. Belo Horizonte, Editora da Universidade de São Paulo \& Livraria Itatiaia Editora.

Clavigero, F.S. 1781. Storia antica del Messico cavata da' migliori storici spagnuoli, e da' manoscritti, e dalle pitture antiche degl'Indiani, e corredata di carte geografiche, e di varie figure: E dissertazioni sulla terra, sugli animali, e sugli abitatori del Messico. Opera dell'abate D. Francesco Saverio Clavigero. Tomo IV. Contenente le dissertazioni. Cesena, Gregorio Biasini.

[Coleridge, S.C.]. 1822. An account of he Abipones, an equestrian people of Paraguay. From the Latin of Martin Dobrizhoffer, eighteen years a missionary in that country. In three volumes. Vol. I. London, John Murray.

Cordus, V. 1592. Pharmacorvm omivm, quae in vsv potiss. svnt componendorvm ratio. Vulgo vocant Dispensatorivm sive Antidotarivm, ex optimis avtoribvs tam recentibvs qvam veteribvs collectvm, ac scholiis vtilibvs illvstratvm, in qvibvs imprimis simplicia diligenter explicantvr. Avtore Valerio Cordo. Cum aliis pluribus ad hanc rem pertinentibus, quae sequenti pagina indicantur. Opera et stvdio Colegii Medici inclytae reipvbl. Norimbergensis jam primam multo emendatius ac selectis compositionibus auctius in lucem editum. Norimbergae, Apud Christophorum Lochnerum \& Johannem Hoffmanum.

Cordus, V. 1598. Dispensatorivm pharmacorvm omivm, quae in usu potissimum sunt. Ex optimis auctoribus, tàm recentibus quàm veteribus, collectum, ac scholiis utilibus illustratum, in quibus imprimis simplicia diligenter explicantur. Avtore primo Valerio Cordo. Nunc cum aliis pluribus ad hanc rem pertinentibus, quae frequentibus indicantur. Opera et stvdio Colegii Medici inclitae reipvbl. noribergensis, multo emendatius ac selectis compositionibus auctius, ex secunda editione publicatum. Cum copioso duplici index. Excudebat Paulus Kaufmann, Noribergae.

Cordus, V. 1627. Valerii Cordi Dispensatorium, sive plarmacorvm conficiendorvm ratio. Cum Petri Covdenbergii, \& Matthiae Lobeli scholiis, emendationibus, \& auctariis. Accessit hac editione, praeter Gvglielmi Rondeletii de Theriaca tractatum, emendatiorem; \& Formvlas selectorvm pharmacorvm, quorum post Val. Cordum vsus passim receptus est, auctiores; alius Fr. Dissaldei eiusdem argumentum Libellus. Lvgdvni Batavorvm, Ex Officina loannis Maire.

Cordus, V. 1666. Dispensatorium pharmacorum omnium, tam gallenicorum, quam chymicorum, quae hodie in usu potiore sunt. Avthore primo Valerio Cordo, nunc verò operâ \& studii Collegii Medici inclytae reipublicae norimbergensis emendatius, ac selectis compositionibus auctius redditum, \& quartò publicatum. Norimbergae, Sumptibus Andreae Endteri \& Wolfgangi Juniores Haeredum.

Coronelli, V.M., Pe. 1691. Atlante Veneto, nel quale si contiene la descrittione geografica, storica, sacra, profana, e politica deglimperij, regni, provincie, estatidell'Universo, Ioro divisione, e confini, coll'aggiunto di tutti li paesi nuovamente scoperti, accessato di molte tavole geografiche, non più publicate. Opera, estudio del Padre Maestro Coronelli Min. Convent., Cosmografo della Serenissima Republica, e Professore di Geografia nell'Università di Venetia, ad uso dell'Accademia Cosmografica dgli Argonauti. Venetia, Girolamo Albrizzi.

Costa, J.P. da. 1997. O manuscrito Valentim Fernandes oferecido pelo académico titular fundador Joaquim Bensade, (1859-1952). Leitura paleográfica, notas e índice pelo académico de número José Pereira da Costa. Lisboa, Academia Portuguesa da História.

Costa e Silva, J.M. da. 1844. Poesias de Joze Maria da Costa e Silva. Socio honorario da Academia Lisbonense das Sciencias, e das Letras, e socio correspondente do Gabinete de Leitura do Rio de Janeiro. Lisboa, Typ. de Antonio José da Rocha.

Couto de Magalhães, A. 1939. Ensaio sobre a fauna brasileira. São Paulo, Secretaria da Agricultura, Indústria e Comércio do Estado de São Paulo, Diretoria de Publicidade Agrícola.

Couto, D. do. 1602. Decada quarta da Asia, dos feitos que os Portvgveses fizeram na conqvista e descobrimento das terras, \& mares do Oriente: em quanto gouernaraõ a India Lopo Vaz de sam Payo, \& parte do tempo de Nuno da Cunha. Composta por mandado do muito catholico e inuenciuel Monarcha de Espanha dom Filipe Rey de Portugal o primeiro deste nome. Por Diogo do Covto chronista e guarda mòr da torre do tombo do estado da India. Lisboa, Impresso por Pedro Crasbeeck.

Couto, D. do. 1612. Decada qvinta da Asia, dos feitos que os Portvgveses fizeram na conqvista e descobrimento das terras, \& mares do Oriente: em quanto gouernaraõ a India Nuno da Cunha, dom Garcia de Noronha, dom Esteuaõ da Gama, dom Garcia de Noronha, dom Esteuaõ da Gams, \& Martim Afonso de Sousa. Composta por mandado do muito catholicos \& inuenciueis Monarchas d'Espanha, \& Reys de Portugal, dom Felipe de gloriosa memoria, o primeiro deste nome: \& de seu filho dom 
Felipe nosso senhor, o segundo do mesmo nome. Por Diogo do Covto chronista e guarda mòr da torre do tombo do estado da India. Lisboa, Impresso por Pedro Crasbeeck.

Covarrubias Orozco, S. 1611. Tesoro de la lengva castellana, o española. Compvesto por el licenciado Don Sebastian de Cobarrubias Orozco, capellan de su Magestad, maestrescula y canonigo de la santa yglesia de Cuenca, y consultor del santo Oficio de la Inquisicion. Dirigido a la Magestad Catolina del Rey Don Felipe III. nuestro señor. Madrid, Por Luis Sanchez, impressor del Rey N.S.

Cunha, A.G. da. (Org.). 1966. Coisas notáveis do Brasil [do Pe. Franciso Soares]. Rio de Janeiro, Instituto Nacional do Livro, Ministério da Educação e Cultura.

Cunha, A.G. da. 1978. Dicionário histórico das palavras portuguesas de origem tupi. São Paulo, Edições Melhoramento \& Instituto Nacional do Livro, Ministério de Educação e Cultura.

Cyprianus, J. 1688. Johannis Cypriani S. Theol.licentiati, \& in Academia Lipsiensi professoris physices publici ordinarii Historiae Animalium, a D. Wolfgango Franzio, theologo witebergensi olim scriprae continuatio in commentario \& supplemento observationum ex recentiori historia naturali, similitudinum, emblematum, hieroglyphicorum, ad usum oratoriae tum civilis tum ecclesiasticae, accedunt indices necessarii, \& inter eos hodego-homileticus in gratiam ministrorum verbi \& theologiae studiosorum. Lipsiae \& Francofurti, Impensis Martini Gabriel. Hübneri, Bibliopolae Dresd.

Dalby, D. \& Hair, P.E.H. 1966. "Le Langaige du Brésil": A Tupi vocabulary of the 1540's. Transactions of the Philological Society, 65(1): 42-66.

Dale, S. 1693. Pharmacologia, seu manuductio ad materiam medicam, in qua medicamenta officinalia simplicia, hoc est, mineralia, vegetabilia, animalia earùmque partes in medicina officinis usitata, in methodum naturalem digesta succinte et accurate describuntur, cum notis generum characteristicis, specierum synonymis, differentiis \& vicibus. Opus omnibus medicis, philosophis, pharmacopoeis, chirurgis, \& pharmacopolis utilissimum. Londini, Sumptibus Sam. Smith \& Benj. Walford, Societate Regiae Typographorum.

Dale, S. 1696. Pharmacologia, seu manuductio ad materiam medicam, in qua medicamenta officinalia simplicia, hoc est, mineralia, vegetabilia, animalia earùmque partes in medicina officinis usitata, in methodum naturalem digesta succinte et accurate describuntur, cum notis generum characteristicis, specierum synonymis, differentiis \& vicibus. Opus omnibus medicis, philosophis, pharmacopoeis, chirurgis, \& pharmacopolis utilissimum. Bremae, Impensis Hermanni Buaueri, Illustris Gymnasii Typographi.

Deckers, R. 1678. Praxis barbettiana cum notis \& observationibus Rederici Deckers, medicinae doctoris, nec non capitum ut \& rerum verborumque indice locupletissimo. Amstelodami, Adrianum Gaasbequium.

Dennler de la Tour, G. 1971. Ursprung der Namen Tapir und Anta. Beitrag zur Etymologie südamerikanischen Tiernamen. Säugetierkund Mitteilungen, 20(1): 144-146. Dennler, J.G. 1939. Los nombres indígenas em guarani de los mamíferos de la Argentina y países limítrofes y su importância para la sistemática. Physis, Buenos Aires, 16(48): 225-244.

Díaz Maderuelo, R. 1986. G. de Carvajal, P. de Almesto y Alonso de Rojas. La aventura del Amazonas. Madrid, Información y Revistas, S.A. (Historia 16).

Dobrizhoffer, M. 1784. Historia de Abiponibus equestri, bellicosaque Paraquariae natione locupletata copiosis barbararum gentium, urbium, fluminum, ferarum, amphibiorum, insectorum, serpentium praecipuorum, piscium, avium, arborum, plantarum, aliarumque eiusdem provinciae, proprietatum observationibus, authore Martino Dobrizhoffer presbytero, et per annos duo de viginti Paraquariae missionario. Viennae, Typis Josephi Nob. de Kurzbek Caes. Reg. Aul. Tipog. et Bibliop.

Dolaeus, J. 1703. Opera omnia, exhibentia non modò encyclopaediam medicam dogmaticam, in qua affectus humani corporis interni; encyclopaediam chirurgicam rationalem, in qua iidem affectus externi; atque sic in utrisque omnes morborum species, à quibus machina illa divina sive corpus humanum affligi unquam observarum fuit, juxta celeberrimorum in medicina antistitum principia plenariè pertractanctur; adeo ut in compendio quodam \& uno intuitu tum veterum, tum recentiorum, Hippocraris, Galeni, Paracelsi, Helmontii, Willisii, Sylvii, Cartesii, \& aliorum sententiae morborum maximè causis \& curatione perspiciantur; quibus ipsius authoris judicium de sede affecta, diagnosi, causa, prognosi, \& curatione, uma cum selectissimis remediorum longâ \& propriâ experientia approbatorum formulis statim adjicitur. Nec non praeter superiora in prioribus editionibus manca \& vitiosa, in ultima hac editione longè auctiora \& correctiora reddita. Cum adjecta nova appendice, quae continet I. Tractatum de theriaca coelesti, ejus usum viresque exhibentem. II. Observationes authoris rariores \& curiosas hactenus tum eruditis communicatas tum privatis scriniis hucusque asservatas. III Commercium ejus epistolare cum celeberrimo quondam archiatro D.D. Jacobi Waldschmidio philosophico-medicum varii argumenti multas continent res curiosas \& utiles. Com IV. Inserta \& adjuncta centuria epistolarum \& observationum ab aliis viris eruditis ab authorem transmissarum; ut nihil nunc omissum videatur, quod tam in theoria quam in praxi medica philiatrorum desiderio satisfaciat. Francofurti ad Moenum, Sumptibus Friderici Knochii.

Donndorff, J.A. 1793. Handbuch der Thiergeschichte. Nach den besten Quellen und neuesten Beobachtungen, zum gemeinnützigen Gebrauch. Leipzig, Weidemannschen Buchhandlung.

Dooley, R.A. 1998. Léxico guaraní, dialeto Mbyá: versão para fins acadêmicos. Com acréscimos do dialeto nhandéva e outros falares do sul do Brasil. Porto Velho, Sociedade Internacional de Lingüística.

Dozy, R. \& Engelmann, W.H. 1869. Glossaire des mots espagnols et portugais dérivés de l'arabe. Seconde édition revue et très considérablement augmentée. Paris, E.J. Brill, Leyde \& Maisonneuve et Cie.

Drumond, C. 1952-1953. Vocabulário na lingua brasilica [Confrontado com o MS. Fg. 3144 da Biblioteca Nacional de Lisboa]. Boletim da Faculdade de Filosofia, Ciências e Letras da Universidade de São Paulo 135 (Etnologia e Tupi-Guarani no. 23): 1-154, 1952; 164 (Etnolologia e Tupi-Guarani no. 26): 1-149, 1953.

Drumond, C. 1952. Vocabulário da língua brasílica. $1^{10}$ vol. (A-H), $2^{\circ}$ vol. (I-Z). (2ª ed., revista e conferida com os MS. Fg. 3144 da Bibl. Nacional de Lisboa). São Paulo, S/e.

Du Chesne, J. 1606. Tetras gravissimum totius capitis affectuum; ex doctissimorum medicorum, tum dogmaticorum, tum hermeticorum, assiduis vigiliis \& accurata theoriae \& praxis observatione elucubrata. Adjectus est in eorundem morborum curatione, praeter vulgarem medendi methodum, ingens selectissimorum medicamentorum spagyricorum numerus: quae magno cum fructu addisci, \& administrari possunt. Marpurgi, Typis Pauli Egenolphi, Typogr. Acad.

Du Chesne, J. 1617. Jos. Quercetani [forma latinizada de Du Chesne], consil. \& medici regii, Tetras gravissimum totius capitis affectuum; ex doctissimorum medicorum, tum dogmaticorum, tum hermeticorum, assiduis vigiliis \& accurata theoriae \& praxis observatione elucubrata. Adjectus est in eorundem morborum curatione, praeter vulgarem medendi methodum, ingens selectissimorum medicamentorum spagyricorum numerus: quae magno cum fructu addisci, \& administrari possunt. Accessit hac tertia editione eivsdem Quercetani, ad brevem Riolani excursum brevis Incursio, olim separatim edita. Marpurgi, Typis Pauli Egenolphi. 
Eckart, A., S.J. [Séc. XVIII]. Vocabulario da lingua Brazil. Códice 3143 da Biblioteca Nacional de Portugal, Lisboa.

Enzina, J. del. 1516. Cancionero de todas la obras de Juan del enzina: con otras cosas nueuamente anãdidas. Çaragoça, Jorge Coci.

Fagnan, E. 1900. L'Afrique Septentrionale ao XIIIe siècle de notre ère. Description extraite du Kitab el-Istibçar et traduite par E. Fagnan. Recueil des Notices et Mémoires de la Société Archélogique du Département de Constantine, Constantine (Algérie) (4) 2 (=Vol. 33): xii + pp. 1-229.

Fagnan, E. 1924. Extraits inédits relatifs au Maghreb (Géographie et Histoire) traduits de l'arabe et annotés par E. Fagnan. Alger, Ancienne Maison Bastide-Jourdan, Jules Carbonel Imprimeur-Libraire-Éditeur.

Farvacques, R. de. 1741. Medicina pharmaceutica, of groote algemeene schatkamer der drôgbereidende geneeskonst. Voorzien met naaukeurige aanmerkingen over veele misbruiken in de chemie en medicyne, welke verbetert worden. Door verscheide groote konstlievenden, op verscheide titels stukswyze voorheen dikwils uigegeven, en naderband overzien, in ordre gebragt, vermeerdert en verbetert door den uitmuntenden Heer, Robertus de Farvacques, eerste lyfmedicus van zyn Koninglyke Majesteit, Karel den Tweden. enz. enz. Met een voorreden van den vermaarden Heer, Hieronimus David Gaubius M.D. en professor en de chemie en medicyne te Leiden. Waar by nu gevoegt is een Ontsloten kabinet der simplicia, of enkele drogereyen, door lohannes Schróder, apotheker te Leiden. Hier is bygevoegt eene naaukerige verhandeling von de Acmelia, een zeer gezegent hulpmiddel voor graveel, steen, en meer andere zwaare ongemakken, door den Heer J. Breinius beschreven, en nu vertaalt. \&c. met plaaten. Zynde nu te zamen een vorkomen kabinet van groot belang de geneeskunde, en artzenybereiding: en ook voor particuliere liefhebbery om geleyen en confituuren te maaken. Drie deelen met plaaten en registers. Te Leiden, Isaak Severinus Boekverkoper.

Felner, R.J. de. (Org.). 1858. Lendas da India por Gaspar Correa publicadas de ordem da Classe de Sciencias Moraes, Politicas e Bellas Lettras da Academia Real das Sciencias de Lisboa e sob a direcção de Rodrigo José de Lima Felner, socio effectivo da mesma Academia. Obra subsidiada pelo Governo de Portugal. Livro primeiro. Contendo as acçoens de Vasco da Gama, Pedralvares Cabral, João da Nova, Francisco de Alboquerque, Vicente Sodré, Duarte Pacheco, Lopo Soares, Manuel Telles, D. Francisco d'Almeida. Lenda de 13 annos, desde o primeiro descobrimento da India até o anno de 1510. Tomo I [Parte I]. Lisboa, Typographia da Academia Real das Sciencias.

Felner, R.J. de. (Org.). 1859. Lendas da India por Gaspar Correa publicadas de ordem da Classe de Sciencias Moraes, Politicas e Bellas Lettras da Academia Real das Sciencias de Lisboa e sob a direcção de Rodrigo José de Lima Felner, socio effectivo da mesma Academia. Obra subsidiada pelo Governo de Portugal. Livro primeiro. Contendo as acçoens de Vasco da Gama, Pedralvares Cabral, João da Nova, Francisco de Alboquerque, Vicente Sodré, Duarte Pacheco, Lopo Soares, Manuel Telles, D. Francisco d'Almeida. Lenda de 13 annos, desde o primeiro descobrimento da India até o anno de 1510. Tomo I [Parte II]. Lisboa, Typographia da Academia Real das Sciencias.

Felner, R.J. de. (Org.). 1860. Lendas da India por Gaspar Correa publicadas de ordem da Classe de Sciencias Moraes, Politicas e Bellas Lettras da Academia Real das Sciencias de Lisboa e sob a direcção de Rodrigo José de Lima Felner, socio effectivo da mesma Academia. Obra subsidiada pelo Governo de Portugal. Livro segundo. Em que se recontão os famosos feitos d'Afonso d'Alboquerque, Lopo Soares, Diogo Lopes de Sequeira, D. Duarte de Menezes, D. Vasco da Gama Visorey, D. Anrique de Menezes. Lenda de 17 annos acabados no anno de 1526. Tomo II [Parte I]. Lisboa, Typographia da Academia Real das Sciencias.

Felner, R.J. de. (Org.). 1861. Lendas da India por Gaspar Correa publicadas de ordem da Classe de Sciencias Moraes, Politicas e Bellas Lettras da Academia Real das Sciencias de Lisboa e sob a direção de Rodrigo José de Lima Felner, socio effectivo da mesma Academia. Obra subsidiada pelo Governo de Portugal. Livro segundo. Em que se recontão os famosos feitos d'Afonso d'Alboquerque, Lopo Soares, Diogo Lopes de Sequeira, D. Duarte de Menezes, D. Vasco da Gama Visorey, D. Anrique de Menezes. Lenda de 17 annos acabados no anno de 1526. Tomo II [Parte II]. Lisboa, Typographia da Academia Real das Sciencias.

Felner, R.J. de. (Org.). 1862. Lendas da India por Gaspar Correa publicadas de ordem da Classe de Sciencias Moraes, Politicas e Bellas Lettras da Academia Real das Sciencias de Lisboa e sob a direcção de Rodrigo José de Lima Felner, socio effectivo da mesma Academia. Obra subsidiada pelo Governo de Portugal. Livro terceiro. Que conta dos feitos de Pero Mascarenhas, e Lopo Vaz de Sampaio, e Nuno da Cunha. Em que se passarão 17 annos. Tomo III [Parte I]. Lisboa, Typographia da Academia Real das Sciencias.

Felner, R.J. de. (Org.). 1863. Lendas da India por Gaspar Correa publicadas de ordem da Classe de Sciencias Moraes, Politicas e Bellas Lettras da Academia Real das Sciencias de Lisboa e sob a direcção de Rodrigo Joséde Lima Felner, socio effectivo da mesma Academia. Obra subsidiada pelo Governo de Portugal. Livro terceiro. Que conta dos feitos de Pero Mascarenhas, e Lopo Vaz de Sampaio, e Nuno da Cunha. Em que se passarão 17 annos. Tomo III [Parte II]. Lisboa, Typographia da Academia Real das Sciencias.

Felner, R.J. de. (Org.). 1864. Lendas da India por Gaspar Correa publicadas de ordem da Classe de Sciencias Moraes, Politicas e Bellas Lettras da Academia Real das Sciencias de Lisboa e sob a direç̧ão de Rodrigo José de Lima Felner, socio effectivo da mesma Academia. Obra subsidiada pelo Governo de Portugal. Livro quarto. A quarta parte da cronica dos feytos que se passarão na India do ano de 1538 até o ano de 1550, em que residirão seis gouernadores (D. Gracia de Noronha, D. Esteuão da Gama, Martim Afonso de Sousa, D. João de (astro, Gracia de Sá, e Jorge (abral). Tomo IV. Lisboa, Typographia da Academia Real das Sciencias.

Fenzl, J.A. 1834. Conspectus animalium medicinalium. Dissertatio inauguralis medica physiographica-pharmacologica quam consensu et auctoritate illustrissimi ac magnifici domini praesidis et directoris perillustris et spectabilis domini decani nec non clarissimorum ac celeberrimorum d.d. professorum pro doctoris medicinae laurea summisque in medicina honoribus ac privilegiis rite obtinendis in antiquissima ac celeberrima Caes. Reg. Universitate Patavina publicae eruditorum disquisitioni submittit Josephus Gustavus Fenzl bohemus tuschkoviensis. Patavii, Ex Officina Sociorum Titulo Minerva.

Fernandez Puertas, A. 1994. Sobre los relieves en la predela del retablo de la Capilla Real de Granada. Anales de la Historia del Arte, Madrid, 4:373-384.

Ferrand, G. 1925. Le Tuḥfat el-Albāb de Abū Hāāmid al Andalusī al-Garnāțī, édité d'après les MSS 2167, 2168, 2170 de la Bibliothèque Nationale et le manuscrit d'Alher, Journal Asiatique. Recueil de Mémoires et de Notices relstifs aux ètudes Orientales publié par la Société Asiatique, Paris, 207: 1-148, 193-304, 8 pls.

Ferreira de Vasconcellos, J. 1555. Comedia Eufrosina. Ao Principe nosso senhor. Coimbra, loã de Barreyra empressor da vniuesidade.

Ferreira de Vasconcellos, J. 1560. Comedia Eufrosina. De nouo reuista, \& em partes acrecẽtada. . . Ioã de Barreyra Impressor da Vniuesidade, Coimbra.

Ferreira, A.B. de H. 1999. Aurélio Século XXI. O dicionário da língua portuguesa (4a impressão). São Paulo, Editora Nova Fronteira.

Ferreira, A.R. 1790. Observaçõens geráes, e particulares, sobre a classe dos mammaes observados nos territorios dos trez rios, das Amazonas, Negro, e da Madeira: Com as descripções circunstanciadas, que, de quazi todos elles, derão os antigos, e modernos naturalistas, e principalmente, com a dos Tapuyas. Códice 21.1.11 da Biblioteca Nacional, Rio de Janeiro. [Transcrito, com ortografia moderna, em Ferreira (A.R.), 1972a: 67-204].

Ferreira, A.R. 1972. Viagem filosófica pelas Capitanias do Grão-Pará, Rio Negro, Mato Grosso e Cuiabá - Memórias - Zoologia - Botânica. [Transcrição e notas por José Cândido de Melo Carvalho]. Rio de Janeiro, Conselho Federal de Cultura. 
Ferreira, J. de S., Pe. 1894. America abbreviada. Suas noticias e de seus naturaes, e em particular do Maranhão, títulos, contendas e instrucções a sua conservação e aumento mui uteis. Pelo Padre João de Souza Ferreira, presbitero da ordem de São Pedro. Natural da villa de Basto. [1693]. Revista trimensal do Instituto Historico e Geographico Brasileiro, Rio de Janeiro, 57(1): 5-145. [0 MS original está na Biblioteca Pública de Évora; cf., Rivara, 1850: 26].

Ferreira, J. de S., Pe. 1918. Noticiario maranhense. Descripção do Estado do Maranhão, em que tempo se descobriu o estado, por quem, que governadores 0 têm governado, como está, suas riquezas e noticias que de presente temos com muitas mais que não se conhecem, e como se pode aumentar, e sua capacidade; donde vierão os moradores Indios deste Estado, e outras peregrinas circumstancias [1685]. Revista do Instituto Historico e Geographico Brasileiro, Rio de Janeiro, 81: 289-352. [0 MS original está na Biblioteca Pública de Évora; cf., Rivara, 1850: 27, que comenta: “Tudo isto não é mais do que os Capitulos $3^{\circ}, 4^{\circ}$ e $5^{\circ}$ da America Abbreviada"].

Fischer, J.B. 1829. Synopsis mammalium. Stuttgardtiae, J.G. Cotta.

Fonseca, F. da. 1940. Protozoarios parasitos. IV. Protozoarios novos de tapirideos. Memórias do Instituto Oswaldo Cruz, Rio de Janeiro, 14: 43-49.

Forster, E.S. \& Heffner, E.H. 1954. Lucius Junius Moderatus Columella On Agriculre. With a recension of the text and an English translation, In three volumes. II. Res Rustica V-IX. London, William Heinemann Ltd., \& Cambridge, Mass., Harvard University Press.

Foulché-Delbosc, R. 1902. Comedia de Calisto \& Melibea (Burgos, 1499). Reimpresión publicada por R. Foulché-Delbosc. Madrid, L'Avenç, Barcelona \& Librería de M. Murillo.

França, E.F. 1859. Chrestomatia da lingua brazilica. Leipzig, F.A. Brockhaus, Livreiro de S.M. o Imperador do Brazil. (Bibliotheca Brasilienze [sic]. Vol. III; Bibliotheca Linguistica. Vol. II).

Frank, J. 1821. Praxeos medicae vniversae praecepta. Partis secvndae volvmen primvm, sectio secvnda, continens doctrinam de morbis colvmnae vertebralis, singvlorvm nervorvm aliisqve ex variis systematis nervosi partibvs ortvm habentibvs nec non ocvlorvm, avrivm, narivm et cavitatvm nasalivm. Lipsiae, Svmptibvs Bibliopolii Kuehniani.

Frank, J. 1841. Praxeos medicae vniversae praecepta. Partis secvndae editio altera emendata et avcta. Volvminis primi sectio secvnda, fascicvlvs prior continens doctrinam de morbis colvmnae vertebralis, singvlorvm nervorvm aliisqve ex variis systematis nervosi partibvs ortvm habentibvs. Lipsiae, Svmptibvs Bibliopolii Kueniani.

Freire, L. 1954. Grande e novíssimo dicionário da língua portuguesa. 2a ed. Rio de Janeiro, Livraria José Olympio Editora. 5 vols.

Fuller, T. 1790. Pharmacopoeia extemporanea sive prescriptorum chilias, in qua remediorum elegantium, \& efficacium paradigmata, ad omnes fere medendi intentiones accommodata, candide proponuntur; cum viribus operandi, ratione, dosibus et indicibus adnexis. Per Thomam Fuller m. phys. Editio nova emendatior, cui adduntur tabula smaragdina Philippi Fraundorffer, Thesaurus Ludovicianus, ac Enchiridion Medicum Practicum Josephi Jacksonii. Venetiis, Apud Josephum Orlandelli.

Gallardo, B.J.; Zarco del Valle, M.R. \& Sancho Rayon, J. (Orgs.). 1866. Ensayo de una biblioteca española de libros rareos y curiosos. Tomo segundo. Madrid, Imprenta y Estereotipia de M. Rivadeneyra, Impresor del Depósito de la Guerra.

Gândavo, P. de M. de. ca. 1571a. Tractado da prouinçia do Brasil no qual se contem a informaçaõ das cousas que ha na terra, assi das capitanias e fazendas dos moradores que viuem pella costa, E doutras particullaridades que aqui se cõtam: como tambẽ da condiçaõ e bestiaes custumes dos Indios da terra, E doutras estranhezas de bichos $q$ 'ha nestas partes, offerecido a muito Alta e serenissima Sõra Dona Catherina Rainha de Portugal Snõra nossa. Visto e approuado pellos deputados da Sancta inquisição. MS no. 2026 (cópia, do início do século XVI) da coleção Sloaniana, British Museum, Londres. [Reproduzido fac-similarmente por Pereira Filho, 1965, q.v.].

Gândavo, P. de M. de. ca. 1571b. Tractado da terra do Brasil no qual se cõtem a informação das cousas que ha nestas partes feito por Po de Magalhaẽs. MS F.G. 552 (cópia do início do século XVII). Lisboa, Biblioteca Nacional de Portugal. (disponível na internet).

Garcia, R. 1923. Glossario das palavras e frases da lingua tupi., contidas na "Histoire de la mission des pères capucins em l'isle de Maragnan et terres circonvoisines"do Padre Claude d’Abbéville. Revista do Instituto histórico e geográfico do Brasil, 94(128): 5-100.

Gato, N. 1511 (3 de janeiro). Carta de Nuno Gato dando conta a El-Rei D. Manuel do cerco que os mouros puzeram a Çafim. Dos fidalgos que occuparam as estancias, e do numero dos inimigos (gaveta 20, maço 1, no. 41). in Ramos-Coelho, q.v. p. 228-232.

Gatti, C. 1985. Enciclopedia Guarani-Castellano de ciencias naturales y conocimientos paraguayos. Asunción, Arte Nuevo Editores.

Gayangos, P. de. 1840. The history of the Mohammedan dynasties in Spain; extracted friom the Naftu-t-tíb min ghosni-I-Andalusi-r'rattib wa tárikh lisánu-d-dín ibniI-Khattib, by Ahmed ibn Mohammed al-Makkari, a native of Telemsán. Translated from the copies in the library of the Bitish Museum, and illustrated with critical notes on the history, geography, and antiquities of Spain, by Pascual de Gayangos, Member of the Oriental Translation Committee, and late Professor of Arabc in the Atheneum of Madrid. In two volumes. Vol. I. London, Printed for the Oriental Translation Fund of Great Britain and Ireland.

Gayangos, P. de. 1843. The history of the Mohammedan dynasties in Spain; extracted friom the Naftu-t-tíb min ghosni-l-Andalusi-r'rattíb wa tárikh lisánu-d-dín ibniI-Khattib, by Ahmed ibn Mohammed al-Makkarí, a native of Telemsán. Translated from the copies in the library of the Bitish Museum, and illustrated with critical notes on the history, geography, and antiquities of Spain, by Pascual de Gayangos, Member of the Oriental Translation Committee, and late Professor of Arabc in the Atheneum of Madrid. In two volumes. Vol. II. London, Printed for the Oriental Translation Fund of Great Britain and Ireland.

Gayangos, P. de. 1858. La Gran Conquista de Ultramar, que mandó escribir el Rey Don Alfonso el Sabio, ilustrada con notas críticas y un glosario por Don Pascual de Gayangos, individuo de número de la Real Academia de la Historia. Madrid, M. Rivadaneyra - Impresor - Editor. [Biblioteca de autores españoles, desde la formacion del lenguage hasta nuestros dias].

Genath, J.J. 1618. Decas I. Dispvtationvm Medicarvm select. Nobilissimas \& utilissimas materias continentium; in gratiam plurimorum artis Asclepiades studiosorum, oretenus \& scriptis saepissimè tale quid à me desiderantium, nunc de novo recusarum per loh. lacobum Genathium, Acad. Basil. Basileae, Typographum. Indicem Disputationum sequens montrabis pagella.

Gesner, C. 1551. Conradi Gesneri medici tigurini Historiae Animalium lib. I de Quadrupedibus uiuiparis. Opvs philosophis, medicis, grammaticis, philologis, poëtis, \& omnibus rerum linguarumq' uariarum studiosis, utilissimum simul iucundissimumq' futurum. Tigvri, Apvd Christ. Froschovervm.

Gockel, E. 1683. Consiliorum et observationum medicinalium decades sex. Collectae, \& per experientiam comprobatae ab Eberhardo Gockelio. Impensis Theophili Göbelii, Bibliopol., Typis Joh, Jabobi Schhönighii, Augustae Vindelicorum.

Goebel, S. 1595. Historia sev brevis descriptio animalis alcis qvod vvlgo vocant Gran bestia, deque illius partium facultatibus, in literatorum \& praesertim occultae naturae indagatorum gratiam. Edita. Per Severinvm Goebelivn Severini f. Borvssvm. Venetiis, Apud loannem de Albertis. 
Goeje, M.J. de. 1885. Bibliotheca geographorum arabicorum. Pars quinta. Compendium libri Kitâb al-Boldân auctore Ibn al'Fakîh al-Hamadhânî. Lugduni Batavorum, E.J. Brill. [Texto árabe].

Goeje, M.J. de. 1892. Bibliotheca geopgaphorum arabicorum. Pars septima. Kitâb al-'Aclâk an-Nafisa VIl auctore Abû Ali Ahmed ibn Omar ibn Rosteh et Kitâb-al-Boldân auctore Ahmed ibn abî Jakùb ibn Wâdhih al-Kâfrib al-Jakûbî. Edit. secunda. Lugduni Batavorum, E.J. Brill. [Texto árabe].

Goeldi, E.A. 1893. Os mammiferos do Brasil. Rio de Janeiro, Livraria Classica de Alves \& Cia. (Monographias Brasileiras I).

Goes, D. de. 1566. Chronica do felicissimo Rei Dom Emavuel, composta per Damiam de Goes, dividida em qvatro partes, das quaes esta he ha primeira [inclui também as partes segunda, terceira e quarta]. Lisboa, Em Casa de Françisco Correa, impressor do serenissimo Cardeal Infante.

Gonçalves Dias, A. 1851. Ultimos cantos, Poesias. Rio de Janeiro, Typographia de F. de Paula Brito.

Gonçalves Dias, A. 1854. Vocabulario da língua geral usada hoje no alto Amazonas. Revista trimensal de Historia e Geographia ou Jornal do Instituto historico e geographico brasileiro, Rio de Janeiro 17: 553-576.

Gonçalves Dias, A. 1858. Diccionario da Lingua Tupy, chamada lingua geral dos indigenas do Brazil. Lipsia [= Leipzig], F.A. Brockhaus.

Goodrich, T.D. 1968. Sixteenth century Ottoman Americana. Or a study of Tarih-i Hind-i garbi. Doctoral Thesis. [New York], Columbia University.

Gray, J.E. 1857. Description of a new species of antelope (Oryx beatrix) from Bombay?, lately living in the menagerie of the Society. Proceedings of the Zoological Sociey of London, 25: 157-158, pl. LV.

Gray, S.F. 1818. A supllement to the pharmacopoeias; including, not only the drugs and compounds which are used by professional or private practitioners of medicine; but also those which are sold by chemists, druggists, and herbalists, for other purposes; together with a collection of the most usual medical formulae; an explanation of the contractions used by physicians and druggists; the medical arrangement of the articles of the London pharmacopoeia, with their doses, at one view; a similar list of the indigenous plants of the British Islands, which are capable of being used in medicine; and also a very copious index, English and Latin. Of the varous names by which the articles have been known at different periods. London, Printed for Thomas and George Underwood.

Grenand, F. \& E. Ferreira, H. 1989. Pequeno dicionário da Língua Geral. Manaus, Secretaria de Estado da Educação e Cultura, Núcleo de Recursos Tecnológicos (Série Amazonas-Cultura regional no. 6).

Grossinger, J.B. 1793. Universa historia physica regni Hungariae secundum tria regna naturae digesta. Tomus I. Regno animalis. Pars I. Zoologia, sive historia quadrupedum. Sumptibus \& Typis Simonis Petri Weber, Posonii \& Comaromii.

Grülling, P. 1670. Tractatus secundus medico-chymicus de secundo in medicina universalis evacuationis genere de medicamentis purgantibus, clysteribus suppositoriis, fotibus \& unguentis laxativis. Francofurti \& Lipsiae, Sumptibus Georgii Henrici Frommanni, Biblio.

Guasch, A., S.J. 1961. Diccionario Castellano-Guaraní y Guarani-Castellano. Sintáctico, freaseológico, ideológico. Cuarta edición, renovada y acrecentada. Sevilla, Ediciones Loyola, Cristo Rey [Asunción, Paraguay].

Guerreiro, F., S.J. 1609. Relaçam annal das covsas que fezeram os Padres da Companhia de lesus nas partes da India Oriental, \& em algũas outras da conquista deste reyno no anno de 606. \& 607. \& do processo da conuersaõ, \& Christandade daquellas partes. Tirada das cartas dos mesmos padres que de là vierão: Pelo padre Fernão Guerreiro da Companhia de lesv natural de Almodouar de Portugal. Vai dividida em quatro liuros: 0 primeiro da Prouincia de lapão, \& China. 0 segundo da Prouincia do Sul. 0 terceiro da Prouincia do Norte. 0 quarto de Guiné, \& Brasil. Lisboa, Pedro Crasbeeck.

Gumilla, J., S.J. 1741. El Orinoco ilustrado, Historia natural, civil, y geographica, de este gran rio, y de sus caudalosas vertientes: Govierno, usos, y costumbres de los indios sus habitadores, com nuevas, y utiles noticias de animales, arboles, frutos, aceytes, resinas, yervas, y raíces medicinales: $Y$ sobre todo, se hallarán conversiones muy singulares à nuestra Santa Fé, y casos de mucha edificacion. Escrita por el P. Joseph Gumilla, de la Compañia de Jesus, misionero, y superior de las misiones del Orinoco, Meta, y Casanare, calificador, y consultor del Santo Tribunal de la Inquisicion de Cartagena de Indias, y examinador synodal del mismo obispado, provincial que fue de su provincia del Nuevo Reyno de Granada, y actual procurador à entrambas curias, por sus dichas misiones, y provincia. Madrid, Manuel Fernandez, Impressor de la Reverenda Camara Apostolica, em su Imprenta, y Libreria.

Gumilla, J., S.J. 1745. El Orinoco ilustrado, y defendido, historia natural, civil, y geographica, de este gran rio, y de sus caudalosas vertientes: Govierno, usos, y costumbres de los indios sus habitadores, com nuevas, y utiles noticias de animales, arboles, frutos, aceytes, resinas, yervas, y raíces medicinales: Y sobre todo, se hallarán conversiones muy singulares à nuestra Santa Fé, y casos de mucha edificacion. Escrita por el P. Joseph Gumilla, de la Compañia de Jesus, misionero, y superior de las misiones del Orinoco, Meta, y Casanare, calificador, y consultor del Santo Tribunal de la Inquisicion de Cartagena de Indias, y examinador synodal del mismo obispado, provincial que fue de su provincia del Nuevo Reyno de Granada, y actual procurador à entrambas curias, por sus dichas misiones, y provincia. Segunda impression, revista, y aumentada por u mismo autor, y dividida en dos pattes. Madrid, Manuel Fernandez, Impressor de el Supremo Consejo de la Inquisicion, y de la Reverenda Camara Apostolica.

Hadj-Sadok, M. 1949. Ibn KhurradâAhbih, Ibn al-Faqih al-Hamadhânîet Ibn Rustih. Description du Maghreb et de l'Europe au III = IX siècle, extraits du "Kitab al-Masalik wa'l-Mamalik", du "Kitab al-Buldañ" et du "Kitab al-A'lâq an-nafisisa". Texte arabe et traduction française avec un avant-propos, des notes et deux index par HadjSadok, Mahammed, Professeur agregé au Lycé d'Alger. Argel, Editions Carbonel, Imp. La Typo-Litho \& J. Carbonel.

Hadj-Sadok, M. 1968. Kitāb al-Ğarāfiyya. Mappemonde du calife al-Ma'mūn reproduite par Fazārī (Ille/IXe s.) rééditée et commentée par Zuhrī (Vle/Xlle s.). Texte arabe établi avec introduction en français (résumée en arabe). [Institut Français de Damas] Bulletin d'Études Orientales, Damas, 21: 7-312.

Haller, A. von. 1788. Bibliotheca medicinae practicae qua scripta ad partem medicinae practicam facientia a rerum initius recensitur auctore Alberto von Haller. Ex eius schedis restituit, auxit et edidit Joachim Diterich Brandis M.D. Medicus hildesiensis, Tomus IV. Ab anno 1626 ad a. 1707. Basileae, Apud Halles, Bernae \& Apud Joh. Schweighauser.

Haltenorth, T. \& Diller, H. 1980. A field guide to the mammals of Africa, including Madagascar. London, William Collins Sons \& Co., Ltd.

Harris, W. 1683. Pharmacologia anti-empirica: Or a rational discourse of remedies both chymical and galenical. Wherein chymistry is impartially represented, the goodness of natural remedies vindicated, and the most celebrated preparations of art proved uncapable of curing diseases without a judicious and methodical administration. Together with some remarks on the causes and cure of the gout, the universal use of the cortex, or Jesuits powder, and the most notorious impostures of divers empiricks and mountebanks. London, Printed for Richard Chiswell.

Heins, U. 1681. D.O.M.A. Dissertatio historico-zoologica de alce, quam in illustri salana praeside M. Uldarico Heinsio, curono, ampliss. Facult. Philos, ajuncto, eruditorum publicae censurae offert Pantaleon Lentnerusm olav. Silesius, A.P.S.M.DC.LXXXI, d. October. Jenae, Imprimebat Joh. Jacob. Beuhofer. 
Helmont, J.B. van. 1707. Johannis Baptistae van Helmnt, toparchae in Merode, Royenburg \&c. Opera omnia, novissima hac editione ab innumeris mendis repurgata, indice rerum av verborum locupletiori instructa, una cum introductione atque clavi Michaelis Bernhardi Valentini, haereditarii in Dishrot. Hafniae, Ex Bibliopolio hafniensi Hieronymi Christiani Paulli.

Henderson, J. 1821. Appendix. Zoology. In: A history of the Brazil; comprising its geography, commerce, colonization, aboriginal inhabitants, \&c. \&c. \&c. London, Longman, Hurst, Rees, Orme, and Brown. p. 501-515

Henry, N.E. \& Guibourt, G. 1830. Farmacopéa razonada, ó tratado de farmacia práctico y teórico. Traducido al castellano con notas y adiciones por el dr. Don Manuel Jimenez. Tomo I. Madrid, Imprenta de los Hijos de Doña Catalina Piñuela.

Hernandez de Gregorio. 1803. Diccionario elemental de farmacia, botanica y materia medica, aplicaciones de los fundamentos de la química moderna á la farmacia en todos sus ranos, aumentado con una nomenclatura moderna muy abundante, y una tabla de materias muy completa, arregladas á la tercera edicion añadida de la Farmacopea Española. Segunda edicion con láminas. Tomo primero. Madrid, Imprenta Real.

Herrera, A. de. 1622. Novus Orbis, sive Descriptio Indiae Occidentalis, Auctore Antonio de Herrera, Supremo Castellae \& Indiarum authoritate Philippi III. Hispaniarum Regis Historiographo. Metophraste C. Barlaeo. Accesserunt \& aliorum Indiae Occidentalis descriptiones, \& navigationes nuperae Australios Jacobi le Maire Historia, uti \& navigationum omnium per Fretum Magellanicum succinta narratio. Amstelodami, Michaelum Colinivm Bibliopolam.

Hershkovitz, P. 1987. A history of the recent mammalogy of the Neotropical region from 1492 to 1850. Fieldiana, Zool. n.s., 39: 11-98.

Hoffmann, F. 1739. Friderici Hoffmanni consiliarii regis intimi, archiatri, academiae et ordinis medicae senioris Opuscula pathologico-practica seu dissertationes selectiores antea diversis temporibus editae, nunc revisa \& auctiores. Accedit ejusdem auctoris Medicus politicus. Cum indice rerum praecipuarum. Venetiis, Ex Typographia Baleroniana.

Hoffmann, J.M. 1719. Obzservatio XXVIII. Spasmus musculi psoas et illiaci interni dextri dolorificus praenuncius arthritidis, pp. 297-299, in Academiae CaesareoLeopoldinae Carolinae Natvrae Cvriosorvm, Ephemerides sive observationvm medico-physicarvm a celeberrimis viris tum medicis, tum aliis eruditis in Germania et extra eam communicatarum Centuria VII. et VIII. Cum appendice. Noribergae, Sumptibus Academiae, Litteris Melchioris Gottofredi Heinii.

Hopkins, J.F.P. \& Levtzion, N. (Coords.). 2000. Corpus of early Arabic sources for West African history. Translated by J.F.P. Hopkins. Cambridge, Cambridge University Press. [Fontes Historiae Africanae, Series Arabica IV].

Houaiss, A.; Villar, M. de S. \& Franco, F.M. de M. 2001. Dicionário Houaiss da língua portuguesa. Rio de Janeiro, Objetiva.

Ihering, H. von. 1894. Os mammiferos de S. Paulo. Catalogo organizado pelo Dr. H. von Ihering Director do Museu Paulista. São Paulo, Typ. Do 'Diario Official'.

Ihering, R. von. 1932. Diccionario dos animaes do Brasil. Boletim de Agricultura, São Paulo, 33: $197-264$.

Ihering, R. von. 1938. Diccionario dos animaes do Brasil. Boletim de Agricultura, São Paulo, 39: 193-336.

Ihering, R. von. 1940. Dicionário dos animais do Brasil. Secretaria da Agricultura, Indústria e Comércio do Estado de São Paulo. São Paulo, Diretoria de Publicidade Agrícola.

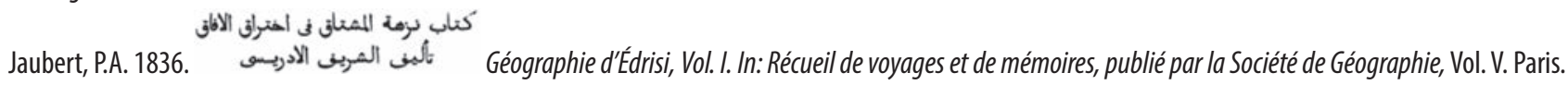

Jimenez, M. 1826. Nomenclatura farmacéutica y sinonimia general de farmácia y de materia médica. Imprenta de los hijos de D. Catalina Piñuela. Madrid, Imprenta de Don Eusebio Alvarez.

Jimenez, M. 1838. Tratado de materia farmacéutica. Madrid, Imprenta de D.N. Sanchiz.

Johnson, W. 1652. Lexicon chymicum. Cum obscuriorum verborum, et rerum hermeticarum, tum phrasium paracelsicarum, in scriptis ejus: Et aliorum chymicorum, passim occurrentium, planam explicationem continens. Per Gulielmum Johnsonum chymicum. Excudebat G.D. impensis Gulielmi Nealand, Londini.

Jonstonus, J. 1652. Historiae naturalis de quadrupetibus [sic] libri cum aeneis figuris. Francofurti ad Moenum, Heredium Nath. Meriani.

Jourdan, A.J.L. 1829. Farmacopea universal, ó reunion comparativa de las farmacopeas de Amsterdam, Amberes, Dublin, Edimburgo, Ferrara. Ginebra, Lóndres, Oldemburgo, Wurzburgo; americana, austriaca, bátava, bélgica, danesa, española, finlándica, francesa, hannoveriana, polaca, portuguesa, prusiana, rusa, sajona, sueca e wurtemburgesa; de los recetarios de Brunswik, Fulda, Hesse, Lipa y Palatinado; de las farmacopeas militares de Dinamarca, de Francia, de Prusia y de Wurzburgo; de la farmacopea de pobres de Hamburgo; de los formularios y farmacopeas de Augustin, Bories, Brera, Brignatelli, Cadet de Gassicourt, Cox, Ellis, Hufeland, Magendie, Piderit, Pierquin, Ratier, Sainte-Marie, Saunders, Spielmann, Swediaur y van Mons. Obra que contiene los caracteres esenciales y sinonimia de todas las sustancias citadas en dichas obras, con la indicacion de las que han adoptado cada preparacion, los diversos procedimientos recomendados para egecutarlas, variantes que presentan en los diferentes formularios, nombres oficiales con que se las designan en los diversos paises, y dósis á que se administran. Por A.J.L. Jourdan, doctor em medicna, Caballero de la Legion de Honor, \&c. \&c. \&c. Traducida al castellano po Don Juan Gualberto Avilés, médico de la Real Inclusa y Colegio de la Paz de esta Corte, y del Hospital de Convalecencia de la misma, y Don Justo Aceñero, profesor de medicina en esta Corte. Tomo II. Madrid, Imprenta que fue de Fuentenebro.

Julian, A. 1787. La perla de la America, Provincia de Santa Marta, reconocida, observada, y expuesta en discursos historicos por el sacerdote Don Antonio Julian, á mayor bien de la Católica Monarquia, fomento del comercio de España, y de todo el Nuevo Reyno de Granada, é incremento de la Christiana Religion entre las naciones barbaras, que subsisten todavia rebeldes em la Provincia. Madrid, Por Don Antonio de Sancha.

Ker, W.A.A. 1920. Martial Epigrams. With and English translation. New York, William Heinemann.

Krausman, P.R. \& Casey, A.L. 2007. Addax nasomaculatus. Mammalian species, 807: 1-4.

Laborie, J.C. \& Lestringant, F. (Orgs.). 2006. Histoire d'André Thevet Angoumoisin, Cosmographe du Roy, de deux voyages par luy faits aux Indes Australes, et Occidentales. Genève, Librairie Droz.

Laet, J. de. 1633. Novus Orbis seu Descriptionis Indiae Occidentalis Libri XVIII. Authore loanne de Laet antuerp. Novis tabulis geographicis et variis animantium, plantarum fructuumque iconibus illustravit. Leyden, Elzeviers.

Lafuente y Alcántara. 1859. Inscripciones árabes de Granada: precedidas de una reseña histórica y de la genealogía detallada de los reyes Alahmares. Madrid, Imprenta Nacional.

Lafuente y Alcántara, E. 1868. Relaciones de algunos sucesos de los últimos tiempos del Reino de Granada. Madrid, Sociedad de Biblióflos Españoles.

Lanzoni, J. 1738. Josephi Lanzoni, ferrariensis philosophiae ac medicinae doctoris in patria universitate lectoris primarii, S.R.I. Academiae Caesareo-Leopoldino Carolinae Naturae Curiosorum socii \&c. Opera omnia, medico-physica et philologica cum edita hactenus, tum inedita. Accedit vita auctoris Hieronymo Baruffaldo Ph. D. ferrariensi, scriptore. Cum indicibus rerum cuique volumini necessariis. Tomus secundus. Lausanne, Sumptibus Marci-Michaelis Bousquet \& Sociosa. 
Lara e Ordonhes, D. de T. 1812. Annotationes. in Anchieta, 1812, q.v. p. 164-178.

Leiste, C. 1780. Anmerkungen über vorstehenden Spanischen Aufsatz des Cudena, in Cudena, q.v. p. 42-160.

Leite, F.R. 2013. A língua geral paulista e o "Vocabulário da língua geral brasílica". Dissertação de Mestrado, Instituto de Estudos da Linguagem, Universidade Estadual de Campinas, Campinas.

Leite, S., Pe., S.J. 1940. Novas cartas jesuíticas (de Nóbrega a Vieira). São Paulo Companhia Editora Nacional. (Biblioteca Pedagógica Brasileira, Série 5a, Brasiliana, Vol. 194).

Leite, S., Pe., S.J. 1949. História da Companhia de Jesus no Brasil. Tomo VIII. Escritores, de A a M (Suplemento bibliográfico - I). Lisboa, Livraria Portugália.

Lemery, N. 1716. Dictionnaire ou traité universel des drogues simples. Où l'on trouve leurs differens noms, leur origine, leur choix, les principes qu'elles renferment, leurs qualitez, leur étymologie, \& tout ce qu'il y a de particulier dans les animaux, dans les vegetaux, \& dans les mineraux. Ouvrage dépendant de la Pharmacopée Universelle. Troisième edition. Revûe, corrigée, \& beaucoup augmentée par l'auteur. Avec des figures en taille douce. Aux dépens de la Compagnie, Amsterdam.

Lemery, N. 1735. Farmacopea universale che contiene tutte le composizioni di farmacia le quali sono in uso nella medicina tanto in Francia, quanto per tutta l'Europa, le loro virtù, dose, e maniere di mettere in pratica le più semplici e le migliori. E di più un vocabolario farmaceutico, molte nuove osservazioni, ed alcuni ragionamenti sopra ogni operazione di Niccolò Lemery, dell'Accademia Reale delle Scienze, dottore in medicina: Tradotta dalla lingua francese. Con tre indici, uno de' capi, I'altro delle materie, él terzo delle infermità, alle quali quivi si trovano prescritti i rimedj. Venezia, Nella Stamperia dell'Hertz.

Leo Africanus. 1563. Della descrittione dell'Africa et delle cose notabili che quiui sono, per Giouan Lioni Africano [1526], fól. 1v-95r, in Ramusio, 1563, q.v.

Léry, J. de. 1578. Histoire d'vn voyage fait en la terre dv Bresil, avtrement dite Amerique. Contenant la nauigation, \& choses remarquables, veuës sur mer par l'aucteur. Le comportement de Villegagnon, en ce païs là. Les meurs \& façons de viure estranges des Sauuages Ameriquains: auec un colloque de leur language. Ensemble la description de plusieurs Animaux, Arbres, Herbes, \& autres choses singulieres, \& du tout inconnues par deça, dont on verra les sommaires des chapitres au commencement du liure. Non encores mis en lumiere, pour les causes contenues en la preface. Le tout recueillis sur les lieux par lean de Lery natifde la Margelle, terre de sainct Sene au Duché de Bourgogne. La Rochelle, Antoyne Chuppin.

Lévi-Provençal, E. 1938. La péninsule lbérique au moyen-âge: d'après le Kitab ar-rawd al mi'tari fi habar al-aḳtā̄ d'Ilbn 'Abd al Mun'im al-Himyarī:texte arabe des notices relatives à l'Espagne, au Portugal et au sud-ouest de la France. Leiden, E.J. Brill.

Liais, E. 1872. Climats, géologie, faune et géographie botanique du Brésil. Paris, Garnier Frères, Libraires-Éditeurs.

Linnaeus, C. 1758. Systema Naturae per regna tria naturae. Ed. X. Holmiae, L. Salvii.

Llano Zapata, J.E. [1757] 2005. Memorias, histórico, físicas, crítico, apologéticas de la América Meridional. Edición y estudios Ricardo Ramírez Castañeda, Antonio Garrido Aranda, Luis Millones Figueroa, Víctor Peralta Ruiz, Charles Walker. Lima, Intituto Francés de Estudios Andinos, Pontificia Universidad Católica del Perú/Fondo Editorial \& Universidad Nacional Mayor de San Marcos.

Loggers, C.0.; Thevenot, M. \& Aulcanier, S. 1992. Status and distribution of Moroccan wild ungulates. Biological Conservation, 59: 9-18.

Lombard, M. 1969. La chasse et les produits de la chasse dans le monde musulman (VIlle-Xle siècle). Annales Economies, Sociétés, Civilisations, 24(3): $572-593$.

Lopez de Gómara, F. 1554. La historia general de las Indias, con todos los descubrimientos, y cosas notables que han acaescido enellas, dende que se ganaron hasta agora, escrita por Francisco Lopez de Gomara, clerigo. Añadiose de nueuo la descripcion y traça de las Indias, con vna tabla alphabetica de las provincias, islas, puertos, ciudades, y nombres de conquistadores y varones principales que alla han passado. Anvers Em casa de luan Steelsio.

Lovell, R. 1661. ПANZSOPYKTONOГIA. Sive Panzoologicomineralogia or a compleat history of animals and minerals, containing the summe of all authors, both ancient and modern, Galenicall and Chymicall, touching animals, viz. beasts, birds, fishes, serpents, insects, and man, as to their place, meat, name, temperature, vertues, use in meat and medicine, description, kinds, generation, sympathie, antipathie, diseases, cures, hurts, and remedies \&c. With the anatomy of man, his diseases, with their definitions, causes, signes, cures, remedies: and use of the London Dispensary, with the doses and forms of all kinds of remedies: As also a history of Minerals, viz. earths, metals, semimetals, their naturall and artificiall excrements, salts, sulphurs, and stones, with their place, matter, names, kinds, temperature, vertues, use, choice, dose, danger, and antidotes. Also an Introduction to zoography and mineralogy, Index of Latine names, with their English names, Universall index of the use and vertues. Oxford Printed by Hen: Hall, for Jos: Godwin.

Luccock, J. 1881. A grammar and vocabulary of the Tupi language. Revista trimensal do Instituto Historico, Geographico eEthnographico do Brasil, Rio de Janeiro 44(1): $1-31$.

Ludovicus, D. 1712. Danielis Ludoivici, archiatri quodam ducal. saxo-goth. Opera omnia, videlicet I. De pharmacia moderno seculo applicanda dissertationes III. cum commenntario. II. De volatilitate salis tartari dissertatio. III. De morbis castrensibus \& dysenteria tractatus duo, in gratiam extereorum a lingua germanica in latinam translati. IV. Observationes physico-chymico-medica XLIIX. ex Ephemeridibus Academiae Natura Curiosorum transcripta. Quibus uti index locupletissinus subjicitur, ita vitae autoris curriculum praeponitur exaratum, a Geogio Wolfg. Wedelio. Lipsiae, Apud Joh. Herbordum Klosium.

Lydekker, R. 1894. The Royal Natural History. With preface by P.L. Sclater, M.A., PhD., F.R.S., Secretary of the Zoological Society of London. Illustrated with seventy-two coloured plates and sixteen hundred engravings by W. Kuhnert. F. Specht, P.J. Smith, G. Mützel, A.T. Elwes, J. Wolf, Gambier Bolton, F.Z.S.; and many others. Vol. II. Section IV. London \& New York, Frederick Warne \& Co.

Machado, D.B. 1741. Bibliotheca Lusitana historica, critica, e cronologica. Na qual se comprehende a noticia dos authores poryuguezes, e das obras que compuserão desde o tempo da promulgação da Ley da Graça até o tempo prezente. Tomo I. Lisboa Occdental, Officina de Antonio Isidori da Fonseca.

Maestro González, P. 1963. Al-Himyari: Kitab ar-rawd al-mittar. Valencia, Gráficas Bautista.

Maffei, I.P. 1605. Ioan. Petri Maffeii, bergomatis, e Societate lesv, Historiarvm Indicarum LibriXVI. Selectarvm, item, ex India epistolarvm Libri IV. Accessit liber recentionum epistolarum, à loanne Hayo Delgattiensi Scoto ex eadem societate nunc primùm exclusus, cum índice accurato. Dvobvs tomis distribvti. Omnia ab auctore recognita, \& emendata. In singula copiosus Index. Antverpiae, Officina Martini Nutij.

Maffei, J.P. 1665. L'histoire des Indes Orientales et Occidentales du R.P. lean Pierre Maffée, de la Compagnie de Jesvs, traduite du latin an françois par M.M.D.P. Avex deux tables. L'vne des chapitres, \& I'autre des matieres, tant geographiques que historiques. Paris, Robert de Ninville.

Magalhães, A.C. de. 1898. Prólogo, in Silva (H.), q.v.

Magini, G.A. 1598. La seconda parte della Geografia di Cl. Tolomeo, la quale, oltre l'antiche tauole d'esso Tolomeo, contiene le moderne ancora, che mostrano la faccia di tutta la Terra, infino à questa nostra età conosciuta, intagliate da Girolamo Porro. Insieme con le loro copiosissimi espositioni fatte dall'Eccellentiss. Sig. Gio. Ant. 
Magini padovano Lettore delle Matematiche nel Pvblico Stvdio di Bologna. Tradotte dal R.D. Leonardo Cernoti vinitiano Canonico di S. Salvadore. Venetia, Appresso Gio. Battista, \& Gorgio Galignani Fratelli.

Maillo Salgado, F. 1998. Los arabismos del castellano en la Baja Edad Media. Tercera edición. Salamanca, Ediciones Universidad Salamanca.

Mair, A.W. 1928. Oppian, Colluthus, Tryphiodorus. With an English translation. London, William Heinemann Ltd., \& New York, G.P. Putnam's Sons.

Mallory, J.P. \& Adams, D.Q. 2006. The Oxford introduction to Proto-Indo-European and the Proto-Indo-European world. Oxford, Oxford University Press.

Manget, J.J. 1683. Messis medico-spagyrica, qva abvndantissima seges pharmacevtica è selectissimis quibusque, tum pharmacologia \& chimiatris, tum celeberrimis inter recentiores practicis, tum variis opeirbvs miscellaneis, nec non cvriosibvs rervm natvralivm scriptoribus resecta compositissimo ordine cumulatur. Opus in varias distribvtvm partes, qvibvs et principia physica hermetico-hyppocraticae, \& composita quaeque medicamenta nobiliora \& mineralia, vegetabilia, satque animália chymico-medicè describuntur. Cum indicibus capitum, rerum, verborum, morborum \&cc. Figvrisqve pluribus aeneis. Coloniae, Sumptibus Philippi Andreae.

Marcgrave, G. 1648. Historiae rerum naturalium Brasiliae, libri octo... Ioannes de Laet, antuerpianus, in ordine digessit \& annotationes addidit, multas \& varias ab auctore omissa supllevit \& illustravit, I + (2) + 293 pp., 3 p.n.n. com índice, in Piso, G., Historia naturalis Brasiliae, Auspicio et beneficio Illustriss. I. Mauritii Com. Nassau illius Provinciae et Maris summi Praefecti adornata. In qua non tantum Plantae et Animalia, sed et Indigenarum morbi, ingenia et mores describuntur et iconibus supra quingentas illustrantur. Batavorum, Franciscum Hackium \& Amstelodami, Lugdun, Elzevirium.

Marcos Antonio, Pe. 1757. Vocabulario das línguas brasilica e portugueza; MS no. 223 do British Museum, Londres (Coleção de Jorge IV).

Margeret, (-). 1669. Estat de l'E,mpire de Russie et Grande Dvchéde Moscovie avec ce qui s'est passéde plus memorable \& tragique, pendant le regne de quatre empereurs: à sçavoir depuis l'an 1599, jusques en l'an 1606. en septembre. Par le Capitaine Margeret. Paris, Chez lacqves Langlois, fils.

Marmol Carvajal, L. del. 1573. Libro tercero y segundo volvmen de la primera parte de la descripcion general de Affrica con todos los successos de guerra, y cosas memorables. Dirigida a la C.R.M. del Rey Don Phelippe segundo deste nombre. Por el veedor Lvys del Marmol Caravaial andante en corte de su Magestad. Granada, Em casa de Rene Rut impressor de libros.

Marmol Carvajal, L. del. 1599. Segvnda parte y libro septimo [- onzeno] de la descripcion general de Africa, donde se contiene las Prouincias de Numidia, Libia, la tierra de los Negros, la baxa y alta Etiopia, y Egipto, cõ todas las cosas memorables della. Dirigida al Rey Don Phlipe nuestro señor segundo deste nombre. Malaga, A cost. Del Autor en la emprenta de luan Rene.

Marmol Carvajal, L. del. 1600. Historia del rebelion y castigo de los moriscos del Reyno de Granada. Dirigida a Don luan de Cardenas y çuñiga Conde de Miranda, Marques de la Bañeza, del consejo de estado del Rey nuestro señor, y su presidente en los dos reales consejos de Castilla, y de Italia. Hecha por Luys del Marmol Caruajal, andante en corte de su Magesytad. Malaga, luan Rene a costa del autor.

Martius, C.F.P. von. 1860. Die Thiernamen in der Tupi-Sprache. Sitzungsberichte der kaiserlichen bayerischen Akadenmie der Wissenschaft zu München, 1860: 471-539.

Martius, C.F.P. von. 1863. Diccionario, Wörterbuch, Tupi-Portuguez-Deutsch, pp. 31-97 \& Nomina animalium in lingua tupi, adjecta synonyma e multis linguis praesertim Brasiliae. Thiernamen in der Tupisprachen, mit Synonymen aus anderen Sprachen und Dialekten, besonders Brasilien, pp. 428-486, in seu Beiträge zur Ethnographie und Sprachenkunde Brasiliens. Glossaria linguarum brasiliensium. Glossarios de diversas lingoas e dialectos, que fallão os indios no Imperio do Brasil. Wörtersammlung brasilianischen Sprachen. Erlangen, Kunge \& Sohn.

Martyr, P. 1530. De Orbe Nouo Petri Martyris mediolanensis protonotarij Cesaris senatoris decades. Compluti, Michaelẽ \& Eguia.

Marx, K.F.H. 1827. Die Lehre von den Giften, in medizinischer, gerichtlicher und polizeylicher Hinsicht. Erster Band; Erste Abtheilung. Göttingen, Dieterichschen Buchhandlung.

Massé, H. 1973. Abrégé du Livre des pays [Kitâb al-Buldân] d'Ibn Al-Faqih Al-Hamadani. Traduction révisée par Ch. Pellat. Damas.

Matta, A.A. da. 1938. Contribuição ao estudo do vocabulario amazonense. Revista do Instituto Geografico e Historico do Amazonas, Manaus, 6(1-2): 21-332.

Menabeni, A. 1581. Apollonii Menabeni medici et philosophi insvbris, Tractactvs de magno animali, quid alcen nonnulli vocant, germani verò elend, \& de ipsius partium in re medica facultatibus: Item Historia cervi rangiferi, \& gulonis filfros vocati. Ad Adolphum II. invictiss. Rom. Imperatorem avgvstvm. Accessit Remb. Dodonaei medici cesarei de Alce epistola. Coloniae, Apud Maternum Cholinum.

Menabeni, A. 1584. Trattato del grand'animale, ó Gran Bestia, cosi detta volgarmente; \& delle sue parti, e facultà; édi quelle del ceruo, che seruono à medici. D'Apollonio Menabeni medico, \& filosofo \& del medemo del ceruo rangiferi, e del gulonez. Dalla latina tradotto nellitaliana lingua da M. Costanzo Felici medico, \& da lui aggiuntoui molti luochi. Et del medemo C. Costanzo Delle virtù, \& proprietà del lupo. Rimino, Per Gio. Simbeni, \& Compa.

Meneses, J.C. de. 1776 (18 de junho). Ofício do [governador da capitania de Pernambuco], José César de Meneses], ao [secretário de estado da Marinha e Ultramar], Martinho de Melo e Castro, remetendo animais no navio São Nicolau para a Quinta Real. AHU_ACL_CU_015, Cx. 123, D. 9352.

Milàns, B. \& Rossell, C.V. 1749. Sysnopsis formularum medicarum, quibus utuntur medici in Generali Barcinonensi Nosocomio, quas studiosè selectas, propriâque experientia comprobatas, ita in unum concinnarunt doctores medici. Editio secunda, ab eisdem variis schedis locupletata, et in multis correcta. Barcinone, Ex Officina Josephi Altès.

Mohamed, M.H. 2012. Between caravan and sultan. The Bayruck of Southern Morocco. A study in history and identity. Leiden, E.J. Brill. (Studies in the History and Society of the Maghrib. Vol. 1).

Molina, G.I. 1782. Saggio sulla storia naturale del Chili. Bologna, Stamperia de S. Tommaso d'Aquino.

Montanus, A. 1671. De nieuwe en onbekende weereld of beschryving van America en t'zuid-land, vervaetende d'oorsprong der americaenen en zuid-landers, gedenkwaerdige togten derwaerds, gelegendheid der vaste kusten, eilanden, steden, sterkten, dorpen, tempels, bergen, fonteinen, stroomen, huisen, de natuur van beesten, boomen, planten en vreemden gewachsschen, gods-dienst en zeden, wonderlikke voorvallen, vereeuwde en nieuwen orloogen: Verciert met af-beeldsels na 't leven in America gemaekt, en beschreeven door Arnoldus Montanus. Amsterdam, Jacob Meurs.

Monteiro, J. [1610]. Relação da Província do Brasil. in Leite (S.), 1949, q.v. p. 393-425.

Montoya, A.R. de, S.J. 1639a. Tesoro de la Lengva Gvarani. Compuesto por el Padre Antonio Ruiz, de la Compañia de lesus, Dedicado a la Soberana Virgen Maria. Madrid, luan Sanchez.

Montoya, A.R. de, S.J. 1639b. Conqvista espiritval hecha por los religiosos de la Compañía de lesus, en las Prouincias del Paraguay, Parana, Vruguay, y Tape. Escrita por el Padre Antonio Rviz de la misma Compañía. Dirigida a Octavio Centrvrion, Marques de Monasterio. Madrid, En la Imprenta del Reyno. 
Montoya, A.R. de, S.J. 1640 (1). Arte, y vocabulario de la lengva guaraní. Madrid, luan Sanchez. [A-E, pp. 1-376].

Montoya, A.R. de, S.J. 1876. Arte, Bocabulario, Tesoro Y Catecismo de la Lengva Gvarani por Antonio Ruiz de Montoya publicado nuevamente sin alteracion alguna por Julio Platzmann. Tomo tercero. Tesoro de la Lengva Gvarani. Leipzig, B.G. Teubner.

Moreno, M.S. [1618] 1967. Relação do Ceará. in Instituto do Ceará, 1967, q.v. p. 181-187.

Mucig, L. 2014. La rappresentazione della natura nelle relazioni di viaggio, italiane e portoghesi, in Africa Occidentale. (Séc. XV-XVI). Tesi di Laurea. Università Ca'Foscari, Corso di Laurea specialistica in Storia del Medioevo all'Erà contemporânea, Venezia.

Neiva, A. \& Penna, B. 1916. Viajem cientifica pelo norte da Bahia, sudoeste de Pernambuco, sul do Piauhi e de norte a sul de Goiaz. (Estudos feitos á requisição da Inspetoria de Obras contra a seca. Direção: Dr. Arrojado Lisboa.) Memórias do Instituto Oswaldo Cruz, Rio de Janeiro, 8(3): 74-224, 28 pls., mapa. [Tb. publ. sep., 1999].

Neiva, A. \& Penna, B. 1999. Viagem científica pelo norte da Bahia, sudoeste de Pernambuco, sul do Piauí e de norte a sul de Goiás. Edição fac-similar. Brasília, D.F., Senado Federal.

Nemnich, P.A. 1793. Allgemeines Polyglotten-Lexicon der Natur-Geschichte mit erklaerenden Anmerkungen von Philipp Andreas Nemnich. Hamburg, Bey Licentiat Nemnich \& Halle, Bey Johann Jacob Gebauer.

Nieremberg, I.E. 1635. Historia natvrae, maxime peregrinae, libris XVI. distincta. In quibus rarissima naturae arcana, etiam astronomica, \& ignotum Indiarum animalia, quadrupedes, aues, pisces, reptilia, insecta, zoophyta, plantae, metalla, lapides, \& altra mineralia, fluuiorumque \& elementorum conditiones, etiam cum prorietatibus medicinalibus, describuntur; nouae \& curiosissimae questiones disputantur, ac plura Sacrae Scripturae loca eruditè enodantur. Accedunt de miris \& miraculosis naturis in Europâ libri duo: item de iisdem in terrâ Hebraeis promissâ liber vnus. Antverpiae, Officina Plantininiana Balthasaris Moreti.

Nogueira, B.C. de A. 1880. Vocabulario das palavras guaranis usadas pelo traductor da "Conquista Espiritual" do Padre A. Ruiz de Montoya. Anais da Biblioteca Nacional, Rio de Janeiro, 7: 1-603 + ix.

Nowotny, K.A. 1964. Mauricio de Heriarte: Descriçam do Estado do Maranhan, Para, Corupa, Rio das Amazonas, Faksimile-Ausgabe aus den MSS 5880 und 5879 der Österreichischen National-Bibliothek, Wien. Graz, Akademische Druck- u. Verlagsanstalt.

Nunes, D. [1538] 1840. Carta de Diogo Nunes escripta da D. João III acerca do descobrimento de sertões aonde podia chegar atravessando a terra de S. Vicente (Provincia de S. Paulo) - Copiada do R. Archivo em Lisboa I Corpo Chron. Part. 3a, Maç. 14, Doc. 10), e offerecida ao Instituto pelo seu socio correspondente Francisco Adolfo de Varnhagen. Revista do Instituto Historico e Geographico Brasileiro, Rio de Janeiro, 2: 375-379.

Nuñez de Castro, A. 1658. Libro historico politico. Solo Madrid es corte, y el cortesano en Madrid. Diuidido em quatro libros. En el primero se discvten las ventajas, que Madrid, ya en quanto poblacion, ya en quanto corte, haze a las demas del orbe. Los tres siguientes instruyen al cortesano con dogmas christianamente politicos, para adorno del entendimiento, aliño de la voluntad, y perfeccion de la memoria. Por Don Alonso Nuñez de Castro, coronista general de su Magestad en estos reinos. A D. Fernando de Fonseca Carviz de Contreras, marques de la Lapilla, cauallero del Orden de Santiago, de los Consejos de Guerra, y Camara de Indias, secretario del Consejo de Estado, y del Despacho Vniuersal. Madrid, Andres Garcia de la Iglesia.

Obelar, R.D. 191-. Vocabulario Guaraní. Tratado puramente práctico. Asunción, Talleres Tipograficos del Estado.

d'Oliveira, J.J.M. 1936. Vocabulario elementar da língua geral brasílica. Revista do Arquivo Municipal, São Paulo, 25: 129-171.

Oliveira, M.L. 2008. A Historia do Brazil de Frei Vicente do Salvador. História e política no Império Português do século XVII. Rio de Janeiro, Versal Editores \& Odebrecht.

Oviedo y Valdez, G.F. de. 1526. Oviedo de la natural hystoria de las Indias. Toledo,Remó de Petras.

Palacios, F. 1706. Palestra pharmaceutica chymico-galenica, en la qval se trata de la eleccion de los simples, sus preparaciones chymicas, y galenicas, y de las mas selectas composiciones antiguas, y modernas, vsuales tanto en Madrid, como en toda Europa, descriptas por los antiguos, y modernos, con las anotaciones necessarias, y mas nuevas, que hasta lo presente se han escrito, tocantes à su perfecta elavoracion, virtudes, y mejor aplicacion en los enfermos. Obra mvy vtil, y necessaria para todos los professores de la medicina, medicos, cirujanos, y en particular boticarios. Dedicase al señor doctor Don Diego Matheo Zapata, presidente, y fundador de la Regia Sociedad Medico-Chymica de Sevila, \&c. Sv avthor Don Felix Palacios, socio de la Regia Sociedad Chymica de Sevilla, y Boticario de esta Corte. Madrid, Por Juan Garcia Infançon, Impressor de la Santa Cruzada.

Palacios, F. 1792. Palestra farmaceutica chimico-galenica, en la qual se trata de la eleccion de los simples, sus preparaciones chîmicas, y galénicas, y de las mas selectas composiciones antiguas, y modernas, usuales, tanto en Madrid, como en toda Europa, descritas por los antiguos, y modernos, con las anotaciones necesarias, y mas nuevas, que hasta lo presente se han escrito, tocantes á su perfecta elaboracion, virtudes, y mejor aplicacion en los enfermos. Obra muy util, y necesaria para todos los professores de la medicina, médicos, cirujanos, y en particular boticários; muy aãdida en esta última impresion. Dedicase al señor doctor Don Juan Higgins, ProtoMédico de los Reales Exércitos, y del Principado de Cataluña, Presidente de la Real Sociedad Médico-Chîmica de Sevilla, y del Real Proto-Medicato, primer médico del Rey nuestro señor Don Felipe V. y de su consejo, \&c. Su autor D. Felix Palacios, Visitador General por S.M. de las Boticas de los Obispados de Córdoba, Jaen, Guadix, y Abadía de Alcalá la Real, Socio de la Regia Sociedad Médico-Chîmica de Sevilla, Exâminador en el Real Proto-Medicato, y Boticario en esta Corte. Madrid, En la Imprenta de la viuda de D. Joaquin Ibarra.

Panaroli, D. 1654. Jatrologismorvm, sev medicinalivm observationvm pentecostae qvinqve vilibus praeceptis, singlaribus medelis, reconditis speculationibus, portentosis casibus refertae. Quibus diversa, eaque curiosa (prout adversa pagina indicabit) in calce adduntur opuscula. Opus certe, non tantum physicis dogmatibus redundans, sed multi'lici eruditione jucundum, philosophiae, ac medicinae amantissimis, apprimè utile, ac necessarium. Dominici Panaroli romani philosophi, \& medici in almae vubis Archilyceo medicina professoris. Hanoviae, Sumptibus Johannin Bayeri, Bibliopol. Francofurtens.

Papavero, N. \& Teixeira, D.M. 2011. Os animais do estado do Grão-Pará segundo um manuscrito do jesuíta Antônio Moreira (ca. 1750). Arquivos de Zoologia, São Paulo, 42(2): 83-131.

Papavero, N.; Teixeira, D.M.; Figueiredo, J.L. de; Barros-Cordeiro, K.B. \& Pujol-Luz, J.R. 2012. A história natural da Região Centro-Oeste brasileira nos "Dialogos geograficos, chronologicos, politicos e naturaes" de Joseph Barboza de Sáa (Século XVIII). 0 primeiro inventário da fauna, flora e recursos naturais do cerrado e do pantanal. Transcrição diplomática dos manuscritos e notas explicativas. Rio de Janeiro,Technical Books Editora.

Paranaguá, N. 1905. Do Rio de Janeiro ao Piauhy pelo interior do paiz. Impressões de viagem. Rio de Janeiro, Imprensa Nacional.

Parenti, P.A. 1745. De medicamentorum dosibus index omnium, qui hactenus prodierint longe locupletissimus. Bononiae, Ex Typographia Dominici Guidotti, \& Jacobi Mellini. 
Parenti, P.A. 1792. Dosium tum ad simplicia tum ad composita medicamenta spectantium index omnium qui hactenus prodierint locupletissime auctus et clarissimorum authorum eruditionibus cum chemicis, tum botanicis; \& galenicis noviter, ac longe exornatus, variisque humani corporia aetatibus accomodatus. Pauli Andreae Parenti una cum antidotario chirurgico in calce libri ab eodem excogitatum chirurgiae professoribus elargito. Editio, post duas bononiensis, secunda veneta. Venetiis, Apud Josephum Orlandelli, nomine q. Francisci ex Nicolao Pezzana.

Parker, J.W. 1942. Luís de Góngora. Poesías: Polifemo, Soledad and other poems. Cambridge, Cambridge University Press.

Paullini, C.F. 1695. Christiani Francisci Paullini De Asino liber historico-physico-medicus, ad normam Imperialis Academiae Caes. Leopoldinae Nat. Curios. scriptus, variisque observationibus, memorabilibus \& coriositatibus conspersus. Francofvrti ad Moenvm, Impensis Joh. David. Zunneri.

Peck, A.L. 1961. Aristotle. Parts of Animals. With an English translation. London, William Heinemann Ltd., \& Cambridge, Mass., Harvard University Press.

Peck, A.L. 1965. Aristotle. Historia Animalium. In three volumes. I. Books I-III. With an English translation. London, William Heinemann Ltd., \& Cambridge, Mass., Harvard University Press.

Pedro de Alcalá, Frei. 1505. Vobabulista arauigo en letra castellana, Granada, luan de Varela de Salamanca.

Pellicer de Salas y Tovar, J. 1630. Lecciones solemnes a las obras de Don Lvis de Gongora y Argote, Pindaro Andaluz y principe de los poëtas liricos de España. Escrivialas Don loseph Pellicer de Salas Tovar, Señr de la Casa de Pellicer, chronista de los Reinos de Castilla. Dedicadas al serenissimo señr Cardenal Infante Don Fernando de Avstria. Madrid, En la Imprenta del Reino.

Pennafort, U. 1901. Mandú (o eremicola). Romance indo-brazileno neontologico e nativista. Ceará, Louis C. Cholowiecki.

Pennant, T. 1771. Synopsis of quadrupeds. Chester, J. Monk.

Pennant, T. 1793. History of quadrupeds. The third edition. Vol. I. London, B. \& J. White.

Pereira Filho, E. de. (Org.). 1965. Tratado da Província do Brasil de Pêro de Magalhães de Gândavo. Edição organizada por Emmanuel Pereira Filho, com leitura e reprodução fac-similar do manuscrito existente na Biblioteca Britânica. Rio de Janeiro, Instituto Nacional do Livro, Ministério da Educação e Cultura.

Pigafetta, F. \& Lopes, E. 1591. Relatione del Reame di Congo et delle circonvicine contrade tratta dalli scritti \& ragionamenti di Odoardo Lopez portoghese per Filippo Pigafetta. Con dissegni vari di geografia, di piante, d'habiti, d'animali, \& altro. Roma, Appresso Bartolomeo Grassi.

Pigafetta, F. \& Lopes, E. 1598. Vera descriptio regni africani, qvod tam ab incolis qvam Ivsitanis Congus appellatur. Per Phlippvm Pigafettam, olim ex Edoardi Lopez acroamatis lingua italica excerpta; nunc Latio sermone donabat ab Avgvst. Cassiod. Reinio. Iconibus \& imaginibus rerum memorabilium quasi viuis, opera \& industria Ioan. Theodore \& Ioan. Israelis de Bry fratrum, \&c. exornata. Excudebat VVolffgangus Richter, impensis Theo. \& I0. Israel. De Bry, frat., Francofvrti.

Pigafetta, F. 1881. A report of the Kingdom of Congo, and of the surrounding countries. Transl. and ed. by Margarite Hutchinson. London, John Murray.

Pigafetta, F. 1999. Relazione del primo viaggio attorno al mondo. Padova, Editrice Antenore.

Piso, G. 1648. Medicina brasiliensi libri quatuor, (4) + 122 pp., I p.s.n. com índice, in seu Historia naturalis Brasiliae, Auspicio et beneficio Illustriss. I. Mauritii Com. Nassaiu illius Provinciae et Maris summi Praefecti adornata. In qua non tantum Plantae et Animalia, sed et Indigenarum morbi, ingenia et mores describuntur et iconibus supra quingentas illustrantur. Lugdun. Batavorum \& Amstelodami, Franciscum Hackium \& Lud. Elzevirium,

Piso, G. 1658. De Indiae utriusque re naturali et medica libri quatuordecim, quorum contenta pagina seqquens exhibet. Amstelodami, Ludovicum et Danielem Elzevirios.

Plusieurs Professeurs du Jardin du Roi, et des Principales Ecoles de Paris. 1823. Dictionnaire des sciences naturelles, dans lequel on traite méthodiquement des différens êtres de la nature, considérés soit en eux-mêmes, d'après l'état actuel de nos connoissances, soit relativement a l'utilité qu'en peuvent retirer la médecine, l'agriculture, le commerce et les arts. Suivi d'une biographie des plus célèbres naturalistes. Ouvrage destinée aux médecins, aux agriculteurs, aux commerçans, aux artistes, aux manefacturiers, et à tous ceux qui ont intérêt à connoitre les productions de la nature, leurs caractères génériques et spécifique, leur lieu natal, leurs propriétés et leurs usages. Tome vingt-neuvième [MANB-MELI]. Paris, F.G. Levrault, Éditeur.

Podgorny, I. 2018. The elk, the ass, the tapir, their hooves, and the falling sickness: a story of substitution and animal medical substances. Journal of Global History, 13: 46-68.

Pomet, P. 1694. Histoire generale des drogues, traitant des plantes, des animaux, \& des mineraux; ouvrage enrichy de plus de quatre cent figures en taille-douce tirées d'aprés nature; avec un discours qui explique leurs differens noms, les pays d'où elles viennent, la maniere de connoître les veritable d'avec les falsifiées, \& leurs proprietez, où l'on découvre l'erreur des anciens \& des modernes; le tout tres utile au public. Par le Sieur Pierre Pomet, marchand epicier \& droguiste. Paris, Chez Jean-Baptiste Loyson \& Augustin Pillon.

Pory, J. 1600. A Geographical Historie of Africa, written in Arabicke and Italian by Iohn Leo a More, borne in Granada, and brought vp in Barbarie. Wherein he hath at large described, not onely the qualities, situations, and true distances of the regions, cities, townes, mountaines, riuers, and other places throughout all the north and principall partes of Africa; but also the descents and families of their kings, the causes and euents of their warres, with their manners, customes, religions, and ciuile gouernment, and many other memorable matters: gathered partly of his owne diligent observations, and partly out of the ancient records and chronicles of the Arabians and Mores. Before which, out of the best ancient and modern writers, is prefixed a generall description of Africa, and also a particular treatise of all the maine lands and isles vndescribed by lohn Leo. And after the same is annexed a relation of the great princes, and the manifold religions of that part of the world. Translated and collected by lohn Pory, lately of Goneuill and Caius College in Cambridge. Londini, Impensis Georg. Bishop.

Potier, P. 1698. Petri Poterii Opera omnia practica \& chymica, cum annotationibus et additamentis utilissimis pariter ac curiosis Friderici Hoffmanni, filii, hallensis, medici electoralis branderburgici, philosophi \& professoris medicinae primarii in Academia Fridericiana. Accessit nova doctrina De Febribus, ex principiis mechanicis solidè deducta. Cum indice locupletissimo. Francofurti ad Moenum, Impensis Friderici Knochii Bibliop., typis Johannis Baueri.

Prazeres [Maranhão], Frei F.N.S. dos. 1891. Poranduba Maranhense ou Relação historica da Provincia do Maranhão, em que se dá noticia dos sucessos mais celebres que n'ella tem acontecido desde 0 seu descobrimento até 0 anno de 1820, como tambem das suas principaes produções naturaes, etc., com um mapa da mesma provincia e um dicionario abreviado da lingoa geral do Brazil, composta pelo autor da Taboa Geografico-Estatística Luzitana. Revista do Instituto historico e geographico do Brasil, Rio de Janeiro, 54: 4-281.

Prévost, A.F. 1758. Histoire générale des voïages, ou nouvelle collection de toutes les relations de voiages par mer et par terre, qui ont été publiées jusqu'à présent dans les différentes langues de toutes les nations connues: Contenant ce qu'il y a de plus remarquable, de plus utile, et de mieux averé, dans les païs ou les voïageurs ont penetré: Avec les moeurs des habitans, la religion, les usages, arts, sciences, commerce, manufactures, \&c. Pour former un systême complet d'histoire \& de géographie moderne, qui représente létat actuel de toutes les nations: Enrichi de cartes géographiques et de figures. Tome cinquante-troisieme. Paris, Chez Didot, Libraire. 
Prévost, A.F. 1773. Histoire générale des voyages, ou nouvelle collection de toutes les relations de voyages par mer et par terre, qui ont été publiées jusqu'à présent dans les différentes langues de toutes les nations connues: Contenant ce qu'il y a de plus remarquable, de plus utile, et de mieux averé, dans les pays où les voyageurs ont pénétré, touchant leur situation, leur etendue, leurs limites, leurs divisions, leur climat, leur terroir, leurs productions, leurs lacs, leurs rivières, leurs montagnes, leurs mines, leurs cités \& leurs principales villes, leurs ports, leurs rades, leurs edifices, \&c. Avec les moeurs et les usages des habitans, leur religion, leur gouvernement, leurs arts et leurs sciences, leur commerce et leurs manufactures; pour former un systême complet d'histoire et de geographie moderne, qui représentera l'état actuel de toutes les nations Enrichi de cartes géographiques, nouvellement composées sur les observations les plus authentiques; de plans et de perspectives; de figures d'animaux, de végétaux, habits, antiquités, \&c. Nouvelle edition, revue sur les originaux des voyageurs, \& où l'on a non-seulement fait des aditions \& des corrections très-considérables; mais même ajouté plusieurs nouvelles cartes, \& figures, gravées par d'haboles maîtres. Tome vingtieme. Amsterdam, Chez E. van Harrevelt \& D.J. Changuion.

Purchas, S. 1625. Pvrchas his Pilgrimes. In five bookes. The sixth, containing English voyages, to the east, west, and south parts of America: Many sea and land fights, inuasions and victories against the Spaniards in those parts, and the Spanish Ilands and coast towns on this side; plantations in Guiana, and many strange aduentures of English-men amongst the Americans. The seuenth, voyages to and about the Southerne America, with many marine obseruations and discoueries of those seas and lands, by English-men and others. The eighth, voyages and land trauels in Florida, Virgina [sic], and other parts of the the Northerne America, French plantings, Spanish supplantings; English-Virginian voyages, and to the llands Azores. The ninth, English plantations, acts, and occurents, in Virginia and Summer Ilands, since the yeere 1606. till 1624. The tenth, English discoueries and plantations in New England, New-found-land; with the Patent and voyages to New Scotland; relations also of the fleets set forth by Queen Elizabeth against the Spaniards. The Fourth Part. London, Printed by William Stabsby, for Henrie Fetherstone.

Purchas, S. 1906. Hakluytus Posthumus or Puchas his Pilgrimes. Containing a history of the world in See Voyages and Lande Travells by Englishmen and others. VolumeXVI. Glasgow, John MacLehose and Sons, Publishers to the University.

Quadros, F.R.E. 1892. Memoria sobre os trabalhos de observação e exploração effetuada pela Segunda Seção da Commissão Militar, encarregada da linha telegraphica de Uberaba a Cuyabá, de fevereiro a junho de 1889. Revista Trimensal do Instituto Historico e Geographico Brazileiro, Rio de Janeiro, 55: 233-255.

Quatremère, E. 1831. Notice d'um manuscrit árabe contenant la description de l'Afrique [Man. de la Bibliothèque du Roi, no. 580]. in Institut Royal de France, q.v. p. 437-664.

Quevedo Villegas, F. 1699. Obras de Don Francisco de Quevedo Villegas, Cavallero de la Orden de Santiago, Señor de la Villa de la Torre de Juan-Abad. Tomo tercero, el qual contiene todas sus poesias. Nueva impression corregida y ilustrada con muchas estampas muy donosas y apropriadas à la materia. Amberes, Henrico y Cornelio Verdssen.

Rackham, H. 1967. Pliny. Natural History. With an English translation in ten volumes. Volume III. Libri VIII-XI. Cambridge, Mass., Harvard University Press \& London, William Heinemann Ltd.

Ramos, A. 1990. Abū Ḥāmid al-Garnātī (m. 565/1169). Tuḥfat al-Albād (El Regalo de los Espíritus). Madrid, Consejo Superior de Investigaciones Científicas. Instituto de Cooperación con el Mundo Árabe. (Fuentes Arábico-Hispanas, 10).

Ramos-Coelho, J. (Org.). 1892. Alguns documentos do Archivo Nacional da Torre do Tombi acerca das navegações e conquistas portuguezas publicados por ordem do Governo de Sua Majestade Fidelissima ao celebrar-se a commemoração quadricentenaria do descobrimento da America. Lisboa, Imprensa Nacional.

Ramsay, G.G. 1928. Juvenal and Persius. With an English translatuon. London, William Heinemann \& New York, G.P. Putnam's Sons.

Ramusio, G.B. 1550. Viaggio attorno il mondo scritto per M. Antonio Pigafetta vicentino Cavalier di Rhodi, nel qual visu: \& lo indrizzo al reuerendissimo gran Maestro do Rhodi M. Philippo de Villiers Lisleadam tradotto di lingua francese nella italiana, fólios 279v-397v, in seu Primo volume delle navigationi et viaggi nel qval si contiene la descrittione dell'Africa, et del paese del Prete lanni, con uarii uiaggi, dal mar Rosso à Calicut, \& infin allisole Molucche, doue nascono le spetierie, et la nauigatone attorno al momdo. Li nomi de gli avttori, et le navigationi, et i viaggi piv particolarmente si mostrano nel foglio segvente. Venetia, Appresso gli heredi di Lvcantonio Givnti.

Ramusio, G.B. 1563. Primo volume, \& terza editione delle navigationi et viaggi raccolto gia da M. Gio. Battista Ramvsio \& con molti \& vaghi discorsi, da lui in molti luoghi dichiarato \& illustrato, nel quale si contengono la descrittione dell'Africa (... .). Venetia, Stamperia de Givnti.

Ramusio, G.B. 1837. Il viaggio di Giovan Leone e le navigazioni di Alvise da Ca da Mosto, di Pietro di Cintra, di Annone, di un piloto portoghese e di Vasco di Gama; quali si leggono nella raccolta di Giovambattista Ramusio.Nuova edizione, riveduta sopra quelle de' Giunti; in molti luoghi emendata; ed arricchita di sei notizie che il viaggiatore, i navigatori ed il raccoglitore regguardano. Volume único. Venezia, Co'Tipi di Luigi Plet.

Ray, P.A.F. (Abbé). 1804. Zoologie universelle et portative, ou histoire naturelle des quadrupèdes, cétacés, oiseaux, poissons, insectes, mollusques, vers, tant indigènes qu'exotiques; jointe à une concordance des divers noms qui leur ont été donnés: le tout disposé selon l'ordre alphabétique, et rapporté à l'ordre méthodique par des tableaux raisonnés. Ouvrage également destiné aux naturalistes et aux gens du monde. Avec un nouveau supplément destiné aux plus récentes connoissances zoologiquers d'après nos meilleurs professerus d'histoire naturelle, Paris. [1a Ed., 1788].

Rzączynskim, G., S.J. 1721. Historia naturalis curiosa regni Poloniae, magni ducatus Litvaniae, annexarumq' provinciarum, in tractatus XX divisa: Ex scriptoribus probatis, servata primigenia eorum prhasi in locis plurimis, ex M.S.S. variis, testibus oculatis, relationibus fide dignis, experimentis, desumpta. Sandomiriae, Typis Collegii Soc. Jesu.

Real Academia Española. 1726. Diccionario de la lengua castellana, en que se explica el verdadero sentido de las voces, su naturaleza y calidad, con las phrases o modos de hablar, los proverbios o refranes, y otras cosas convenientes al uso de la lengua. Dedicado al Rey nuestro señor Don Phelipe V. (que Dios guarde) a cuyas realeas expensas se hace esta obra. Compuesto por la Real Academia Española. Tomo primero. Que contiene las letras A.B. Madrid, En la Imprenta de Francisco del Hierro, Impressór de la Real Academia Española.

Renou, J. 1608. Ioan. Renodaei med. parisien. Institvtionvm pharmacevticarvm. Libri qvinqve. Quibus accedit de Materia medica. Libri tres. Omnibus succedit Officina pharmaceutica, siue Antidotarium ab eodem auctore commentariis illustratum. Ad DoM.D. Laurentium archiatrum. Parisiis, Apud viduã Gulielmi de la Nouë et Dionys de la Nouë.

Restivo, P., Pe. 1893. Lexicon Hispano-Guaranicum. "Vocabulario de la lengua Guarani" inscriptum a Reverendo Patre Jesuita Paulo Restivo secundum Vocabularium Antonii Ruiz de Montoya anno MDCCXXII in Civitate S. Mariae Majoris denno editum et adauctum, sub auspiciis Augustissimio Domini Petri Secundi Brasiliae 
Imperatoris posthae curantibus IIlustrissimis Ejusdem Haeredibus ex unico qui noscitur Imperatoris Beatissimi exemplari redimpressum necnon praefatione notisque instructum opera et studiis Christiani Frederici Seybold, Doctoris philosophiae. Stuttgardiae, In sedibus Guilielmi Kohlhammer.

Rieger, J.C. 1743. Introductio in notitiam rerum naturalium et arte factarum, quarum in communi vita, sed praecipue in medicina usus est; exponens materiam medicam seu historiam simplicium, medicamenta composita eorumque componendorum rationes, \& therapeuticas remediorum classes; unà cum terminis apud botanicos, chemicos, \& pharmacopoeos vulgo receptis. Per alphabeti ordinem digessit Joannes Christophorus Rieger, Riesenburgo Prussus. Tomus PrimuS.A. Apud Petrum Gosse, Bibliopolam, Hagae Comitum.

Robertson, J.A. 1906. Magellan's Voyage around the world by Antonio Pigafetta. The original text of the Ambrosian MS., with English translation, notes, bibliography, and index. Cleveland, The Athur H. Clark Company.

Rocque, C. 1967-1968. Grande enciclopédia da Amazônia (1ª edição, 2a reimpressão). Vol. 1 (A-B), 1967; Vol. 2 (C-D), 1968; Vol. 3 (E-I), $1968 ;$ Vol. 4 (J-N), $1968 ;$ Vol. 5 (0-R), 1968; Vol. 6 (P-Z), 1968. Belém, PA, Amazônia Editôra Ltda.

Rodrigo de Yepes, F. 1583. Historia de la muerte y glorioso martyrio del Sancto Innocente, que llaman de la Guardia, natural de la ciudad de Toledo. Con las cosas procuradas antes por ciertos ludios, hasta q' al Sãcto Innocente crucificarõ: y lo succedido despues. Con otros tractados de mvcha doctrina y prouecho, que son los de la plana siguiente. Collegido de diversos y fidedignos testimonios, con mucha diligencia y estudio, por el P.F. Rodrigo de Yepes, professo y predicador del monesterio de S. Hieronymo el Real de Madrid. Dirigido al muy illustre señor el licẽciado Guardiola, del Consejo supreno de su M. señor de la Villa de la Guardia. Madrid, luan Yñiguez de Lequerica.

Rodrigues, J., S.J. [1605-1607] 1940. A Missão dos Carijós. in Leite (S.), 1940, q. v. p. 196-246.

Rojas, F. de. 1499. Comedia de Calisto y Melibea. Burgos, Fradique Aleman de Basilea.

Rolfinck, G. 1686. Thearrum practicum in quo producuntur et examinantur omnes in medicina speciali occurrentes affectus, in commodum omnibus medicae arti faventibus exstructum. Â Guernero Rolfincio, phil. et med. doct. et professore publico nunc post beatum ejus obitum summo studio cum veterum \& neotoricorum placitis refertum \& editum ac indice completo ad auctum. Francofurti et Lipsiae, Impensis Johannis Christophori Weidneri Bibl.

Roma, F.M. 1664. Luz da medicina, pratica regional, e methodica, guia de enfermeyros. Directorio de prncipiantes, e summario de remedios para poder acodir, e remediar os achaques do corpo humano, começando do mais alto da cabeça, e descendo athe o mais baixo das plantas dos pés; obra muito util, e necessaria, naõ so para os professores da arte da medicina, e cirurgia, mas tambem para todo o pay de familias; de q se poderao aproveitar pobres, e ricos na falta de medicos doutos. Composto pelo doutor Francisco Morato Roma, medico da Camara de Sua Magestade, e do Santo Officio da Inquisiçaõ, cavalleiro professo da Ordem de Christo: Accrescentado nesta ultima impressaõ com o Tractado unico das tersans perniziozas e malignas, e Compendio de varios remedios de Cirugia, recopilado do Thesouro de Pobres, e outros autores, por Gonçalo Rodrigues de Cabreyra. Coimbra, Na Officina de Francisco de Oliveira, Impressor da Universidade, e do Sancto Officio.

Roncalli, F. 1747. Europae medicina a sapientibus illustrata et a comite Francisco Roncelli parolino observationibus adaucta. Brixiae, Ex Typographia Marci Vendrameni.

Roosevelt, T. 1914. Through the Brazilian wilderness. New York, Charles Scribner's Sons.

Rosa, J.V. da. 1905. Chorographia de Santa Catharina. Florianopolis, Typographia da Livraria Moderna.

Roulin, (-). 1835. Mémoire pour servir a l'histoire du tapir et description d'une espèce nouvelle appartenant aux hautes régions de la Cordillère des Andes. Mémoires presentés par divers savans a l'Académie Royale des Sciences de I'Institut de France, et imprimés par son ordre. Sciences Mathématiques et Physiques, Paris, 6: $557-640,3$ pls.

Saint-Hilaire, A. 1830. Voyages dans l'intérieur du Brésil. Première partie. Voyage dans les provinces de Rio de Janeiro et Minas Geraes. Tome second. Paris, Grimbert et Dorez, Libraires.

Salazar, P. de. 1570. Hispania victrix. Historia en la qual se cuentã muchas guerras succedidas entre christianos y infieles assi en mar como en tierra desde el año de mil y quinientos y quarenta y seys hasta el de sessenta y cinco. Con las guerras acontecidas en la Berberia entre el Xarife y los reyes de Marruecos, Fez, y Velez. Compuesta por Pedro de Salazar vezino de la muy noble villa de Madrid. Dirigida a la S.C.R.M. del rey Don Philippe segundo nuestro señpor. Medina del Campo, Vincente de Millis.

Sampaio, A.J. de. 1944. A alimentação sertaneja e do interior da Amazônia. Onomastica da alimentação rural. São Paulo, Companhia Editora Nacional. (Biblioteca Pedagógica Brasileira, Série 5a, Brasiliana, Vol. 238).

Sampaio, M.A. 1986. Vocabulário Guarani Português organizado por Mário Arnard Sampaio. Porto Alegre, L\&PM Editora.

Sampaio, T. 1914. O Tupi na geographia nacional. Memoria lida no Instituto Historico e Geographico de S. Paulo. Segunda edição, correcta e augmentada. São Paulo, Empresa Typographica "O Pensamento".

Santo Antonio, C. de. 1711. Pharmacopea lusitana reformada. Methodo pratico de preparar os medicamentos na fórma galenica, \& chymica. Offerecida ao excellentissimo senhor Thome de Sousa, Coutinho, Menezes, e Castel-Branco por D. Caetano de S. Antonio conego regulsr de Santo Agostinho, boticario do Real Mosteyro de S. Vicente de Fóra. Lisboa, Impresso no Real Mosteyro de Saõ Vicente de Fóra.

Santos, A.V. dos. 1952. Capítulo 110. Zoologia de todos os animaes quadrupedes terrestres e aquaticos, Peixes e Aves que povoão os tres reinos da natureza, e tem nos contornos do muniçipio de Paranaguá, pp. 105-110, in seu Memoria historica, chronologica, topographica e descriptiva da Çidade de Paranaguá e seu Municipio [MS de 1850]. Curitiba, Museu Paranaense.

Santos, R.L. 1996. Permanência e inovação no teatro português do Séc. XVI: a Comédia Eufrosina. Revista da Faculdade de Ciências Sociais e Humanas, Lisboa, 9: 261-268.

Schmeller, J.A. 1847. Ueber Valentĩ Fernandez Alemã und seine Sammlung von Nachrichten über die Entdeckungen uns Besitzungen der Portugiesen in Afrika und Asien bis zum Jahre 1508 enthalten in einer porugiesischen Handschrift der königl. Hof- und Staats-Bibliothen zu München. Abhandlungen der philosophischphilologischen Classe der Königlich Bayerischen Akademie der Wissenschaften, München, 4 (3): 1-73.

Scholfield, A.F. 1959. Aelian. On the characteristics of animals. With an English translation. In three volumes. III. Books XII-XVII. William Heinemann Ltd., London \& Cambridge, Mass. Harvard University Press.

Schott, G. 1667. P. Gasparis Schotti Regis Curiani e Societate Jesu, olim in Panormitano Siciliae, nunc in Herbipolitano Franconiae gymnasio ejusdem Societatis Jesu Matheseos Professoris, Physica curiosa, sive mirabilia naturae et artis libris XII. comprehensa, quibus pleraque, quae de angelis, daemonibus, hominibus, spectris, 
energumenis, monstris, portentis, animalibus, meteoris, \&c. rara, arcana, curiosaq' circumferuntur, ad veritatis trutinam expenduntur, variis ex historia ac philosophia petitis disquisitionibus excuriuntur, \& innumeris exemplis illustrantur. Ad serenissimum ac potentissimum principem Carolum Ludovicum, S.R.I. Electore, \&c. Cum figuris aeri incisis, \& privilegio. Editio altera auctior. Herbipoli [= Würzburg], Joannis Andreae Endteri \& Haeredum, Volfgangi Jun.

Schröder, J. 1648. Quercetan. Rediviv. Hoc est ars medica dogmatico-hermetca ex Quercetani scriptis digesta. Francofurti, Sumptbus Joannis Beÿeri.

Sclater, P.L. \& Thomas, 0. 1899-1900. The book of antelopes. In four volumes (1894-1900). Vol. IV. London, H.H. Porter.

Semmedo, J.C. 1704. Polyanthea medicinal. Noticias galenicas, e chymicas, repartidas em tres tratados, dedicadas ao excellentissimo senhor D. Miguel Angelo, por Joam Curvo Semmedo, Cavaleyro Professo da Ordem de Christo, Familiar do Santo Officio, \& Medico da Familia Real. Lisboa, Na Officina de Antonio Pedroso Galram.

Semmedo, J.C. 1718. Memorial de varios simplices que da India Oriental, da America, \& de outras partes do mundo vem ao nosso Reyno para remedio de muytas doenças, no qual se acharàõ as vitudes de cada hum, \& o modo com que se devem usar. [S.L.] [s.n.]. [Republicado como apêndice, e paginação independente, em Semmedo, 1726].

Semmedo, J.C. 1726. Polyanthea medicinal. Noticias galenicas, e chymicas, repartidas em tres tratados, dedicadas ao eminentissimo senhor Cardeal de Souza, por maons do excellentissimo senhor D. Pedro Antonio de Norinha por Joaõ Curvo Semmedo, Cavalleyro Professo da Ordem de Christo, Familar do Santo Officio, Medico da Casal Real. Terceyra vez impressas, \& augmentadas. Lisboa, Na Officina de Antonio Pedrozo Galram.

Senna, N. 1924. Toponymia geographica de origem brasilico-indigena em Minas Gerais. Revista do Archivo Publico Mineiro, Belo Horizonte, 20 : 193-337.

Shipton, J. 1711. Pharmacopoeiae Collegii Regalis Londini remedia omnia succintè descripta: Unà cum catalogo simplicium ordine alphabetico digestorum: Quibus annexum est Manuale ad forum: Nec-non Pinax posographicus. Editio quarta prioribus emendatior \& auctior. Huic insuper adjiciuntur pharmaca nonnulla in usu hodierno apud medicos Iondinensis. Accessit item in calce Prosodia medica observatu non indigna. Curâ Ja. Shipton pharmacopoei lond. Londini, Impensis J. Walthoe, M. Witton, G. Conyer, J. Nicholsonm J. and B. Sprint. D. Midwinter, T. Ballard. B. Cowse, W. Innis.

Silva, A.L. da. 2008. Animais medicinais: conhecimento e uso entre as populaç es ribeirinhas do rio Negro, Amazonas, Brasl. Boletim do Museu Paraense Emilio Goeldi. Ciências Humanas, Belém, 3(3): 343-357.

Silva, H. [ca. 1913]. Caças e caçadas no Brasil. Rio de Janeiro, H. Garnier.

Silva, H. 1922. As antas do Brasil. Anta sapateira - anta xuré - anta commum. Almanack agricola brazileiro, São Paulo, 1922: 105-106.

Simpson, G.G. 1941. Vernacular names of South American mammals. Journal of Mammalogy, 22(1): 1-17.

Slane, W.M. de [Baron]. 1856a. Histoire des Berbères et des dynasties musulmanes de l'Afrique Septentrionale par Ibn-Khaldoun. Traduite de l'arabe par M. le Baron de Slane interprète principal de l'armée d'Afrique. Tome troisième. Alger, Imprimerie du Gouvernement.

Slane, W.M. de [Baron]. 1856b. Histoire des Berbères et des dynasties musulmanes de l'Afrique Septentrionale par Ibn-Khaldoun. Traduite de l'arabe par M. le Baron de Slane interprète principal de l'armée d'Afrique. Tome quatrième. Alger, Imprimerie du Gouvernement.

Slane, W.M. de [Baron]. 1859. Description de I'Afrique Septentrionale par El-Bekri. Traduite par M. de Slane. (Suite). Journal Asiatique, ou Recueil de Mémoires, d'Extraits et de Notices relatifs à l'Histoire, à la Philosophie, aux Langues et à la Littérature des Peuples Orientaux, Paris (5) 13: 469-519. [Também publicado como livro, 1913].

Smith, H.H. 1884. The Naturalist Brazilian Expedition. Paper III. - São João do Monte Negro. American Naturalist, 18(6): 578-586.

Soares, F., Pe. 1590. De algũas cousas mais notaueis do brasil, e de algũs costumes dos indios. MS no. 154, Tomo 119, fóls. 1020r-1026r, Coleção Jesuítas, Madrid, Biblioteca de la Real Academia de Historia. [cf., Cunha, 1966].

[Soares, F., Pe.] 1966. Coisas notáveis do Brasil. Rio de Janeiro, Instituto Nacional do Livro. (Dicionário da Língua Portuguesa, Textos e Vocabulários 6).

Sommerfeld, J.C. 1701. Lexicon pharmacevtico-chymicvm latino-germanicum \& germanico-latinvm. Continens terminorum pharmaceuticorvm \& chymicorum, tàm usualium, quàm minus usualium, succintam ac genuinam explicationem; cum versione germanica, \& additione signorum, quotquot hactenus innotuére, characteristica. Cuiaccessitvocabularium germanico-latinum locupletissimum, vegetabilium, animalium \& mineralium, in officinis pharmacevticis \& aliàs usitatorum. Adjuncti sunt sub finem characteres metallorum, mimeralium, planetarum, ponderum, aliarumque rerum chymicarum. Opus et medicis, \& pharmacopoeis, \& aliis de notitia harum rerum sollicitis, necessario \& perutile. Authore Johann. Christoph. Sommerhaff/Pharmacopoeo neo-hanoviensi. Norimbergae, Impensis Joh. Ziegeri \& Georg. Lehmanni, literis Christiano Sigismvndi Frobergii.

Souza, G.S. de. 1825. No. I. Noticia do Brazil, descripção verdadeira da costa daquelle Estado, que pertence à Coroa do Reino de Portugal, sitio da Bahia de Todos os Santos, p. 1-342. In: Academia Real das Sciencias, Collecção de noticias para a historia e geografia das nações ultramarinas, que vivem nos domínios portugueses, ou Ihes são visinhas: publicada pela Academia Real das Sciencias. Tomo III. Parte I. Lisboa, Typographia da Academia Real das Sciencias.

Souza, G.S. de. 1851. Tratado descriptivo do Brazil em 1587. Revista do Instituto Historico e Geographico do Brazil, Rio de Janeiro 14: xi,1-423.

Souza, G.S. de. 1971. Tratado descritivo do Brasil em 1587. Edição castigada pelo estudo e exame de muitos códices manuscritos existentes no Brasil, em Portugal, Espanha

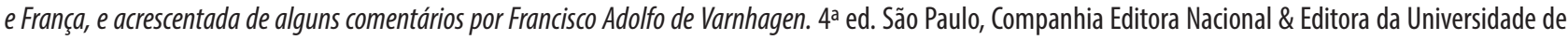
São Paulo.

Spalowsky, J.J.N. 1795. Zweyter Beytrag zur Naturgeschichte der verfüssigen Thiere. Wien, Ignaz Alberti's Witwe.

Spix, J.B. von \& von Martius, C.F.P. 1823. Reise in Brasilien aus Befehl Sr. Majestät Maximilian Joseph I. Königs von Baiern in dem Jahren 1817 bis 1820 gemacht und beschrieben von... Erster Theil. Mit einer geographischen Charte und fünfzehn Abbildungen. München, M. Lindauer.

Spix, J.B. von \& von Martius, C.F.P. 1828. Reise in Brasilien aus Befeh/ Sr. Majestät Maximilian Joseph I. Königs von Baiern in dem Jahren 1817 bis 1820 gemacht und beschrieben von... Zweiter Theil bearbeitet und herausgegeben von Dr. C.F.P. Martius. Mit vier Charten und vier und zwanzig Abbildungen. München, I.J. Leutner.

Spix, J.B. von \& von Martius, C.F.P. s/d. Viagem pelo Brasil 1816-1820. $2^{a}$ Ed. São Paulo, Companhia Melhoramentos. v. 2.

Stradelli, E. 1926. Vocabulario da lingua geral portuguez-nheêngatu e nheêngatu-portuguez, precedidos de um esboço de grammatica nheêngauimbê-séua mirî e seguidos de contos em língua geral nheêngatu poranduva. Revista do Instituto historico e geográfico do Brasil, Rio de Janeiro, 104(158): 5-768.

Suarez de Ribera, F. 1721. Resoluciones de consultas medicas, su autor el doctor Don Francisco Suarez de Ribera, del Gremio, y Claustro de la Vniversidad de Salamanca. Medico titular, que ha sido de las Villas de Vsagre, de Tornabacas, de Garganta la Olla, de Xaraì, del Barco de Avila, de Medina del Capo, de la Ciudad de Segovia, y al 
presentente de la Villa de Piedra-Hita, \&c. Dedicase al excelentissimo señor Don Luis de Mirabal, governador, y presidente del Real Consejo de Castilla. Madrid, En la Imprenta de Antonio Gonçalez de Reyes.

Swaab, J. 1756. Q.D.B.V. Specimen inaugurale medicum De Ventriculi et intestinorum ratione habenda, in ordine ad aestimandas medicamentorum vires auspice Deo Optimo Maximo atque inclytae Facultatis Medicae indultu placidae eruditorum disquisitioni submittit, ac promotore praenobili, clarissimo, \& experientissimi viro ac domino D. Georgio Mattheo Gattenhoff, philosophiae \& medicinae doctore, ejusdémque in antiquissima Electorali Heidelbergensium Universitate professore publ. \& ordinario h.t. decano summum doctoratus medici gradum. Obtinet Joseph Swaab, mannheimensis, natione Judaeus. Die Septembris anno MDCCLVI. Heidelbergae, Typis Joannis Jacobi Haeber, Typographi Aulici Academici.

Sylveira, S.E. da. 1618. Intentos da jornada do Pará. in Biblioteca Nacional, 1905, q.v. pp. 201-206.

Sylveira, S.E. da. [1624] 1979. Relação sumária das coisas do Maranhão. São Luís, Universidade Federal do Maranhão e Serviço de Imprensa e Obras Gráficas do Estado.

Tapia y Salzedo, G. 1643. Exercicios de la gineta. Al principe nvestro señor D. Baltasar Carlos por Don Gregorio de Tapia y Salzedo cauallero de la Orden de Sant-lago, Procurador de Cortes de la vila de Madrid, y Comissario de los Reynos de Castilla, y Leon, por su Magestad en la lunta de la Administracion de los Reales Seruicios de Millones. Madrid, Por Diego Diaz.

Tastevin, C. 1923. Nomes de plantas e animaes em língua tupy. Revista do Museu Paulista, São Paulo, 13: 687-763.

Tate, R.B. \& Macpherson, I.R. 1974. Don Juan Manuel. Libro de los Estados. Oxford, Clarendon Press.

Taunay, A. d'E. 1914a. Lexico de lacunas. Subsidios para os diccionarios da lingua portugueza. Lexico de termos vulgares, correntes no Brasil, sobretudo no Estado de São Paulo, e de accepções de numerosos vocábulos, ainda não apontados nos grandes diccionarios da lingua portugueza e colleccionados por Affonso d'Escragnolle Taunay. Revista do Instituto Historico e Geographico de São Paulo, São Paulo, 16: 5-223. [Também publicado separadamente, cf., Taunay, 1914b].

Taunay, A. d'E. 1914b. Lexico de lacunas. Subsidios para os diccionarios da lingua portuueza. Tours, Imprimerie E. Arrault et Cie.

Teixeira, D.M. 1993. Brasil-Holandês. Dutch-Brazil. Theatrum rerum naturalium Brasiliae. Icones Animalium Brasiliae. Rio de Janeiro, Editora Index.

Teschauer, C., S.J. 1912. Apostilas ao "Diccionario de vocabulos brasilieiros". Petrópolis, Typographia das "Vozes de Petropolis".

Thevet, A. 1558a. Les singvlaritez de la France Antarctiqve, avtrement nommée Amerique: \& de plusieurs Terres \& Isles decouuertes de nostre temps. Paris, Chez les Heritiers de Maurice de la Porte.

Thevet, A. 1558b. Les singvlaritez de la France Antarctiqve, avtrement nommée Amerique: \& de plusieurs Terres \& Isles decounertes de nostre temps. Anvers, Imprimerie de Christophle Plantin.

Thevet, A. 1561. Historia dell'India America detta altramente Francia Antartica, di M. Andrea Tevet. Tradotta di francese in lingva italiana, da M. Givseppe Horologgi. Vinegia, Fabriel Giolito de' Ferrari.

Thevet, A. 1575. La Cosmographie Vniverselle d'André Thevet Cosmographe dv Roy. Illustree de diverses figvres des choses plvs remarquvables vevës par l'Autheur, \& incogneuës de noz Anciens \& Modernes. Tome second. Paris, Guillaume Chaudiere.

Thiry, J. 1995. Le Sahara libyen dans I'Afrique du nord médievale. Leuven, Uitgeverij Peeters en Departement Ossterse Studies. (Orientalia lovanensia Analecta 72).

Tibiriçá, L.C. 1989. Dicionário Guarani-Português. São Paulo, Traço Editora.

Tierno, J.C. 1954. Dicionário zoológico. Contendo, por ordem directa e inversa, todos os termos registrados nos dicionários mais correntes da língua portuguesa. Lisboa, Edição da Tertúlia Edípica.

Tissot, (-). 1789. Traité de l'épilepsie. Lausanne, Chez François Grasset et Comp.

Torres Delgado, C. 1988. El ejercito y las fortificaciones del Reino Nazari de Granada. Gladius, (Vol. Especial): 197-317.

Tralles, B.L. 1740. Virivm, qvae terreis remediis gratis hactenvs adscriptae svnt, Examen rigorosivs; qvo simvl mvitarvm traditionvm practicarvm mythologia et vanitas dilvcide declaratvr, atqve ad rationalem magis pharnacorvm electionem, variorvmque morborvm sanationem, praesvntibvs recentossimis artis principiis. Via ostenditvr. Avctore Balthasare Lvdovico Tralles, medico vratisl. Premittitvr operi dissertatio De freqventi fatvuorvm remediorvm in praxi qvotidiana vsv eivsque cavsis potioribvs. Vratislaviae \& Lipsiae, Apud Michaelem Hvbertvm.

Triller, D.W. 1764. Dispensatorivm pharmacevticvm vniversale sive Thesavrus medicamentorvm tam simplicivm qvam compositorvm locvpletissimvs ex omnibvs dispensaoriis, qvotqvot haberi potverunt permvultisque aliis libris de materia medica ac remediorvm formvlis et cdeleberrimorvm deniqve medicorvm tvm vetervm tvm recentiorvm operibvs congestvs, digestvs, et variis observationibvs practicis selectioribvs instructvs cvrante Daniele Wilhelmo Trillero, phil. et med. d. Consil. Avl. Reg. Pol. et Elect. Saxon. med. prof. primarr. Witteberg. et ill. Acad. Scientisar. Bonon. Sodali. Tomvs secvndvs. Pharmcopoeam vniversalem seu composita continens. Francofvrti ad Moenvm, Apud Franciscum Varrentrapp.

Trinidad Sanabria, L.T. 2007. Gran diccionario Avañeêe ilustrado. Guaraní-castellano/castellano-guaraní. Buenos Aires, Editoral Ruy Diaz.

Untzer, M. 1616. D.0.M.A. Matthiae Untzeri, doctoris medici, \& physici reipubl. Hallensis ordinarij. IEP0NO5010ГIA chymiatrica. Epilepsiae seu morbi sacri, accuratissima, juxtà hippocratico-galenica atq' hermetica principia, descriptio, eiusdemque per remedia elegantissima ac probatissima cùm dogmaticorũ, tùm chymicorum, methodica curatio. Duobus libris comprehensa. Et boni publici gratiâ, nunc in lucem edita. Halae-Saxonum, Typus exscripsit Christophorus Bismarcus.

Vaeça, H. de. [ca. 1510]. Las cosas que pasaron entre los Reyes de Granada desde el tiempo del Rrey Don Juan de Castilla, segundo de este nombre, hasta que los Catholicos Reyes ganaron el Rreyno de Granada, scripto y copilado por Hernando de Baeça, el qual se halló presente á mucha parte de lo que cuenta, y lo demas supo de los Moros de aquel Reyno y de sus corónicas. Hernando de Vaeça: de la suma que hizo estando en Granada de las cosas de aquel rreyno. in Lafuente y Alcántara, E. (Org.).q.v. p. 1-44.

Valentini, M.B. 1704. Museum museorum, oder vollständige Schau-Bühne aller Materialien und Specereyen nebst deren natürlichen Beschreibung, Election, Nutzen und Gebrauch, aus andern Material-Kunst- und Naturalien-Kammern, Oost- und West-Indischen Reisz-Beschreibungen, curiosen Zeit- und Tag-Registern, Natur- und Arzney-Kündigen, wie auch sebst-eigenen Erfahrung, zum Vorschub der studierenden Jugend, Materialisten, Apotheker und deren Visitatoren, wie auch anderer Künstler, aus Jubelirer, Mahler, Färber, u.s.w. also verfasset, und mitetlich hundert sauberen Kuppferstücken unter augen gelegt von D. Michael Bernard Valentini. Frankfurt am Mayn, In Verlegung Johann David Zunners.

Valentini, M.B. 1716. Michaelis Bernhardi Valentini, archiatri hassiaci \& prof. medici gisseni, Historia simplicium reformata, sub Musei Museorum titulo antehâc in vernaculâ edita, jam autem in gratiam exterorum, sub directione, emendatione, \& locupletatione autoris, á D. Joh. Conrado Beckero, medico alsfeldensi, latio 
restituta, Accedit India literata, e lingua belgica primum in germanicam translata, nunc verò, ad desiderium exterorum latinitate donata, longe auctior reddita, novisque figuris aeneis illustrata à Christoforo Bernhardo Valentini, M.B. Filio. Francofurti ad Moenum, Ex Officina Zunneriana apud Johannem Adamum Jungium.

Valentini, M.B. 1720. Amphitheatrum zootomicum tabulis aeneis quamplurimis exhibens historia animalium anatomicam è miscellaneis S.R.I. Academiae Naturae Curiosorum, diariis Societatum Scientiarum Regiarum, Parisiensis, Anglicae et Prussiacae, Actis Hafniensibus \& Lipsiensibus, zootomiis anatomicorum celeberrimorum aliisque scriptis rarioribus collectam. Accedit methodus secandi cadav. humana, cum enchiresibus injiciendi ceram, hydrargyrum \& stannum in vasa sanguifera \& lymphatica, ut \& ars dealbandi ossa pro sceletopoeia, cum osteologia, tabulis myologicis aliisque mss. rauianis, hactenus summoperè expetitis, accurante variisque notis \& figularis illustrante Michaele Bernhardo Valentini, archiatro \& pp. gisseno. Francofurti ad Moenum, Sumptibus Haeredum Zunnerianorum \& Joh. Adami Jungii.

Valentini, M.B. 1843. Institutiones medicinae practicae quas ad usum juventutis digessit Petrus Aloysius Valentini ex Collegio Med. Chir. in Romana Universitate professor in Nosocomiis S. Spiritus S. Mariae dementium S. Joannis nationis florentinae medicus primarius et in eorum primo physiologiae lector ac plurium academiarum socius. Vol. VIII. Primum ordinem morborum nervei systematis complectens. Romae, Ex typographia Contendini.

Valle, L. do, Pe. 1585. Vocabulario na lingua brasilica. MS. Fg. 3144 da Biblioteca Nacional de Lisboa. [cf., Drumond, 1952, 1952-1953].

Varnhagen, F.A. de. 1874. Descripção do Estado do Maranhão, Pará, Corupá e rio das Amazonas, feita por Maurício de Heriarte... no anno de 1662, por mandado do Governador gerall Diogo Vaz de Sequeira, dada à luz por $1^{a}$ vez. Vienna d'Austria, Imprensa do filho de Carlos Gerold.

Vasconcellos, J.F. de. 1555. Comedia Eufrosina. Ao Principe nosso senhor. Coimbra, loã de Bsrreyra empressor da vniuersidade.

Vasconcellos, S. de, S.J. 1658. Vida do P. Joam d'Almeida da Companhia de lesv, na Provincia do Brazil, composta pello Padre Simam de Vasconcellos da mesma Companhia, Prouincial na dita Prouincia do Brazil. Dedicada ao senhor Salvador Correa de Sâ \& Benauides dos Conselhos de Guerra, \& VItramarino de Sua Magestade. Lisboa, Officina Craesbeeckiana.

Vasconcellos, S. de, S.J. 1668. Noticias cvriosas, e necessarias das covsas do Brasil. Pello P. Simam de Vasconcellos da Companhia de lesvs, Natural da Cidade do Porto, Lente que foi da Sagrada Theologia, \& Prouincial naquelle Estado. Lisboa, Officina de loam da Costa.

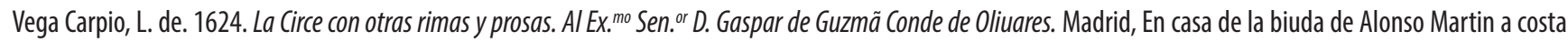
de Alonso Perez.

Veigl, F.X. 1798. Franz Xavier Veigl vormaliger Missionar der Gesellschaft Jesu. Gründliche Nachrichten über die Verfassung der Landschaft von Maynas in Süd-Amerika bis zum Jahre 1768, nebst des herrn V. Anselm Eckarts Zusätze zu Pedro Cudenas Beschreibung der Länder von Brasilien. Mit einer Lankarte und Kupfern. Nürnberg, Bey Johann Eberhard Zeh.

Velez de Arciniega, F. 1613. Historia de los animales mas recebidos en el vso de la medicina: donde se trata para lo que cada vno entero, ò parte del aprouecha, y de la manera de si preparacion. Dirigida al illvstrissimo señor Don Bernardo de Sandoual y oxad, arçobispo de Toledo, inquisidor general, y del Colegio de Estado de su Magestad, \&c. Compvesta por Francisco Velez de Arciniega su boticario, natural de la billa de Casarrubiod del Montem residente em Corte. Madrid, Em la Imprenta Real.

Vera y Figueroa, J.A. de. 1632. El Fernando o Sevilla restavrada. Poema heroico escrito con los versos de la Gervsalemme Liberata del insigne Torqvato Tasso. Oferecido alla magestad de Filippo IV. el grande monarca de España, emperador de las Indias, por D. Ivan Antonio de Vera, y Figueroa, Conde de la Roca, Comendador de la Barra, Gentilhombre de la Boca de sv Conseio, y Contadvria Maior de Hacienda. Embaxador Extraordinario en Savoia, Ordinario en Venecia. Milan, Por Henrico Estefano.

Vera, F. 1903. Diccionario gramatical Guarani Español. Talleres Mons. Lasagna, Asunción.

Vicente do Salvador, Frei. 1627. Historia do Brasil. Códice no. 49 da coleção "Livros do Brasil” do Arquivo Nacional da Torre do Tombo, Lisboa [apud Cunha, 1978, q.v.; leitura diplomática em Oliveira (M.L.), 2008].

Vieyra, A. 1773. Dictionary of the Portuguese and English languages, in two parts; Portuguese and English, and English and Portuguese: Wherein I. The words are explained in their different meanings, by examples from the best Portuguese and English writers. Il. The etymology of the Portuguese generally indicated from the Latin, Arabic, and other Languages. Throughout the work are interspersed a great number of phrases and proverbs. Part I. - Portuguese and English. London, J. Nourse.

Vigier, J. 1714. Thesouro apollineo, galenico, chimico, chururgico, pharmaceutico, ou compendio de remedies para ricos, \& pobres. Contem a individuaçam dos remedios simplices, compostos, \& chimicos com as suas proporcionadas doses, postos em particulares classes pela ditincçaõ de capitulos dos achaaques, que costumaõ infestar o corpo humano. Acrescentase huma breve raciocinaçam da escola moderna sobre as causas efficientes, \& quando se devem applicar certos remedios. Ultimamente formulas de receitas preciosas para os magnates, \& de menos preço para os plebéos. Dividese em duas partes; a primeyra contèm remedios para os achaques internos; a segunda para os externos. Offerecido ao excelentissimo senhor D. Nuno Alvarez Pereyra de Mello, Duque do Cadaval, Marquez de Ferreira, Conde de Tentugal, \&c. Por Joam Vigier, natural do Reyno de França, \& morador nesta Corte de Lisboa. Lisboa, Na Officina Real Delandesiana.

Viré, F. 1986. Lamt. in Bosworth et al., q.v. p. 651-652.

Visconde da Carreira, 1841. Chronica do descobrimento e conquista de Guiné, escrita por mandado de ElRey D. Affonso V, sob a direcção scientifica, e segundo as instrucções do illustre infante D. Henrique. Pelo chronista Gomes Eannes de Azurara. Fielmente trasladada do manuscrito original contemporaneo, que se conserva na Biblioteca Real de Pariz, e dada pela primeira vez à luz por diligencia do Visconde da Carreira, precedida de uma introducção, e illustrada com algumas notas, pelo Visconde de Santarem, e seguida d'um glossario das palavras e phrases antiquadas e obsoletas. Paris, J.P. Aillaud.

Wallace, A.R. 1853. A narrative of travels on the Amazon and Rio Negro, with an account of the native tribes and observations on the climate, geology, and natural history of the Amazon valley. London, Reeve \& $C$.

Wallace, A.R. 1972. A narrative of travels on the Amazon and Rio Negro. The tenth edition of 1889. With a new introduction by H. Lewis McKinney. New York, Dover Publications.

Wappaeus, J.E. 1884. A geographia physica do Brasil refundida (edição condensada). Rio de Janeiro, G. Leuzinger \& Filhos.

Wecker, J.J. 1750. Joh. Jacobi Weckeri, basiliensis, medici colmar. De Secretis Libri XVII. Ex variis auctoribus collecti. Methodice digesti, et Mizaldi, Alex. Pedemontani atque Portae secretis imprimis locupletati, novissima hac editione non solùm ab innumeris mendis obscuritateque purgati, sed et Theodori Zvingeri, archiatri basiliens. celeberrimi, Additonibus e pharmacia et chymia utilissimis adaucti. Acessit index locupletissimus. Basileae, Apud Joh. Rod. Thurneisen.

Wiet, G., trad. 1937. Ya'kubi - Les Pays. Le Caire, Imprimerie de I'Institut Français d'Archéologie Orientale. (Publications de l'Institut Français d'Archéologie Orientale, Textes et traductions d'auteurs orientaux, Tome I). 
Wolff, J. 1690. Jacobi 2 golff/phil. \& med. D. Academiae Leopold. Imper. adjuncti Scrutinium amuletorum medicum, in quo de natura \& attibutis illorum, uti \& plurimis illis, quae passim in usum tam in thoria [sic] quam praxis vocari sveverunt, ac in specie de Zenechtis, vel quae pesti opponuntur, agitur; superstitiosa atqve illicita notantur \& rejiciuntur, \& varia, non in medicinae solùm, sed etiam aliarum facultatum usum afferuntur \& illustrantur, ad normam Academ. Leopoldino-Imper. Curios. adornatum. Lipsiae \& Jenae, Apud viduam Reinhardi Warchtleri.

Wüstenfeld, F. 1849. Zaharija ben Muhammed ben Mahmud el-Caswini's Kosmographie. Erster Theil. بـ اب عايت الغخلوقات. Die Wunder der Schöpfung. Aus den Handschriften der Bibliotheken zu Berlin, Gotha, Dresden und Hamburg. Göttingen,Verlag der Diteterichschen Buchhandlung.

Wüstenfeld, F. 1866-1873. Kitäb Mu'ǧam al-buldān: [aus den Handschriften zu Berlin, St. Petersburg und Paris auf Kosten der Deutschen Morgenländischen Gesellschaft

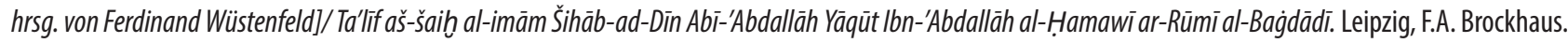
$6 \mathrm{v}$.

Zimmermann, E.A.W. 1780. Geographische Geschichte des Menschen, und der vierfüssigen Thiere. Zweiter Band. Enthält ein vollständiges Verzeichniss aller bekannthen Quadrupeden. Leipzig, Weygandschen Buchhandlung.

Zwelfer, J. 1675. Pharmacopoeia regia, seu Dispensatorium novum locupletatum et absolutum, annexâ etiam Mantissa Spagyrica: in quibus vera et accurata methodo selectissimorum medicamentorum compositiones et praeparationes traduntur, quae cùm servatis suorum ingredientium virtutibus, tum iisdem exaltatis, medico, in profligandis humani corporis aegritudinibus, ad vota servitura sunt. Cui accessere bini Discursus apologetici authore Joanne Zwelfer, palatino, M.D. Noribergae, Sumptibus Michaelis \& Johan. Friderici Endterorum. 